\title{
G G 000005655
}




\section{SAUNDERS'}

\section{MEDICAL HAND-ATLASES.}

-

THE series of bouks included under this title are authorized translations into English of the world-famous

\section{Lehmann Medicinische Handatlanten,}

which for scientific accuracy, pictorial beauty, compactness, and cheapness surpasis any similar volumes ever published.

Each volume contains from 50 to 100 colored plates, besides numerous illustrations in the text. The colored plates have been executed by the most skilful German lithographers, in some cases more than twenty impressions being required to obtain the desired result. Each plate is accom. panied by a full ar.t appropriate description, and each book contains a condensed but aderuate outline of the subject to which it is deroted.

One of the most valuable features of these atlases is that they offer a ready and satisfactory substitute for clinical observation. Such ob. servation, of course, is available only to the residents in large medical centers; and even then the requisite variety is seen only after long years of routine hospital work. To those unable to attend important clinics these books will be absolutely indispensable, as presenting in a complete and convenient form the most accurate reproductions of clinical work, interpreted by the most competent of clinical teachers.

While appreciating the value of such colored plates, the profession has heretofore heen practically debarred from purchasing similar works because of their extremely high price, made necessary ly a limited sale and an enormous tyense of pruduction. Now, however, by reason of their projectel universal translation and reproduction, affording intermational dis. tribution, the publisher's have been enahler to secure for these atlases the best artistic and professional talent, to produce them in the most elegant style, and yet to offer them at a price heretofore unapproached in cheapness. The great success of the undertaking is demonstrated by the fact that the volumes have aiready appeared in nine different languages - (ierman, English. French, Italian, Russian, Spanish, I)anish, swedish, and II ungarian.

The same careful and competent editorial supervision has been secured in the English edition as in the originals. The translations have been edited by the leading American specialists in the different subjects. The volumes are of a uniform and convenient size ( $5 \times 7 / 2$ inches), and are substantially bound in cloth.

(For List of Books, Prices, etc. see back cover.) Pamphlet containing specimens of the Colored Plates sent free on application. 


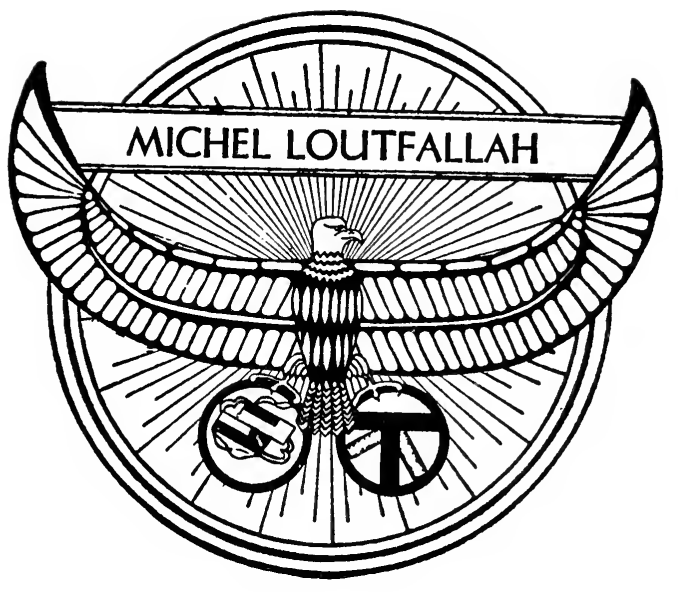





\section{A TLAS}

() $\mathrm{FHH}^{\mathrm{T}}$.

\section{EXTERNAL DISEASES OF THE EYE}

INCLUDING A BRIEF TREATISE

ON THE

\section{PATHOLOGY AND TREATMENT}

BY

PROF. DR. O. HAAB

of Zürich

AUTHORIZED TRANSLATION FROM THE GERMAN

FUITEL BY

G. E. DE SCHWEINITZ, A.M., M. D.

Professur of Ophthalmology in the Jefferson Medical College, Philadelphia;

Consulting Ophthalmolugist to the Philadelphia Polyclinic; Ophthal-

mic surgeon to the Philadelphia Hospital and to the Orthopedic Hospital and Infirmary for Nervous Diseases.

\section{With 76 Colored Plates and 6 Engravings}

PHILADELPHIA

W. B. SA U N D E R S

925 Walnut Streft

I 899 
COPYRIGHT, 1899,

BY W. B. SAUNDERS. 


\section{$B$}

\section{EDITOR'S PREFACE.}

This volume forms an excellent companion-book to Professor Haab's "Atlas of Ophthalmoseopy and Ophthalmoscopic Diagnosis," and is exactly what night be expected from an anthor of such wide clinical experience and trained observation. Beginning with the examination of the eye-that is, with functional testing-the student is easily and gradually led from one examination to another, and made familiar with the best methorls of investigating the organ of sight for the detection of morbid processes. Following this are the chapters on diseases of the eye, the most important of which are clearly described and the best therapentic measures briefly recorded. As Professor Haab himself has pointed out, there is much difficulty in portraying in colors the external diseases of the eye; but, in spite of this, he has succeeded in furnishing an admirable series of plates, to each one of which a brief elinical history is appended, which thoroughly illustrate the text. Perhaps it is not too much to say that while one is reading this manual he distinctly feels that he is in the atmosphere of a large clinic. 
The Editor has compared the translation with the original, and can testify that although it is not precisely literal, it is none the less singularly accurate, and always convers with faithfulness the author's meaning. Oceasional editorial comments are placed in hrackets. It is hoped that this book will prove of we not only to physicians whose opportunities do not permit them to see large numbers of external ocular disorders, but alon to teachers and students of ophthalmology. 


\section{PREFACE.}

AT the request of the publisher I molertook the task of preparing the present atlas and aceompanying treatise, although at the time I fully appreciated how diffieult it is to give a faithful reproduction of the external discases of the eye. But after reeing the work of Mr. J. Fink, of Munieh, at my elinic last summer, I became convineed of his ability to aecomplish anything within the range of the illustrator's art.

With the exception of a few pictures which I alrealy had in my collection, the illustrations were all painted from mature, the artist utilizing any suitable cases that happenerl to come to the clinie. We therefore had to depent largely on chanee for a complete collection of suitable elinieal pietures; but we were fortmate enough to obtain and commit to canvas the most important of such diveases as lend themselves to illustration.

Some things which cannot be satisfactorily reproduced on paper-as, for instance, certain corneal lesions-were not even attempted; while other deficiencies in the collection are explained by failure to secure the necessary clinical material. 
In the treatise on pathology and treatment which accompanies the plates I have confined myolf to essentials-above all, to a detailed description of methods of examination, which I deemed most important to students and practising physicians. For this reason less space has been devoted to operative technique and more to the pathology and to non-operative treatment.

I wish to express my sincere appreciation of the publisher's effints to bring the atlas up to the standard of the excellent series of which it forms a part.

(). HAAB. 


\section{CONTENTS.}

Examination of the Eye in Disease . . . . . . . . . . . 17

1. External Inspection by Daylight . . . . . . . . . . . . . 20

2. Tension of the Eyeball . . . . . . . . . . . . . . . . . 36

3. Testing Acuteness of Vision . . . . . . . . . . . . . . . 38

4. Examination with Lateral Illumination . . . . . . . . . 46

5. Examination by Transmitted Light . . . . . . . . . . . 4s

6. Examination with the Inverted Image . . . . . . . . . 50

7. Examination with the Upright Image . . . . . . . . . . . 50

8. Accommodation . . . . . . . . . . . . . . . . 50

9. Measuring the Field of Vision . . . . . . . . . . . . . . 55

10. Measuring the Light-sense . . . . . . . . . . . . . . . . . . 59

11. Testing the Color-sense . . . . . . . . . . . . . . 60

19. Examination for Disturbances of Mohility . . . . . . . . 62

Ietection of Malingerers . . . . . . . . . . . 74

Diseases of the Lachrymal Apparatus (PLATES 1-3) . . . . . . . To

Dacryostenosis, Dacryocystitis, Ectasia of Lachrymal Sac.

Diseases of the Eyelids (Plates 4-10) . . . . . . . . . . . . . .

1. Inflammations.

Herpes Zoster and Erysipelas . . . . . . . . . . . . 9.2

Eczenı . . . . . . . . . . . . . . . . 94

Seborrhea . . . . . . . . . . . . . . . 9 9

Hordeolum . . . . . . . . . . . . . . . . 100

Chalazion . . . . . . . . . . . . . . . . 10 ?

2. Anomalies in the Shape and Position of the Eyelids . . . . 104

Congenital Ptosis . . . . . . . . . . . . . . . . 104

Eetropion . . . . . . . . . . . . . . 105

Entropion . . . . . . . . . . . . . . . 106

3. Injuries of the Eyelids . . . . . . . . . . . . . . . . . 107

4. Tumors of the Eyelids . . . . . . . . . . . . . . . . . . 108 
Diseases of the Conjunctiva (PLATEs 11-19)

A. Conflucut Inflammations.

1. Simple ('atarrhal Conjunctivitis . . . . . . . . . . . . . 109

2. Follicular Conjunctivitis . . . . . . . . . . . . . . . 112

3. Gonorrheal conjunctivitis . . . . . . . . . . . . . . 113

4. Diphtheritic Conjunctivitis . . . . . . . . . . . . . . . . 119

5. Trachoma . . . . . . . . . . . . . . . . . . 121

6. Spring-conjunctivitis . . . . . . . . . . . . . . . 126

B. Circumseribed Inflammations.

7. Eezematous, Phlyctenular, or serofulous Conjunctivitis . . 129

8. Pemphigus . . . . . . . . . . . . . . . . . . . . . 134

9. Variola . . . . . . . . . . . . . . . 135

10. Acne . . . . . . . . . . . . . . . . . . 135

11. seleritis. . . . . . . . . . . . . . . 135

1?.) Tuberculesis . . . . . . . . . . . . . . . . . . . 136

13. Syphilomata and Leprosy . . . . . . . . . . . . . . 138

Injuries of the Conjunctiva.

1. Foreign Bodies . . . . . . . . . . . . . . . . . . . . . 13-

¿. Ecchymoses . . . . . . . . . . . . . . . . . . . . . 139

3. Burns . . . . . . . . . . . . . . . . . . . . . . . . . . 139

Pterygium . . . . . . . . . . . . . . . . . . . . 140

Tumors of the conjunctiva . . . . . . . . . . . . . 141

Diseases of the Cornea (PLATES 20-28) . . . . . . . . . . . . 143

A. Diffuse Inflanmations.

1. Parenchymatoms Keratitis . . . . . . . . . . . . . . . 143

B. ('ireumscribed Inflammations.

๖. Eezematous Keratitis . . . . . . . . . . . . . . . . . . 149

3. Herpes corneg . . . . . . . . . . . . . . . . . . . . 155

Herpes Zoster . . . . . . . . . . . . . . . . . . . 15.5

Herpes Febrilis . . . . . . . . . . . . . . . . . 156

4. Hypopyon Keratitis . . . . . . . . . . . . . . . . . . . 159

5. Catarrhal Eleer . . . . . . . . . . . . . . . . . . 16\%

Injuries of the cornea . . . . . . . . . . . . . . . . . 16-

Malformations of the Cormea . . . . . . . . . . . . . . . . 169

Diseases of the Sclera (Plite 29) . . . . . . . . . . . . . 171

1. Inflammations of the Sclera . . . . . . . . . . . . 171

$\therefore$ Injuries of the siclera . . . . . . . . . . . . . . . . . 173

Diseases of the Iris and Ciliary Body (I'LATW:30 and :31) . . . . . 17

1. Inflammations . . . . . . . . . . . . . . . . . . . . 17

Srmptoms of Iritis . . . . . . . . . . . . . . . . . . 17t 
PAlif

Symptoms of Cyclitis . . . . . . . . . . . . . . . . . . . .

Causes of Iritis . . . . . . . . . . . . . . . . . . . . . . . . . .

Sympathetic Ophthalmitis . . . . . . . . . . 184

2. Injuries of the Iris . . . . . . . . . . . . . . . . . 1 1 -

3. Tuuors of the Iris and Ciliary Body . . . . . . . . . . . 1nin

Diseases of the Lens (Plates 3:-34) . . . . . . . . . . 1KR

Gataract . . . . . . . . . . . . . . . . . . 186

a. Partial stationary cataracts.

1. Anterior Polar Cataract . . . . . . . . . . . . 191

2. Posterior Polar Cataract . . . . . . . . . . . . 191

3. Perinuclear, Lamellar (ataract . . . . . . . . . . . 19.2

b. Progressive cataracts.

1. Senile Cataract . . . . . . . . . . . . . . . . . 193

2. ('ongenital Cataract. . . . . . . . . . . . . . . . 195)

3. Traumatic c'ataract . . . . . . . . . . . . . . . 195

4. Complicated Cataract . . . . . . . . . . . . 196

Dislocation of the Lens . . . . . . . . . . . . . . . 197

Diseases of the Vitreous Body (Plate 35) . . . . . . . . . . . . . 199

Glaucoma (PlATE 36) . . . . . . . . . . . . . . . . . . . . 203

1. Primary Glatcoma . . . . . . . . . . . . . . . . . 203

a. Inflammatory Giaucoma . . . . . . . . . . . . . 204

b. Non-inflammatory or Simple Glaucoma . . . . . . . . . $20 \pi$

Infantile Glatucoma . . . . . . . . . . . . . . . 20k

2. Secondary Glaucoma . . . . . . . . . . . . . . . . . 211

Diseases of the Orbit (Plates 37-40; Figs. C, D, E, F) . . . . 211

1. Inflammations . . . . . . . . . . . . . . . . . 211

2. Injuries of the Orhit . . . . . . . . . . . . . . . . . . 215

3. Tumors of the Orbit . . . . . . . . . . . . . . . 216 



\section{LIST OF ILLUSTRATIONS.}

Plate 1. Daeryocystitis.

Plate 2. Dacryocystitis with Rupture of the Abscess through the skin.

Plate 3. Lachrymal Fistula on the Right Side; Ectasia of the Lachrymal Sac on the Left; Bilateral Epicanthus.

Plate 4, a. Papular Syphilide.

Plate 4, $b$. Eczematous Blepharitis.

Plate 5. Meibomian or Internal Hordeolum.

Plate 6, a. Eczematous Blepharitis.

Plate 6, $b$. Molluseum Contagiosum and Exterual Hordeolum.

Plate $7, a-c$. Multiple Chalazion.

Plate 8. Blepharochalasis on both sides.

Plate 9. Blepharochalasis. Ptosis. Epicanthus.

Plate 10. Subcutaneous Hemorrhage in the Lids after Fracture of the Base of the skull.

Plate 11, $a, b$. Dermoid Tumor.

Plate 12. Gonorrheal conjunctivitis in the New-horll.

Plate 13, $a, b$. Diphtheritic Conjunctivitis.

Plate 14, a. Trachoma of the Lower Lid.

Plate 14, $b$. Subconjunctival Ecchymoses (Hyphæma ('onjunctivæ).

Plate 15, a-d. Spring-conjunctivitis.

Plate 16, a. Chaff-particle at the Corneal Iargin.

Plate 16, $b$. Pterygimm.

Plate 17. Eezema of the Conjunctiva and of the Face.

Plate 18, a. Marginal Eczema-pustule.

Plate 18, $b$. Epithelioma of Cornea and Conjunctiva.

Plate 19, $a, b$. Lime-burn of the Conjunctiva and Cornea.

Plate 20. Herpes Zoster Ophthalmicus.

Plate 21. Foreign Body on the Cornea and Dermoid Cyst of the Orbit.

Plate 22. Eczema of the Cornea and Conjunctiva on Both sides.

Plate 23, a. Perforation of the Cornea by an Eczematous Ulcer, with Adhesion of the Iris. 
Plate $23, b$. Iacula of the Cornea.

Plate 21. Herpes Cornege Febrilis.

Plate :5, 1 . Iferpes Cornege Febrilis.

Plate 25, b. Hypopyon-keratitis.

Plate 26, $a, b$. Serpiginons Llcer of the Cornea: Pterygium.

Plate 2\%. Silpuration of the Cornea from serpiginous Ulcer; Pan. ophthalmitis.

Plite 2d, ". Trachoma, with Panuts of the Cornea.

Plate 2s, $b . \quad$ Phthisis Bulbi Anterior; Caleareous Degeneration of the (ornea.

Plate 2s, c. I'arenchymatuus Keratitis.

Plate 29, ". Soleritis.

Plate 29, b. Sequelae of seleritis and sclerotizing Keratitis.

Plate 30, a. Sarcomal of the Iris.

Plate 30, b. Siphilitie Iritis.

Plate 31. Syphilitic Condylomatous Iritis.

Plate 32, a. Sienile Catarat.

Plate 3\%, b. Trammatic Cataract.

Plate 33, a, b. Zonular Cataract.

Plate 33. Incipient Senile (ataract.

Plate 34, ". Anterior Polar ciatarat.

Plate 34, b. Subeonjunctival Displacement of the Lens.

Plate 35, a. Suppuration in the Vitreons, caused by a Piece of Irom.

Plate 35, b. Panophthahmitis from the Entrance of a Piece of Iron into the Vitreous.

Plate'36, a. Acute Glancoma.

Plate 36, b. Laceration of the Iris and Lens by a spicule of Iron.

Plate 37. Sarcoma of the Choroid.

Plate 3-, n, b. Glioma of the Retina.

Plate:39. Exophthalmos.

Plate 40. Pulsating Exophthalmos of the Left Eye.

\section{FIGURES IN TEXT.}

Fig. A. Diagram showing Action of Extermal Eye-muscles . . . 63

FIc. B. Diagram showing Double Images in Paralysis of the Superior Rectus, Inferior Oblique, Inferior Rectus, and superior Oblique of the Left Eye . . . . . . . . . . . il

Fic. C. Dermoid Cret of the Orbit . . . . . . . . . 216

Fic. 1). Bone-cyst, due to Eutasia of the Ethmoid cells, Frontal Sinus, and Nasal Cavity . . . . . . . . . . . 218

FIti. E. Angioma of the Orbit . . . . . . . . . . . . 220

FIti. F. Cancer of the Upper Mlaxilla and orbit . . . . . . . . 2223 


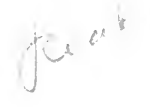

\section{EXTERNAL DISEASES OF THE EYE.}

\section{EXAMINATION OF THE EYE IN DISEASE.}

Is ophthalmology, as in other fields of medieal activity, success in diagnosis depends, above all, upon the experience of the diagnostician. Only second in importance, however, is a definite, systematic routine in examination, the faithful observance of which will eventually become seeond nature to the surgeon, so that he will almost instinctively apply all the varions methods of examination one after the other in their proper order.

Owing to the ease with which both the exterior and the interior of the eveball an be reen, the great majority of its external as well as its internal alterations and discases can be determined with albolute certainty, ustally at the first examination. Those cases in which the diagnosis must be confirmed or corrected by oherving the course of the disease or the effect of treatment (e.r jurantibus) form a small minority and in only a very few diseaseprocesses is the true interpretation obtained from the autops. The ophthahmic -urgeon is rarely forced to conchude his diagnosis with the phrase "sectio docebit" -a virtual admision of failure.

Nevertheless the practice of ophthalmology, if based on the proper recognition of lisease, is by no means without its difficulties. The physician is confronted and perhaps misled by a multitude of proceses differing but slightly from each other, by a rich variety of clinical pictures, and by the difficulty of recognizing many important pathologic conditions in the eye, either because the lesions to be looked for are very small or because they are apparently unimportant-that is, they present well-nigh imperceptible deviations from the normal. 
To this diversity of phenomena, on the one hand, and to the extraordinary demands on the observer's eyesight, on the other, must he attributed the many cases of mistaken diagnosis which, in spite of the ease and clearness with which both the exterior and the interior of the eye can be seen, unfortunately oceur in this, as in other branches of medicine. The most deplorable result of such diagnostic error is blindness, which occurs only too frequently, as, for instance, in eases of glaucoma.

It is therefore important for the student of medicine to familiarize himself as much as possible with ophthalmology, as he is likely at any time, as a practising physician, to be obliged to resort to ophthalmic surgery, which he will then ralize is as vital a branch of medicine as surgery or obstetrics, for to many people blindness is as great a calamity as death itself.

The student will readily appreciate the importance of a thorongh training in ophthalmology if he will reflect for a moment that it is often impossible to refer an eye-patient to a specialist, unless one happens to reside in the same place or in the immediate neighborhood. To be sure, evepatients are often transportable-i.e., able to travel-but not always, when it happens that the morbid process, as, for example, in certain forms of glaucoma, has much debilitated the subject by pain, romiting, etc.; or when a new-born infant is concerned, whom the parents object to send on a journey ; or when certain external conditions, such as advanced age, poverty, ete, make travel impossible; or, finally, when the ocular disonder is accompanied by other grave disturbances which put travelling out of the question.

In many cases the loss of time alone incurred by consulting a specialist resiling at a distance might entail irreparable injury on account of the fatal delay in applying the proper remedies and the consegnent ravages of the disease in the delicate organ, which the most skilful hand is unable afterward to remedy.

Mention has been made of the great demands on the 
examiner's eyesight in the study of ocular affections; the same remark applies to the actual practice of ophthalmology. It is therefore quite in order, before beginning a detailed description of the most efficient method of examination, to devote a few words to the most essential requisite in such an examination-the visual apparatus of the observer. I have often observed that medical men take up ophthalmology as a specialty without fully realizing the prime importance of good eyesight in this branch of medicine.

Although the use of a lens (corneal loupe) may to some extent correct defective eyesight in the examination of the anterior portion of the eye, yet in working with the ophthalmoscope imperfect visual acuity is always a distinet disadvantage. A person with marked astignatism suffers most in this respect both in examining the exterior and the fundus of a diseased eyeball; it is only with the greatest difficulty that he is able to see the most essential points, if they do not escape him altogether.

A moderate degree of myopia (1-3 D) is less troublesome than hypermetropia. As age advances the hypermetropic eye requires convex glasses, which are a great obstacle to delicacy in examining and operating; or, at least, are very unpleasant and multiply the difficulties of the task.

Binocular vision, the power to see with both eyes at once, is, of course, essential for obtaining a correct stereoscopic picture; and as the diagnosis of many pathologic changes in the eye depends on a correet understanding of the appearances in the fundus, one who is able to study them with one eye only is thereby deprived of a very important aid, especially when a rapid survey of a given phenomenon in all its dimensions is desired. Again the lens can throw itself into the breach and make up for the absence of binocular vision ; but in operating its use is out of the question, or is at least a disadrantage. By long practice he who has but one sound eye at his disposal, or whose eyes do not work together properly, may pos- 
sibly overeome the defect to some extent; but he will almost certainly be ontstripled in the race by better equipped eompetitors. Even if he has suceeded, atter much trouble, in correcting the defect by long practice and by the use of various appliances, ases of musual difficulty either in operating or exploring will always present themselves, in which he will be more or les: at a disalvantage compared with one whose eyeright is perfect.

Althongh I have known oculists who practised their profession successfully in spite of aggravated astigmatism or the virtual loss of one eye, my advice to a medical man who eontemplates devoting himself to ophthahmology is no less emphatic, not to do so, muless, upon eareful examination, it is foumd that each eve has at least 1.5 the visual acuity of the average normal eye, that hinocular vision is perfect, and that he is not color-hlind. Any one who, lacking these requisites, takes up ophthalmology as a specialty, will find it difficult to attain proficieney and will be in constant danger of being distanced by men who are better equippod by nature.

To introduce the student to the study of ophthalmology we shall first give a detailed description of the methorls which lie at the fommation of the examination for diagnostic purposes. After that the plan of study will eonsist. ehiefly of accurate descriptions, with illustrations, of pathologic processes and their numerous varicties.

The first step in the examination of an eye-patient, be the disease external or internal, is

\section{External Inspection by Daylight.}

The patient is placed on a chair facing a window, in a strong light, the observer standing with his back to the window. It is better not to take the history until after the examination, exeept the most necessary points or such as the patient cannot be prevented fiom giving, as the correct interpretation of oljective signs would be dis- 
turbed by incorrect data and explanations on the part of the patient.

The entire person is first rapilly inspected, and any departure from the nomal noted. Abnormal appearance of the face-pallor, redness, or yellow, eacheetic discoloration-the signs of rapirl loss of flesh, ete., must be carefully noted. It is especially important to look for traces of disease in the exposed parts of the skin, the face, the neck and throat, and the hands. This examination should inelude a search for recent or old exanthemata, especially cozema, syphilitic cruptions, etc.; or the scars of such skin-lesions. Next the examiner looks for signs of injury to the integument, as abrasions, contusions, subeutaneous hemorrhages, or womnds of any description, and should be careful not to forget them, if found, especially when the eve is said to have been injured. This examination must never be neglected in eases which from the beginning come to the notice of courts of law, or in which an actionable accident is alleged as the cause of the disorder.

The condition of glands under the jaw and at the angle, at the back of the neck, and in front of the oar should be investigated to determine if there is any swelling or any sears or fistulae. Joint-affeetions and old ankyloses should also claim attention.

Alopecia, if of recent development, is important as pointing to the possible presence of syphilis, which so often plays a part in liscases of the eye. Eezena and seborrhea of the hairy scalp are also valuable diagnostic signs, as will be explained more in detail later on.

The result of this preliminary inspection of the exposed portions of the skin and of the glandular system, etc, will determine whether it is necessary to examine the skin of the entire borly; in any case this examination, as well as that of the body in general, can wait; and attention is next directed to the exterior of the eye. It is adrisable not to examine the eye at short range at first, as certain general appearances, such as traces of epuptions, slight differenees between the right and left sides of the 
face, differences in the palpebral fissures of the two eyes and in the size and shape of the eyeballs, are best appreciated from a distance.

If there is a squint of one eye, we test the mobility of the eyeball by making the patient look to either side and up and down. The same examination is repeated if one eye is more prominent than its fellow, a condition called piotiusion. Under certain circumstances testing the mobility may have to be postponed, and inspection is continned.

The region of the lachrymal sac (to the nasal side of the inner canthus) is first examined. If the least degree of swelling, and especially if redness, is observed, it ought to suggest catarrh or inflammation of the lachrymal sac-in short, dacryostenosix, which must then be borne in mind. The abnormal contents of the sac can often be squeezed out by pressure with the finger through the lachrrmal puncta, even when there is no visible swelling of the lachrymal sac, and only a slight increase of fluid in the eye-socalled "swimming" of the eye-to suggest defective discharge of the lachrymal fluid.

Dacrrostenosis cannot be diagnosed with certainty without flushing the lachrymal duct, a procedure which is best undertaken at the end of the examination. We shall discuss this point in detail when we come to treat of disease of the lachrrmal apparatus.

Before proceeding to the study of the eve itself and any defects there may be in it, a rapid inspection is made of the eyelids for the purpose of noting any abnormal conditions, such as misplaced cilia or deformed or diseased palpebral margins; for these structures are frequently the seat of discase. It should be carefully noted whether the lachrymal puneta are in their proper places (at the nasal extremity of the lid) and whether they communicate with the tear-lake (lacus lacrimalis).

If the eye is opened naturally, the region of the palpebral fis-ure is inspected without touching the lids. If the palpebral fissure is too narrow, the lids may be gently drawn apart and the inner surface of the lower lid ex- 
amined by drawing the lid downward, if the previonsly found conditions make it desirable.

The inner surface of the upper lid may also be examined at this point by everting the lid. Often, however, it is advisable to defer this procedure or sen to omit it altogether, since it may not be necessary, if the disease is intermal, and would interfere with the tests for vismal acuity, or at any rate umeessarily distress the patient. In leep wounds of the eyeball the act may be downright harmful.

Eversion of the eyclid is cffected as follows: The left thumb, held with its volar surface nearly in a horizontal plane, is pressed on the eyelid a little below the evebrow so as to draw the skin gently upward, enough to obliterate the wrinkles (in clderly people), and at the same time to separate the palpebral margin from the eyeball. Next the lid is seized with the thmmb and index-finger of the right hand, either by the cilia, or, if there are none, by a fold of skin near the margin, and drawn downward, while the patient is told to look down as much as posible. The lid is now taut and ean be turned over the left thumb, which is at the same time moved lownward, presing the upper edge of the tarsus back and down, while the right hand draws the lower margin of the lid forward and upward. If it is found imposible to evert the lid in this way, a probe or glass rod may be substituted for the left thumb. This will enable one to accomplish it even when the patient is awkward and fails to look down, or shuts his eyes convulsively. The more gentle the operation the better it will sueceed; and the clumsier the hand of the operator the more violent will be the struggles and the greater the difficulties. The lid can also be everted with one hand; but this method is not to be recommended, as it is too severe.

While the inspection of the eyelall and of the inner surfaces of the eyelids usually presents no special difficulties in the aduit, it is a much more troublesome matter in the ease of new-born infunts and children, and requires 
certain special precantions which merit particular deseription. I have often observed unsatisfactory results in the examination and treatment of children which were due solely to the inexperience and want of skill of the operator, ignorant of the proper methods of overeoming the resistance which the little sufferers nsually offer to the manipulations. Here again the rule is to conduct the examination with firmmesindeed, but with all possible forbearance, not only beeause the strugales increase in proportion to the want of delicacy, but al-o because a sudden wrenching apart of the eonvulsively closed eyclids is apt to result in serious injury to the cornea and in lacerations of the onter canthus; or the fissures in the outer canthus eaused by the action of the lachrymal fluid, a frequent canse of blepharospasm in children, are aggravated and thereby tend to enhance the spasm, which in tum delays recovery.

In order to examine and treat with comfort, safetr, and despateh children "1]' to the age of ten years, the first step is to put them into the proper posture. The operator takes his position so that he has the window or lamp to his right or left; the nurse or, if she is a sensible woman, the nother sits opposite him, holding the ehild's legs moder one arm. The child's hack is supported on the nurses lap and its head rests on, or is held between, the operator's knees (which he has previously eovered with a towel). (In the ase of new-born children cale must be taken not to exert too grat pressure on the head.) After the nurse has secmed lowth the child's hands the examination can proceced quictly and withont listresing the little one, the light falling full on its face.

First, the eyes are carefully dried with ahsollent cotton. Wet, slippery evelids cammot be separaterl cither in adults or in children, beanse the fingerse cammot secure a hold without the use of such forese as to provolie spasm. In many aases it is an adrantage to wrap the fingers with ganze before attempting to soparate the erelicls. If with all these precantions it is fomnd imposilile to separate the lids on aceomet of swelling or spasin, or both, they shonld 
be gently and carefully drawn apart with I ex:marre's lidelevator, are being taken that the surface opposed to the eyeball is perfectly smooth, so als to aroid injuring the cornea. The instrument must, of comrse, be absolntely. rlean. One elevator for the upper lid is mistally all that is needed. Ift, as often happens in private practice, there is no elevator at hand, the physician an easily improvise one from an ordinary hairpin by bending the closed end sol as to form a hook about $1 \mathrm{~cm}$. long, which may then be earefully inserted under the evelid. The hairpin must be perfectly smooth, and cleaned by lieating before it is used. It is much better to resort to this primitive device than to foree the lids apart with the maided fingers, for it requires a very skilful hand to separate such tightly cloced eyelids in a struggling ehild without an instrument and without injuring the corncis.

Eversion of the eyelid, on the other hand, is very eaty in such children; indeed, it often oceurs when it is not desired. One of the chief uses of the elevator is to prevent eversion, as the object of the examination is ustually to inspect the cornea and surrounding parts, rather than the inner surfaces of the lids, and if the latter are everted inspection of the cornea is imposibible.

It is often necessary to evert the upper eyelid in the examination and treatment of ophthalmia neonatorim. In such cases any injury to the cornea by the finger-nail would be fatal ; the least scratch or the slightest loss of tisne might entail the loss of the eye. Henee the holder should always be used when the eyeball is inspected, especially if the lids are swollen. As has been pointed out, inspection of the imner surface of the lids in snch eases is quite easy, becanse the upper lit umally turns over as soon as the skin is drawn upward. If it fails to doso, however, the operator should wait until the baby cries, when the lid can easily be everted, even in the later stages after the swelling has subsided. Gentle traction of the outer canthus toward the temple assists the eversion and tends to fix the lid in the ererted position (ectropion). 
In treating children with severe blepharospasm the following mut be borne in mind: Even after the operator has tinally succeeded in opening the lids the cornea cannot always be seen, because it is convolsively rolled upward. Scolding the child only makes matters worse; the only thing to do is to wait patiently, avoiding all presure on the part- to be examined and encouraging the child hy speaking to it kindly. Usually the evelall is rolled downward somer or later, if only for a short time, so that the cornea can be inspected. If the spatsm is so severe that the eye fails to rotate downward of its own accord, a few drops of coeain should be instilled and the result awaited. Forecp shonld be used only as a last resort; the parts are first thoronghly cocainized and the instruments must be handled as genty at posible.

Aways insist on making a thoroingh examination of the cornea and surrounding parts until a clear view of the entire corneal region has been obtained, no matter how much the child cries and struggles. The greatest care is nece-sary not to exert undue presiure on the eveball, for such children often have deep ulcers of the cornea, whieh are liable to burst from the slightest pressure on the ere, causing permanent injuries by inearceration of the iris, distortion of the pupil, etc. Indeed, rupture of the floor of the uleer may result in los- of the eve through infection, especially if the arrstalline lens is forced through the perforation, an aceident which quite easily may happen.

So much for the technie of the external examination of the eve in children, the importance of which eannot be overe-timated.

In the inspection of the eyeba11, to which we now turn our attention, the following precautions are to be observed: If there is redness, its nature-i.e., first, its sitnation and, second, its color-affords an important clue to the seat of the diseate, and therefore to the diagnosis. The following points are to be noted: 
A practised eye readily distinguishes between inflammation of the conjunctiva, in which the conjunctival vessels are congested, and inflammation of the cornea or iris, although both conditions produce a redness of the eye. The first condition is called conjunctiral, the second ciliary, congestion. The first, or conjunctival congestion, is characterized by the fact that it is most intense where the blood-ressels are most marked-i.e., at the fornix and in its immerliate neighborhood-and decreases in intensity as it approaches the corneal margin, being absent in the immediate neighborhood of the cornea, so that there is a zone about $5 \mathrm{~mm}$. broar in which the blood-ressels are very pale (see Plate $14, a$ ). This centripetal increase in the intensity of the congestion also appears in the marked redness of the caruncle, situated at the inner canthus, and of the plica semilunaris next to it on the temporal side, which is very conspicuous in conjunctival inflammation, and even at a distance betrays the congestion of the conjunctival vessels, as, for instance, in acute conjunctival catarrh.

Ciliary or cireumeorneal congestion, on the contrary, increases as the corneal margin is approached, is most distinct at the corneal margin, and diminishes uniformly at every point as the periphery of the anterior segment of the globe is approached (see Plate 21). The most distinctly congested corneal zone is from 3 to $7 \mathrm{~mm}$. wide, and corresponds approximately to the zone least involved in pure conjunctival congestion. Hence, whereas conjunetival eongestion decreases in intensity as it approaches the corneal margin, ciliary congestion diminishes in intensity as it recedes from the corneal margin. The bloodvessels concerned in ciliary inflammation are so deeply placed and, in part, so minute that they cannot be seen as well as the conjunctival vessels.

Dissegarding the question of localization, quite a difference in the color of the two forms of congestion may be observed, if one has a good eve for color. The color of a conjunctival congestion is yellowish or "brick-red;" that 
of a ciliary congestion is more bluish, "pink," "scarlet," or "erushed raspberry" (Plates 21 and $30, b$ ).

The differences in color and in localization are readily explained by the arrangement and distribution of the hlood-rescels concerned in each form of congestion.

Conjunctival congestion is due to abnormal distention of the conjunctival vestels, barely visible in the normal eye on aceount of their tenuity. The ressels in the sclerotic portion of the conjunctiva make their appearance at the fornix, and from all sides radiate forward and outward toward the cornea, brealing up into arborizations as they proceed and thereby becoming more and more minute. This enlargement furnishes the anatomical explanation of the diminution of the intensity of a conjunctival congestion as it approaches the cornea. As these vessels are very superficial, they show the true color of the blood when overtilled, which in thin lavers is a yellowish-red. Moreover, the conjunctival resels ean be recognized by their mobility with the shifting of the conjunctiva, which is but loow cly attached to the sclerotic, especially at some distance from the cornea. This mobility is often of sorvice to clear up any doubts about the nature of such a b) lond-resiel.

The resels that are responsible for ciliary or ciremcorneal congestion are very different in their arrangement and distribution. In the first place, they are situated benerth the conjunctiva. They also are but faintly visible in the normal eve; in fact, only the arterioles are virible, their accompanying venules becoming manifest only when the eve is inflimed. These arterioles proeed from the tendons of the recti muscles, either singly or in pair's, pursue a very tortunse comse in radiating lines to the comen, and suddenly disippear at points several millimeters distant from the corneal margin, by entering the sclerotic, in which they ramify, and contribute largely to the blood-supply of the ciliary body and iris (ciliary region). Their points of entrance inte the sclerotic are often distinctly tinted and plainly visible. They are 
called the anterior ciliary vessels, while those which enter the ehoroid at the back of the eyeball are known as the posterior ciliary ressels. The anterior ciliary vessels, before entering the selerotic, form ramifications, the branches of which anastomose with one another and form a dense plexus of eapillary loops around the eornea. Since both the larger arterial trunks and their more minute branches about the eornea lie beneath the conjunctira, between it and the selerotie, ${ }^{1}$ they do not move with the shifting of the conjunetiva, and present a bluish (lilac or violaceous) coloration, for the simple reason that the eonjunctiva acts as a turbid medium, through which the bloor has a bluish tint. If a thin layer of milk is spread over a black surface, the milk appears blue, and in a similar way the bluish tint which we observe in the ciliary vessels is formed.

It must be borne in mind that the superficial conjunetival ressels and the deeper ones of the eprisclera communicate with each other at the corneal margin, so that the conjunctiva receives some of its blook-supply from the ciliary region, through certain small branches which enter it from the episcleral, pericorneal plexus, and which in it (usually in straight lines) run backward (anterior eonjunetival ressels). This explains why a ciliary congestion of some duration gradually produces more or less hyperemia of the conjunctival system also, resulting in a combination of the two forms of congestion. The converse, however, is not true: So long as the cornea is not affected a long-eontinned conjunetival congestion is not apt to induce ciliary congestion.

The eornea posiesses the peenliarity that as soon as it sutfers the least injury from a scrateh-wound, the entrance of a forcign body, or inflammation from any eause, the characteristic uniform circumcorneal congestion immedi-

1 Occasionally a ciliary artery, ruming from without and below, or from withont (temporal) inward toward the cornea, is seen lying in part within the conjunctiva and movable with it. Such a branch is derised from the palpebral arteries. 
ately makes its appearance and thus brings the lesion promptly to the surgeon's notice. The injury or inflammation may be very slight and much time and care may be required for its detection; hence, in every case of ciliary congestion the cornea should be subjected to a thorough examination. If nothing abnormal is found in the cornea by the methods presently to be described in detail, the cause of the circumcorneal congestion must be sought in irritation or inflammation of the iris or ciliary body (iritis, cyclitis).

The foregoing description applies to general congestions affecting the entire area of distribution of each system of blood-vessels; in addition, we have to consider the local or circumscribed congestions which occur in both systems and which may be limited to a small area. This happens, in the case of the conjunctiva, when there is a local, circumscribed lesion-for example, a slight wound or localized inflammation in the form of an eczema-pustule (phlyctenule)instead of a general process affecting the entire mucous membrane, as, for instance, in acute catarrh. Under such circumstances the hrperemia, which is superficial and yellourish-red in color, is limited to the immediate neighborhood of the injury or inflammatory center ; or, to be accurate, to the system of ressels in the affected area.

In a localized ciliary congestion the appearance is different. The color is darker and more bluish ; the vesscls can scarcely be made out; and the color does not disappear upon pressure with the finger on the evelid as readily as in conjunctival congestion. Circumscribed ciliary congestion is caused by inflammation of the sclela, which usually is circumscribed, or hy a deep wound of long standing in the sclera.

It is this accurate knowledge of the differences between the various forms of congestion which enables the practised examiner to diagnose a given case with a rapidity which astonishes the beginner. For instance, he recognizes conjunctival catarh at a glance by the alnormal color at the inner canthus, in the region of the caruncle, plica semi- 
lunaris, and adjoining conjunctiva. In another case, guided solely by the ciliary congestion, he promptly locates the seat of the inflammation or injury in the eornea, although the injured spot is barely visible. He then looks for further signs of the morbid process, and in a short time the diagnosis is formulated and eren the etiology determined. For instance, a patient enters the room with the characteristic alopecia and red blotches on the forchead, along the line of the hair, strongly suggestive of syphilis. There is a ciliary congestion in one eye; on further inspection the pupil is found to be irregular in ontline (instead of round) from serrations which encroach on the papillary border, and in the iris there are yellowish-red, thickened areas. The diagnosis of syphilitic iritis is reached in less time than it takes to read this example. Not to anticipate, however, we will proceed to describe the method of examining that important structure, the cornea, which is such a frequent seat of disease.

Examination of the Cornea.- $\mathrm{We}$ e determine two things : First, the condition of the surface; and, second, the transparency.

The surface of the normal cornea acts like a small convex mirror in reflecting a sharply defined, small upright image of objects placed in front of it with the usual distortions incident to convex mirrors. Thus the image of window-bars reflected from the corneal mirror of a patient seated before the surgeon appears slightly bent (convex), but clear-cut and distinct. This image of the windowbars is utilized to test the condition of the corneal surface, by allowing it to fall conseentively on different parts of the cornea. The patient is required to follow the uplifted finger as it is moved up and down and to either side while the surgeon watches the reflection in the cornea and is able to detect the slightest inequality in its surface. Such slight irregularities are not uncommon, and may be of several kinds:

1. The image in one part of the cornea, without being at all distorted, may appear somewhat indistinct; the 
surface is evidently oparue at this point, it looks as if it had been breathed upon, and, like a moist window-pane, is a poor reflector. Opacities of this kind usually correspond to inflammatory areas. Opacity of the entire cornea indicates either a general inflammation or glancoma. 'The precise nature of such an opacity will be described later; for the present, suffice it to say that in many cases this opacity alone should lead us at least to suspect glaucoma, and may point the way to a correct diagnosis; we therefore emphasize the importance of noting accurately the reflecting powers of the cornea.

2. The image of the window-bars may be perfectly clear and distinct, but the distortion may be greater than normal. It may be limited to a portion of the image, or it may be gencral. In the first case the distorted portion of the image is usually found to correspond to an area which, although smooth, is either depressed below, or elevated above the general level, or presents a plane surface. The latter condition is sometimes called a ficet.

The distortion may be general. Two conditions are possible. Either the entire surface is rough and irregular, or beset with numerous facets, as, for instance, after repeated ulcerations; or, more rarely, the general distortion of the image is due to incorrect curvature of the entire cornea, giving it a more or less conical shape, a condition termed leratoconus. The image is very small at the aper of the cone and increases in width as it approaches the corneal margin, where the lateral portions of the membrane (between the conter and the margin) take part in the reflection. Keratoconns is a scrions disturbance to vision; it is most surely recognized by observing the nature of the corneal image-another reason for training the ere in the study of corneal changes.

3. Under certain circumstances opacity may be combined with irregularity of the surface, as, for example, more or less rough depressions from recent ulcers, or opaque elevations from imprisoned foreign bodies, or a 
rongh prominence due to an epithelial neoplasm. Foreign bodies embedded in the cornea are a very common ocentrence in practice; their presenee can always be discovered by the disturbance they cause in the corneal reflections. The following precaution is needful in many cases: Slight irregularitien of the cornea, such at follow eezema, for instance, are more easily detected if the flow of tear's is checked for a moment; hence, if it is very eopious, the lidk must be held open and the fluid allowed to run off, before the inspection is begun.

After the condition of the corneal surface has been determined in this mamner, we proceed to test its trensperency. This is often disturbed in morbid procestos, notably in inflammations. Colorless blood-corpuscles invalling the corneal tissue produce a general or local opacity, ranging, according to the kind and degree of inflammation, from an almo:t impereptible, bluishli-gray film to complete opacity, grayish-white, or, if the inflammation is purulent, even distinctly rollow in color. The eye should be carefully trained to recognize the slightest degree of rellowish discoloration, as it indicates that the disease his asimed a distinctly purulent character and the prognowis is proportionately grave. The yellow color of such an infiltration an be seen better by laylight than by artificial light.

()ther colorations of a more reddish hue on a gray background sometimes oreur in the cornea. Newly formed blood-rescols enter the inflammatory area from the corneal margin and form a delicate plexus which produces a faint reddish sheen. Usnally at least the larger branches ean be seen with the naked eye.

Another form of opacity, with or without blood-ressels, is produced by the scars left by former infiltrations which ended in ulceration. Sometimes these cicatricial opacities are distinctly whitish or grayish-white, so that we speak of white spots or lenkomatr. When the dots are not very pronounced their grayish color is so like that of a recent infiltration that a beginner finds it diffieult to distinguish 
between the two forms; not so the experienced practitioner, however, for he knows that a recent inflammatory infiltration, whether it is localized or diffuse, aluays has a dull surface, whereas an old macula posisesses a good reflecting surface. Once more the value of studying the reflecting properties of the cornca is exemplified, since it is important to be able to distinguish between an old opacity and a recent corneal inflammation. Opacities of long standing usually have a bluish tint, but the surest way to recognize them is by their smooth surface.

With the growth of accident-insurance the ability to determine the age of a corneal opacity becomes more and more desirable. It frequently happens that holders of accident-insurance policies attempt to ascribe to a recent accident an opacity which has existed for some time, in the hope of obtaining damages for it along with the recent injury. The following example may serve to illustrate the importance of carefully examining for corneal opacities : A patient exhibits ciliary congestion, suggesting the probability of corneal disease. There is, in fact, a circumscribed corneal opacity, and the diagnosis of keratitis seems plausible, especially as he complains of pain in the eye ; but on inspection the opaque area is found to be perfectly smooth; further examination shows that the pupil is not quite round and that the iris is dull and discolored; in short, it turns out to be a case of iritis. The corneal opacity is due to a former inflammation which the patient had in his youth, and he is, of course, much impressed when we tell him that he had inflammation once before in the same eye.

In persons with blue or gray irides, corneal opacities, being practically of the same color as the iris, camnot be readily distinguished except over the black pupil. Artificial light, presently to be described, is needed-indeed, the information afforded by lateral illumination is so valuable that it must never be omitted, even in the examination of persons with dark irides.

In the mean time, we continue the examination by day- 
light, examining the anterior chamber and its posterior boundaries, the iris, and the crystalline lens.

First we note whether the anterior chamber is of normal depth, abnormal depth, or shallow, by ascertaining the distance of the iris from the cornea in each cye and comparing one with the other. For example, the temporal half of the anterior chamber may be quite shallow, while the nasal half is abnormally deep. This usually indicates that the lens is displaced outward toward the temporal side. If this is the case, a slight tremor of the nasal portion of the iris is observed when the eye is moverl. 'The tremor may extend over the entire iris, especially if the lens is absent, as, for example, when it is dislocated into the vitreous body.

Abnormal contents of the anterior chamber, such as a grayish-yellow or yellow exudate, blood, ete., must not be overlooked. A narrow, yellowish band, or mere line in the lowest portion of the anterior chamber, inclicates the presence of pus and is considered a serious symptom. The phenomenon is called hypopyon. Foreign bodies are occasionally met with in the anterior chamber.

Pathologie discolorations of the iris-in inflammation, for instance-can be seen much better by daylight than by artificial light, which is always more or less yellow. The normal color of the two eyes must be compared, as the color of the two irides may differ in health, although rarely.

Comparison of the two pupils in respeet to size, shape, and reaction to light is of the highest importance. As is well known, difference in the size of the two pupils may be a very grave symptom, indicating disease which may involve much more than the eye alone; for example, paresis or tabes.

The size of the pupil is also affected by light and convergence. A preliminary examination may be made by alternately illuminating and shading the eye with the hand; but in most cases this must be supplemented by an examination with artificial light. To obtain a correct idea 
of the shape of the pupils they must be examined in a dark room.

Abnormal coloration of the pupil, erystalline lens, and vitreous body is best scen by daylight. Bluish-gray or grayish-white dots and streaks in the pupillary region indicate eataraet. In clerly people a slight, grayish filminess is sometimes observed, aplarently in the deptlss of the lens, which has often led inexperienced men to diagnose cataract; the phenomenon is produced by the increased reflecting power of the lens, due to the sclerosis of age. Cataract cannot positively be said to exist unless examination with artificial light, in the manner to be described, reveals distinct opacities in the substance of the lens.

Finally, the appearances in the deepest portion of the eye, the vitreons body, are noted in the examination by daylight. Every shade of rellow, red, brown, gray, ol blue may be seen reflected in its substance. These reflections are often of grave ignifieance, as, for example, in the condition shown in Plate $38, a$, where they indieate the presenee of a very malignant tumor on the retina. Similar clinieal appearances may be dne to inflammatory exudates in the vitreous body or to severe hemorrhages, in which case the color of the hlood is more or less pronomnced.

So much for the examination of the eye by daylight. Wre may conclude it by testing the

\section{Tension of the Eyeball.}

The degree of intraocular pressure is tested with the finger-tips, just as we test the consistency or fluctuation of a tumor. The patient is told to look straight before him or very slightly downward, so that the tips of the two index-fingers an be placed alose together on the npper lid, over the region hetween the upper margin of the comea and the equator of the eychall. (rentle pressure is exerted alternately with anch tinger, the other preventing the erlobe from rolling or moving to one side. The arms should be held in an easy and perfectly sym- 
metrical position, so that the muscular tension is the same in both arms, and to do this the operator must stand in front of the patient, not to one side. For similar reasons it is better to use the two index-fingers, instead of the index and middle fingers of the same hand.

The patient must be careful to aroid extreme downward rotation of the eyeball, as it might have the effect of raising the tension by increasing the pressure of the external eye-muscles. In rotating the globe downward the inferior rectus and superior oblique exert a direct pressure upon it, and the elevators (superior rectus and inferior oblique) do likewise, because they are put on the stretch and thereby brought into close contact with the eye. Slight as it is, this increase in the tension is enough to affect the accuracy of the test.

It is not possible to obtain trustworthy results in patients who during the examination tightly close the lids, especially in screaming children. By persuasive and careful examination it is usually possible to accomplish the end in the case of an adult, even when the eyeball is sensitive to the touch. With children it is different, and in eases of suspected increased intraocular tension narcosis may be needed before the examination is satisfactory.

The beginner will do well to practise this important part of the examination as much as possible on normal eyes, so as to become thoroughly familiar with the resistance of a normal eyeball.

This method of estimating intraocular tension with the fingers is, of course, not very accurate, depending, as it necessarily does, on the subjective feeling of the surgeon, which is largeiy a matter of experience. When the tension is excessively high or excessively low there can, of course, be no doubt that the eye is abnormal; but slight departures from the normal are not always so easy of detection, especially as there are individual variations within physiologic limits. Thus the eyes in youth are usually less resistant to the touch than in old age, when the sclera has become rigid. Here again "practice makes perfect," and the experienced can, as a rule, dispense with the instruments that have been devised to measure intraocular tension, except in very unusual cases. These instruments, ealled tomometers, have their fallacies; some are very complicated and it is not always convenient to use them. The most serviceable, as far as mo experience goes, are those designed by A. Fick and Maklakow, both of which yield fairly accurate results if properly 
handled. To obtain accurate results with Fick's tonometer an assistant is needed, and great care is necensary. Maklakow's method is easier and simpler.

The ideal war to express the tension would he by the number of millimeters in a column of mereury corresponding to the intraculatr pressure in each ease. Instead, however, as the tension is tested with the finger-tips, we designate increased resistance by $\mathrm{T}+1, \mathrm{~T}+2, \mathrm{~T}-3$, and decreased resistance by $\mathrm{T}-1, \mathrm{~T}-2, \mathrm{~T}-3$, where $\mathrm{T}+3$ denotes that the finger is mable to produce any appreciable depresion in the eyoball, and $\mathrm{T}-3$, that the finger feels no resistance whatever-the globe is " as soft as mush."

The examination is now continued either by artificial light or the examiner proceeds to the functional testing of the eve. The choice will depend on whether the employment of the latter is necesiry, or even posible. If, on account of spasm in the licls, tears, violent pain, or serious injury, it is imposible to test the acntenes of rision, it must, of course, be postponed. In medionlegal cases, however, it is advisalble to test the vision of each eve if it is at all posible. Holders of accident-insmance policies do not, as a rule, malinger at the first examination, though they may do so later on, and it is often very useful (in such eases) to know in time the arnteness of vision of the minjured aye.

The functional test is alio called the subjertire examination, as distinguished from the oljective, with which we have been dealing so far, because the examiner relies on the lata obtained from the patient. If it is deeided to apply this test, the first step consists in

\section{Testing Acuteness of Vision.}

The test is first applied to each eve separately : later, to both at onee.

It is well to form the hallit of examining the right eye first, and to preserve the same order in writing the history, as it makes it easier to molerstand at any future reading. 
As the acnteness of vision is nimally tested for the purpose of correcting errors of refraction, incopia, hypermetropia, or' astigmatism, a set of lenses should be at hand.

The first requisite is a good light, to insure sufficient illumination of the signs-nsually lotters-by the rearling of which the acuteness of vision is determined. The trpe-card is therefore hung in a strong light opposite, or next to a window. If the examiner is able to discern with ease the letters which eorrespond to his own visual power the light is sufficiently strong. This control-test should never be omitted, as any diminution of the light affeets the vistal acnity unfavorably. As schweigger aptly says, the improvement in a patient's eyesight which we observe at sucesive examinations is very often an improvement in the weather rather than in the disease. If, therefore, the darlight is not strong enough to illuminate the type-card joperly, artificial light must be used. The source of light may be the sime as that used for the ophthalmo-copic examination later on, care being taken to protect the patient's eyes with a shade, so that the light fills only on the type-card.

A transparent type-eard may also be employed to insure a good illumination of the test-letters. The card is fastened to the window and a mirror is placed opposite at the proper distance, the patient rearling the letters as they are reflected in the mirror. This arrangement las the advantage of enabling the examiner to stand near the patient and the type-eard at the same time, so as to point to the letters he is to read. In a small rom the necessary distance from pationt to type-ard an best be obtained by this device.

The test for acutenes- of vision is based on the following considerations: Suppose we were to test the vision l,y the simplest posible means, by asking the patient to teli, for instance, how many fingers we had stretched ont on the background of our black eoat. A normal eye would be able to distinguish such large objects at a great distance; in fact, we should have to move away 50 meters before the 
fingers would appear indistinct. This would be the limit ; at a greater distance than 50 meters a person with normal eyes could no longer recognize the fingers with certaintr. Now, if another perion were mable to count the same fingers when placed more than 25 meters away, that person would posies only half the visual power, or $\frac{25}{5}$, because the object to be perceived hy him would have to be brought nearer by one-half the distance. If the distance had to be reduced to 10 meters, to enable a person to count the fingers, his vision wonld evidently be equal to one-fifth the normal, or $\frac{10}{50}$; and at 5 meters the risual acuity would be $\frac{1}{10}$, or $\frac{5}{50}$. The acuteness of rision can therefore be expressed by "fiaction in which the numerator indicutes the greatest distance at rhich the person examined is able to recognize an object, and the denominator the greatest distance at which a normal eye can recoggnise the same oljectin other words, the normal distance for that object. For the outstretehed fingers this distanee is 50 meters. Normal vision is therefore represented by $\frac{50}{50}$, or 1 ; abnormal vision, by some fraction of 1 .

Now, if we were actually to adopt this plan of testing the acuteness of vision we should find this ruming backward and forward with ontstretched fingers over a distance of 50 meters rather troullesome. Therefore, instead of varying the distance from the patient to the olject, we vary the size of the object. We nse test-objects of varying normal distances. Suppose, for instance, we chonse 5) meters once for all as the distance for applying the test; it is evident that an object 10 times smaller than the outstretched fingers will have to he used as the standard. Such an olject would be, for instance, a letter $7.5 \mathrm{~mm}$. in height. Letters of this sime can just be discerned by a normal eye at a distance of is meter's ; their normal distance, therefore, is 5 meters; and we place the number 5 over a row of letter's of this size which form the lowest line on the type-card.

In the next line alowe, the lotters are twice as large; a normal eye shonk therefore be able to reat them at twice 
the distance, or 10 meters. This row of letters is designated by the number 10 , which is their normal distance. If no smaller letter's than these ean be discerned, vision is $\frac{1}{2}$, or, keeping the same fraction, $\frac{5}{10}$.

The letters in the third row are three times as large as those in the first row (which are $7.5 \mathrm{~mm}$. high); a normal eye should therefore be able to read them at three times the distance, or 15 meters. This row is marked 15, its normal distance. If an individual cannot read any letters smaller than these, his vision is evidently $\frac{1}{3}$, or, keeping the same fraction, $\frac{5}{15}$.

The letters in the fourth row are four times as large as those in the first row, and are designated by their normal distance, 20 meters. If these letters, which a normal eye ean read at four times the distance, or 20 meters, are the smallest that ean be diseerned, rision is evidently $\frac{1}{4}$, or $\frac{5}{2 \pi}$.

The letters in the fifth row are six times as large as those in the first row, and above them is a single large letter, ten times as large as the first, which correspond respectively to visions of $\frac{1}{6}$ (or $\frac{5}{30}$ ) and $\frac{1}{10}$ (or $\left.\frac{5}{50}\right)$. The normal distance at which the sixth row should be read is $6 \times 5, \mathrm{or}^{3} 30$, and it is accordingly marked 30 ; similarly, the large, single letter at the top is marked 50. The largeletter test is equivalent to the finger-test.

Now we can measure visual acuities ranging from $\frac{5}{10}$ (or $\frac{1}{2}$ ) to $\frac{5}{50}$ ( or $\frac{1}{10}$ ) withont changing the position of the type-card, which remains fixed at a distance of 5 meters. Or, the type-card may be fixed at a distance of 10 meters, in which case the readings would be $\frac{10}{10}=1, \frac{10}{15}=\frac{2}{3}, \frac{10}{20}=\frac{1}{2}$, $\frac{1}{3} 0=\frac{1}{3}$, according to the letters the patient is able to read.

It appears therefore that the numerator in the fraction corresponds to the distance in meters of the patient from the type-card, and the denominator corresponds to the distance at which the type should be read normally. Example: The distance of the patient from the eard is 5 meters; if the type marked 15 is discerned the vision is $\frac{5}{15}$, or $\frac{1}{3}$.

A simpler way of stating the rule is: Above the line 
pent the distence that suits the pretiont; belour the line, the distenee that suits the nomenel ene.

In the example given above, the patient reads the type which a normal eve discerns at 15 meters, at no greater distanee than jo meters-that $i$ - at a distance equal to $\frac{1}{3}$ the normal distance ; hence his visual acuity is only $\frac{1}{3}$.

This extremely practical sr-tem of te-ting the acutencsis of vi-ion we owe to snellen, and his type-ards, which we have just deseribed and which an he bought in any bookstore), are now universally used; at leart his srotem is alwars followed, whether his own type-ards or ithers constructed on the same principle by other anthors be used. Some trpe-cards are designed for even smaller fractions, or decimals are substituted for common fractions, etc.

When a tran-farent type-card is nsed it is placed beside the patient, and the mirror is meters away; the row of letters marked 10 therefore represents the normal type, and the numorator $i=10$, insteal of 5 , since the lotters are actually 10 meters distant from the patient.

For children and illiterate persons fork-lilie figures, $\mathbf{E} \boldsymbol{\omega} \boldsymbol{m}$, in various positions, of the sime size as the letters, are used. These figures posess the additional alvantage of being uniform in shape. whereas some letters, a: V O L, are earier to read than others, like $\mathbf{B} \mathbf{R} \mathbf{N}$ ()n the othere hand, this quality of not being equally legihe is usenful in the examination of malingerers. For if a pationt roals all the letters in one row easily and withont he-itation. he is alwars able to di-cern one or more of the (asere ones in the next row also; and if he fails to do this. malingering, or at least exageration of his condition, maly be stepereded. As a control-test the vision is tried

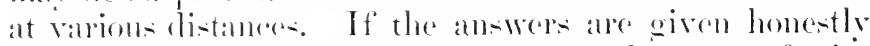
the result will always be opportmetely the same; for instance, $\frac{3}{15}, \frac{2}{11}$. $\frac{1}{5}$. when the tert is male at the distanees of 3,2 and 1 moter rejectivels. The malingerer, on the other hame, is apt to claim better. or at least the same, visual acuteness ats the type-card is bronght nearer; henee 
a suspected malingerer should always be tested at varions distances.

The same plan may be adopted if the patient fails to read even the largest letter, although it is better in such a ease to ask him to count the outstretehed fingers, the result being recorded as "Counts fingers at 0.2 , or 2 , or 4 meters," ete. If he is mable to count fingers, we try if he can see movements of the hand at $0.2,0.5$ meter, etc., and record: "Perceives movement of the hand at . . . meters."

When even this power no longer exists, the perception of light should be tested in a dark room, by alternately covering and uneovering a lamp or eandle, noting the distance at which the light is pereeived. It is only when (qualitative) light-pereeption is absent that we speak of blindness or amaurosis.

In testing the accommodation for the purpose of selecting glasses, etc., consecutive texts in varying sizes of type are substituted for the letters. The trpe-cards after Snellen) are provided with these texts, which are eompiled on the same principle as the letters.

The foregoing description has been made as easy as possible, and differs somewhat from that nsully given, which reads simply: Acuteness of vision is detormined by finding the smallest subtended angle in which the ere can recognize the shape of a given object. For objects at the same distance this angle is assumed proportional to the size of the object, which is sufficiently accurate for small angles. For larger angles the size of the object must be taken as equal to twice the taugent of halj the angle. Hence the respective letters on the trpe-card are not exactly 3 , or 5, or 10 times as large as the letters which are $7.5 \mathrm{~mm}$. long, but only approximately. In order to express the visual angle in commensurable terms a conventional unit has been selected. For this purpose an angle of 5 ' (inimutes) is taken for the recognition of letters the thickness of which is oue-fifth the height. In the formula $r=\frac{d}{D}$, $d$ stands for the distance at which the letter can be distinctly recognized; $I$, for the distance at which the letter subtends an angle of $5^{\prime}$ (minutes); and $I$, the visual acuity.

The angle 5 is arbitrary; it corresponds to the average normal vision. Many persons see quite elearly at a snaller visual angle; thus, the letters numbered 5 mar be discerned at a distance of 7.5 , or even 10 meters. Such persons would possess a vision equal to $1 \frac{1}{2}$ and double the normal respertively. 
It is important to observe the following precaution in testing the acuteness of vision. When, in the examination of the right eye, for instance, the left eye is to be excluded from the risual field, it must not be covered with the hand or fingers, except possibly with the hollow of the hand, so that the eve can remain open. It is better to use a pair of testing-ipectacles in which the left lens is replaced by a disk of tin or pasteboarl, which euts off the view without closing the eve. Pressure on the eye with the hand or finger, even for a short time, disturbs vision by altering the normal outline of the cornea, so that the acuteness of vision obtained is incorrect. Any one can convince himself of the truth of this statement by pressing upon his eye for a short time.

Now, suppose the right eve, for example, is to be tested. We first note the visual acuity withont glasses-in other worls, the uncorrected rision. If this is found to be less than 1, the effect of concave or convex lenses of rarying strengths is tried. The weakest concave or strongest convex lens that produces the best vision indicates the degree of subjective myopia or apparent hypermetropia. If spherical glasses fail to bring the vision up to 1 , crlindrical glasses must be tried. Crlindrical lenses, phus or minus 1 (or even other cylindrical lenses), are held in front of the eve, in a horizontal, vertical, or either of the two oblique directions, to see whether a combination of spherical and exlindrical lenses, or crlindrical lenses alone, produce the best vision. The direction of the axis of the cylinder is best recorded as follows: Axis vertical, or A. r. or, simply, $\|$; Axis horizontal, or A. h. or $=$; axis $x$ degrees temporal or nasal above-i. e., the upper end of the axis deviates $x$ degrees from the perpendicular to the temporal or nasal side.

The notes of the test for visual acuity would then read something like this:

$$
\begin{aligned}
& \text { R. } \frac{5}{30}-1.5 \mathrm{sph} . \frac{5}{10} \text { o cyl. }-0.75 \| \mathrm{V}=1 \text {. } \\
& \text { L. } \frac{5}{50} \text {. No improvement with glasses. }
\end{aligned}
$$


[Ordinarily, in this country, this record would be ats follows: R. E. $V=\frac{5}{30}$ without correction; with $\left.-1.5 \mathrm{I}\right)$ sph., $0-0.75$ I cyl., axis $90^{\circ} \mathrm{V}=\frac{5}{5}$ or 1 . I. E. V $\frac{5}{50}$; no improvement with glasses._En.]

In this patient's left eye we may have noticed a central corneal opacity, which explains the low visual anduty of $\frac{1}{10}$; or we may find, in another case, upon continuing the examination, that the amblyopia is cansed by discalse in the fundus.

In the above record of the right eye (R.) the uncorrected vision is $\frac{1}{6}$; with a spherieal lens the visual power is raised to $\frac{1}{2}$; and finally the effect of the eylindrical lens is to bring the vision up to 1 .

Ophthalmologists have their own system of numbering spectacle-lenses. Ordinarily a lens is designated by its focal length ; but spectacle-lenses are mumbered accoring to their refractive power. A lens of 1 meter focus is taken as the unit, and, with the exeeption of lenses 0.5 and 0.75 , all others are multiples of the meter-lens, or diopter, as it is also called. I lens of 2 I) therefore has a refractive power twice as great as a lens of $1 \mathrm{I}$ ), and consequently half the focal length, or 0.5 meter ; a lens of 3 D has three timen the refractive power and one-third the foeal length of a lens of 1 I) (meter-lens or ml), ete., for the refractive power of a lens is the inverse of its focal length. The smaller the foeal length the greater the refractive power.

To find the focal length of a lens in the dioptric system divide $100 \mathrm{by}$ the number of diopters. Thus, the focal length of a lens of $3 \mathrm{D}$ is $\frac{100}{3.0} \quad 3.3 .3 \mathrm{~cm}$; that of a lens of $8 \mathrm{D}, 12.5 \mathrm{~cm}$. To find the number of diopters for a given focal length-10 em., for example-divide $100 \mathrm{ly}$ the number of $\mathrm{cm}$. in the focal length : $\frac{100}{10}=10 \mathrm{I}$; for $20 \mathrm{~cm}$. the number of diopters is 5 , ete.

In the old srstem a lens of 1 inch focus was the unit, and all the lenses in use were fractions of this unit. No. $\frac{1}{2}$ had a focal distance of 2 inches; No. $\frac{1}{3}$, a foeal distance of 3 inches, ete. The number of the lens gave the focal 
distance (more correctly, the radius of curvature) and the refractive power at the same time, and consequently took the form of a fraction. The diopter ( $\mathrm{Ml}$ ) corresponds to lens $\frac{1}{40}$ in the old system. To change from the new system to the old, divide the number 40 by the number of diopters; to change from the old system to the new, divide the same number $(40)$ by the denominator of the fraction. For example, a lens of $2 \mathrm{D}$, new system, is $\mathrm{No} \cdot \frac{1}{20}$ in the old ; lens $N_{0} . \frac{1}{8}$, old system, corresponds to a lens of $5 \mathrm{D}$ in the new system. The lenses in the two systems are practically the same, the nomenclature only being different.

The refractive power of the eve, as determined with spectacle-lenses by the so-called suljective test, is not always quite accurate, because aecommodation comes into play, whereby nyopia may be exaggerated or hypermetropia diminislied. Absolutely correct results can be obtained only by objective examination with the ophthalmoscope, or by the schmidt-Rimpler method, or with the shadow-test. ${ }^{1}$

After the acuteness of rision has been ascertained the examination is continued by artificial light in a lark room, the first step being

\section{Examination with Lateral Illumination.}

This part of the examination is important on account of the information it affords as to the condition of the anterior segment of the eyeball, which cannot be obtained at all, or but imperfectly, in any other way, especially if a good corneal loupe is emploved.

The lamp is placed on a table to the right and a little in front of the surgeon, who sits facing the patient. With a convex lens of $15-20 \mathrm{D}$, which is found in the ophthalmoscope-ase, the light is thrown into the ere under observation so as to foens on the parts which it is clesired to examine with special care. The rays collected by the

1 For a full description of the objective methods of testing the refracting power of the eye, see the author's Grundriss und Atlas der Ophthatmoskopie. 
lens form a small brilliant image of the flame of the lamp at this point. The parts of the cornea, iris, ete., illuminated in this way are thus brought into a bright light and stand out in strong relief against the dark background of their surroundings. Suppose, for example, the iris to be discolored, so that a gray opacity in the overlying eornea cannot be seen; if only the cornea is illuminated, the iris, being in shadow, forms a good background for the opacities in the cornea and they at once become visible. Or, if the cornea is left in shadow and the iris only illuminated, any changes in the latter and in the pupil ean be seen. The most minute alterations in the cornea, iris, and crystalline lens, which would escape detection in the strongest daylight, can be discerned by this method.

To obtain the best results with lateral illumination a loupe is necessary. Irutnack's spherical loupe is the best, as it covers a fairly large field. The loupe is held in the left hand, the right manipulating the iiluminatinglens. The proper coöperation of the two lenses, on which the success of the method largely depends, is no easy matter to accomplish and requires a great deal of practice. Among other things, this methorl enables us to locate accurately certain minnte depositions on the posterior surface of the cornea which oceur in iritis and in cyclitis, and which cannot be detected in any other way. Similar small gray dots occur in the erystalline lens; but they ean readily be distinguished from the former with the aid of a loupe. For when the depositions on the comea are clear and distinet, the crystalline lens must be out of focus ; and, on the other hand, to make a close examination of the lens the loupe must be held nearer the eye, whereupon the cornea necessarily disappears from the field. (Hence, if depositions on the cornea and grayish dots in the pupil are present at the same time, we ean study the two conditions separately, which may be of great value.) If eren by using the loupe the surgeon finds it difficult to see the depositions on the cornea, let him move his head to and fro (after he has focussed the cornea with a strong light 
Shining on it), and the spots will he seen to follow the motions of the head and heoome pertectly di-tinct. Fometimes it is diffienlt to distinguish the depositions firom minute dots on the anterior surface of the cornea. In that case a few particles of alomel are applied to the cornea with a camel's-hair brush. The patient will not be ineomvenienced if only a very little alomel is applied, which ean be aceomplished he tappling the brush with the finger after it hat heen dipped in the calomel. Now the dots on the anterior surfare of the cornea ean earily be seen distinct from those on the posterior surface, epereially if the surgeon moves his head fiom side to sille as before, or the particles of alomel are put in motion by the act of winking.

If the pupil an he dikated, it is posible with lateral illumination to lonk into the vitreoms boly. The light must enter the ere as nearly as posible in perpendienlar lines, and the sureon, standing elose to the lamp, direct:his eaze along the entering beam of light. In this way foreign bodies, hemorrhages. neoplasms, and rlotachmentsof the retina in the anterior portion of the vitreous an be detectod and their color studied.

The next procedure is the

\section{Examination by Transmitted Light.}

This important part of the examination serves to eonfirm and show even more clearly some of the results oltained hy lateral illumination. It also reveals the fainte-st inction of the pupil to light. For the rest, its chine object is to detect oparitios in the rofracting media, the (o) mea, lens, and vitrens borly.

The lamp heine plateed a little behind and to one side of the patient, the sureron throws the reflection of the lamp into the cye he means of the ophthahmoserpe, illu-

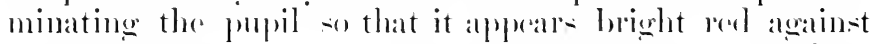
the dark barkeromul of the rye, which is in shatow. The pupil contracts as son as the light strikes it, muless 
there is pupillary paralysis from any ause. By noting the character of the beam of light as it emerges from the pupil, after being reflected from the fundus, we can detert any opacities there may be in the pupillary areal, manifesting themselves an more or less intense shatows which intercept the light-enecially if they are located in the cornea, lens, or vitreous body. Opacities due to cataract are brought out very distinctly in this way (ser Plate $33,6, c)$, particularly the fainter opacities of lamellar eataract, which often oecerr in a rudimentary form only. Opacities in the anterior or posterior poles of the erytalline lens ean aloo be seen, whether the nuclens be dear or oparue. If the patient, while the pupil-area is steatily illuminated, is directed to look mp or to one side, an opacity in the anterior pole will more with the pupil, in the center of which it remains fixed. An opacity in the posterior pole, on the contrary, remains stationary, and appears to move downward when the gaze is direesed upward, beeane the pupil moves upwarl in front of it. A posterior opacity from pigmentary degeneration of the retina can be distinetly seen only by transmitted light. It alwars lies clowe to the corneal reflex.

To study minute changes in the cornea, anterior chamber, and iris a stronge convex lens may be need with advantage in the examination by tramimitted light. The delieate blood-resoles, which often persint for some time in the cornea after parenoly ynatons keratitis, are best seen with a "loupe-mirror" ; they appear as fine, dark lines against the red barkgromend of the pupil, which hats previonsly been dilated, if posible. Ileporits on the posterior laver of the cornea also beenme visible. In these examinations a strong convex lens, such as is used under certain circumstances in the later stages of ophthalmoscopie examination, is fixed behind the sight-hole of the ophthalmoseope, and the surgeon appreacheseso sose to the eye moler examination that its cormea lies within the foeal distance of this convex lens. The lens need not be very powerful $(+6$ or $+8 \mathrm{D})$, or a lens of $+15 \mathrm{D}$ to 
$+18 \mathrm{D}$ will answer if the ophthalmoscope happens to contain such a one.

[An ophthalmoscope should always be provided with a +16 or +20 D lens in its series. Examination of the transparent media with sueh a lens is most important, particularly in the study of late corneal lesions.-ED.]

When the examination by means of transmitted illumination has been eompleted, and not till then, we proceed to the ophthalmoscopic examination proper, beginning with

\section{Examination with the Inverted Image,}

which is followed by

\section{Examination with the Upright Image.}

A detailed description of these two methods is found in my Gimudiss und Atlas der Ophthalmoskopie, to which reference has been made.

This ends the examination for most, though not for all, patients. It may now be necessary, for instance, to measure the

\section{Accommodation.}

In practice, accommodation is measured by finding the nearest point, $\mathrm{P}$ (punctum proximum), at which the smallest readable print ean be deciphered. Each eve is first tested separately, by bringing the test-type closer and closer, until the letters become blurred and illegible. This shortest reading-distance is then measured with a rule, the zero-point being held opposite the sclerocorneal junction. When the accommodation is good, as in young eves, and the test-card can be hold very close to the eye, a successively smaller trpe must be used as the distance is diminisherl, becanse larese print can be read even without proper aceommodation in "diffusion-cireles." The smallest readable type should therefore be selected for the test. 
In measuring the accommodation the refractive power of the eye must be accurately known, as the formula

$$
A=\mathrm{P}-\mathrm{R}
$$

is used in the calculation, in which $\mathrm{P}$ and $\mathrm{R}$ (punctum remotum) are expressed in diopters. The number of diopters for $\mathrm{P}$ is found by taking the number of the lens whose focal length equals the distance of $\mathrm{P}$ from the cornea. If, for example, the distance from the near point to the cornea is found to be $20 \mathrm{~cm}$., $P$ is expressed by 5 $\mathrm{D}$, the number of the lens which has a focal length of 20 cm. That we are justified in expressing the distance of the near point from the cornea by the number of a lens appears from the following considerations: Suppose the case of an emmetropic eye having no power of accommodation. If an object is placed $20 \mathrm{~cm}$. distant from the cornea no distinct image will be formed on the retina, since the rays of light will be brought to a focus behind the retina, for the shorter the distance of an object from a convex lens or a combination of two convex lenses (such as is formed in the eye by the cornea and the aqueous humor and erystalline lensi, the greater the distance from the lens to the image on the other side. In order, therefore, to obtain a distinct retinal image of an object $20 \mathrm{~cm}$. in front of an ere incapable of accommodation, the rays of light coming from the object must be rendered parallel, since only parallel rays entering the resting, emmetropic eye are collected on the retina. This would be aceomplished by holding a lens of $20 \mathrm{~cm}$. focal length close in front of the eye, since rays coming from the focal point of a convex lens emerge in parallel lines on the other side. A distinct image of the object would, therefore, be formed on the retina; and the eye is said to be "adjusted" or accommodated for such an object by a lens of $20 \mathrm{~cm}$. focal length. In other words, an cmmetropic eye is accommodated for near objects by a lens whose focal length is equal to the distance of the object from the eye, the lens 
being assumed to be in contact with the cornea. If an eye has the power of adjusting itself to a near object without the aid of such a lens, it does so by increasing the refractive power of its crrstalline lens, through the act called accommodation, by an amount equal to the refractive power of the artificial lens that would be required.

For an emmetropic eve the number of the lens which expresses $P$ at the same time gives the value of $A$. For, since the distance of $R$ is infinite, $R=0 \mathrm{D}$; hence, in the above example, $\mathrm{A}=5 \mathrm{D}$.

In myopic and hypermetropic eves, on the other hand, $R$ represents a certain number of diopters, corresponding to the degree of myopia or hypermetropia present. For ametropic eves, therefore, the refractive power must first be ascertained by one of the objective methods before the accommodation can be determined.

For myopic eyes the number of diopters which express the degree of myopia must be subtracted from the number of diopters which correspond to the distance of the near point. For example: If $\mathrm{P}$ is found at $8(\mathrm{~m} .,=12.5 \mathrm{I}$, and myopia $=3 \mathrm{I}$, then $\mathrm{A}-9.5 \mathrm{I}$.

For hypermetropic eyes, on the other hand, the number of diopters which express the total hypermetropia is anded to the number of diopters correponding to P. If, therefore, the near point for an eye of $4 \mathrm{I}$ hypermetropia is found at $10 \mathrm{~cm}$., the acommodation is $14^{\circ} \mathrm{I}$ ).

The exact state of affairs in hypermetropia is an follows: In facultative hypermetropia, in which $R$ is virtually behind and $P$ in front of the ere, the formula reads: $\dot{A}=\mathrm{P}-$ $(-R)=P+R$. In absolute hypermetropia, in which both $\mathrm{P}$ and $\mathrm{R}$ lie behind the eye-i.e., both are negattive-the formula reads: $\mathrm{A}=-\mathrm{P}-(-\mathrm{R})=\mathrm{R}-\mathrm{P}$; or, in other words, $A$ diminishes the hypermetropia by the amount of $\mathrm{P}$.

'To ascertain whether a patient has normal aceommodation, it is needful to know the amplitude of accommodation corresponding to his age; for the range of accommodation decreases from year to year, because the 
elasticity of the lens gradually diminishes. The following table supplies this information:

\section{Table of the Range of Accommodation for the Different Ages.}

\begin{tabular}{|c|c|c|c|c|c|c|}
\hline & $\begin{array}{l}\text { Near point } \\
\text { (P. p.) in } \\
\text { meters. }\end{array}$ & \multicolumn{2}{|c|}{$\begin{array}{l}\text { Far point (P. r.) } \\
\text { in meters. }\end{array}$} & \multicolumn{3}{|c|}{$\begin{array}{l}\text { Range of accommodat } \\
\text { in diopters. }\end{array}$} \\
\hline 10 . & . . 0.07 & & $\infty$ & 14 & & \\
\hline 15 & 0.08 & & - & 12 & & \\
\hline 20 & 0.1 & & - & 10 & & \\
\hline 55 & 0.12 & & - & 8.5 & & \\
\hline 0 . & 0.14 & & - & 7. & & \\
\hline 35 & 0.18 & & - & 5.5 & & \\
\hline 40 & $0.2 \cdot 2$ & & - & 4.5 & Pr. & \\
\hline 45 & 0.28 & & - & 3.5 & 0.5 & \\
\hline 50 & 0.4 & & - & 2.5 & 1.5 & \\
\hline 55 & 0.66 & -4 & (H. 0.25) & 1.75 & 2.5 & $(2.25)$ \\
\hline 60 & 2 & -2 & (II. 0.5) & 1.0 & 3.5 & $(3.0)$ \\
\hline 65 &.-4 & -1.3 & (H. 0.75) & 0.5 & 4.25 & $(3.5)$ \\
\hline 60 & . . -1 & -0.8 & (H. 1.25) & 0.25 & 5.0 & $(3.75)$ \\
\hline 75 & -0.5 & -0.57 & (II. 1.75) & 0 & 5.7 .5 & $(4.0)$ \\
\hline 0 . &.-0.4 & -0.4 & $(\mathrm{H}, 2.5)$ & 0 & 6.5 & (4.0) \\
\hline
\end{tabular}

We have two reasons for wishing to know the normal range of accommodation: First, because it enables us to compute the luss of accommodation in discase; and, second, because when the physiologic decrease in the power of accommodation has reached a certain point it interferes with the power of seeing near objects, a condition termed presbyopic. As age advances civilized man is forced to resort to the use of convex glasses. As long as vision is distinct at a distance of $25-3.33 \mathrm{~cm}$.- that is, so long as A equals 4-3 D-no appreeiable inconvenience is noticed; but beyond that point the reading of fine print begins to be troublesome, because the book cannot be held close to the eve. Either the individual chooses larger and larger trpe and a better light, or gives up fine needlework, or the aid of spectacles is invoked to supply the defoetive accommodation. The strength of the glasses must be regulated according to the kind of work for which they are intended. A cobbler, whose working-distance is 40 
em., needs only half as strong glasses as does a draughtsman who works at a range of $20 \mathrm{~cm}$.

In the table presbyopia is assumed to begin when the near point has receded to a distance of $25 \mathrm{~cm}$. from the cornea; or, in other words, when A begins to be less than $4 \mathrm{D}$. The degree of presbyopia and the number of the lens necessary to correct it are readily found by subtracting the existing power of accommodation, expressed in diopters, from the working-distance desired. Example: Distance desired, $33 \mathrm{~cm} .(=3 \mathrm{D})$; existing accommodation, $2 \mathrm{D}$; number of spectacle-lens required, $1 \mathrm{D}$.

The foregoing applies to the emmetropic eye, and in this connection the following facts must be borne in mind: The above table shows that hypermetropic change begins at the age of 55 , on account of the lessened refractive power of the crystalline lens. This tendency of the emmetropic eye to become hypermetropie must be taken into account when glasses are prescribed, by increasing the strength of the lenses in proportion to the degree of hypermetropia present. The necessary correction is indieated in the column of numbers marked Pr. But if ataract is present, the refractive power of the lens is at first increased, thereby compensating for the hypermetropia due to age. For such eases the numbers in the second column, or even lower ones, must be need.

For eyes that were originally hypermetropic the spectacles prescribed for presbyopia must, of course, be eorrected for the degree of hypermetropia normally present; while for myopic eyes the degree of myopia must be subtracted from the number of the preshyopia-glasices. Presbyopia makes itself felt later in short-wighted persons than ii those who possess normal vision. [If the patient is antigmatic this refractive defect must be properly nentralized._-ED.]

In measuring normal accommodation, or the decrease in accommodation due to disease, the following facts are to be remembered: When the aceommolation is very slight, and the distance of the near point eorrespondingly great, 
the patient is mable to read print of any kind, and we have to produce an artificial near point by means of convex glasses. If, for example, it is found that the patient ean read fine print with a 6 I I lens at a distance of $10 \mathrm{~cm}$., his acemmodation is ecpual to $10 \mathrm{D}$ (the number of diopters which are equivalent to $10 \mathrm{~cm}$.) less the power of the lens, or $4 \mathrm{D}$. If the patient is 10 years old, his accommodation ought to be $1+\mathrm{D}$, and he therefore lacks $10 \mathrm{D}$.

\section{Measuring the Field of Vision.}

In many diseases of the eve and in a number of nervous affections it is necessary to measure the field of vision. Whereas visual acuity depends on the functionating power of the center of the retina only, the limits of the field of vision are determined by testing the perceptive powers of the entire surface of the retina, and particularly of its peripheral portions. With perfectly good visual acuity there may coexist gaps in the field of vision, so-called scotomata ; or there may be regular or irregular concentrie comtractions-irregular when the field is contracted more in one part than in others. One-half of the visnal field may be wanting, wisually on both sides, a eondition termed hemianopsiat or there may be so-called homonymous defects, dark areas of the same size and shape oceupying symmetrical portions of both halves of the visual ficld (for example, absence of the left upper quadrant on both sides).

The limits of the field of vision can be roughly ascertained by very simple means, and it is better always to make at least such a superficial examination rather than omit it altogether hecause no suitable instrument of precision happens to be at hand.

The simplest way is the following: The patient, either sitting or lying down-for the examination sometimes has to be made on a patient in bed-is placed opposite the surgeon, at a distance of about 0.5 meter, so that the faces 
of the two are in parallel planes. The patient is then required to tix his left eye, the other being covered, upon the surgeon's right eye, which is directly opposite. Keeping his eye stealily fixed on the patient's, the surgeon then gradually brings his ontstretched fingers nearer and nearer to the line joining his own eye and the patient's, in a plane midwar between them. If, for instance, the right hand is extended with two fingers held up, the fingers can be seen and counted by indirect vision, without diverting the gaze from the patient's fate. If the fingers are gradually brought nearer to the line of rision, both surgeon and patient ean keep them in sight, supposing both to po-iess a normal field of vision; but if the patient's field of vision is small, or much restricted on the temporal side, he will not be able to see the fingers until they are quite near the comnecting line. To make sure that the patient really sees the fingers, the surgeon may alternately more them and hold them still and ask the patient to tell him whether they have moverl or not. In this way the surgeon ascertains how far the visual field extends in all ilirections, by comparing it with the limits of his own field, although, of comre, the result camnot be set down in figures.

In many eases of very defeetive vision this simple methor is the only one arailable, as the patient is mable to see any but the coarsest test-objects.

If the lens is blurred by cataract the flame of a candle in a dark room, which is a more intense stimulus to the retina, must be used for a test-object. The surgeon screens the light with his hand and brings it successively into the different regions of the fichl, and, after removing his hand, asks the patient to tell which direction the light comes from. This projection-test. as it is alled in eontradistinction to the ordinary method, may also be performed with the ophthalmosenpe by throwing on the eye to be examined the reflection of the lamp from various direetions. It forms a very important part of the examination in cataract, as it reveals any pathologic changes in the 
eye-ground which had been obscured by the disease. If, for instance, the patient fails to locate the light promptly in the upper segment when it is held opposite the upper part of the eye, operation for cataract is not advisable, as there are probably some detachments in the lower portion of the retina.

In the exact measurement of the visual field the limit: are acenrately noted in angular degrees by means of an instrument designed for the purpose. This instrument, called a perimeter, also affords a means of testing the power to perceive colors (color-sense). The perimeter shows us that the normal eye does not distinguish colors clearly in the peripheral portions of the field, where black and white are still pereeptible. The limit for black and white forms the outer boundary of the visual field; next, proceeding toward the center, comes the limit for blue. The power of recognizing blue therefore extends furthest toward the periphery, while the limits for red and green lie suceessively nearer the center.

In using the perimeter the following rules must be borne in mind, or the result will be of no value:

1. The test-objects must be sufficiently illuminated, as in testing the acuity of vision; white objects must be a pure white, and the color of colored object- perfectly clear and distinct, not soiled nor faded by use. Hence the testobjects are to be made of white or colored paper, about 2 $\mathrm{cm}$. in diameter, and renewed from time to time; they are then pasted on a small card affixed to a carrier, which can be moved on the are of the perimeter from the periphery toward the center.

2. It is necessary to keep a strict watch on the patient to see that his eve remains constantly fixed on the center or zero-mark of the perimeter. Unless the patient is unusually intelligent or accustomed to the examination, his eye will have a tendency to swerve from the zcro-point and turn toward the approaching test-object, and he will announce that he sees it. It is manifest, however, that he has seen it by direct, not by indirect, vision; his 
statement is therefore worthless, and the test has to be applied anew for that meridian. To overcome this troublesome and time-consuming tendency on the part of the patient the surgeon must take his stand behind the perimeter, and face the patient and control him with his gaze.

3. When the color-limits are to be determined the patient must not be told the color of the test-object beforehand; but he is to name the color as soon as he sees the object. When the white mark is used, however, he should be told to pay no attention to the color, but to say "Now" as soon as he sees anything moving.

4. The measurement is not to be made while the patient is tired; and should therefore oecupy as short a time as possible. When the eves are fatigued the examination is apt to show a narrower field than really exists.

A record-chart (after Förster), with the outline of a normal field of vision printed on it, is used to record the result of the examination.

A great variets of perimeters have been devised. The one recommended and first introduced into practice by Förster is both simple and serviceable. It consists of a semicircle, rotating around a central pivot, with a chin-rest at the center of curvature for the support of the patient's chin. A very good instrument, in mr opinion, has lately been constructed by Ascher. It possesses the advantage that the field of vision can be projected and directly outlined on a real hemisphere, without the surgeon's bejng obliged to give up control of the patient's eyes, as is the case with other hemispheres. The hemisphere, which is not very large and easy to handle, is made of transparent celluloid. The test-objects are moved about on the ontside of the hemisphere and the limits of the field immediately marked ont with soft chalk, the patient holding the instrument himself in a comfortable position. [A self-registering perimeter-for example, McHardr's-is most useful.-ED.]

Abnormalities in the field of vision are often of great significance. Besides indieating functional disturbance in certain parts of the retina, they may lead to the discovery of interruptions in the optic nerve or in any part of the visual tract as far as the cerebral cortex in the occipital lobe, or of disease of the cortex itsclf.

Among eve-affections, separation of the retina from the choroid is a frequent cause of disturbances in the visual 
field. Constrictions in the field correspond to the areas of separation, a detachment in the upper portion of the retina producing a constriction in the lower part of the visual field. Pigmentary degeneration of the retina, under certain eireumstances, produces marked eoneentric constrictions. Disseminated scotomata are found in diffuse choroiditis; central scotomata in disease of the maeula lutea, ete. Atrophy of the optic nerve from any cause is also followed by constriction of the visual field, more particularly of the color-limits, and especially the limit for green. I)isease of the papillomacular bundle gives rise to central scotoma. Obscuration of the same half of each visual field (hemianopsia) points to a disturbance behind the chiasm, in the domain of the right tractus, or in the pathway to the right cortex, or in the cortex itself. Speaking generally, homonymons defects in the ficld of vision indicate discase of the opposite hemisphere, at some point posterior to the ehiasm. ${ }^{1}$

\section{Measuring the Light $=$ sense.}

The pratice of measuring the light-sense, which is neecsiry in a limited number of cases, was also introduced by För-ter, who designed a suitable instrument for the purpose, the photometer."

IVhereas a normal eye ean read the letters on a typecard even when the light is comparatively poor, there are certain diseases in which reading is posible only in a good, strong light. These diseases chiefly affect, not the nervous pathway behind the retina and in the course of the optic nerve, but the perceptive layer itself, the specialized epithelium, whether they originate in the retina or are secondary to disease of the choroid. In syphilitic choroiditis or in the active stage of simple choroiditis, in

${ }^{1}$ A brief survey of the most important disturbances in the field of vision, for clinicians, practising physicians and students, fully described and illustrated, will be found in iny Augenäratliche Cruteirichtungstufeln, Magnus Heft v., Breslau, 1s93.

"More correctly, "photoptometer," as the term photometer is applied to instruments for measuring the intensity of a source of light. 
pigmentary degeneration, or in detaelment of the retina, the light-sense often diminishes to a hundredth of the normal. The same is true in so-called idiopathic nightblindness (nyctalopia), the cause of which is probably to be sought in the retina, but is not well understood.

Förster's photometer eonsists of an oblong box $(30 \mathrm{~cm}$. long, $22 \mathrm{~cm}$. wide, and $17 \mathrm{~cm}$. high), painted black on the inside. One of the short sides is piereed by two sightholes for the patient's eyes, and a third opening, through which the interior is illuminated by a standard candle enclosed in a case. The size of the opening can be regulated by means of a shutter and serew. On the opposite side of the box are a number of rertical black lines of varying thiekness on a white background, on which the light can be thrown with varying intensity by the aid of the shutter. The smaller the opening, and consequently the less the amount of light needed to recognize the vertical lines, the better the light-sense. The size of the opening is read off on a scale and the light-sense computed from it. If, for example, a patient requires an opening 10 times as large as suffices for a normal eye to distinguish the marks, his light-sense is 10 times lesis, or $\frac{1}{10}$ of the normal.

It is an essential condition of trustworthy results that the patient's eyes be thoroughly rested and accu-tomed to the dim light. He should therefore be in a dark room at least ten minutes before the examination is begun.

\section{Testing the Color $=$ sense.}

It has been found that among men from 4 to 5 per cent. are eolor-blint, although among women the percentage is almost zero. As the most nsual form is red-green colorb) lindnes-, which discqualifies a man for serviee as a sailor or railroad employee, it is necessary to test with scientifie acenracy the power of pereeiving color. Many colorblind persons have learned by practice to conceal their infirmity, and are able to name any given color correctly 
without really seeing it; hence certain precautions are needful in making an accurate test of the color-sense. If, for example, a color-blind person is given a red and a green object he will, as a rule, be able to distinguish between them by the difference in the amount of light they reflect; but if the confusion-colors are added he will find it very difficult, if not impossible, to pick ont the required color. As red and green appear to a colorblind person like shades of gray, yollow, and blue, he is apt to confuse them with those shades. The following methods of examination are employed:

1. A large number of varionsly colored skeins, about as large as the little finger, are prepared, comprising the colors of the spectrum and numerous shades of gray, brown, and rose. The yarns being heaped up before the subject in a confused mass, a light-green test-skein is first laid down beside them in good daylight, on a colorless background (such as a black table). If the subject under examination is blind for red and green he will choose some confusion-colors [i.e., with or without the greens-grays, drabs, stone-colors, fawns, pinks, ycllows]. Next a rose skein is laid on the table: $A$ person with red-green blindness will now choose blue shades, because he does not see the red in the rose skein; while one who is blind for blue and yellow will choose red skeins, becance he does not see the blue in the rose. This method was first proposed by Seebeck and more fully developed by Holmgren; but it fails to detect many cases of color-blindness in individuals who have trained themselves to recognize colors.

2. The so-called tissuc-pape' contrast-test may be used. If a black or gray letter, on a colored background, is covered with tis-ne-paper, it appears to have the complemental color of the backgronnd; green, for example, if the background is bright red. The greenish tint, however, is very delieate and camnot be perceived by a color-blind person. The thickness of the tissue-pajer must be accurately regulated, and none lut an expert can be trusted to perform the test. [This test is not of much practical 
value.-ED.] Pflüger's tablets for the detection of colorblindness are constructed on this principle.

3. Another method of detecting color-blindness consists in the use of colored figures on a colored background, confusion-colors being used for both figures and background, and the shape of the figures obscured as much as possible by a mosaic arrangement of lots, so that only the color can be plainly perceived. The dots forming the figures must be of the same color as the background. Stilling has utilized this method in his "pseudoisochromatic plates for the detection of color-blindness." The test is a delicate one and quite simple in its application, so that it need not be performed by an expert. By its aid we can detect any diminution in the color-sense for a particular color, as well as total color-blindness. The plates also contain figures for the detection of persons who pretend color-blindness. They are to be commended for the accurate determination of disturbances of the color-sense.

\section{Examination for Disturbances of Mobility.}

In paralysis of the eye-muscles the ordinary test of requiring the patient to look up and down and to either sicle is not sufficiently accurate, and must be supplemented by a careful study of the double images which occur. Obvionsly, if the left abducens, for instance, is completely paralyzed, it is easy enough to demonstrate that the left eve fails to move to the left when the patient is told to fix an object held in front of him and a little to the left side. In this case there will also be a deriation of the eye toward the nasal side, because the internal rectus preponderates (convergent squint); but if the paralysis is only partial, we must investigate the double images before we can make an aceurate diagnosis, especially if, as frequently happens, several muscles are involved.

If the paralysis is recent, the patient usually consults an oculist for the diplopia and accompanring visual vertigo ; but as the paralysis progresses, the diplopia becomes less 
noticeable, although it is possible even in old cases to detect its presence by using suitable means-holding a red glass in front of the eye, or producing vertical diplopia with an appropriate prism.

In order to understand the varions forms of diplopia which occur in paralyses of the ocular muscles it is only necessary to remember the origins and insertions of the external eye-muscles. The accompanying diagram (Fig. A), which the student can at any time sketch for himself, will help to make the matter clear.

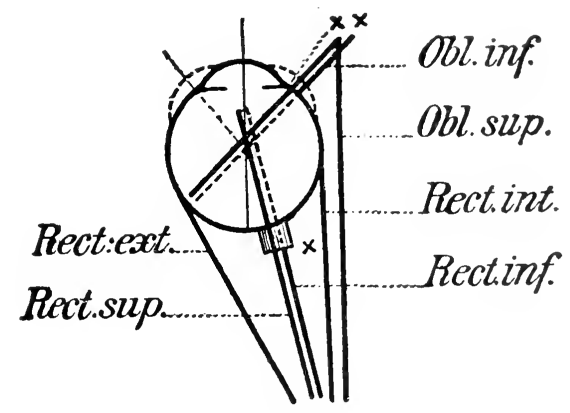

FIG. A.

The course of the recti muscles is easily remembered by bearing in mind that they all arise at the apex of the orbit, around the optic foramen, and are inserted into the sclera 7-8 $\mathrm{mm}$. behind the sclerocorneal junction. The plane of the internal and external recti coincides with the horizontal meridian; while the plane of the superior and inferior recti forms an acute angle with the vertical meridian of the globe, as their insertion is a little more temporal than their origin.

'The superior oblique (or trochlear) also takes its origin at the optic foramen and proceeds forward parallel to, and a little above the internal rectus until it reaches the trochlea, or pulley of the superior ohlique, from which point its direction, backward and outward, really begins. 
Practically, therefore, it passes around the globe in that direction (backward, outward, and downward), beneath the superior rectus, and is inserted behind that muscle, near the horizontal meridian, and a little behind the equator.

The inferior oblique arises in front, on the inner floor of the orbit, opposite the lower extremity of the lachrymal erest of the lachrymal bone. It embraces the globe from below, in the same plane with the superior oblique, and is inserted behind and above, on the onter aspect of the globe, between the insertion of the external reetus and the optic nerve.

If we imagine a gigantic orbit with a globe of such dimensions that we can just encircle it with both arms, we can imitate the action of the recti museles by taking a position to the nasal side of the optic-nerve entrance, at the point $x$ on the diagram. By embracing the globe in a horizontal plane we should initate the action of the internal and external recti; if, on the other hand, we were to embrace the globe in a vertical plane, we should imitate the action of the superior and inferior recti. Incidentally we -hould notice that the globe harl a tendency to sip sidewars, as, from om position on one side, we should be holding it obliquely.

To imitate the artion of the oblique muscles we should have to take our stand on the inner portion of the orbit, in front, at the point $x x$ in the cliagram, and grasp the globe in a direction from before ontward and backward, $\rightarrow$ that our hands would almost meet on the onter and posterior portion.

If we further imagine this gigantic ere to be earily movable about its axis we shall obtain a clear idea of the actions of the various muscles by turning it in imagination with our hands, as described. If we imagine ourselves, with our hands on the insertions of the muscles, turning the globe from the three points mentioned, we note the following effect:-

In the first position, with our arms embracing the globe 
in the horizontal merilian, we simply turn it to and for, the cornea moving from one canthus to the other in a horizontal platue. If we imitate the action of the superior and inferior reeti, we note that when we tilt the globe upwarl the cornea does not move directly upward, but, owing to our somewhat nasal position, slightly inward as well, and the upper extremity of the vertical meridian is inclined slightly inward (toward the nose). If, on the other hand, we exert a downward pull with the arm which represents the inferior rectus, the globe is rotated downward, the cornea is drawn slightly inward, and the lower extremity of the vertical meridian is brought nearer the eenter of the ere-i.e., inelined inward (toward the nose).

If "we imitate the action of the oblique muscles (from the position $x \cdot x$ ), the eye being in the primary position, the pull of the superior oblique gives the corneal an ontward and downward direction, beeanse the globe is elevated behind; and the pull of the inferior oblique gives the cornea an ontwarl and upward direction, because the globe is depressed behind.

But if we suppose the eye to be looking outward (toward the temple) (compare Fig. A), so that the cornea is in the outer canthus, we can readily appreciate that the oblique muscles will have an almost exchusively rotatory action, with rery little elevation or depression. "If, on the contrary, we suppose the eye to be turned inward (toward the nose) and looking directly at us, the oblique muscles will act almost exclusively as elevators or depressors.

As to the direction in which the oblique nuscles rotate the ereball, the effect of the superior oblique is to incline the upper, that of the inferior oblique the lower, extremity of the vertical median inward. By rotation is meant turning of the eye about any axis rumning from before backward through the lobe.

Returning onee more to the superior and inferior recti, we can readily understand that this pair is also capable of rotating the eye when it is directed inward, but not as much as the oblique muscles. When the eye is directed 
outward (toward the temple), the superior and inferior recti act exclusively as clevators or depressors.

Evidently, then, we need only to know the comse of the varions muscles in order to understand their actions and the position they give to the cornea.

The internal rectus is an adductor, the external an abductor of the cormea.

The superior rectus elevates the cornca and inclines the upper extremity of the vertical meridian inward when the eye is in the primary position.

The inferior rectus depresses and slightly adducts the cornea and inclines the lower extremity of the vertical meridian inward when the eye is in the primary position.

The superior oblique depresses and abducts the cornea (rotating it downward and ontward) and inclines the upper extremity of the vertical meridian inward.

The inferior oblique elevates and abducts the cornea (rotating it upward and ontward) and inclines the lower extremity of the vertical meridian inward.

To draw the cornea directly upward from the primary position, the superior rectus and inferior oblique must coöperate ; to turn the gaze directly downward, the coöperation of the inforior rectus and superior oblique is required; while adduction and abduction from the primary position are effected solely by the action of the internal rectus and external rectus respectively.

Haring now firmly fixed the actions of the muscles in our mind, we are ready to take up the analysis of the double images which oceur in paralysis. Let us again suppose the left external rectus (abducens) to be paralyzed. If a test-olject-a candle, for instance-is held before the patient in a lark room, in such a position that he must turn his eves to the left in order to fix it without turning his head, he will tell us that he sees two images of the flame side hy side on the same level. This may be explained as follows: The normal right eye fixes the flame correctly; but the left eve annot be turned to the loft far enongh for the image of 
the flame to be formed on the forea centralis (as in the right eye), and the image falls instead on a point of the retina a little to the nasal side of the fovea centralis. An image formed to the nasal side of the fovea centralis will be projected outward-i. e., to the temporal side of the visual line. It is situated in the visual field, on the temporal side of the fixation-point, the deviation toward the temple in the vismal fiekd being proportional to the deviation of the retinal image from the fovea centralis toward the nose. If the light is moved still further toward the left, the right eve will follow it; while, on the other hand, only the retinal image of the left eve will move nasalward and its false image correspondingly temporalward-i. e., to the left. 'The fillee image (image of the affected eye) is so called because it is indistinet, for images formed outside the macula lutea are faint, beeoning more and more indistinct as the periphery is approached. In the ease before us the patient sees the image of the right eve in its proper place; that of the left eye, on the contrary, to the left or temporal side-there is homonymons or simple diplopia.

If the candle is moved batek toward the right on the same level, the two images begin to approach each other; and when a point directly opposite, or slightly to the nasal side of the center of the eye has been reached, the patient sees single, as he also does when looking still further to the right. It appears, therefore, that diplopia oecurs only when the test-object is brought within the field of action of the palsier muscle; the error can be corrected by turning the head (instead of the eyes) to the left.

In paralysis of the left external rectus abducens, which under normal conditions eontrols the outward movement of the cornea, the fillie image lies to the left of the real image. For similar reasons, on the other hand, if the internal rectus of the left eve is paralyzed, the false image is displaced to the right-in that ase there is heteronymons or crossed diplopia.

If the superior reetus is affected, the eye lags in eleva- 
tion and slightly in abduction, so that the retinal image is formed below, and a little to the outer sile of the forea centralis. Hence the image of the left or affected eye lies above, and a little to the inner side of that of the right or sound eye, its upper extremity being inclined slightly inward from failure of the superior rectus to rotate the eyeball. The absence of rotation becomes more marked as the ere is turned further inward, because the pull of the superior rectus is more oblique in adduction and therefore exercises a more pronounced torsion-effect. If, on the contrary, the eye is turned ontward, the torsion-effect of the muscle does not come into play at all, its only effect being to elevate the cornea, and the vertical distance between the two images is therefore increased. Lateral separation of the images, which is not great, is most pronouncel when the eve is in the primary position.

If we were to investigate the double images in panalysis of the oblique muscles in the same way, we should arrive at the following general conclusion: The direction in which the false image separates from the true image always corresponds to the direction in which the eye is moved by the affected muscle; or, better: The imcige of the affected eye is ahereys projerted in the divertion touraid which (if it were able to perform its function) the prealyzed muscle vould rotate the corriea ; and the image is inclived in the direction tourard which the affected muscele in the sound state would incline the rertial merislian.

Let us take another example: Suppose the left superior oblique is paralyzed. Its unaided action on the eye in the primary position is to rotate the cornea outward and downward and to tilt the upper end of the vertical meridian inward. This is precisely the direction toward which the image of the left ere is projected : it is foumd to the outer (temporal) side of, and below, the image of the right eye, with its upper end inclined inward, toward the nose (compare Fig. B). The double images in paralysis of the superior oblique are, of conrse, found in the lower portion of the tield of fixation, since the muscle is a depressor of 
the eornea, its depressing action being most marked when the eye is directed inward. Hence, when the light is held low and toward the right, the vertical distance between the images is greater than it is when the eye is forced to turn outward and downward. When the eye is directed outward and downward, the superior oblique rotates the vertical meridian inward; hence the image of the left eye exhibits a greater nasal inclination above and the vertical soparation is at the same time diminished. The image of the left eye therefore always remains to the left of that of the right; in other words, there is homonymous diplopia, because the superior oblique is an abduetor.

In paralysis of the inferior oblique, which, when it normally aets alone, rotates the cornea ontward and npward and tilts the upper extremity of the vertieal meridian toward the temporal side, the image of the affected eye is found to the onter side and above its fellow, with a temporal inclination in its uppor extremity. Again, the vertical separation of the double images is greatest when the eye is turned inward, and their obliquity most pronomeed when the eye is turned toward the temporal side. The double images are homonymons, and the diplopia must be sought in the upper portion of the field of fixation.

In paralysis of the superior rectus, which normally rotates the eornea upward and inward and tilts the upper extremity of the vertical meridian towarl the nose, the image of the affected eye is found above and somewhat to the inner side of its fellow, with a slight nasal inclination above. In abduction the nasal inclination is diminished and the vertical separation of the images increased.

In paralysis of the inferior rectus, which normally rotates the cornea downward and slightly inward and tilts the lower extremity of the vertical meridian toward the nose, the image of the affected eye is found below and a little to the inner side of its fellow, with a slight nasal inclination in the lower extremity. The nasal inclination 
is distinct only when the gaze is directed inward ; it diminishes when the eye is turned toward the temple, while the vertical separation of the images increases.

To determine with certainty which of the two images belongs to the right and which to the left eve, a red lens is held before one of them. The inage of the eve that has the red lens before it appears red, while the other has its normal color.

It is essential to determine in which ere the paralysis exists, or whether both eyes are affected." This is determined by the following rule: That image is fulse and belongs to the diseased eye uhlich trarels anday firom the other image in approximately the same direction as that in which the test-light is mored; for the hurrying onward of the image and the lagging of the cye from paralysis are correlated phenomena.

If, for example, we find that the image of the left eye travels faster than that of the right in the same direction as the light when it is moved toward the left, the paralysis is in the left cre and the left external reetus (alducens) is paralyzed. If we now move the light toward the rightposibly in the cximination of the same patient-and the image of the right eye travels faster than that of the left, we conclude that the right external rectus (abducens) is also paralyzed.

If, whein the light is raised, one of the double images aloo moves upward, and moreover still higher upward, we conclurle that the higher the light is elevated this image, travelling in advance upward, belongs to the paralyzed eye, ete.

In order to make an accurate analysis of the double images in a given ase it is esential that their positions should be indieated on a diagram-for example, like the one shown in Fig. B-which is intended to illustrate paralyis of the obligne mucles and of the superior and inforior reeti. For this purpose a cross is construeted of two linus and the position of the donble images is sought for in nine places with the aid of the test-light and marked 
Rect. sup. links
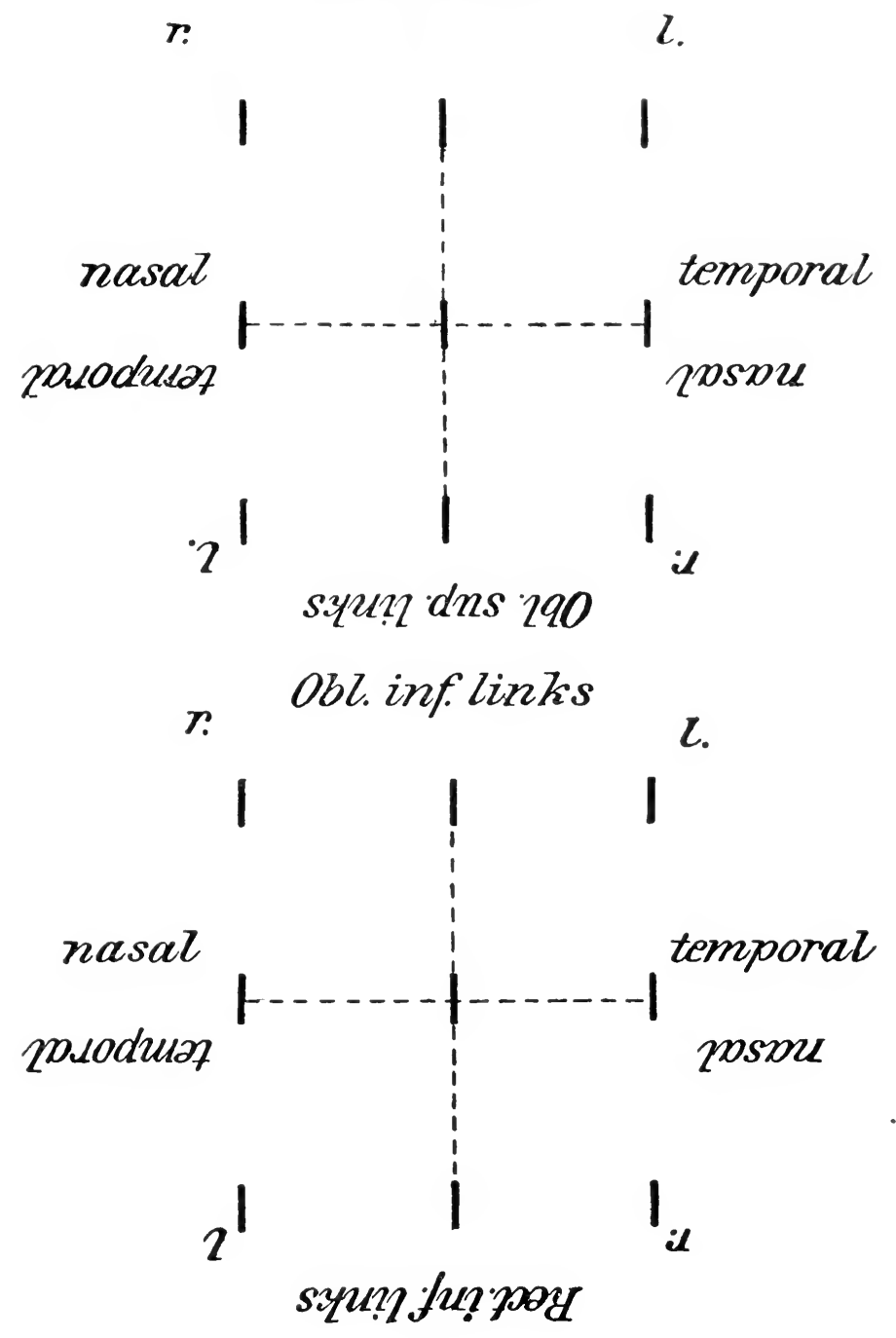

Fig. B. 
on the diagram as follows: First, in the center, then above and below and right and left, corresponding to the cross, and then again right, and the left above and right and left below. It is better for the surgeon to mark the positions of the images as they are given him by the patient, who sits in front of him. Thus, the image of the left eye, which separates to the left in paralysis of the external reetus (abducens), is marked in the diagram to the right as the surgeon stands faeing the patient, etc. Sometimes the patient is asked to mark the positions of the double images himself; the appearance of the chart in that case is quite different, the image of the left eye (in the example) appearing on the left sicle of the chirt, instead of on the right. Hence it is necessary to know how the diagram was made, and it must never be neglected to mark which side is right and which left. If the surgeon records the positions of the images, $r$ (right) must be written in the upper left-hand corner; if the patient does the marking, $i$ is put in the upper right-hand corner. A glance at the position of the letters $i$ and $l$. in Fig. B informs ns that the positions of the double images were recorded by the surgeon.

Woinow has followed this method in his tables showing the double images in paralyses of the evemuscles; these tables are mueh to be commended for purposes of diagno:i- especially in eases in which several muscles are involved. Thoinow gives a number of examples of such multiple paralyes to facilitate their diagnosis.

I have emphasized this matter of the different methods of recording the phenomena of diplopia because it is a frequent souree of confusion to the beginner.

When the paralysis has existed for sone time it is often very diffieult to make a correct diagno-is. beeause the patients have learnt ly practice to suppress one of the double inages. Nevertheless they often complain of

1 Woinow, Veber dıs Terhalten ter Doppelbilder bei Augenmuskellähmungen, in 15 Tafeln elurgestellt, Vienna, 1050. 
visual disturbances, because in certain rotations of the eyeball the diplopia still confuses them. For this reason one must examine with especial care in these directions, down and in, for example, in paralysis of the superior oblique; and by holding a prism in the appropriate position in front of the eve the diplopia in such cases may be developerl. suppose there is an old paralysis of the left external rectus (abducens). The patient does not see double with a red glass, even in the region of diplopia (to the left of the median line); but if a prism of about $10^{\circ}$ is placed before the eye, with the base up or down, so as to produce vertical cliplopia, he at once becomes conscious of a double image, because the image which has been displaced by the prism now appears in an mmsual location on the retina and is at once perceived by the patient. A glass rod has been suggested for such cases by Maddox; it mar also be used for recent cases. Such a rod, or a series of rods, lying side by side and colored red, makes the flame of a candle appear like a long red line, which impresses it-clf more sharply on the patient's conscionsness and brings out the exact position and obliquity of the double image.

The studr of the double images enables us to distinguish between paralytic and concomitant squint. Concomitant or ordinary squint depends mpon not a paralysis, but an abnormal position of the eye which is not limited in its rotations. In convergent squint, for instance, the power of adduction may be increased beyond the normal, the excess corresponding to the amomnt by which abduction is diminished, resulting sometimes in the complete disappearance of the cornea in the inner eanthus during vigorous adduction. The eye does not lag behind its fellow nor fail to accompany it in all its movements; always, howerer, maintaining the same abnormal position. The double images, if there be any at first, correspond to these conditions ; the distance between them remains constant in whatever direction the eye be turned, and in a short time the diplopia disappears altogether, as the squinting eye learns to suppress its image. 


\section{Detection of Malingerers.}

\section{Examination for (Simulated) Amblyopia.-} The retection of pretended amblyopia, or exaggeration of defective eyesight, is a task requiring some skill on the part of the examiner.

As some responsibility attaches to the performance of the test, a review of the methods employed will not be amiss. Either to escape military service, or, more frequently, to establish a claim for damages, the subject under examination attempts, by giving wrong answers, to make his eyesight appear wore than it really is. A claimant for damages exaggerates the injury in the hope of obtaining more damages; the recruit wishes to escape conscription on account of defective evesight ; the statements of hrsterical patients are often proved to be incorrect.

It is natural to suspect malingering if the result of the -ubjective examination fails to agree with the result obtained by objective tests-i. e., if function is claimed by the patient to be abnormal where nothing structurally abnormal is found. But it must not be forgotten that congenital amblyopia occurs with perfectly normal anatomic conditions. Unilateral or bilateral amblyopia is met with particularly in hypermetropic persons, with otherwise healthy eyes, and even appropriate lenses fail to effect any improvement.

Complete blindness of both eyes is rarely simulated; but frequently blindness of one eye is. In the latter case the simulation is more easily exposed than if defective vision only is claimed for one or both eyes. If blindness of one eye is claimed, pupil-contraction to direct light-stimulus and the consenual contraction of the other eve (contraction of the pupil of the other eve when light falls on the cre under examination) can be investigated with great aire; but there are rare cases of pupillary reaction to light in both eves, although one of them is absolutely sightless. On the other hand, a pupil may fail to contract on exposure to light, though vision is perfect, 
because the iris is paralyzed or fixed by synechise. For these reasons it is better to adopt the foillowing methods:

1. The patient is asked to read while a card is held vertically against the book in the median plane in such a way as to divide the page into two columns. If the subjeet is really blind of one eye he will read only the eolumm opposite his somml eye; but if he is pretending he will read both eolumns. Sometimes a pencil or a ruler held against the page suffices to convict the malingerer, for it does not disturb his reading; while if he were really blind of one eye he would leave out the words covered by the peneil. An experienced malingerer often betrays himself at the very beginning of the examination by rapidly closing the eye he claims to be blind, in order to get his bearings. The examiner should be constantly on the lookont for this maneuver, whitever methor be used.

2. The subject is taken into a dirk room and a lighted candle is slowly moved from the sound eye toward its fellow. If the patient perceives the light after it has become hidden from the sound eve by the intervening bridge of the nose-as seen by the shadow east by the latter-it is proof that he sees it with the eye he claims to be blind. This method often fails to expose a clever cheat.

3. The tests performed with prisms are more trustworthy in their results; they have been the means of exposing many frands. If a prism is held, with the base toward the temple, before a person with normal vision, and he is asked to fix a test-object, usually the flame of a candle, a slight movement of adduction will be observed in the eye behind the prism. It is the natural result of the effort to achiere single vision ; for the prism produces lateral diplopia which is immediately and without difficulty overeome by adduction. The impulse to bring the double images together is so strong that the test rarely fails. The prism must be placed before the supposedly blind eve. [The same test, as pointerl ont by Priestley Smith and E. Jackson, may be used to detect feigned binocular blind- 
ness: I lighted candle is placed before the subject in a lark room. He is not required to "look" at the eandle, being nominally blind; but the eandle is placed about where he appears to be looking. A prism $6^{\circ}-8^{\circ}$ is then placed before one eye, its base, for example, toward the temple. If the patient sees, the ere will rotate inward, and when the prism is removed, a movement of " recovery" outward will take place.-Ev.]

Another plan is to place the prism, base down, before the admittedly sound eye and ask the patient whether he sees one or two candles. If both eyes are sound, the image of the eye behind the prism is above that of its fellow. If, therefore, the suljject acknowledges that he sees two images it is a proof that both eves are sound. As many malingerers, however, are aware that admission of binocular vision would expose them, the test must occasionally be varied by producing diplopia in the admittedly soind eye. For this purpose a strong prism (about $15^{\circ}$ ), with the base $n$, is gradually carried up from below in front of the eve. As soon as the lower half of the pupil is covered by the erlge of the prism diplopia begins, becanse those ravs which have passed through the prism are refracted, while the others enter the pupil directly. By covering the other eve we convince the subject that it is possilile to see double with one eye. Now the supposedly blind eve is uneovered and the prism at the same time carried a little higher, so as to cover the entire pupil. If the subject again acknowledges binoculur vision, it is evident that he is malingering, and the risual acuity of the pretenderl blind eve may even be tested with a type-card withont his sn-pecting it. The higher of the two images in the case described corresponds to the supposedly blind eye. A naked prism is the best for this test.

4. A high convex glass of about $6 \mathrm{D}$ is placed before the sound eye, which is thereby rendered (artificially) myopic and camnot read fine print at a greater distance than about $17 \mathrm{~cm}$. The book is first held within that dis- 
tance, and then gradually moved further awar. If the act of reading is found to be possible at a distance greater than 17 cm., it must have been performed by the other eye.

Detection is somewhat more difficult when defective vision only is pretended, or when, as is frequently done in suits for damages, an attempt is made to exaggerate an existing defect, at when a subject with a visual acuity of $\frac{1}{3}$ claims to possess only $\frac{1}{10}$. In such cases it should be borne in mind that malingerer's, as we have already pointed out, are very apt to give contradictory answers when the test for visual acuity is applied at different distances. [Any refractive error should be corrected by oljoctive methods and tests for acuity of sight made with the proper lenses.-ED.] The cleverest malingerer will find it difficult always to pick out the letters which correspond to his true visual acuity, if the distance of the type-(ard is rapidly ehanged, or if he is asked to read the test-letters in a mirror. Besides, he will show an inclination to stop at the end of a line and claim that he camnot read any letters in the following line, wherear really, if all the letters, even the most difficult ones, in one line are read without difficulty, one or two of the easiest letters in the following line can always be made ont. As we have said before, this should at least excite a suspicion of malingering.

Another plan is to exclude the armittedly somnd eye from vision, withont the patient's knowledge, by placing an appropriate lens before it, as described under 4 . With the type-card some distance off, lenses of sucessively higher degrees of concavity are placed before the somd ere; with the weaker glasies the eye is still able to see the distant trpe-card; as soon, however, as a leus of about 10 I) is used, distant vision is impossible. If rearling is still performed it must be by the other eye, which was claimed to be blind. The acuteness of vision of the supposedlly blind eye can thus be measured at the same time.

A very useful device for the detection of expert malingerers is the stereoscope, especially as constructed and 
equipped with plates by M. Burehardt. ${ }^{1}$ By this method, which I have practised for many years, the cleverest malingerer's can be exposed and their true visual acuity ascertained. The stereoscopic plates are so arranged that the subject under examination is quite unable to tell with which eye he is reading the test-letters.

To ascertain the true condition of atfairs when an already existing defect has been aggravated by an accidental injury, a complete examination is usually needful. The method of the erect image furnishes the most trustworthy information as to the effects of corneal opacities or cataract on the visual acnity. The faet that a distinet inverted image is obtained does not necessarily prove that vision is good, for it may be obtained in cases in which vision is considerably impaired by astigmatism, due to corneal opacities, or by a partial eataract. The visual acuity must, therefore, be judged solely by the distinctness of the erect image.

\section{DISEASES OF THE LACHRYMAL APPARATUS.}

The source of the lachrrmal secretion, the lachrrmal gland, which is situated in the upper outer angle of the orbit, close to the orbital margin, is rarely attackerl by di-ease (inflammation, carcinoma, sarcoma, adenoma, etc.). On the other hand, the surgeon's skill and patience are often invoked for the relief of disturlances in the drainage-system, usially in the form of stenoses.

Excessive flow of tears (epiphora) is rarely due primarily to malposition of the inferior punctum lichrymale (from eversion or ectropion of the lower lid). In most ases ducryostenosis is the basic evil, the obstruction sometimes oceurring as high up as the canaliculi. Not infrequently ocelusion of the lower analiculus is caused by

1 M. Burchardt, Proktische Iningustik der Simulation ron Gefïhlslä̉mung ron schwerhörigkeit und rou Schwachsichtigkeit, Berlin, 1878, Gutmann'sche Buchhandlung. Mit Stereoscop, Tafeln, und genauer Gebrauchsanweisung. 
tranmatism. If the lower lid is torn at the imner canthus by a blow with the fist or a stick, the lower eanalieulus is usually divided. In rare cases epiphora is due to the presence of a concretion, usually a mass of fungus, in the lower canalienlus; but in the great majority of eases the primary eause is a stricture in the lachrymomessel denct, which forms the communication between the lachrymal sae and the inferior meatus of the nove.

The lachrymal sac, to the nasal side of the inner canthus, lies partially embedled in a groove of the lachrymal hons (fossa sacei lacrimalis), which is bridged over in front by the internal palpebral ligament. This structure can be brought plainly into view as a tense, horizontal band by drawing the eyelirl outwald, toward the temple.

The lachrymonasal duct is lodged within a bony canal, the narrowest portion of which corresponds to the opening of the lachrymal sae into the duet; this point is therefore the most frequent seat of stricture. Stricture or oeclusion also oceurs in the lower extremity of the canal, being eaused by swelling of the mucous nembrame either of the nose (usially temporary) or of the duct itself. In order to understand the occurrence of olstructions in the drainage-system, which are particularly common in the early stages of the disease and are often only temporary, it must be remembered that the lachrymonasal duct (like the inferior meatus of the nose) contains a venous plexus resembling cellular tissue, which from its great liability to eongestion is very apt to produce a temporary occlusion. This also explains the excessive flow of tears in eoryza. Unlike the lachrymal sac, the nasal duet is surrounded by bone and cannot expand when the secretion acemmulates in excess, so that swelling of its vascular lining rapidly produees a stenosis which may eventually become permanent.

For these reasons catarh of the lachrrmonasal duct usually forms the first stage of a long and tedions process which may drag on for rears. The eatarrhal condition either originates in the nose and extends into the nasal duct, or it begins in the lachrymal sac and spreads down- 


\section{Plate 1.}

Dacryocystitis.-The region of the left lachrymal sac bulges forward; there are inflammation and pain on pressure; the adjacent portions of the lid are edematolis. A slight fluctuation is felt at the apex of the tumor. A tear is seen in the furrow running from the inner cantluus toward the swelling. The patient, who is jo years old, has been in the habit of expressing the mueus and pus in the sac at regular intervals for the past fifteen rears. Inflammation began a week ago. Subsequent course: Rupture of the abscess outward, without formation of a fistula.

wart. The aggravation of the epiphora which is observed to follow a fresh attack of nasal eatarrh speaks for the first view; while, on the other hand, it happens not infrequently that the lachrymal sae is filled with a mucous secretion when there is no obstruction in the duct and the content- of the sac can be expressed through it into the nose. But the chief factor in the etiology of epiphora is lereditury predisposition. [This observation is not in accord with the Editor's experience, although no doubt heredity plays a part.] The family history must be carefully investigated. Most patients are relicetant to admit any" hereditary taint, and prefer to give a "cold" as the caise of their trouble, just as they do for so many other diseases. Arrested or defective derelopment of the bones of the skull, especially of the nose and adjaecnt parts, may possibly constitute a predisposing condition. Thus, stenosis of the lachrymal eanal is sometimes met with in subjects with flat roses or asmmetric facial development. If we consider, however, that children are less sulject to the complaint than adults, in spite of the fact that they have smaller ducts and suffer more frequently from corvza, we are forced to the conclusion that something else besides mechanical comditions is responsible, probably a natumal predisposition favoring the growth of pathogenic fimgi in the lachrymal sac and lachrymonasal duet. Fuele a predisposition is simply an individual pecoliarity, which, like other dispositions, may be inherited.

That the lachrymal sac is often the abode of the most virulent pathogenic germs is one of the earliest discoseries of the bacteriologic studs of the eye. Whether the presence of these fungi is the canse or the 
$\frac{0}{6}$
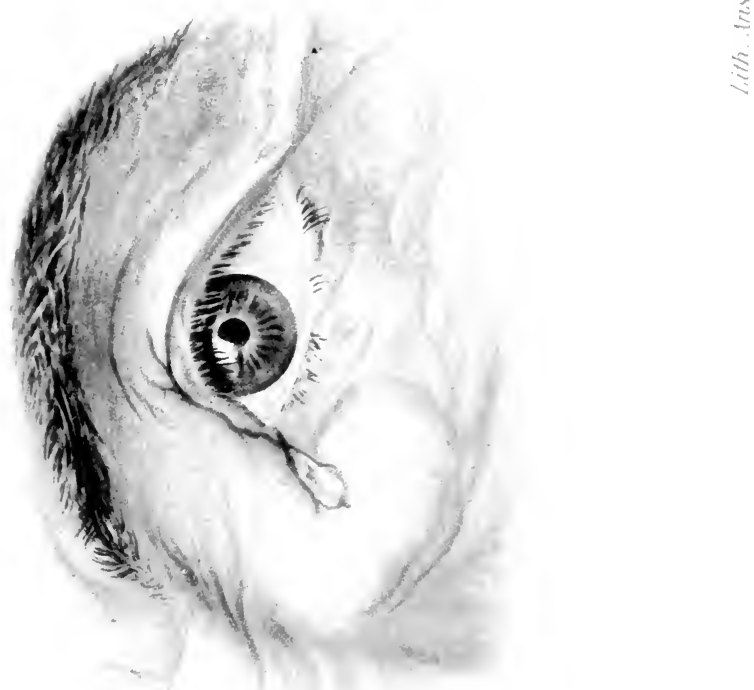

effect of the cataryal condition is still an open question. But if wo ansider that suppuration of the eyeball oceasionally follows an operation for cataract, even when the lachrymal sale contained practically no secretion, showing [in the most umpleasant mammer] that such noxious germs must have been originally present in the sac, we shall incline to the opinion that the germs are primary, not secondary, to the catarrh. These fungrus-colonies reveal their presence in other ways, for I cammot conceive how a simple catarh should be able to ocelucle the natsal dnet in places, narrow as it is, while it is quite asy to understand that the mucons membrane conld be eroded and made to ulcerate by the action of germs and the toxin they produce, loading cventually to strictures and adhesions.

The infections nature of the contents of the lachrymal sac in epiphora is further proved by the fact that the slightest injuries are followed by suppuration and by the occurrence, in most cases, of conjunctivitis and hlepharitis. In itself the epiphora is hardly serions enongh to indure either the surgeon or the patient to undertake treatment; but the complications that are likely to follow are of such grave significance that treatment is imperatively demanded.

Epiphora is always the first symptom to appear. 'The lachrymal fluid is increased in quantity and accumulates in the palpebral fissure without overflowing, or it overflows and necessitates constant wiping of the eyes. The condition is aggravated by exposmre to wind, smoke, or dust. In addition to the inconvenience caused by the constant necessity of drying the eyes, there is the more serious disturbance to vision, becanse the acenmulated fluid forms a layer over the cornea which act sas an incorrect refracting medium through which the optical image appears distorted, especially when the gaze is directed downward. When both eyes are affected the risual disturbance is particularly troublesome.

In spite of all these inconveniences the patient very often neglects his condition, especially if he knows what an unpleasant treatment is before him, so that the secondary results of dacryostenosis rarely fail to appear. On the other hand, there are extraordinary cases in which a stenosis occasions but little inconvenience, and is, in fact, overlooked until accidentally discovered by the intro- 


\section{Plate 2.}

Dacryocystitis with Rupture of the Abscess through the Skin.The redness and swelling in the region of the lachrymal sac have abated somewhat, but the upper lid still exhilsits some inflammatory cdema. The patient is 64 years old ; he has been troubled for some time with epiphora of the right eye. On Say 1. 1897, a few drops of fluid were injected into the nasal duct, and it was found that permeability was not entirely lost. Inflammation set in on May 10, and two days later the abscess ruptured and pus was ciischarged, after which the inflammation subsided without the formation of a fistula. On May 20 another attempt was made to inject a few drops of bichlorid solution into the nasal dnet, and proved successful. Since then the probe was used for some time, and finally a style was left in position.

duction of a sringe, preparatory to an operation for cataract, for instance. In most asos, howerer, epiphora is present from the legimning and is soon followed by conjunctivitis and blepharitis. The patient wakes up in the morning to find his erelids glued together; the ere grows more and more sensitive to smoke and dust, and conjunctival congestion oceasionally makes its appearance. The itching and burning of the inflamed palpebral margins from eezema cause the patient intense amnoyance, and deformity sometimes results. If the cornea is abraded in the slightest degree and the lachrymal sac contains infeetions material, hypopyon-keratitis may develop and threaten the patient's eyeright. This happens hecause as soon as the normal outflow of the lachrymal fluid is interfered with, the pathogenic germs readily find their way into the conjunetival sar and set up -uppuration.

The active interchange of germs which has been experimentally proven to take place between the conjunctiva and the palpebral margin explains why the process so frequently extends to the lids, which. in adlition, offer many sning recesses for the growth of bacteria in their numerous glands and gland-iluets. It mav be that the growth of the mierouranisms is further facilitated by the constant irrigation of the parts. Many patients are driven to consult the sureon he intense inflammation of the lachrymal sac ancl its (o) 

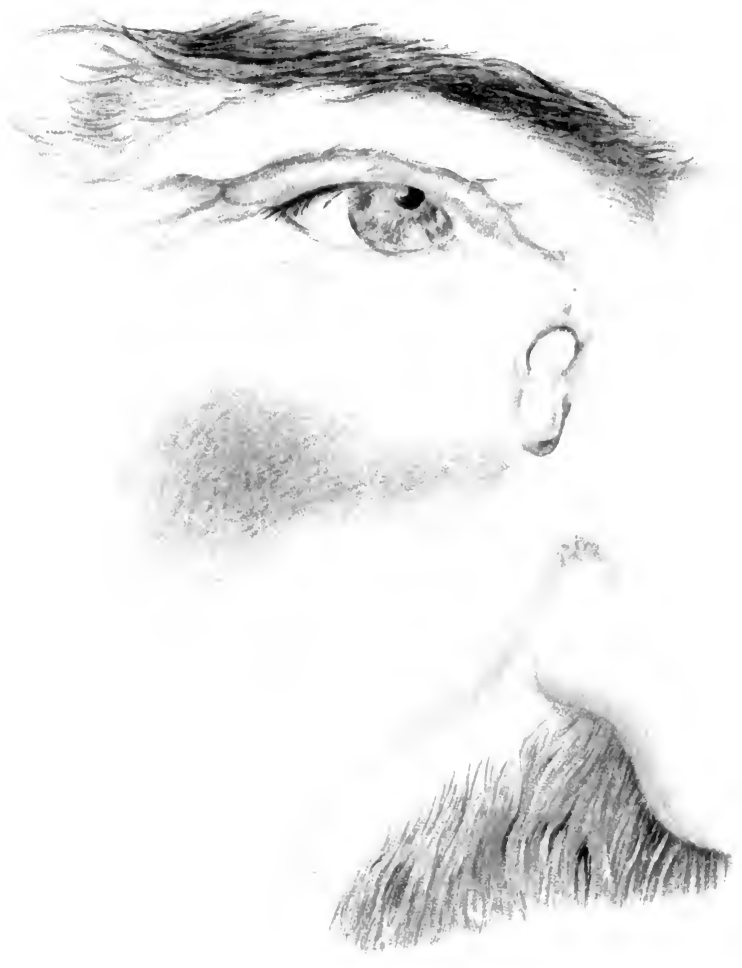

By some process which is not well understood the infectious material finds its way from the lachrymal sale into the surrounding tissues and rets up an intense phlegmonous inflammation resembling erysipelas, for which it is sometimes mistaken. The skin is very much inflimed, in places edematous (on the lids), and very tender to the touch (see Plates 1 and 2 ); but the lachrymal sate ean be distinetly felt at the center of the inflammatory area; and as the disease progresses, the lachrymal abscess ruptures and a purulent secretion is discharged. Sometimes the abscess points from 1 to $2 \mathrm{~cm}$. below the internal palpebral ligament, instearl of at the position of the sac. This so-called dacryocystitis nearly always involves the surrounding tissues as well as the sac itself; the permeability of the lachrymonasal duct may persist in spite of the inflammatory process, the intensity of which depends more on the presence of infectious material and its entrance into the surrounding tissue, than on the degree of stricture, although the condition is always preceded by more or less epiphora and obstruction of the duet.

If, as is usually, but not invariably, the case, the abscess ruptures through the skin (Plate 2), a lachrymal fistula may be formed (Plate 3). Fortunately this is a comparatively rare occurrence, from which it may be argued that the accumulation of pus is probably more marked in the tissues surrounding the wac than in the sac itself.

Quite often the fistulous opening in the abscess, after discharging pus for a time, closes of its own aceord and the inflammation disappears without leaving a trace. If a lachrymal fistula is formed, it usually persists as a very fine opening which eventually exudes pure hachrymal fluid (Plate 3). If the condition lias lasted a long time, chronic distention of the lachrymal sac (ectasia) is sometimes associated with the fistula. [Lachrymal fistula may be mistaken for a buccal fistula bolow the margin of the orbit. -Ev.]

Ectasia of the lachrymal sac (also called mucocele, lachrymal tumor) may levelop in the later stages of the 


\section{Plate 3.}

\section{Lachrymal Fistula on the Right Side; Ectasia of the Lachrymal} Sac on the Left; Bilateral Epicanthus. - A tear-drop is seen at the opening of the fistula on the right. On the left side the fistulous opening does not extend as far as the sac. The right eye shows some ciliary rongestion, due to a slight degree of keratitis (not visible in the picture). latient, a man, 29 years old, has been troubled with watering of the eyes since his thirteenth year. In $1-a t$ he was admitted to the clinic for dacrocystitis on the left side: the sac was incised and a probe passed, but the flow of pus could not be arrested. At the time a scar was noticed on the right side, where he had been treated for dacryocsstitis before, in some other clinic. At present, impermeable stricture of the nasal duct on both sides. On June 1:, 18\% , both lachrymal sacs were extirpated.

process, with or without the formation of a fistula. It is at once recognized by noting that the normal depresion at the nasal side of the inner canthus has disappeared or has given place to more or less prominence (Plate :3), and by the absence of inflammation in the skin. Pressure ipon the swollen sac expresses the contents, consisting of viscid, glairy mucus or a mucopurnlent mixture, through the canaliculi or into the nose; many patients themselves discover this method of obtaining relief. There is always danger that the ectasia may tum into a dacrvocystitis.

When the accumulation of mucopus in the lachrymal sac is very great, dacryocystitis blemmohocien results. This is really nothing but the result of an active purulent eatarrh of the mucous membranc of the lachromal sac. It often learls to inflammation of the conjunctival sac, the eyelicls, and possibly even of the cornea, not to mention the lachrymal sac itself and its surromdings. The catarhal secretion is mueous or purulent, depending on the kind of microörganisms present in the sac.

A catarhal condition once established in the lachrrmal sac, even though the secretion be only mucous and the nasal duct not obstructed, epiphora still persists because the opening from the sac into the duct is stopped up with mucus. 
$\frac{0}{5}$
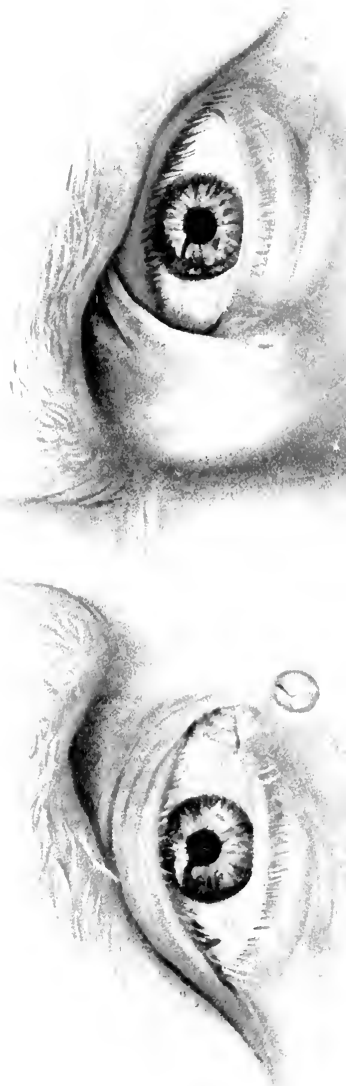

Diagnosis.- In the diagnosis the following points must be borne in mind :

simple epiphora may be due to a nervous disturbance or to abnormal irritability of the nasal mucous membrane [and to refractive error and insufficiency of convergence or to exophora.-ED.].

An abnormal aceumulation of fluid in the lachromal sac is detected by presing on the sac with the finger in an outward direction, from the nose toward the eye.

In order to ascertain whether the epiphora is caused by a stricture in the nasal duet, a few drops of liquid are injected into the lower canaliculus. The lower eanaliculus is ehosen because it is somewhat wider than the upper and admits the nozzle of the srringe more easily. Sometimes the canalieulus has to be dilated with a blunt probe (or a straightened hairpin) before the syringe ean be introduced. The nozzle of the syringe should not be larger than that of an Anel srringe, or about $0.7 \mathrm{~mm}$. in diameter. A Pravaz srringe, made entirely of glass, including the nozzle, and holding 2 grams, is the best for the purpose. I consider the use of an ordinary syringe, whether the piston be made of leather or anbestoin, inadmisible, even for the nasal duct, on account of the extreme difficulty of sterilizing it and the consequent danger of infecting the canal. As a rule, the sime siringe is used for everybody, whether the stenosis is aveptic or not.

As the injection of a neutral fluid $(0.8$ per cent. saline solution) is practically painless, it may be performed in all cases without risk of deterring the patient from continuing the treatment, as frequently happens if a probe is introduced for purposes of diagnosis.

If the flud is slowly injected into the lower canaliculu: in this way, while the head is bent slightly forward, it will pass out through the corresponding nostril, if the duet is patulous. If the patient is lying down, as is the case sometimes in the examination of ehildren, the liquid trickles into the throat and the act of swallowing announces the permeability of the duct. If the lumen is 
only partially occluded, part of the liquid flows back through the upper canaliculus; if occlusion is eomplete, the cutire dose is forced ont in a fine stream.

In the diagnosis of phlegnonous inflammation it is to be remembered that two other diseases present similar clinical pictures :

1. Furuncle is not uncommon in the region of the lachrymal sac, and is readily distinguished by the fact that it is never preceded by epiphora, and by the permealility of the naisl duct, although some difficulty may be experienced in introducing the srringe on account of swelling about the punctum lachrymale.

2. Hlecola abses may rery closely simulate a daeryocrstitis. Suppuration at the root of a tooth, especially the ipper canine, sometimes produces an abscess in the region of the lachrymal sac, which may rupture in the same spot as a true lachrymal abscess. If an alveolar abscess exists, the upper alveolar border on the corresponding side is swollen and tender to the touch. [A track of suppuration leading to the anterior frontal or ethmoidal cells and opening just above the imner anthal ligament may be mistaken for chronic lachrrmonasal disease.-Ev.]

From erysipelas the affection is easily distinguished if the tenderness on pressure and swelling of the lachrymal sac are considered.

The differential diagnosis from tuberenlai or syphilitic inflammatory processes in the bones about the sac and nasal duct is somewhat more difficult. The general habit must be taken into aecount, glandular swelling at the maxillary angle looked for, and the condition of the bone ascertained by means of a somd. If it is learnt that a probe has already been introduced, especially during the inflammatory stace of the process, the possibility of injury to the bone must be ansidered. The bone does not become inflamed spontaneously in simple stenosis, even when followed by dareryoerstitis.

Finally, we may mention that rencinomer and sareome of the rpper maxillary bone sometimes eneroach on the 
region of the lachrymal sac and produce a swelling which bears some resemblance to a phlegmon. The fatal error of mistaking a malignant growth for an affection of the lachrymal sac ean be avoided by noting the diffuse swelling below the sac and the permeability of the nasal duct, and by observing that there is less sensitiveness to presswre than in phlegmonous affections. $[A$ cyst in front of the lachrymal sac (prelachrymal eyst) or a solid growth in the same region may simulate dacryocystitis. Prelachrymal abscess also oecur's, and may result in a fistula in front of, but not communicating with, the lachrymal sac. - ED.]

A distended lachrymal sae, without inflammation (Plate $3)$, is sometimes mistaken for a dermoid cyst of the orbit (Plate 21 and Fig. C) or an osteoma of the ethmoid bone (Fig. D). We shall return to this subject in the section devoted to diseases of the orbit.

Prognosis.-The prognosis in dacryostenosis is always grave, as even apparently mild cases often refuse to heal. Not that simple epiphora or the assoeiated conjunetivitis and blepharitis, troublesome though they be, are to be feared ; the gravity of the disease lies in the danger to the cornea and hence to the eyesight. In three-fourths of all the eases of hypopyon-keratitis, which works such havoc in the entire visual apparatus, the eorneal infeetion is primarily cansed by an obstruction in the lachrymonasal canal.

The prospect of reeovery is brightest when the proper treatment has been applied from the beginning of the malady and there are no false passages made by previons unskilful use of the probe. Under the most skilful treatment the result will depend on the duration of the disease, the condition of the contents of the sac, and the number and permeability of the strictures. If the sae has once lost its elasticity through excessive distention, there is small hope of cheeking the epiphora, even if the nasal duct is clear, for the draining-mechanism is irremediably injured. A normal sae acts like a pump by foreing the fluid into 
the lachrymonatsal duet; its anterior wall is drawn forward during clesure of the lid by the action of the orbicularis palpebrarum, to which the internal lateral ligament is attacherl, and when the muscle relaxes the wall returns to its original position by virtue of its own elasticity, expresing the contents of the sac into the canal. This manenver is imposible when the anterior wall is permanently distenderl.

The progno:is is on the whole farorable in certain cases of obstruction in infants, which are due to deficient communication between the lachrymal canal and the nasal duct, and disappear when continuity is established. The anomaly usually disappears of its own accord in a few weeks, even when a considerable degree of purulent catarrh has developer in the lachrymal sac, provided the condition is not aggravated by the introduction of a probe.

Treatment.- The treatment of the diseases of the lachrymal apparatus that have been described has two main oljects: 1. Remoral of the obstruetion in the duct; 2 . Removal of the germs which canse the morbid secretion in the lachrymal passages.

In many cases a cure is effected by merely complying with the second indication, treatment being directed solely against the catarrh of the sac and duct. There are cases in which the permeability of the duct is not entirely lost, and the obstruction produced by swelling and accimulations of mucus is only temporary. In such cases-they are usually of recent origin-simple irrigation with an antiseptic fluid answers every purpose, as a rule. From 5 to 10 c.c. of a disinfectant or astringent solution are injected with a so-called glass syringe every day, or every few days. A $1: 5000$ solution of mereuric chlorid (even $1: 10(0)$ is rery well borne) is recommended as a disinfectant; for an astringent, a 1 per cent. solution of silver nitrate or a weak zine solution is used.

In every case the watarh and swelling in the nasal avition mist receive alppropriate treatment (nasal douche, (auterization, etc.). I have seen cases of epiphora perma- 
nently cured by cauterization in the nose, which had stubbornly resisted treatment with probes.

If the obstruction is due to syphilitic processes in the nose, ulcerations, etc., general antisy philitic treatment must be inaugurated at once.

The injections should be kept up for some time, even if the fluid at first fails to pass into the nose, as a few repetitions of the procedure sometimes suffice to remove the obstruction. The lachrymal sac must always be thoroughly washed at the very outset, especially if a probe is to be introduced into the canal for the purpose of removing a stricture, in order to avoid aggravating the condition by scattering the germs contained in the sac when the probe is passed.

In many cases the use of probes to remove the strictures is mavoidable. But in my opinion (other specialists may differ with me on this point) the use of a probe is to be recommended only in recent cases, where it can be introduced without much difficulty. If the strictures are numerous and offer so much resistance that a considerable effort is needed to effect an entrance, especially if the sae is already distended, it is better to spare the patients the hardship of the procedure, which even cocain cannot render painless. Their description of the "horrors" of the operation may deter many others from subjecting themselves to the treatment, who then put off the dreaded interview with the surgeon until driven to it by the very complications which make the treatment hopeless. If some permeability still exists, and a few drops of a 5 per rent. solution of eocain can be injected into the duct, the introduction of a probe is not very painful, and its use in such cases is to be recommended; but if the stricture is impermealle, cocain is of little use, since it fails to reach the desired spot.

The following suggestions, based on a large experience in the use of the probe, may not be unwelcome:

It is much better to introduce the probe throngh the upper canaliculus, because, when the instrument is raised 
to the vertical position, as it must be in order to glide into the duct, the distortion is less severe than in the lower analiculis. This distortion sometimes has the disagreeable effect of obliterating the opening of the canalieulus into the sae, making it absolutely impossible to pass the probe into the sate; and when afterward the upper canaliculus is incised in order to continne the treatment, its opening is also found to be obliterated, or soon becomes - - The upper canaliculus is not much harder to split than the lower one. If the operator experiences the least litticulty in thi- part of the operation, he would better give 11!) the treatment altogether; for the proper introduction of a probe is a far more delicate matter, and should only be attempted hy a pratised hand, or it does more harm than gond. In my opinion the introduction of a probe requires the skill of a specialist and is quite as diffieult as any of the larger operations on the eye.

The maneuver will undoubtedly be attended with less pain and better results, if a few days are allowed to elapse after the slitting of the canaliculus, the incision being prevented form healing. The following rules must not be neglected on any accomnt: The probe used at the first trial should not be smaller than Bowman's No. :) or 4 ; these two sizes, in fact, suffice for the entire treatment. Before rai-ing the instrument to the vertical position, preparatory to pushing it into the duet, the operator should make sure that the point is in eontart with the anterior wall of the sar ; he determines this by the increased resistance of the bone. strong pressure should never be used. When fiurther arlvance heomes imposible, the instrument should he left in place a quarter of an hour, and further attempts postpened until the next xémee, two or three days later. In this way it is often posible to gain a little ground at atch sucersive trial, without using undue force, until finally permeability is established at the third or fourth risit. To make sire that the probe has really entered the mose, a fow drops of lignid ane then injerted with a de IIreker's eammula-sringe, with which the canal should 
be irrigated at every subsequent introfluction of the probe. The syringe is provided with a bulb, and in using it the eontents (1:5000 mercuric chloride) are gradually squeezed out as the syringe is withdrawn. If the probe camnot be passed or withdrawn without using foree, it is better, in my opinion, to abandon the treatment with probes, which, it is true, is quite feasible, but mostly does not furnish permanent cures, because the strictures constantly form anew and the hardships of the treatment are out of all proportion to the results obtained. If, after one or two trials, the liquid injected with the syringe preparatory to another attempt with the probe fails to pass into the nose, the treatment with somuls is best abandoned. Whether self-retaining sounds or styles will then furnish better results remains to be seen. I have never seen any permanent good results in such cases; the original state of atfairs never failed to return after their removal.

If the lachrymal sac is the source of the secretion in these old eases, it is best to extirpate it. If it contains but little secretion, it may be cleansed as well as posible by repeated injections and then disinfected, after which the eanaliculi are to be closed by electrolysis (with a platinum wire).

If the ac is much distended, extirpation is indieated at once, as in that ease even permealility of the duct, if it conlel be established, would not check the excessive flow nor obviate the danger to the cornea.

For new-born infants the treatment should be limited to regular evacnation of the sac by pressure with the finger until communication with the nose is established; this may take several weeks. In addition a $\frac{1}{2}$ per cent. zine solution is dropped into the eve once a day, for the purposing of controlling the conjunctival catarrh.

I am aware that my views on the treatment of eye-diseases differ from those usually advanced, particularly in the limited field accorded to the use of probes. These views are the result of twenty years' careful observation of patients and a study of their subsequent history. Because a patient has stopped coming for treatment is no reason to assume that he is cured. In recent cases the passing of probes, if performed with 
the proper technic and as gently as possible, is often followed by good, permanent results. It is for old cases that I wish to combat the routine applieation of this therapentic method. One of my patients, on whom I performed extirpation of the sac on both sides, later had a probe passed hy a colleague who knew nothing of the operation. The patient had consulted him for a different eye-trouble, and as the eye, of course, watered a good deal, a probe was immediately introduced and forced through in spite of the resistance encountered.

[While the Editor agrees with the author as to the necessity of avoiding the indiscriminate use of probes, as to the value of antiseptic irrigation of the lachrymonasal canal and the paramount importance of intranasal treatment, he regards his views on lachrymal treatment in general as too pesimistic. It should be remembered that distingui-hed authorities-e. \%., Theobald and Snell-regard many failures to cure lachrymal disease as due to inadequate size of the probes, and advocate probes $3-4$ $\mathrm{mm}$. in diameter.]

\section{DISEASES OF THE EYELIDS.}

\section{Inflammations.}

The skin of the evelids is subject to the same diseases as the skin covering the rest of the borly. The eyelids alone may be affected, or the eve-affection may simply form part of a general process involving other portions of the body. Acute diseases, such as errsipelas, herpes zoster, varioli, furuncle, anthrax, ete., are met with, as well as chronie processes, among which eczema in its various forms and seborrhea decerve special mention.

Erysipelas and herpes zoster of the lids are occasionally mistaken one for the other; a careful inspection, however, at once reveals the real nature of the disease. In herpes zoster the inflamed area is confined to one side of the face (Plate 20), because the skin-lesion is caused by disease of the trigeminus, and therefore corresponds to the area supplied by that nerve. The first branch is most frequently attacked, the second much less frequently, and the 
third very rardy, if ever. If the first branch of the nerve is discased, the eruption appears on the forehead, as far as the median line, on the upper lid and its immediate surroundings, on the sirle of the nose (anresponding to the distribution of the nato(iliary nerve), and on that part of the hairy scalp supplied by the nerve. In eryipelas the cruption is, of course, not eonfined within such limits. Moreover, the vesicles in erysipelas are large, while in herpes zoster they are small and coalesce in patehes, eorresponding to the terminal distributions of the nerves. They at first contain a clear fluid which later becomes purulent, and in a short time they dry up and form seabs. From admixture with hemoglobin the scabs are monally of a dark-brown or black color (Plate 20), giving the disease its characteristic appearance which lasts for several dars. The erlges of these seabs are indented, in aceordance with the irregular patches of vesieles from which they are formed, and have been described as resembling a geographical malp. The same irregularity of outline characterizes the sears, which are sightly depressed (at first red, later becoming white), and remain visible for years, showing that the corium is involved in the vesicular eruption, which is not the ase in erysipelas or herpes febrilis.

Herpes zoster ophthalmicus, like herpes zoster in other parts of the body (e. \%., in the area supplied by the intercostal nerves, so-called "rose-girdle"), is further characterized by the oecurrence of severe neuralgic pains, both before and during the eruptive stage, and even during the period of convalescence, many patients complaining of pain in the region supplied by the affected nerve for weeks after subsidence of the eruption. In many cases, on the other hand, there is anesthesia of the affected area during convalescence. The morbid proeess quite frequently involves the cornea; we shall speak of this again in the section deroted to inflammations of the cornea.

The treatment of the skin-lesion in herpes zoster consists in fostering the lealing of the scabs; for this purpose either a dusting-powder, consisting of white rinc oxid 
and rice-stalch, or vaselin, may be nsed. For the relief of the neuralgia the munterrupted current of electricity has been adroeated.

Eczema ocempies a prominent place among diseases of the eyelids.

The dry form, eroma squemosum, attacks the surface of the lids and contiguous areas. The skin is rough and somewhat inflamed; the patient complains of itching. A speedy cure is usually effeeted with oil of ade (which must not be allowed to enter the eye) or with 5 per eant. ichthvol ointment.

The moist or vesicular variety is much more common, both on the surface of the lids and particularly on the ciliary margin, where it leads to the disease called blepluritis ulcerose. Eezema on the surface of the lids is usually associated with the same disease on adjoining areas, the hairy scalp, the ears, ete. ; the treatment consists in cleanliness and the applieation of Hebra's ointment.

Blepharitis excematose often oceurs in combination with this process, although it also oceurs independently, and in that case is apt to be very refractory. It is also observed secondary to conjunctival catarh or to keratitis, from maceration of the lids by the conjunctival secretion or the exresive flow of tears; and, finally, it is met with as a concomitant to a form of ecrema which, as we shall see later, firequently attacks the conjunctiva and cornea in serofulous and ancmic subjects. Children are particularly liable to this trilogs, and frequently afford us an opportunity of observing the simultemeous oceurience of the proces on the lids, the conjunctiva, and the cornea, assoriated often with eezema of the nose, month, ears, and bairy sealle. It would appear, therefore, as Horner no doubt correctly thinkis, that rlimioally at laast there is a annection between these three different manifestations of (oexmal (blepharitis, eonjunetivitis, and keratitis eezematosa), althould we still lack anatomie or bacteriologic proof of thrir identity. Ipon eloser inspection we observe that the individial vesieles possess a circulde outline 
and son produce ulcers of varying depth, which on the cutaneous surface of the lids beeone covered with seals, while, of course, on the conjunctival mucous membrane and on the cornea no such scab-formation can take place.

Herginal eczemu presents various clinieal pictures, according to the type and intensity of the process. Solitary, flat, round pustules, of a yellowish color, may be scattered among the tufts of matted cilia, or pierced by a single cilimm (Plate $4, b$ ); or the yellow pustules are replaced by the woll-known eezema-scabs, removal of which with the cilium-forceps reveals the small round ulcer beneath, with the discharge of a few drops of thin pus. The uleers sometimes form a continuous series, or several of them coalesce. If they penetrate to the deeper layers of the corium, as a result of suppuration, the roots of the eilia are destroyed and the characteristic yols in the eycleshes: appear (Plates $4, b ; 6, a$; and $23, b)$. In severe types of pustular eczema, such as oceur in children of marked scerofulous habit or after measles, the four lids may become involved. The surface of the lids becomes edematons, the edges thickened and inflamed, and the entire palpebral margin is covered with erust, through which the tufts of matted cilia are seen projecting. On careful inspection of the upper lid small pustules, still covered with epidermis, may be seen underneath the crusts. When the latter are removed, part of the eilia usually come away with them, exposing the moist and bleeding surface of the palpebral margin covered with deep ulcers.

If the inflammatory proces is protracted, the cilia drop out in ever-increasing numbers or become misplaced inward by the cicatricial contractions which follow the healing of the ulcers, and cause abrasions on the cornea (trichicesis). The palpebral margin becomes permanently thickened and a squamous form of eezema continues for some time to torment and disfigure the patient. Eventually either entropion or ectropion may result : the former in consequence of the cicatricial contractions on the inner surface of the lid-margins; the latter on account of the 


\section{Plate 4.}

11. Papular syphilide from Mracek. Atlas of silphilis and the Venerenl Inivenses, l'late 20 ).

b. Blepharitis eczematosa, associated with slight eczematous keratitis (whence the ciliary congestion) and eczema of the ear. The pationt, who had been sutfering for some time from inflammatory eczema of the eyes, had earrings jut in his ears, with the sole result that the ears also became eczematous and the lobe inflamed. About the middle of the. lower lid there is a gap in the lashes from a previous attack of eczema: on the upper lid recent eczematoms uleers are seen.

eicatrization which is ultimately brought about on the onter surface by the ince-sant materation. In the case of the lower lid the derelopment of ectropion is also fostered by the meehanical drawing down of the margin when the ere is wiped.

The eczema which follows a dacrontenosis may, in riew of its etiologr, be clas-orl a- a spectal form. ('hronic conjunctival catarly from any cance nsmally leats to the development of marginal exmema in the end.

From a clinical point of view eezemal of the lids should be clased with diseases due to dirt, everoblly in children. A few chromic abes may perhaph he explained on the theory of natmal predisposition. In other atses the disarse i- fostered he a debilitated comelition of the organiom, in children e-pecially by serofula, anemia, and acoute disease- like meates, whooping-eough, ote.

The diagnosis in mareinal eczema presents no erreat difficulties; the differential diagnosis from squamons blepharitic or seborhea of the lids will be discusiced in the section devoted to that diseate. The prognosis in acute cases is correspondingly farorable; in ehronic erzema amone adults, which is, on the whole, a rarer oemorence. it is les-fiarorable.

The treatment shomld be both general and local, based on a caroful ansideration of the etiologia conditions. s.rupulous cleanlines and general supporting remedies are the first requisites. The local treatment is directed 


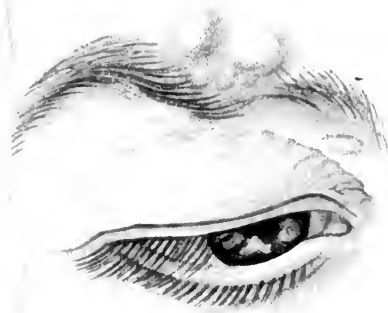

a

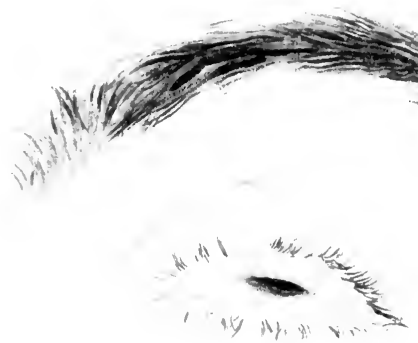

b
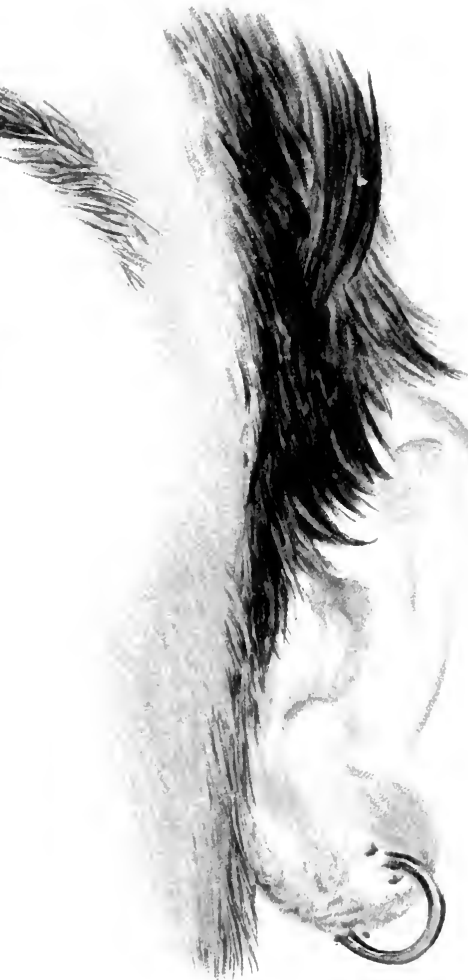

principally toward the removal of such cansal conditions as dacrositenosis and conjunctival catarrh.

Eezoma in contignons areas must also be subjected to vigorous treatment. The seabs are to be first softened with Hebra's or with white precipitate ointment, 1 per cent., in the form of a plaster, and then removed. The exposed ulcers are then covered with the same ointment or painted with a 2 per cent. solution of silver nitrate, or even touched lightly with the mitigated stick. The canterization-scab must not be disturbed, and when it comes away of its own aceord the application is repeated, and so on intil no more ulcers appear.

Children should have their eyes bandaged after the ointment has been applied, to prevent rubbing with the hands. Compresses steeped in bichlorid solution have been reeommencled to keep the parts perfectly clean, parrticularly if eezema of the cornea is present. I $1: 5000$ solution is used. In a very few individuals a bichlorid dressing induces eczoma ; if "so, it is at once detected; in all other cases this form of wet dressing does not produce eczema.

Extraction of the rilia is to be recommended only in chronic eczema in arlult:, and should be followed by an application of tincture of iolin to the palpebral margin; the tincture must not be allowed to enter the conjunctival sac. The same remerly is employed in all eases of chronic thickening and inflammation of the palpebral margins. If the moist form changes into the synamons variety, oil of carle is substituted for tincture of iodin.

Seborrhea of the palpebral margins (Horner), also known as squemons blephreritio, is an affection which is often confounded with eczema. The differential diagnosis is not difficult, if the following points are borne in mind:

Marginal coborrhea very often follow in the wake of similar discase in the harir sealp, characterized by falling ont of the hair, the formation of dry scales, and a fatty secretion. The lashes gradually droj ont, the itching becomes intense, and the patient is finally driven to consult 


\section{Plate 5.}

Meibomian or internal hordeolum in the temporal third of the right upper lid, of four dars' duration. Mild conjunctiral catarrh has existed for some time, hence the conjunctival congestion. Course: Spontancous evacuation of pus through the conjunctiva. Treatment of catarih undertaken to prevent recurrence of the inflammatory process in the lid.

a doctor when his eqes have become more and more sensitive to radiating heat and can no longer stand the strain of continuous use, especially if, as often happens, conjunctival catarrh and horeleolum add their quota to his discomforts. The inflamed and, in chronic cases, thickened margins exhibit the cardinal symptom of the disease: Scales, appearing either as a fine white powder among the cilia, or of a more pronounced bramny character, in rare cases mixel with a fatty secretion to form larger scabs, presenting a certain likeness to the crusts in eczema; but on removal of the scabs with the cilium-forceps no ulcers are found on the skin, which is red and smooth and covered with thin epidermis. The cilia also are characteristic in this disease: the longer the process has lasted the shorter, thinner, and more sparsely distributed will be the erelashes. robbing the eye of its chief ornament. The inflamed and thickened margins take on a deeper red at arch fresh irritation or eongestion, and the eyelashes are ultimately reduced to a thinly scattered low of almost colorles hairs. In eczema we have normally developed cilia alternating with areas entirely denuded of hair; in seborrhea, on the contrary, the cilia are uniformly sparse and poorly developor, showing that we have to deal with a skin-discase which directs its attacks principally against the hair-follicles.

Heredity plạs an important rôle in this form of blepharitis. The discase often hegins in youth, and many people suffer firm it all their lives. Although we have, as yet, no proof that the disease is due to a microörganism, there are many reasons for thinking that it is contagious.

Diagnosis.-In addition to eczema, phthiriasis-i. e., 


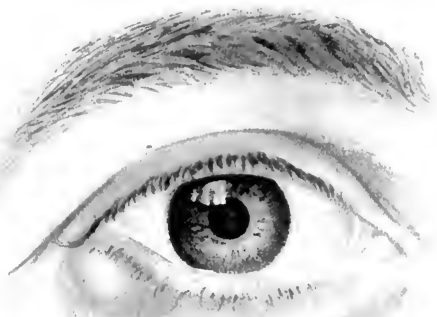



the presence of liee among the eyelashes-may be mistaken for this affection. The parasites nowally belong to the variety phthirius inguinalis, or erab-louse; hearl-lice rarely attack this region. The lisease may be mistaken for mollusem eontagiosum (Plate 6, b) if the nodules are small and the examination has been very supertieial.

Prognosis.-The disease is a serions one. Not only is the eye disfigured and its nefulness impaired; but if the cilia are lost, the eonjunetival catarrh which ensues is alpt to resist all treatment, and may in the conrse of years produce ectropion, which, in turn, brings on disease of the cornea and other more serions complications. The disease ean unly he cured in youth. In later life the evil may be palliated or temporarily rhecked; but it recurs ats soon as the conditions are firorable: radliated heat, nightwork, ete.

The treatment should match the disease in stublommness. Other hairy parts of the body, if the seat of seborrhea, must be treated with lotions of : Carbol, 5 perent.; sulph. precip., 2 per cent., mixed with equal part of aleohol and eau de Cologne, or with sulphur ointment. The eyes must be thoroughly cleansed every morning with a fine linen aloth, after having been airefully rubbed the night hefore with an ointment consisting of "tmpeth mineral (hasic mereuric sulphate), or

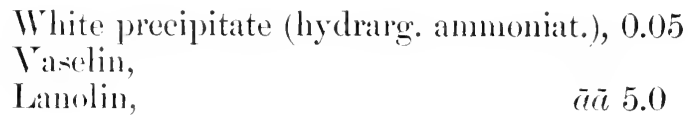

The ointment is to be applied immediately before going to sleep. Salves which tend to become rancid only ageravate the evil. In winter the eyes should be washed with warm water. This treatment imust be preseribed for several months from the very outset. In chronic cases tincture of iodin may he nied with alvantage. [An excellent ointment for iquamon- bepharitis is one composed of 3 per cent. of milk of sulphur and 3 per cent. of resorcin. 


\section{Plate 6.}

a. Eczematous blepharitis of long standing, so tinat on one side numerous gaps, on the other only the squamous form of the disease, are seen.

b. Molluscum contagiosum and external hordeolum in a girl, 17 years old. The uniformly small nodules are most unmerous in the region of the eyes; a few isolated ones are also seen on the rest of the face and on the upper part of the body; but they lase not as yet spread to the lower portions. The nodules show the eharacteristic central opening or depression. The external hordeolum which is seen on the lower lid, a little to the nasal side of the center, is merely an accidental complication.

The scales should first be removed with a 5 per cent. solution of chloral (Gradle) or with a solution of sodium bicarbonate. Pagenstecher's ointment (yellow oxid of mercury) is useful in ulcerated and eezematous blepharitis, as is also aristol ointment. In all cases of blepharitis an essential part of the treatment is the thorough correction of any existing refractive error. This alone will suffice to cure many mild cases.-ED.]

The various glands in the lids frequently beeome the seat of inflammation. We have two varieties to deal with: 1. About 600 sebaceous glands, which accompany the cilia on both the upper and the lower margins, the socalled glands of Zeiss; 2. The long, acinous Meibomian glands, which lie elosely packed in the tarsus, in perpendicular lines to the palpebral margin. They are praetically enlarged sebaceons glands, opening on the free border of the lid and by their oily secretion preventing the tears orerflowing.

Hordeolum.- Suppuration of a sebaceous gland leads to the formation of the well-known stre or external hordeolum (Plate 6, b. lower licl, to nasal side of center); while the same process in one or more Meibomian glands produces the so-called internal hordeolum, a much more serious disturlance, the inflammation being more extensive and the pain proportionately greater. The redness and swelling of surrounding parts are so great as to simulate the picture of eryipelas or ophthalmic blennorrhea. The lids 
Tab. 6.

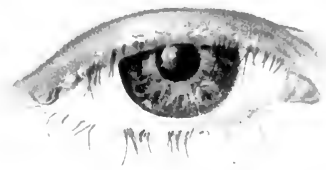

a

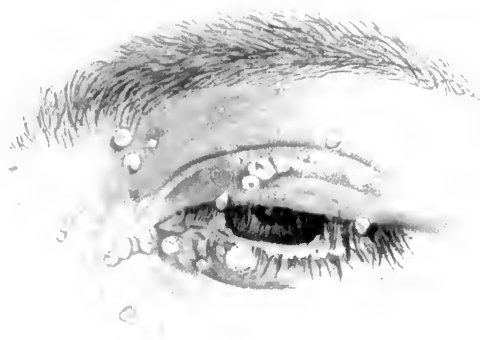

b 

and the conjunctiva may be edematom, especially if the purulent focus is situated near the outer eanthus. This is easily found by palpating the inflamed lid, ats it is extremely painful; sometimes it corresonds with a small rellow pustule on the margin of the licl. It marks the ipening of the duct of the inflamed Meibonian gland or glands. If the patient ean bear the discomforts of the procedure, it is sometimes possible to inspect the inner surface of the lid and note the aecumulated pus shining through the conjunctiva. For the small alseess which forms in a short time is more likely to rupture through the conjunctiva than through the skin. With the bursting of the albseess the pain and discomfort cease and the swelling subsides.

Both the internal and the external hordeolum, but especialiy the latter, may recur for weeks or even months, first in one and then in another of the four pal pebral margins. The process is fostered by seborrhea and chronic conjunetival catarrh ; but the first fundamental eondition is the presence of pyogenic microörganisms. I onee had occasion to observe how the introduction into the eonjunctival sac of a virulent culture of staphylocoecus aurens caused the occurrence of hordeola.

There is every justifieation for elassifying these two forms of gland-inflammation, as well as chalazion (to be described), moler the head of acne, as Horner has suggesterl.

Neither variety of hordeolum produees permanent injury, and the treatment is quite simple. Active poulticing with linseed-meal is recommended, both to alleviate the suffering and to shorten the process by bringing the abscess to the point of spontaneous evacuation or incision. [Repeatedly applied compresses soaked in hot carbolized solution or in hot water containing 33 per cent. of fluid extract of hamamelis is preferable._ED.] The knife should be used as soon as a distinet purulent focus is seen through the conjunetiva, the inci-ion being made from within, perpendicular to the margin. 


\section{Plate 7.}

1. Chalazion on the upper lid of a roung man; developed during the list iwo months. Incision from within and evacuation resulted in cure.

b. Multiple chalazion, on the right eye of a young woman ; dereloped gradually during the last six months.

$\therefore$ The lower lid of the sane side, seen from within Conjunctiva shows proliferation resembling granulation. Evacuation from within. ('ure.

To prevent the recurrence of hordeola I have found it adrisable to preseribe a collyrium for several weeks after the subsidence of the inflammation. This is composed as follow: Zine sulphate, 0.1 to 20.0 of a solution of sublimate, $1: 5000$ or $1: 10,000$. Seborrhea, if present, must be treated.

From what has been said it is evident that chalazion and horleolum are more or less related. In most cases the chalazion develops slowly, withont giving rise to inHammatory srmptoms; occasionally, however, its inception or subsequent course is attended with inflammation. 'The norlule in the course of weeks or months may attain the size of a pea or half a cherry (Plate 7, "1); quite frecurently it is multiple (Plate $7, b$ ), in which ase its favoritr sat is in the upper lis. The skin is not inflamed at fir-t. and, whether the growth be single or multiple, always moves with the shifting of the swelling, which is only movable with the tarsus. The conjunctiva on the imner surfare of the lid is red and swollen, and sometimes hypertophied, as if it were the seat of gramulations (Plate $7, \cdots)$ Thi- i- mole particularly the ase when the tumor is preparing to lurst or has already doneso. The contents of the morlule are gravish and ean often be seen through the walls. Anatomie "xamination shows that the tumor is situated within the tarsu-. and therefore originates in one or more Meibomian glands. The content consist of a soft, grayish-red mass of cranulations, more or less liquirl in the anter. The walls of the tumor are formed by the dense comnective tisue of the tarsus. Microscopic 
Tah. 7.
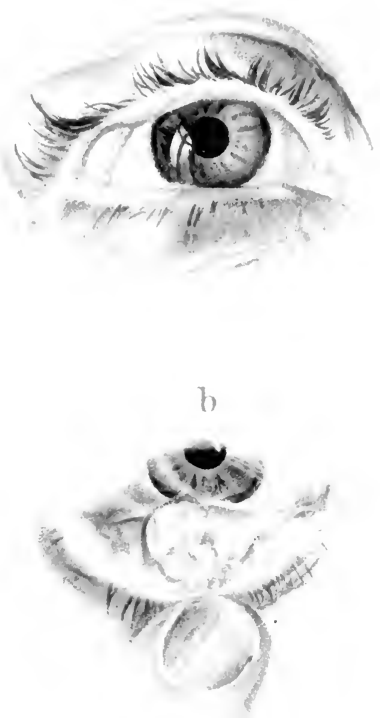

C 

examination reveals that the chalazion begins with a proliferation of the epithelium in the acini of a Meibomian gland, the acini beeoming surrounded by an ever-increasing inflammatory infiltration of the tarsus. As the glands are destroyed the small-cell infiltration increases and forms granulation-tissue, with a few giant cells, so that the entire growth comes to resemble a tuberenlar proliferation, although the process has nothing whatever to do with tubereulosis. On the contrary, this chronic inflammation of the Meibomian glands is probably due to another bacillus, which I found in several eases in small numbers. It was difficult to stain. Perhaps it is identical with that described later hy Deyl.

One argument in sipport of the specific nature of chalazion is the fact that it is always preceded by mild, chronic catarrh of the conjunctiva, and that the formation of other chalazia is best prevented by checking the conjunctival catarrh by means of the preparation of zine referred to in commection with hordeolum. We also know that chronic conjunctival eatarrh farors the growth of pathogenic microbes in the conjunctival sac.

Chalazia must be removed as soon as they have attained a certain size; very small ones need no treatment. A large conjunctival incision is made rumning vertically to the palpobral margin and the eontents scraped out with a euret. The caprule is allowed to take care of itself, so that the swelling does not subsirle until one or two weeks after the operation. If the operation is properly performed, the tumor will not reeur. If the growth is nearer the skin and threatens to burst, a horizontal incision may be made through the skin parallel to the lid-margin and the contents removed in that way. A chalazion must never be cauterized from the conjunctival sile, as the resulting cicatrization learls to trichiasis and entropion. [The conjunctival hyperenia induced by eye-starin is a constant callse of chalazia and hordeola; therefore the necessity of correcting the refraction of the eve if it is anomalous.-ED.] 


\section{Plate 8.}

Blepharochalasis on Both Sides.-The patient is 31 years old : otherwise quite well; no sugar or albumin in the urine. The disease began eleven years ago; the eyes are mnch disfigured by the redness and swelling of the lids. Dilated reins are seen in the inflamed skin. In this case, as in the last, there is a suggestion of epicanthus, the skin of the upper lid being overlapped by the fold of epicanthus, more so on the right than wn the left side. The results of operative removal were very satislactory. Only a narrow strip of skin and orbicularis was excised; the lower lip of the wound was firmly attached to the upper margin of the tarsus by means of eight sutures.

\section{Anomalies in the Shape and Position of the Eyelids.}

Congenital ptosis (Plate 9), or drooping of the upper link, from paralysis or defective development of the levator palpelire superioris, is nsually bilateral, while the arepuived form commonly ocerms only on one side. Acfuired ptosis often follows paralysis of the srmpathetic, being directly caused by paralysis of the involuntary Iiiller's muscle, an accessory of the levator palpebra. The condition is characterized by contracted pupil and vasmotor paralysis on the affected side of the face. Pto-i- due to paralysis of the oculomotor nerve is more marked and the pujil of the affected eye is mally dilated.

Thr congenital anomaly known as epiecouthus (Plates 3 and 9) comsists of a crescentic fold of skin which surround and partially covers the internal canthus. The condition is normal in the Mongolian race and in many new-lum infant- of the Cancasian rare. eradually disappraring among the latter as the bridge of the nose is more fully developerl. If the fold persists to adult age it must he pemosed he direct excision : the practice of exeising an olliptical piece of -kin from the bridge of the nose is un-atisfactory, in my opinion.

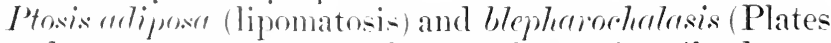
8 and 9) are two congenital anomalies primarily due to defertive attachment of the integument to the upper marein of the tarsus and the tendon of the levator. The 
$\frac{0}{6}$
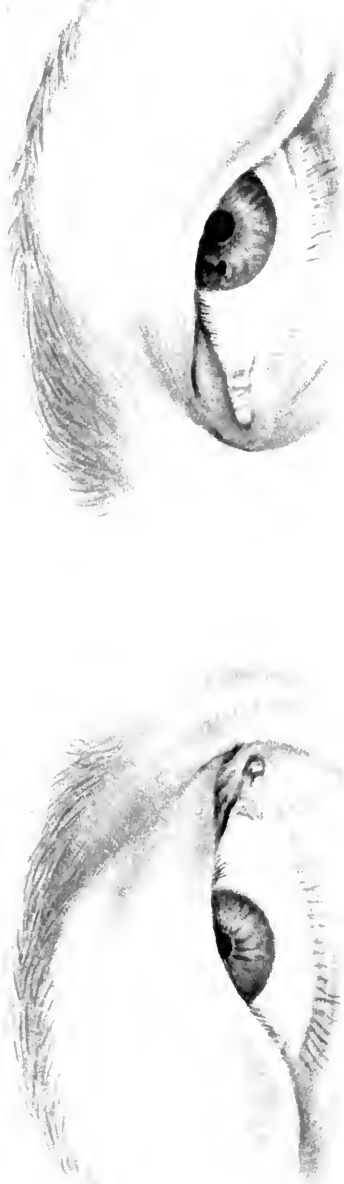

skin eamot be raised with the lid, and hamgs down like a pouch over the palpebral margin, producing a marked deformity. Aceording to Fuchs, the skin is very thin and slightly hyperemic. The two anomalies may be corrected by excising a portion of the redundant skin and attaching it by means of sutures to the upper margin of the tarsis (Hotz's operation).

The foregoing anomalies are rare compared with the conditions termed cotropion and entropion.

Ectropion (also called eresion of the licl-margin when very slight) occurs in the lower lid when the skin and tarsis become rolaxed-senile eretropion; or in consognence of cicatricial contraction of the skin after trammatism-ricativial ectropion. The ricatricial form develops in earies of the orbital margin, after burns, scalds, nleerations, ete., or through the gradual cieatrization attending the repeated excoriations and eczematous eruptions brought on by constant maceration and wiping of the eyes in dacrostenosis and chronic "atalrh.

The paralytic form is produced by palsy of the facial nerve which supplies the orbicularis palpebrarmm. The lower lid only is everted, the upper lid being drawn upward by the preponderance of the levator and Mïller's musele. The direct result is lagoplethelmos, or inability to close the eye, especially during sleep, which is apt to produe conjunctival catarh. Another important form of lagophthalmos is due to protrusion of the eye from tumors of the orbit and exophthalmic goiter.

sprestic ectropion is sometimes met with in young persons, due to abnormal contration of the orbicularis palpebrarum. It is corrected by replacement and a suitable bandlage.

The remaining varieties of ectropion demand surgical treatment, by means of which, above all things, the clongation of the lid that is often present must be corrected by excising a wedge-shaped portion of the tarsus and conjunctiva (after the method of Kuhnt or Dimmer's modification of his operation). If the ectropion is slight, Snellen's 


\section{Plate 9.}

\section{Blepharochalasis in the Later Stages; Congenital Ptosis ; Epican-} thus.-The patient, 26 years old, is terribly disfigured by the malady. It could not be definitely ascertained whether the ptosis was congenital. The characteristic wrinkles are seen on the forehead. The epicanthus is partly congenital and partly caused by the blepharochalasis; deep, ugly looking pits are concealed under the folds. The skin of the upper lids is relaxed and hangs down in folds. In the upper portion of the right upper lid a few vertical folds are seen. The same swelling of the lids, seen in the freceding case, was formerly present. The malady hegan spontaneously with swelling and inflammation, when the patient was five years old. The redness and swelling gradually disappeared in his thirteenth year and gave place to the present condition. The r'sults of opcrative treatment were very satisfactory. A larger piece of kin was cut away than in the preceding ease, mostly from the nasal portion of the upper lid, for the purpose of correcting the epicanthus. In placing the sutures the needle was introduced through the lower margin of the wound, then through the upper margin of the tarsus, and passed out through the tendon of the levator about ; $\mathrm{mm}$. higher up, and finally through the upyer margin of the wound. Eight stitches were put in on each side. The action of the lid was materially improved and the cosmic result excellent.

suture -uffices; the patient should be adrised to wipe the ere from helow upward.

Entropion, especially of the lower lid, may also be caused by spastic eontractions of the muscular fibers. It is seen most frequently in elderly people with relaxed eyelids and small, decp-set, or deficient eychalls, associated usually with blepharospasm. The condition is usually temporary and can be corrected by simply drawing the skin away from the palpebral fissure and securing it with allesive plaster or a Gaillard suture.

(ricativicial enterpion is a more serious injury and generally requiresoperative treatment. It is eaused by cicaltricial shortening of the conjunctiva after trachoma, diphtheritic conjunctivitis, hurning or salding of the conjunctiva, and not infrequently after exessive therapentic rantrerization.

siymblepherom is a cohesion between the eyelids and the 


$$
\begin{aligned}
& = \\
& =
\end{aligned}
$$

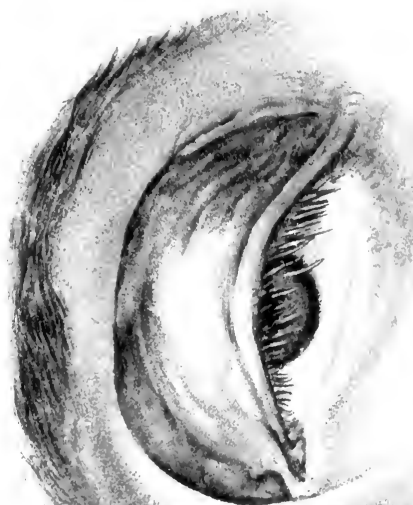

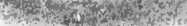

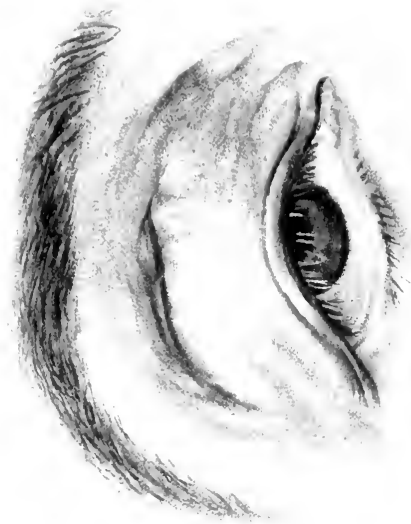



ball which sometimes develops as the result of burns and ulceration.

Sometimes the free edges of the lids become adherent to each other, in which case the condition is called ankyloblepharon.

The term blepharophimosis is applied to a condition in which the palpebral fissure is apparently shortened by the passage of a vertical fold of skin over the outer canthus. The commissure is normal underneath the fold of skin, which can be made to disappear by outward traction with the finger. If the palpebral margins have actually grown together at the outer commissure, the condition is more correctly designated as ankyloblephoron.

\section{Injuries of the Eyelids.}

Injuries of the evelids are very common. The skin in this region is loosely attached to the underlying tissues and very extensible, faroring the development of severe subcutaneons hemorrhages which cause varions discolorations, ranging from red to dark blue or black. The lids are swollen, particularly if there is subeutaneous emphysema, as in fractures or fissures of the orbital bones, which permit the escape of air from the nasal and other "avities (sinus frontalis, ete.). The thin, nasal wall of the orbit is particularly liable to fracture, expecially the cribriform plate of the ethmoid bone, and the escaping air distends the lids so that they feel like an emphysematous lung. Sometimes there is protrusion of the creball. These symptoms, however, look more alarming thain they really are and the patient nsually escapes with nothing worse than a "black eye." A far greater significance attaches to the subcutaneous hemorrhages cansed by fracture of the base of the skull (Plate 10). In this accident the blood sometimes is forced forward as far as the evelids, and the resulting ecchymosis in the lower part of the ocular conjunctiva and in the lower lid (rarely also in the upper) constitutes an important symptom. 


\section{Plate 10.}

Subcutaneous Hemorrhage in the Lids after Fracture of the Base of the Skull.- The hemorrhage is more marked in the upper than in the lower lid, which is the opposite of what is usually observed. Patient is 24 yoars old, male. Four days before, he jumped from a moving ear and struck on the back of his heal. He was uneonseions twenty-four hours and complained of headache for a long time afterward. No other lesion was fomml. ('ured after a rest of several werks, part of the time in bed. No prmanent injuries.

Permanent injuries mar result from a cut serering the upper lid or dividing one or the other liel in a vertical line, unles.s the wound is promptly and carefully sutured. Especial eare must be taken to bring the edges of the romml together accurately at the fiee border of the lids. If the lower lid is torn at the imner canthus, permanent interruption of the lower canaliculus usually results in spite of the most careful application of sutures; this has heen referred to on p. 79. Fortmotely, the upper canaliculus under ordinary condition- is able to carry off the lachromal fluid.

In powder-burn the particles of powler are best removed by buming with the electric antery after the womnd has healed.

\section{Tumors of the Eyelids.}

Benign Tumors. - Vanthelasima securs in middleatged persons, expecially women, and oceasiomally requires nperative treatment on account of the deformity. The patcher atre of a vellowi-h-brown eolor and slightly raised ahowe the surromding skin. Both eres are usually afforcted, the patehes being smmetrically distributed above and below the inner eanthus.

Hollnswem rontregiosmm, at its name implies, is apt to spread over the body of the patient and infect those who come in enntact with him. The papules are as large as a pea or a cherry, and appear in large numbers, preferably on the lids and their surroundings. In proof of the con- 


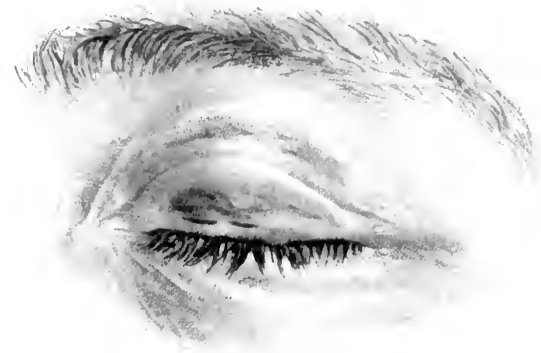



tagious nature of the disease I may state that I inoculated mrself with it snecessfully about twelve years ago, that being one of the earliest snceesful inoculations on record. The growth, which was taken from the eyelid of a child, took six months to develop. Epidemies of the disease have been observed in schools.

Milinm, or an oceluded sebaceous gland, appears as a small elevation which is sometimes confounded with molluscum contagiosum in its first stages. The shallow central depression, however, through which the milky contents of the molluscum can be expressed, is not seen in the milium. With the microscope certain peculiar, shining, spherical bodies are found in mollusca which establish the diagnosis.

Each nodule must be removed with the galvanocantery, curet, ete.

Fibroma molluscum, or molluscum simplex, uarts, and cutencous corms: are occasionally seen; also ungiomutu, telangiectatic and carernous tumors. The latter are usually congenital, and should be removed as early as posibible.

Malignant Tumors.-Carcinome and sareome, the former preferably on the palpebral margin, the latter often melanotic, usually begin in the tarsus.

\section{DISEASES OF THE CONJUNCTIVA.}

\section{A. CONFLUENT INFLAMMATIONS.}

\section{Simple Catarrhal Conjunctivitis.}

IVe distinguish an acute and a chronic form. In acute conjunctivitis the inflammatory symptoms are more pronounced and the bulbar eonjunctiva is involved, while catarrh, especially the chronic form, is usually limited to the palpebral conjunctiva.

The objective symptoms are: Abnormal secretion of mucus or pus, congestion, swelling of the mucous membrane producing a roughness in the tarsal conjunctiva, 
the formation of folds in the region of the formix, and swelling of the semilunar fold and carmele. In purulent catarh there may be edema of the bulbar conjunctiva and the lids themselves are more or less swollen.

The lids are glued together in the morning; the patient (omplains of burning and itching and a gritty feeling. Owing to a film of mucus on the corneal there is a temporary haziness, which disappears as soon as the patient wipes his eyes. If the layer of musus is very thin, the patient sees colored rings around the lamp (iridescent vision), as in glaucoma. Photophobia, blepharo pasm, and pain are not marked as long as the cornea is not involved. so that the lids are more easily separated than is the case in eorneal inflammations. Later in the course of chronic catarrh the lid-margins and the cornea mav become inflamed, especially in elderly people giving risc to the so-called marginal or atarithal ulcer, or to purulent ulcers.

Etiology._A variety of pathogenic microörganisms are found in the conjunctival sac during catarrth. Among those which are known to produce enjunctivitis are: (1) the gonorocen: (-

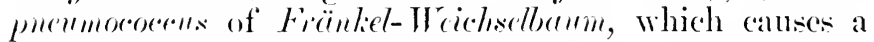
mild and not neecsarily contagious form of eatarrh, and is found oftener in children than in adults ; ${ }^{\prime}(3)$ the stieptocorens, which prodnces aither simple or pendomembranons diphtheritic inflammation. Whother the staphylococei which are often found in the anjunctival sale are capable of alusing conjunctivitis or not, is still an open question.

The following bereilli may give rise to enjunctivitis: (1) the diphtheriter berillus (soe diphtheritic eonjunetivitis); (2) the Koch-Wrelis' bacillus, which under certain conditions sets up a severe, (ontagious inflammation in children

' [There are a number of ohervations on record, particulary these of llambl (ifford, which indieate that puemococeus-conjunctivitis may also be an aflection which i= distiuctly contagions, which attacks adults, which passes from one "yc to another. and which elinically is difficult to differentiate from Koch-Wecks bacillus conjunctivitis.-ED.] 
and adults [acute contagious conjunctivitis, vulgarly known as "pink eye."-ED.]; (3) the diplobacillus of I Worax and A.cenfeld, the occasional cause of a slow, protracted form of conjunctivitis. [It is not infrequently found in stubborn cases of subacute conjunctivitis.-ED. $]$

As far as our present knowledge of simple catarrhal conjunctivitis goes, different bacilli may be found in clinically identical forms; and, conversely, the same bacilli may give rise to different clinical appearances (Bach).

Among other causes which produce, or at least aggravate, conjunetivitis may be named: Bad ventilation, dust, smoke, alcoholic abuse, blepharitis, dacryostenosis, foreign bodies in the conjunctival sac, etc.

Diagnosis. - This is based on the symptoms described. Corneal complications may be detected by observing ciliary congestion and irregularities in the surface of the membrane.

Prognosis.-This is excellent in young subjects, althongh in elderly people and in cases in which the exciting eauses cannot be removed, the treatment may present some difficulties.

Treatment.-This is primarily concerned with the removal of the exciting causes. Locally, astringents, either applied by the surgeon himself, or in the form of eye-drops or ointment entrusted to the patient. The mucous surfaces may be painted with a 1 per cent. to 2 per cent. solution of argentic nitrate according to the degree of purulent secretion. For a collyrium preseribe zinc sulphate $0.05-$ 0.1 in 10.0 of distilled water, or $1: 10,000$ sublimate solution ; the latter solution remains sterile longer. If the cornea is not involved, lead acetate $0.1-0.2$ in 10.0 of distilled water, or $u n g$. amylo-glycerini (glyceritum amyli), may be useful; but if the cornea is involved, incrustations of lead may follow its wse and retard the healing of the corneal injury. In obstinate cases a variety of remedies must be tried: Copper sulphate, tannin, alum (0.5 per cent.). Collyria are to be used once or twice a day; ointments are 


\section{Plate I .}

a. Dermoid tumor in a child, aged 1 year. The growth is congenital and is growing very slowly.

$b$. The same in a man, aged 21 years. The characteristic hairs, often seen in a dermoid tumor, are present. The tumor in this case also has grown very little since birth. After removal a small, gray spot appeared on the cornea.

applied once a day with a glass rod. Atropin is quite unnecessary mless there is a corneal complication. [Frequent cleansing of the conjunctival sacs with saturated boric-acil solution, or with boric acid and saline solution, is advantageous. If reaction is high, iced compresses are useful. 'Tine is especially valuable in diplobacillus conjunctivitis.-ED.]

\section{Follicular Conjunctivitis.}

A chronic form of eatarrh, characterized by the formation of numerous granulations on the conjunctiva, more particularly in the retrotarsal folds (Plate 14, a). The nodules appear singly or in rows, are of a pinki-h-gray color, and vary in size from 1 to $3 \mathrm{~mm}$. ; the larger ones are more or less transparent.

The disease belongs to childhood and early adult life, and may run its course without marked subjective symptoms; or the child may be troubled with blinking (nirtitatio) and inability to continue at close work. As a rule, there is little or no secretion.

Diagnosis.-Follicular conjunctivitis is often confounded with trachoma; but the distinction may be made by observing that the granulations are most numerous in the lower retrotarsal fold, while in trachoma they are found chiefly in the upper curve of the formix.

Prognosis.- The disorder may run a slow and tedions course; or it may disappear withont leaving a trace.

Treatment. - Learl, either as an ointment or in solution, as a collyrium (Plumb. acet. 0.1-0.2 to 10.0, aque destill. or ung. amylo-glyeerini). [Excellent collyria also 


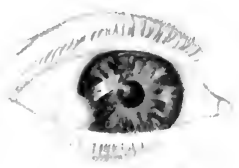

a

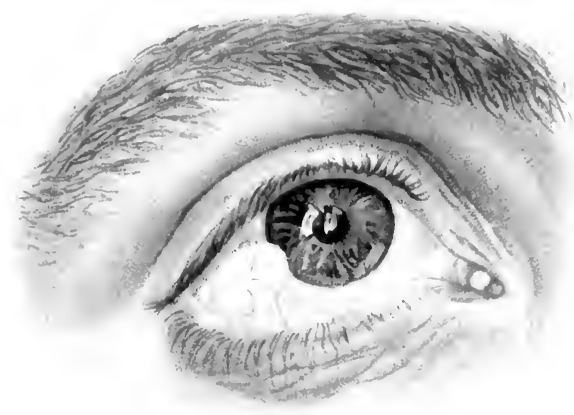

b 

are: Borie-acid solution to which a few minims of alcohol to the ounce have been added, and boric acid in saturated solution ; applieations of moderate astringents like tannin and glycerin (5 per cent.) are suitable ; but if the disease is stublorn, the follicles should be expressed with suitable forcep.-.ED.]

\section{Gonorrheal Conjunctivitis.}

Gonorrheal conjunctivitis is caused by infection of the conjunctival sac with Neisser's gonococeus; and, while it may occur at all ages, is most firequently seen in infants, in whom it is due to the entrance of genital secretion into the ere at the time of birth, or later to contact with the mother's soiled fingers. Later in life the genitalia (now and then also in very young girls who suffer from a virulent lenkorrhea) or another eye similarly affected are the souree of infection. Doctors and nurses are constantly exposed to infection from this source.

The importance of this disease cannot be overrated; it is the direct canse of blindness in one-third of all the cases, being surpased in this respeet only by small-pox in countries where vaceination is not sufficiently enforced. Most cases of blindness are eansed by ophtheimire neomertomm, which, in spite of the higher standard of midwifery and more competent medical treatment of the present day, defies all efforts to eradicate it, beeause of the negligenee on the part of the persons in attendance in not seeking medical assistance early enough, and becanse the discase is and always will be dangerons in spite of the improved methods of treatment. It is therefore much to be desired that the prophylactie measures advocated hy Crede might meet with more general adoption, especially in the quarters of the poor and thoughtless, who now furnish the great majority of virulent cases.

Ophthalmia, or blemorrhene neonatorum [eonjunctivitis neonatorum], usmally begins on the third day after birth, with swelling and redness of the lids, and a diseharge con- 


\section{Plate 12.}

\section{Gonorrheal Conjunctivitis in the New-born.}

sisting of bloorl and serum, which has beon likened to bonillon. Both eres are monally atfected, one a little later than its fellow. The onjunetiva in the first stage is red amd swollen, but smooth. Exlema is nsmally alsent in infints.

After a few dass the serections become more purulent, the swelling of the lids diminishes, and the skin over the liks appears wrinkled; the conjunctiva is soft and puckered into folds, the color deepens to a rark red, the surface is rough and velvets, and longitudinal folds appear in the region of the fornix. At this time thick, rellow pus is socreted in large quantities and oozes ont of the palpebral fis-sure (Plate 12) or collects in the folds of the conjunctival cul-de-sia.

Drring this second, or true gonorrheal stage, which mas last for weeks, the comea is in the greatest danger. The secretion, if not removed from the conjunctival sac, attacks the cornea ; at first a small, gray patch appears at, or a little holow, the center of the membrane; it increases rapilly in size and is soon converted into a suppurating uleer, which spreads over the entire surface and may lead to perforation. If perforation takes place, the suppurative process invales the decper tissues and gives rise to virulent inflammation in the anterior portion of the ere, or even to penophthalmitix. Slomghing of the entire cornea may easily lead to prolapse of the lens; in smaller perforations there is more or less allhesion of the iris to the opening, and a strephylome may result. If the perforation is very small and centrally situated, the cormea may escape with a rentral marula: hint in this ase the lens may suffer from the proloned rontact with the nleerated portion of the cornca, the curlothelial cells of the anterior eapsule pro-

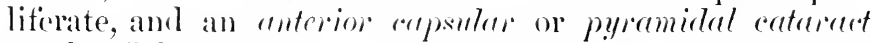
results (Plate :34, a). The resulting comeal opacity may be much less than the lenticular; but not infrequently 
Tab. 12.
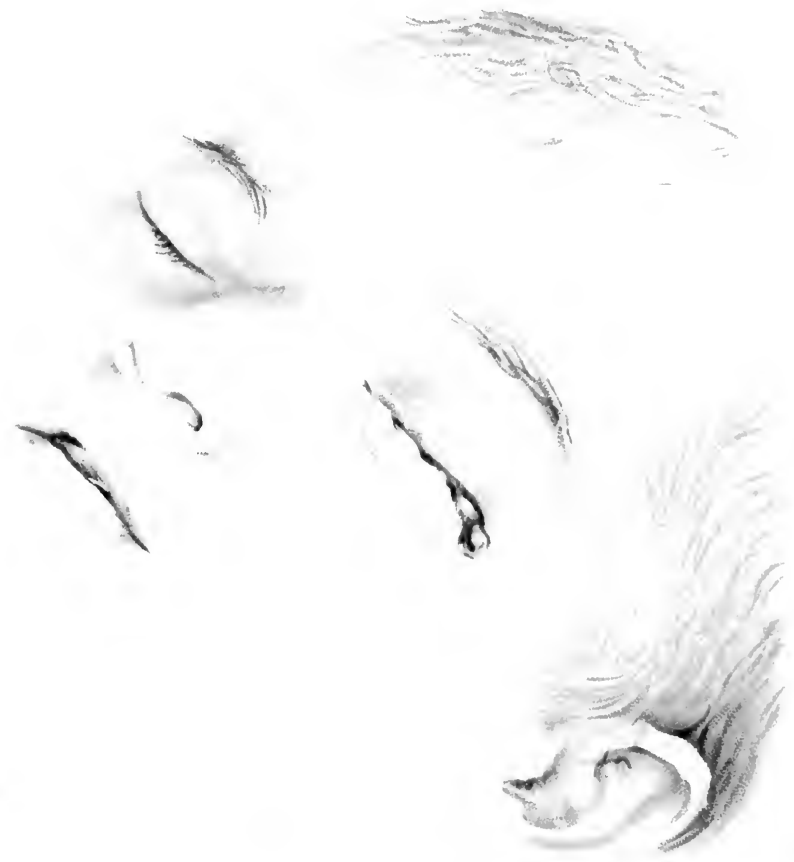

large white spots, or lenlomete, remain and interfere materially with vision.

In older children and in alults the inflammation runs a more acute course. 'The swelling and infiltration of lids and eonjunctiva are much more marked, and there is severe edema of the bulbar conjunctiva, the edges of the cornea being covered by the overhanging folds of the chemotic membranc. The corneal tirste is in constant danger of being croded by the masices of pus alcenmulated under these folds, and matrginal ulecrs of the corneat atre consecquently more frequent in adults than in children. Their detection is often difficult, becanse they develop unseen under the shadow of the swollen conjunetivit. These marginal uleers are characterizol by rapici spreat, and often result in extensive sloughing of the eornoa. Under certain conditions an ulcer may develop in the center.

In some instances where the infiltration in the palpebral conjunetiva, especially of the upper licl, is very great, the tis-ues assume a vellowish-gray eolor, resembling a diphtheritic membrane. There eares alre fraught with great danger to the cornea.

Diagnosis.-This ammot be definitely established without a microseopic examination of the secretion and the detection in it of gonocoeci, although the severity of the process, in arlults at least, is such ar to leave no doubt of the virulent nature of the inflammation. It must be remembered, however, that both infants and adults are liable to oceasional attacks of nom-rirulent purulent eatarrh which elosely resemble a light attack of gonorrhea. Moreoser, it is particularly desirable that the disease be recognizod before it has boeome fully developed, in order that the proper precautions may be taken to protect the matfected eye. For ordinary purposes a cover-glass preparation, stained with fuchsin, will give all the necessity information; if liplocoeci are found congregated about the nuclei of pus-corpuscles, the diag- 
nosis may be considered established. For accurate demonstration of the gonococei cultures are necessary.

The prognosis is somewhat more favorable in infants than in adult patients. If a new-born infant is seen early enough, there is no reason why the eye should not he saved, if the proper treatment is employed, with two reservations: If it is not tainted with hereditary sy philis, or very much enfeebled by other disease. In oliter patients recorcry is alwars very doubtful ; total or partial destruetion of the cornea is to be feared even with the most carcful management. It is one of the most dangerous diseases to which the eye is subject. I have repeatedly seen the loss of hoth eyes take place in spite of the most energetic and painstaking treatment.

Prophylaxis is a matter of the greatest importance in purulent ophthalmia. ('redés method is a practically certain preventive of its oceurrence in the new-born, and may materially influence the severity of the process in the arliilt. It consist - in the instillation of one deop of a 2 pereent. solution of silver nitrate into the eye inmediately after the first bath. No other measures are necessary exrept the proper precautions against subsequent infertion. This methol has proved very successul and demomstrates conclusively that silver nitrate is the most affective remedy against gonorocei, a very small quantity suffieing to eheck their further growth.

All gomorrheal patients, and those who come in contact with them or with patients snffering from gonorrheal conjunctivitis, must be carefully warned of the great danger of infection. If one eye only is affected, as frepuently happens in adults, the somd eye should he protected fiom contact with the infections secretion he a collodion shield as som at the diagnosis is definitely settlod. The eye is covered with a thin part of cotton over which a piece of linen is fitterl. and the aleres elued to the skin with collodion, after which the entire dresing is given a scomel coat of eollowlion. 'To make sure that infection has been surcessfiully warded off; the shied must be loosened every 
day, for the first few days, and the eye thoronghly inspected. [Buller's shield, or a watch-erystal fastened over the somd eve with strips of ganze and collorlion, is a more easily managed dresing and permits ready inspection of the eye-ED.] In infants the application of such a shield is not practicable, nor is it often necesinary, as both eyes are usually affeeted from the hegimning.

Treatment. - During the entire course of a gonorrheal conjunetivitis the first duty of the attendant is to keep the eonjunctival sac absolutely clean by constant removal of the discharge. To rednee the swelling and inflammation ice-cold compresses are applied at short intervals, the eye being earefully wiped with a pledget of cotton every time the compress is ehanged. The compresses must be washed in a 1 per cent. solution of potasium permanganate before they are put back on the ice, and the same solution should be used by the surgeon in cleansing the eye at aach examination. In the begimning, while the inflammation is at its height, cold compreses should be applied day and night; later, the cleansing proeess at least must he kept up during the entire night. If the seeretion is very abumdant, the attendant should separate the lids every quarter of an hour, so as to allow the pus to run off; but in no case is he to wipe the conjunctival sale. That duty must be performed by the surgeon himielf, from one to three times a day or oftener, as the severity of the process demands. [As collyria in purulent ophthalmia the Editor prefers a saturated boric-acil solution, or mereurie chlorid, $1: 8000$, or formaldehyd, $1: 6000$. He has alto had excellent results with potassium-permanganate solution $(1: 2000)$ used in copious irrigations- 1 liter at a time. Vaselin rubbed on the lids and introdueed into the conjunctival sac is of great advantage. Reeently, protargol and argonin have been advoeated in place of silver nitrate in purulent ophthalmia. They may be used in from 2 to 5 per cent. solutions.

Silver nitrate is the best remedy for ehecking the secretion. As a strong caustic solution would endanger the 


\section{Plate 13.}

a. Diphtheritic conjunctivitis in a small boy. This picture shows a higher degree of inflammatory swelling and injection of the conjunctiva than the last. The skin of the lower lid and the region about the inner canthus are infiltrated and eroded in places by the purulent discharge.

b. The everted npper lid of the same patient, showing the deep diphtheritic infiltration of the conjunctiva, which is of a yellowish-gray color.

vitality of the cornea, a 2 per eent. solution is usually employed; but in neglected ases, in which the swelling of the conjunctiva is unusually great, it may be neeessary to use the solid stick. The more active the purulent secretion the more frequent should be the applieations; in adults two brushings a day may be needed; in faet, the nitrate should be applied as soon as the eschar has separated, and that, in turn, depends on the amount of discharge. The important point to be remembered in eanterizing the eonjunetiva is that it must not be practised until there is a free discharge of pus; in other words, not before the seeond or gonorrheal stage. As long as the conjunctiva is tense and swollen and there are fibrinous deposits and diseolored areas cauterization is harmful.

When the silver nitrate is to be applied, the child is made to assume the position deseribed on p. 24. Fach lid, in infants and adults, is to be crerted separately and thoroughly painted with the solution, but in such a way as to avoid contact with the eornea. The retrotarsal folds, which are always the seat of greatest swelling, should receive special attention. After the desired eschar is formed, the exeess of nitrate is to be washed away with water, or, if the mitigated stick has been used, with a saline solution, to prevont injury to the cornea. Protaronol has lately been recommended for this purpose, but its efficacy still remains to be proserel.

Ulreation of the eornea is not a contraindieation for silver nitrate; on the contrary, it is then the only available remedy and must be apjlied with all the more thoroughness. The conjunctival sae should be earefully freed 

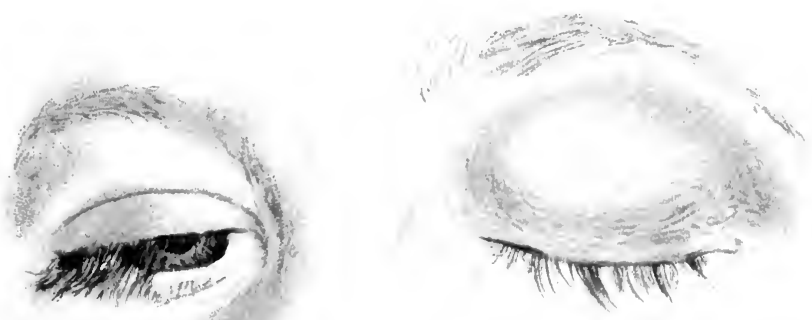

a

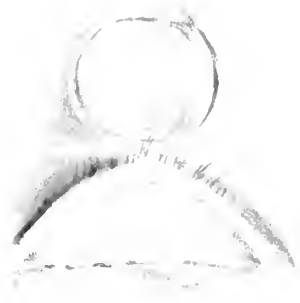

b 

firom atherent particles of secretion before silver nitrate is applied.

In adults it is advisable in severe astes to divide the onter canthus by a horizontal incision with soisors. It facilitates eversion of the lid, allows the conjunctival sar to be eleansed more readily, and relieres the pressure on the bull, which is so damgrepous to the cornea.

\section{Diphtheritic Conjunctivitis.}

This disease, which is alused hy the Lëffler bateillus, produces alterations of varring legrees and (dinieal appearanees. In one ase the diphtheritic symptems are most eonspicuons-intense inflammation, swelling of the lids, deep infiltration of the comjunctiva (Plate 1:3, b), producing a grayish-rollow discoloration and followed by

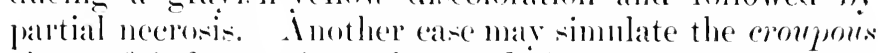
form of inflammation : the exudation is superficial and laals to the formation of a glayi-h-white or yellowi-h, fibrinous mombrane containing few cellular elements, which is detached with more or less difficulty and reappears again and again for soreral days, without inflicting any more sorions injury on the mueois membrane than a slight blecling. The false membrane nsually does not extend over the bullate cemjunctiva. The clinical pieture in both the erompous and the diphtherite forms varies widely aecopling to the extent and intensity of the process.

In severe diphtheritic conjunctivitis the infiltration inrolves the bulbar conjunctiva and may threaten the eornea ; the danger to vision in such cascs is very great, total blindness often resulting from soughing of the comea. Sometimes the skin of the adjacent area shows diphtheritic symptoms (Plate 1:3), the neighboring lymph-olands are swollen, and there is general prostration with fever. The neerosis may be so extensive that the conjunctiva looks like a picee of yollow rubber. In the course of ten to fourteen days the diphtheritic inflammation undergoes 
resolution, the secretions of blood and serum give place to a more and more purulent discharge, the uleers in the conjunctiva heal, and the resulting cicatri ial contraction may produce entropion. The greater the intensity of the diplitheritic or crompous inflammation the more abundant the discharge of pus in the second stage, so that the latter is sometimes spoken of as the gonorrheal stage.

Diagnosis.- Now that the diphtheria-bacillus is known, the diagnosis presents less difficulties than formerly. The diphtheritic nature of croupous conjunctivitis, first demonstrated by bacteriologic methods, is clinically confirmed by the observation that simple laryngeal diphtheria mar be contracted from a patient suffering from diphtheritic conjunctivitis. In addition, bacteriology teaches us that other pathogenic micrörganisms, such at staphylococei, premenococei, and especially streptococei, are capable of producing both the superficial, pseudomembranous, and the deep, necrotic form of conjunctivitis. Staphylococei and streptococei are nearly always found associated with the diphtheritic bacillis. The EmstNeisser method of staining affords the readiest means of testing the virulence of the bacilli found. The fact that fibrinous deposits and supicions areas are sometimes seen in gonorrheal ennjunctivitis renders a bacteriologic examination imperative.

The prognosis depends on the severity of the inflummatory process. It is materially better since the introduction of diphtheria-antitoxin, except when streptocoeci form the principal exciting canse, as these microörganisms appear to be sperially dangerons to the cornea. If extensive sloughing of the comea has set in, even antitoxin is unable to stay the process.

Treatment.-Sulucutaneons injections of Behring's diphtheria-antitoxin shonld be practised as early as possible. In light cascs sompulous coleanliness is nsually all that is necolcel. In the enonorphoal stage painting with a 1-2 per ecut. solution of silver nitrate is indicated. Cold compresses may be used with some advantage in the 
initial stages; in the infiltrative form hot applications are more suitable. As the disease is extremely infections the patient must be kept in strict isolation.

\section{Trachoma (Granular Conjunctivitis).}

This disease, which is also known as Eyyptian or granular ophthalmia, arises ly infection, the acute form, characterized by the presence of a more or less purulent secretion, being particularly contagious. For this reason both eyes are usually affected. The disease often lasts for years; in the chironic form, which is the most common by far, there is little or no secretion.

Trachoma is often so insidions in its onset that it escapes detection for a long time. When it is well established the palpebral conjunetiva and retrotar-al folds become uniformly swollen and present a rough, meven appearance.

Two varieties of granulations are distinguished:

1. The so-called papillary gramulations; the papillae which are normally discernible in the tarsal conjunctiva and produce the peculiar velvety appearance seen in all forms of chronic eatarh, become enormonsly hypertrophied and form raspberry-like elevations. They are, as a rule, more numerous in the upper than in the lower tarsal conjunctiva.

2. Follicular gramulations, most abundant in the retrotarsal folds, foreing their way through the superficial lavers of the mueous membrane in the frorm of hemispherical, semitransparent bolies of a grayish-pink color, arranged in dense parallel rows and converting the retrotarsal folds into a thick, unyielding mass. The granulations are less congpienous in the tarsal enjunctive, because they are smaller and less numerous and completely buried in the swollen, papillary mucous membrane; but even in this situation they may sometimes be seen as small, bright, circular spots of a yellowish color.

A characteristic feature of the disorder is the appear- 


\section{Plate 14.}

u. Trachoma of the Lower Lid.-Male, aged :4 years. A few granulations are seen in the retrotarsal fold of the upper lid. His oceupation (carpentry) obliges him to work in a dusty atmosphere, and no doubt is partly responsible for the disease. We observe the conjunctival injection characteristic of conjunctival catarrh.

b. Subconjunctival Ecchymoses (Hyphæma Conjunctivæ).-The hemorrhage in this case was caused hy a slight injury, but the same symptom sometimes oceurs in whooping-cough.

ance, in most eases, of the cornoal complication known as رemmus (sce Plate 28, $\iota$ ). 'This (omsists of a grayi-h-piuk, gramular deposit of vascular tis-ne, which nsmally begius at the 11 p)er masegin of the cornea and gradually extends downwarel to ent in a fairly well-defined horizontal boundary. The blood-vessels forming the pannus rommunicate with the conjunctival vesscls and form a venoms plexus in the cellular tissue of the deposit, which doring the greater part of the process is limited to the space between the colneal epithelium and Bowman's menbrane, hut mar in the later stages penctrate more deeply. Panmus is in every respect analogoms to trachomatoms disease of the eomjunctiva, and is therefore nore tlam a simple mechanioal irritation due to friction of the granmlations. It mav rauso mole or less visual distumbance, or eren total blinelness.

ricentiontion is a conspicume feature of the last stages of trachoma. As the retrotar-al folds regain their normal thickues, the mucous membrane covering them contracts as it is gralually romvorted into commective tissue, and a notwork of grarish-white scal-lines makes it-aplealranee an the tarsal conjunctiva. These cicatricial changes and the atrophy which oceurs in the tarsal plates give rise to meteopion, and the firetion of the eilia on the romea in turn acomates the panmms, so that uleeretion of the ronenee not inferemently results.

Trachoma is a veritahle couse to the comntries where the disease is endemic; its victims suffer for vears and 
Tab. 14.

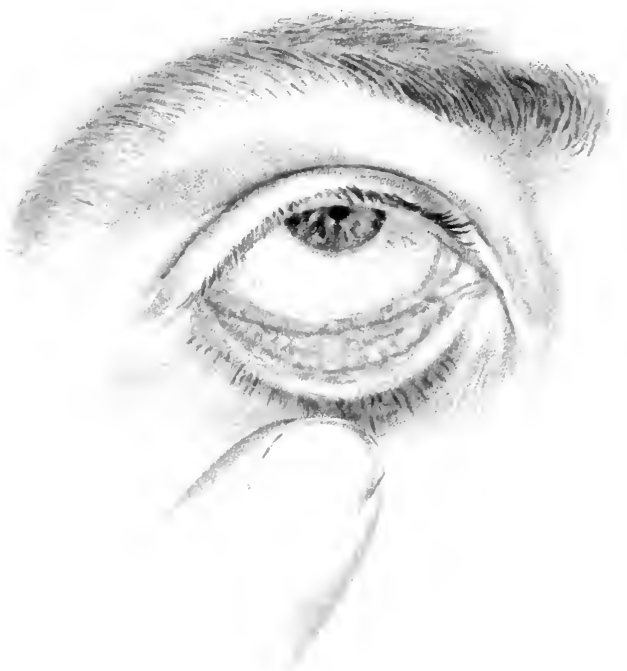

it

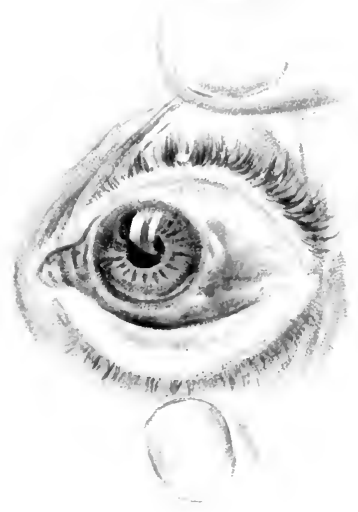

b 

are usually incapacitated for work most of the time; many of them become blind.

Fortunately, its geographical distribution is limited. It occurs most frequently in Arabia and in Egypt ; is. Europe the inhabitants of low-lying regions (Belgium, Holland, Hungary, the comntries bordering on the lower Damube, and Italy) suffer most, the higher regions heing exempt from the disease. The poorer classes are usually attacked.

The subjective symptoms are essentially the same as those of catarrh. Ptosis is a more or less constant symptom in the early stages and gives the patient a characteristic appearance. As the cornea becomes involved the discomfort of the patient increases, and if the pannus invarles the pupil, vision is affected.

The course varies widely, according to the severity of the process and its tendency to acute exacerbations or chronicity; the most unpleasant feature is the constant occurrence of rolapses, even after recovery seems to be established, althongh they are partly due to the patient's neglect in abandoning the treatment too soon. In some cases papillary granulations are more conspicuous; in others the follicular type preponderates; in a third class of eases the two forms are fomd associated. During the last stages cieatricial trachoma and its disastrons sequelæ are often observed. The latter include entropion, trichiasis, xerosis of the conjunctiva, connective-tissue change of the cornea, and, finally, a general devastation of the conjunctival cul-de-sac by srmblepharon. On the other hand, the pannus may disappear under appropriate treatment, and regeneration of the conjunctiva take place if (icatrization has not been too extensive.

The cause of trachoma is a specific poison, the exact nature of which we do not know as yet, althongh specific microörganisms of trachoma have been deseribed by more than one observer. Certain external conditions, such as crowded quarters, poverty, bad air, and a low altitude, undoubtedly tend to foster the disorder. An interesting fact in connection with the relation of trachoma to alti- 
tude is that the inhalbitant- of Switzerland have so far escaped infertion, althomgh numbers of Italian laborers suffering from the disease come into the eountry every rear and live in tolerable proximity to the natives. It has also been observel that recovery from the discase is hastened by sojourn in the mountainous regions of Switzerland and the Caucasus. [Acoording to Burnett, trachoma may ocenr at an altitude of 4700 foet. Van Millengen denies the influence of altitude and the immunity of rertain races. Nevertheless the disease is almost unknown in pure negroes.-Ev.]

The diagnosis in the initial stage is often rery diffirult; indeed, it may bo imposible at first to distinguish the disease from follicular conjunctivitis. Generally speaking, the gramulations in trachoma are most numerons in the upere retrotarsal fold, which, like its follow hehind the lower lid, soon heeomes thickened and assmmes a reddish-yellow tint. sometimes trachoma is confounded with spring-eonjunctivitis, although it has nothing whatever in common with that disorder. In spring-eonjunetivitis the nolules are more flattened than in trachoma, and slightly pedunculated, while the rest of the tarsal conjunetiva is covered with a peenliar milky tilm. If, in addition, the characteristic proliferations about the eorneal margin are present, the distinetion is easily made; moreover, there are no granulations in spring-conjunctivitis. Aente trachoma may be mistaken for eronoriheal conjunctivitis.

Prognosis.-It follows from what has been said that the prognosis is exceedingly grave; at least in respect to a speedy recovery, apecially if the patient is not in good ciremotances and mable to follow the protracted eourse of treatment necessiry to effect a cure.

Treatment. - Is the discase is a long and tedions one, the treatment must be proportionately a--iduous. It may be divided into three methorls: Isacal medication, mechanical treatment, and operative procedures. Recovery 
is materially assisted by favorable extemal conditions, especially pure air, if possible in a mountainous region. Among local remedies silver nitrate in 2 per cent. solution, and copper sulphate, in the form of a stick or a crystal (the end of which has been romded off by rubbing it on a wet eloth), or in the form of an ointment, are recommended. Both remedies are usually applied once a day; in severe inflammation with active seeretion silver nitrate is imperatively demanded. (The greater the secretion the more energetically the nitrate should be applied.) After the discharge has ceased, treatment with coppersulphate erystal is to be begun and continued for months or even years. The conjunctiva is arefully gone over with the crystal as often as once a day at first, later at longer intervals, until the swelling has antirely subsided and the mueous membrane appears white and smooth. Later on the patient may be directed to paint his eyes himself with an amylo-glycerin salve containing $\frac{1}{2}-1$ per cent. copper sulphate. Some patients even learn to use the crystal. [Excellent applications which may be used at home are tannin and glycerin (5 per cent.), or boroglycerid (20 per cent.).-ED.] If a relapse occurs, with renewed secretion, the silver-nitrate solution is again resorted to, unless the irritation is too great, in which case a weak sublimate solution may be substituted. A few drops are instilled into the conjunctival salc and wet compresses applied to allay the inflammation.

The granulations are best removed by mechanical means: By picking them out one by one with a needle and expressing their contents between the thumb-nails, or by squeezing them out with Knapp's roller-forceps. They may also be destroyed with the galvanomutery. Keining's method of brushing the granulations daily with a 1:2000 sublimate solution combines mechanical remoral with medicinal action. Excision of the diseased retrotarsal folds is apt to be followed by grave cicatricial changes in the conjunctiva and is not to be recommended. 
On the other hand, the deformities of the lids which often result must be corrected by surgical means.

Pamnus usially requires no special treatment. If the vascular tissue is musually thick, cauterization may be practised with great eare. If ulcers develop in the cornea, copper sulphate must be used instear of silver nitrate [and the treatment suitable for corneal ulcer instituted.-ED.]. The patient and his attendants should be duly impresed with the importance of observing proper preeautions against the spread of the discase. If possible the patient should be isolated, especially if the disease appears in large borlies of men, as in an army.

\section{Spring=conjunctivitis (Fruehiahr's Catarrh).}

spring-eatarrh is the only process in the human body, with the exception of freckles, that is exclusively dependent on atmospheric heat, so much so that it does not attain its full development in eool seasons. It is a diffuse inflammation, involving the entire conjunctiva, although localized deposits are sometimes observed.

The disease is quite rare in some localities, and oecurs most frequently in young men, giving them a strikingly pale and languid appearance and often lasting for years. Owing to the slight degree of ptosis which is misually present the patients have the same dull, sleepy look that is seen in trachoma.

One characteristic smptom is a peculiar yellowish-red discoloration of the conjunctiva on either side of the eornea (Plate 15, d). The remaining objective phenomena may be divided into three gromp:

1. Hypretrophy at the sclerocomeal junction, consisting of smowth, semitrinsparent molules, of pinkish color and waxy alppearance, fomml whiefly on either side of the cornea, hut oceationally encroaching on the upper and lower regments of the limbus (Plate 15, a and d). These nodules never undergo degeneration.

2. The so-called tessellated or precement-gindundetions on the tarsal conjunctiva (so called on account of their resem- 
blance to street-parement). 'They consist of hard, flattened masses, pinkish in eolor, and upon close inspertion are seen to be slightly peduneulated (Plate 15,b). The -urface of these granulations often exhibits a bluish tint, which may extend over the rest of the tarsal conjunetival, constituting the thire simptom, riz.:

3. Milly opacity, in some places like a delicate canterization-film, in others resembling a plate of smooth, bluish-white enamel (Plate 15, c).

These srmptoms are not always found associated in every case. Any one of the three groups may be wanting, or they may be present in varying degrees of intensity. The hypertiophied limbus may encroach upon and practically conceal the eornea on all sides ; or this symptom may be absent altogether and the graunlations on the talral conjunctiva may attain such proportions as to cause ulcerations in the cornea by their frietion (rarely). In other cases they may be very few in number, scattered here and there in small groups, while the intervening tissue exhibits the milky opacity which has been clescribed.

The limbus-form is often followed by the formation of a small crescentic opacity in the cornea, ruming parallel to the periphery and resembling a segment of arcus senilis; it often perwists for years after the disease has run its course.

A more or less constant symptom is found in the mucons or mucopurulent secretions which collect in threads on the retrotarsal folds and surrounding tissues. This gives rise to some of the symptoms seen in catarrh, as itching, stinging and burning pains, inability to do fine work, and gluing of the lids in the morning. General aggravation of the symptoms nsially follows exposure to excessive heat. Thie disorder appears to be influenced more by heat than by the direct action of the sun, the patients suffering less severely in high altitudes in spite of the greater power of the sun's rays.

The diagnosis is based on the state of the weather and the pathologie changes described. The disease is some- 


\section{Plate 15.}

Spring-conjunctivitis. $-a$. Patient is a robust and otherwise health farmer, 24 years old. In winter and during a protracted spell of cool weather in summer the disease practically disappears; moderate amount of secretion. The conjunctiva of the lower lid is covered with a milky film ; that of the upper is normal. The tissues about the corneal margin are hrpertrophied aud encroach to the extent of from 1 to $2 \mathrm{~mm}$. on the membrane.

$b$ and $c$. Clerk, aged 19 years. For the last three years the inflammation has regularly made its appearance in May, and lasted the entire summer. There are no follienlar granulations to be seen anywhere. The right npper lid shows the tessellated appearance of the hypertrophied tissnes; on the left lower lid the milky opacity is illustrated.

d. In this patient (male, aged 14 years) the characteristic yellowish injection is clearly seen to the temporal side of the cornea, merging into the marginal hypertrophy, which is also well marked.

times mistaken for trachoma $(\%, r$.) and marginal eczema of the cornea (marginal keratitis). The latter can always he recognized by the ensuing ulceration in the cornea. When the disease occurs in elderly people, as it oceasionally does, some difficulty may he experienced in distinsuishing it from an incipient cancer. Even a microscopic cxamination of the lyperplastic tissue about the limbus does not always clear up the diagnosis, since the same almormal preponderance of epithelial elements and tendency to send out long villous processes into the subjacent (omnective tissue (which also shows marked hypertrophy) are seen in spring-conjunctivitis. Seither granulations nor follicle-formation can he detected with the microscope.

Prognosis. - Two factors combine to render the progno-i- unfarorable: Onr inabilitr to control the chief exciting cause, the weather, and the want of a specific remecly.

Treatment.-Although all kinds of remedies, new and old, have heen sugrested, the treatment is still essentially palliative. A 1 pereent. lead ointment may be used, proviling three is no corneal nlceration. Good results have heen obtained in some cases by inmetions and massage with 1-2 per cent. yellow meremre-oxid ointment, or 

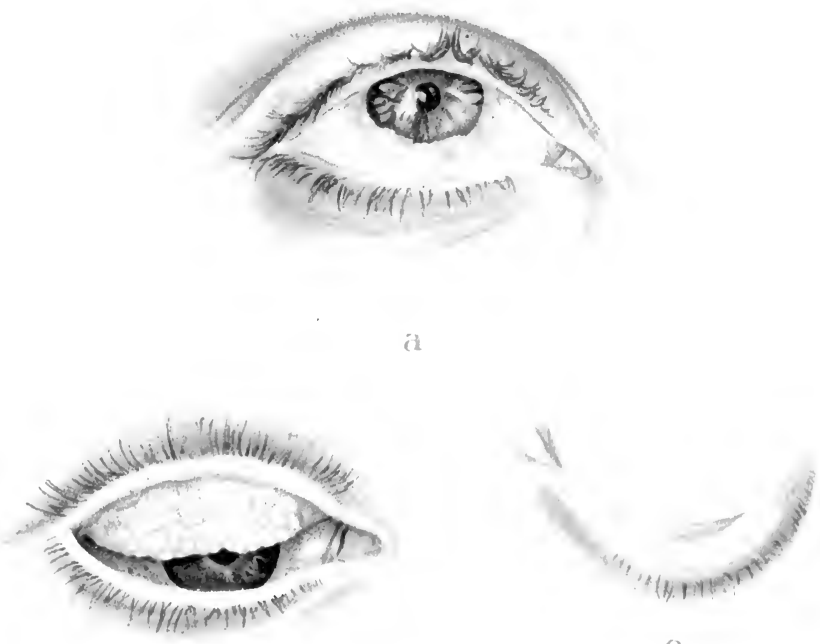

b
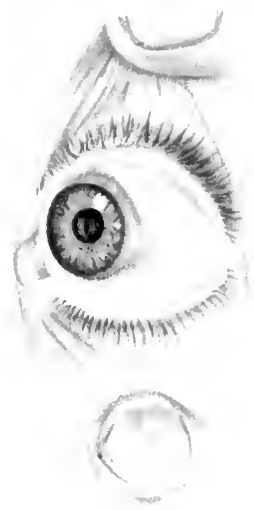

with dilute acetic acid, 1 drop to 10-20 drops of water, as a collyrium. Relief is sometimes ohtained from surgieal removal of the latrger nodules. [Boroglycerid atets well; the internal administration of arrenic has some repute.-En.]

\section{B. CIRCUMSCRIBED INFLAMMATIONS OF THE CONJUNCTIVA.}

In contralistinetion to the eonfluent forms of inflammation, in which the palpebral conjunctivie are chiefly involved, we find that in the circumseribed varieties the pupillary region is the prineipal seat of the lesion. The most important representative of the group is

\section{Eczematous, Phlyctenular, or Scrofulous Conjunctivitis.}

This is absolutely the commonest form of all inflammattions of the conjunctiva, general or circumseribed. Horner gave it the name of eczema. Its dermoid eharacter becomes manifest by the distinct clinical assoeiation with eczemat of the lids, face, and head, on the one hand, and of the cornea itself, on the other, and by its appearance, in eommon with all other forms of eczema, in serofinlous subjects. In the absemere of a scrofulons habit, some reduced comlition of health and nutrition, either from anemia or as a result of measeses sarlatina, pertussi-, etce, will nisially be recognized as the predi-posing eause. The disease oreurs most frequently during the scrofulous period-i. e., in childhood; ravely in the first year of life or after puberty. It rarely appears for the first time in adult life, but is sometimes soen in persons who have had an attack in their childhood.

Like other diseases of the eve, phlyctenular conjunctivitis chiefly attacks the ill-fed and ill-kept children of the poor. II' find associated with it swollen submaxillary and rervical glands, chonic nasal catarrh and eezema of the nasal mucous membrane, and eczema of the upper lip. [The rhinopharyngeal lesions are always present in 
these eases, and if they are not actually the cause of many attacks, certainly aggravate them; in short, they must be cured if the diseatse is to be eradicated.-Eo.] The lip and the nose eventually become the seat of an unsightly swelling, which combines with the general putfines: of the face to form a characteristic clinical pieture in eases of long standing. If the eornea is involved in the infiltrative process, the excessive lachrymation, by its constant irrigation of the lick, produces niarginal eczema and, later, spasm and photophobia, on account of which the children hold their dirty hands over their eves or bury their faces in the pillow and thereby aggravate the condition.

Although eczemen of the conjunctira and corneal eczemen oceur together or within a short interval of each other, and are therefore parts of the same process, we shall discuss the two conditions separately, because prognosis and treatment are materially different in the two affections.

Cnless the pustules are very numerous, eezema of the conjunctiva does not produce any marked irritation, as the general appearance of the patient shows. Lachrymation may be somewhat excesive, and some photophobia may be present ; but, as a rule, the eve can be opened without much difficulty. If the patient complains of irritation, the eornea must be carefully examined for eczema.

The seat of predilection is the circumeorneal zone, especially the limbus or sclerocorneal junction. This soealled "inarginal eezema" [marginal phlyetenular keratitis ] is the commonest manifestation of the process in the cornea and in the conjunctiva. The more remote portions of the conjunetiva are les-sulject to the disease. The retrotarsal folds and tarsal onjunctive are exempt or, at most, cxhibit atarrhal smptoms.

The size of the pmitules is invereely proportional to their number; usually ther measure from 1 to $2 \mathrm{~mm}$. : but if they are vere fow in number they may attain twiec that size (:) to $4 \mathrm{~mm}$.). Sometimes the pristules are so minute that they ean be recognized as clevations only by the disturbance of reflection which they produce; the 
conjunctiva and the cornea look as if they were sprinklex with glass-dust. Is each individual pustule, whether large or small, is surrounded by a zone of inflammatory tisine, the appearance in this form-when the pustules are very minute-resembles the red injection and swelling of catarrh, so that the term erzemotous cuturh is used with great propriety. From the fact that the lids beeme much swollen and inflamed, these cases are also designated as catarh with swelling. Eczematoms catarrh sometimes oceurs in combination with a more discrete eruption of larger pustules.

The trpical eczema-pustule or phlyctemule is circular in form, and, when recent, appears as a small, reddish-gray elevation eapped with a layer of smooth epithelium. It is surrounded by a zone of marked conjunctival injection. On the second day after its appearanee the covering separates and is replaced by a small, circular mass of gray or yellow neerotie tis-ne (Plates 17 and 18). The yellow spot gradually encroaches on the body of the pustule, so that the larger ones are eventually converted into small round ulcers, only slightly raised above the level of the conjunctiva. As the healing process goes on the pustules become more and more flattened, the inflammatory zone contracts, and the site of the uleer is covered with new epithelium. The disease lasts from one to two weeks and never attackis the solera.

The cornea is very often affected, either alone or in association with the eonjunctiva. In come eases only the cornea is attackerl in one eye, and the conjunctiva, without the cornea, in the other. 'The cornea is most liable to be involved in the multiple form. characterized by the presence of innmmerable gramular elevations.

As in other parts of the body, the eczema is distingruished by its occurrence in successire corops; pustules in all stages of development are seen at the same time with the scars of a former attack.

The corneal eczema may be primary, or seeondary to marginal eezema of the conjunctiva. The seeondary form 
is observed at a (1) simple marginal irritation, to be discussed later; (2) the exeavated or fummel-shaped ulcer; (:) fascicular keratitis; (4) phlyctenular (eezematous) marginal pammus; and (5) marginal ring-ulcer (annular ulcer).

Eezema of the conjunctiva rauses little discomfort, as the general appeanance of the patient shows; he usmally seek - relief for a slight stinging-pain during the eruptive stage and the feeling as if the eye contained a foreign body; oecasionally the lids are glued together in the morning.

The diagnosis is readily made if it is borne in mind that eczema preferably attack- romng subjects, while carcinoma, which in its initial stage resembles an eezemapustule and aloo begins at the corneal margin, oceurs only in elderly persons. Another fundamental difference is, that carcinomatoms nodule- never undergo the rapid degeneration which puts a speedy end to the life of an eezemapustule. Cancer displars the general characters of a solid growth, and ulceration, if it oceurs at all, is delayed a much longer time. Nevertheless I have seen several eases of carcinoma which were at first diagnosed and treated as eczema by the family physician, and the loss of precious time oecasioned hy this error led to a fatal termination.

scleritis, which is characterized loy the formation of that, cireular elevations from 3 to 5 mm. in diameter, may in its initial stage be confounded with eezema. An old ease of scleritis can be recognized by the slate-colored tint of the sclera remaining from an earlier attack, while in recent cases the diagnosis is established by observing that the apithelial covering of the nodules is intact and does not undergo necrotic change. The scleritic focus, moreover, is surromeled by a bluish injection, while in eczema the congestion is of the conjunctival trpe and is more superficial. Finally, there is much more pain, both spontaneous and on pressure, in scleritis.

A superficial observer might mistake a case of marginal eczema of the conjunctiva for sproing-conjunctivitis; but 
the nodules in the latter disease do mot begin to degenerate at the top like comema-pustules. In doubtful areen it is only necessary to remember that circumseribed eruptions. and their ulcers are always approximately circelder in shape.

The prognosis in simple conjunctival cezema is always favorable, whether the pustules be laree or imall. The divease is never dangerous, although it may occarion at good deal of discomfort if it is protracted. is an index of the serofulous habit or debilitated condition of the patient, it is always of some signiticance, because the cornea in such eases may at any time beeome involved and endanger the integrity of the visual apparatus.

The treatment is quite simple. 'The pustules might with propriety be allowed to heal spontancous ly ; but it is better to assist the healing process by dusting the affected areas with powdered ealomel, as a more radical cure is thereby effected and the danger of reconrence is reduced to a minimum. For the latter reason the treatment shonld be continued for two weeks after the uleers have healed.

Experience has tanght the value of the following precautions in the use of alomel as a dusting-powder: It should not be employed if there is a recent corneal losion or any general irritative condition ; henee it is contraindieated in "catarrh with swelling." The drug must be perfeetly pure and as fincly powdered as powible by being sifted through a cloth. The applications should be made with a camel's-hair brush (the exces being removed by tapping against the finger), at the same hour every day, either clirectly on the puistule or on the lower retrotarsal folk. If the patient is taking large doses of potassium iodid at the time of treatment calomel is contraindicated, as the eanstic effect on the conjunctiva would be too great. Iodin is eliminated by the conjunetiva as by other murous membranes - that of the nose, for instance (hence potasiumiodid eatarrh of the eonjunctiva, nose, ete.) -and combines with ealomel to form iodids of mereury, which act ats severe causties. I have seen eschars due to this chemieal 
reaction as thick as a diphtheritic membrane covering the entire conjunctiva.

If eczema is complicated with severe catarrh, the secretion must be controlled by painting the eonjunetiva with a $1-2$ per cent. solution of silver nitrate before ealomel is applied; but if there is much inflammatory swelling, the irritation should first be allayed by the application of hot compreses steeped in lead-water.

Atropin is usually quite mmecessary in enpjunctival eczema, as the pain is not severe enough to demand it: use [a warm collyrim of boric acid is valuable.-Es.].

The local applications should always be supplemented by general medicinal tratment of the fundamental disease and by tonies to improve the patient's general health. This matter will be referred to again in comnection with the treatment of corneal eezema. [In all these eases the rhinopharyn is always more or les- di-eased and requires as-icluons care.-En.j

()ther localized eruptions are rare in the conjunctiva compared with eczema; we mar mention, however, pemphigus, eqriolu, and rene. In rare instances maenlar and papular syphitides, pityriusis, psoricsis, irhthyosis, ete., are met with, nsually as forming part of a general process.

\section{Pemphigus.}

Pemphigu: gradually leads to the condition formerly termed "escential shrinking of the conjunctiva." The conjunctival sac in the course of years becones completely obliteratod. the lids are immorably tixed to the eyeball, and the cornea, owing to the losin of nictitation, becomes ulcerated and thrown into folds. Bulla are rarely seen, owing, probably, to the dolicate structure of the memhrane; instead, the comjunctiva is covered with gray patches, deprived of epitholium and covered with a lardareoms seretion, which later are comserted into cicatrices, while fresh lesions appear in other situations. In some aates the mucous memblane of the mouth is similarly 
affeeted, or there is pemphigus of the general integument to indicate the nature of the conjunctival lesion.

The prognosis is gloomy, as no effective treatment has as yet been diseovered.

\section{Variola.}

There is grave danger that the pustules about the lower corneal margin may give rise to a seeondary comeal atfecetion in the form of marginal ulcers or deep purulent infiltration, resulting in perforation-staphyloma, purulent iridochoroiditis, and panophthalmia. These sequele, which are not noticed until the conjunctival disease has subsided, are the most frequent causes of blindness after small-pox.

\section{Acne.}

Acne may produce nodules about the corneal margin which elosely resemble eczema-pustules. The eruption is frequently seen on the cornea of patients the subjects of aggravated aene rosacea. The infiltration resembles that seen in eczema; it is gray in eolor, slightly raised above the surrounding level, is more persistent, and leaves a more pronounced opaeity than the eezema-pustule. I have known it to produce almost complete opacity of both cornere in the course of years.

\section{Scleritis.}

In scleritis I have sometimes seen the eonjunctiva in the diseased area dotted with a number of round, flat nodules, from 1 to $2 \mathrm{~mm}$. in diameter, which were distinguished from exzema-pustules by the absence of conjunetival congestion and by the faet that they did not degenerate, hut persisted for days and weeks" and were gradually absorbed. Under the microscope they were seen to consist of masses of growing connective tiswlle, fairly rich in cellular elements. I have never been able satisfactorily to explain the relation of these nodules to the scleritic process. 
Finally, we must include among the circumsoribed inflammatory processes in the conjunctiva the various forms of infectious granular tumors, chicf among which is

\section{Tuberculosis.}

'Tuberculosis is always chronic, and oceurs either independently or in association with lupus of the face. In nearly every case the nature of the disease manifest: itself hy swelling, and occasionally by cheesy and purulent degeneration of the preanricilar and submaxillary lympl-ylands. Sometimes the process is purely local, or it laat no signs of tubereulosis are found in other organs of the body. In other instances the patient exhibits sign of a general tubercular infection in lungs, lymphatic glands, joints, etc. Occasionally the process begins in the nose and the infection is carried to the ere thromgh the larhromal duct. In the conjunctiva it appears tirst at a more or less circumscribed focus of tubercular infiltration, or as a single nodule, or the tubercles are scattered orer a laroer area. The tuberculous growth is more or less completely enclosed in a capsule of granulation-ti--ine, which materially increases the extent of the focus; neither tubercular nodriles nor hacilli are to be found in the excised growth. These are only found in the deeper layers of the hypertrophied tisue, if they are found at all; the bacilli are never present in large numbers any more than in other forms of ehromie tuberenlosis.

The tubereles rapielly become chees and break down, and the conjunctiva becomes covered with tubereulous. uleess with purulent or chees flows and surromeled hy erranulation-ti-sue. In the intervals between the ulcers, which may be quite numeroms if the proeess becomes extensive, miliary tubereles ale oceatsionally secn, and sometimes true follirles. resembling trachomatoms grannlations. In protrated a ases the cintire palpebral conjumetiva of both lids exentually lecomes diseased, grarlually the proess encroaleses on the pupillary region, and the 
cornea may be completely obscured by the formation of a dense pannus. The scars which sometimes form in the conjunctiva often produce a condition which clorely simulates trachoma, especially if both eyes are affected, as oceasionally happens.

Pain is usually inconsiderable and depends ehiefly on the accompanying catarrh; later, if keratitis develops, the patients may suffer some discomfort.

The diagnosis is based on the swelling of the preauricular lymph-gland and on the formation of ulcers with purulent floor's, phenomena which do not oceur in trachoma. Under certain conditions, if the process is confined to the tarsal region, a round nodule closely re. sembling a chalazion may be formed on the lid; even Bammgarten once mistook a tubereular nodule in this situation for a chalazion. In doubtful cases the diagnosis should be confirmed by inoculation, if tubercle-bacilli cannot be demonstrated.

The prognosis in all cases is very grave, as the growth may recur after the most careful excision. If the focus is very small, a cure may be effected by the radical removal of the proliferations; but if there is general involvement of the conjunetiva and of the lids, it is difficult to arrest the process. In the case of two young men of marked tubercular habit who came to me late in the diseare, the sight of both cyes was destroyed; and in another case, that of a roung woman, one eyc became entirely blind and the other very nearly, in the course of year's.

The treatment consists in the thorough removal, as far ar posible, of the diseased tissues by oprative means, and in the application of iodoform. Infortunately the drug cannot always be brought into close contact with the tuberculous nodules. I have never seen any good results follow the use of either the old or the now (modified) tuberculin preparation; the latter was tried lately in a case with lupus of the face, and neither the tuberenlous nor the lupons process showed any improvement. Gen- 


\section{Plate 16.}

a. Chaff-particle at the corneal margin. The patient, a peasant-girl, does not know how long the foreign body has been in the eye, but the vacular development of the cornea shows that it must have been there for some time.

b. Pterygium in an elderly man. It has spread over the cornea gradually during the last few months. The obliteration of the plica semilunaris is well shown.

aral constitutional remedies should, of eourse, be added to the loeal treatment.

\section{Syphilomata and Leprosy.}

Syphilomata and leprosy are oceasionally met with, the former very rarely. In leprosy the region about the (o) meal margin becomes the seat of yellowish, semitransparent tubercles, with few blood-ressels, which may penetrate into the sclera or spread over the surface of the mprnea. The breaking down of the tubercles is followed hy extensive tis-ne-destruction. In addition, the tubereles appoar in the iris and produce iritis and eyclitis, which ance further injury to the eve.

\section{INJURIES OF THE CONJUNCTIVA.}

1. Foreign bodies are firequently fomnd in the conjumctival sac. I small body usually lodges on the inmer surface of the npper lid, noar the margin ; larger ones often find their way under the upper retrotarsal fold, where ther may remin for some time and give rise to sammlations and catarthal secretion. The fold in snch abse must be carofully seraped ont and cleansed with a probe. Aericultural patients oceasionally present themselves with a particle of chaff' (Plate 16, a) or the wing of an insect fimly cmbededed near the corneal margin. The eoncave horder of the foreign body is nsually directed towarl the cye, so that it gets a firm hold of the tissues and often remains for weeks, and may eause new blood- 
Tab. 16 .

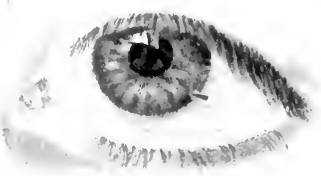

a

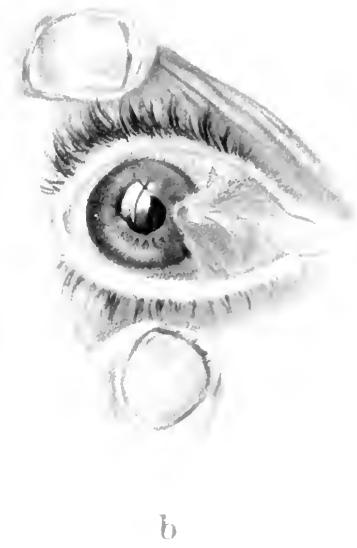



ressel formation and even granulations. Somctimes it is found on the cornea itself.

2. Ecchymoses of the conjunctiva (hyphamal conjunctive, Plate 14,b) are quite common, either as the result of injuries, such as seratches or ent-wounds, or from stasis of the blood during a paroxysm of whoopingcough, or ordinary cough in elderly people with waik vessel-walls. It has been observed especially in persons who are the subjects of marked arteriosclerosis with or without nephritis, and who nsually die of apoplexy ; hence the phenomenon is significant from a diagnostic point of view. Wounds of the conjunetiva should be closed with sutures as soon ats possible.

3. Burns, eaniced by molten lead or iron, hot ashes, etc., or by acids and allialine lyes, and particularly by slaked or inslaked lime (mortar), are among the commonest acciclents. The usual seats are the lower portion of the eonjunctival sac and the lower segment of the colnea (Plate 19). The epithelium is destroyed and the necrotic tissue appears grayish or bluish-white, while the arjacent conjunctiva is intensoly swollen and inflamed, and occasionally suffused with blood. Burns on the cornca give rise to similar whitish spots; these soon lose their epithelial corering (Plate 19, b), nleers are formed, and a ricatricial opacity results, which, if situated in the center, may interfere seriously with visual acuity. In the conjunctiva the injury is followed by cicatricial contractions, shortening of the mueous membrane, general shrinking of the conjunctival sac, and the development of symblepliaron.

In the cornea the eroded area sometimes becomes corered by a process of conjunctiva, forming a so-called p.everlojterygium.

Treatment.-The ultimate effects of a lime-burn are much more serions than appears at the first glance, and great care is therefore necessary in the treatment. The injured ere must not be washerl with water, as such a proceeding would dissolve more of the canstic material and diffuse it over the conjunctival sac. The cleansing is best 


\section{Plate 17.}

Eczema of the Conjunctiva, associated with Severe Eczema of the Face.-An ill-nourished faetory-girl, 15 years old, with sallow, puffyface, aftlicted with ehronic rhinitis, eezema of the nose and face, and eezematous catarrh of both eyes, with considerable secretion. At the nasal border of the cornea, in the right ere, a pustule is seen, situated partly on the conjunctiva and partly on the cornea. In the left ere there is a single pustule on the bulbar conjunctiva. to the temporal side of the cornea, the margin of which is also beset with minute pustules (not seen in the pieture). The facial eczema was subjected to suitable treatment, the conjunctiva painted with silver nitrate, and later dusted with calomel. The patient was subjected to diaphoresis. After a two months' course of treatment, which was marked by many relapses, a complete cure was effected without injury to the eres.

effected with a brush dipper in oil, after which a concentrated solution of sugar, which combines with lime to form an insoluble (ompound, may he instilled into the eye. If the burn was cansed by an acid or by an alkali, use a substance which will neutralize the caustic agent. 'To allay the pain and isolate the injured tissue as much as possible, vaselin containing 1 per cent. of atropin may be rubbed in ; this also has a tendency to prevent alliesions between the lids and bulb. But it is not always possible to prevent the development of symblepharon, and an operation subsequently becomes necessary.

\section{PTERYGIUM.}

This anomaly consists of a triangular Hap of conjunctiva, which hr a verr gradual proeess, lasting month or vears, eneroaches on the cornea either from the natal or the temporal side (Plates 16, b, and 26, a). In severe ases the growth eventually covers the pupil and eanses permanent diminution of vision. Wherever the pterygium beomes allherent to the cornea a permanent superfic ial opacoity remains.

The ptergium develope from a pingurenle, a yollowish elevation not infrequently seen in clelerly people on either the nasal or the temporal side of the cornea. It is often 

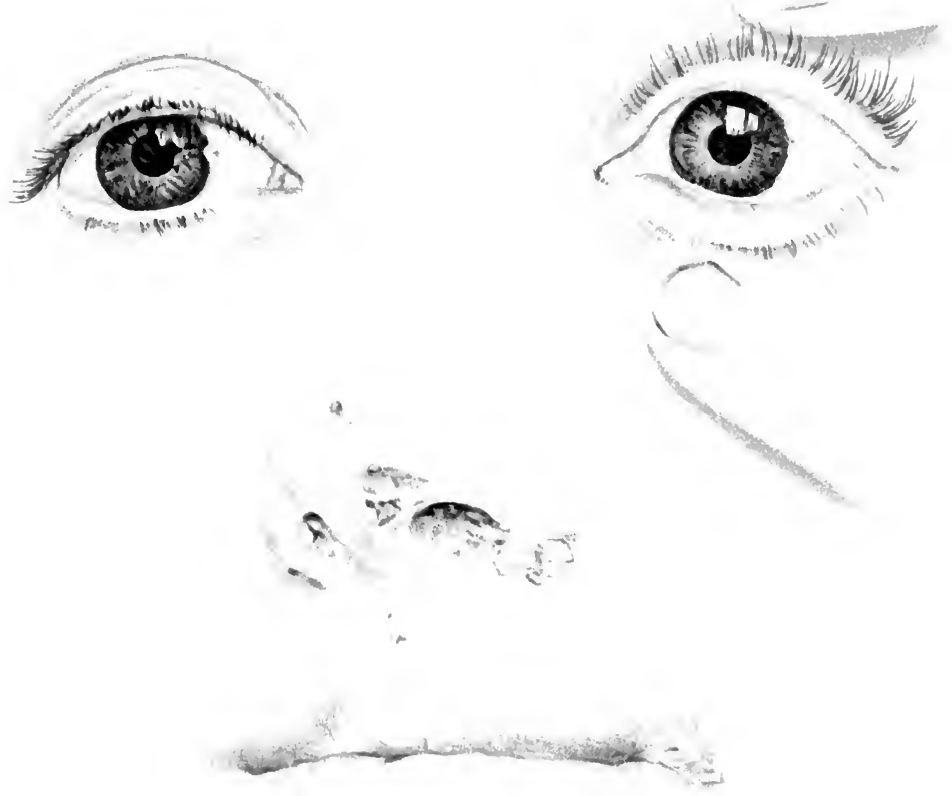

eaused by exposure to wind and dust. The yellow color, which gave origin to the name, is not due to fat, but to hyaline degeneration and an overgrowth of clastic fibers. The mechanism involved in the movement of the pinguecula and adjacent eonjunctiva toward the eornea is not well understood.

Two forms of pterygium are distinguished, the porgressice and the stutionre\%. The latter is smooth and light in texture, non-inflammatory, with a flattenerl, filmons apex; it gives little pain. 'The progresive ptergerium, on the other hand, is suceulent and inflamed; the apex or the entire central border is swollen and grayish-red in color. A large pterrgium exerts a good deal of trantion on the conjunctiva, so that the semilunar fold is often obliterated (Plate 16, b).

The sequele of pteryium are eonjunetival catarrh, defornity, and eventually diminished rision by obseuration of the pupil or diplopia from motor disturbances in the globe.

The treatment eonsists in operative removal of the growth and reposition of the eonjunctiva; canterization is usually of no avail. The growth, howerer, is liable to recur even after radical surgical removal.

\section{TUMORS OF THE CONJUNCTIVA.}

Benign Tumors. - The commonest form is the rlermoid grouth (Plate 11, a and b). The eornea is nsually involved to a greater extent than the illustrations show. The tumor is always congenital, and ehiefly troublesome on aceount of the deformity it produces. Its usual seat is the external or the inferior margin of the cornea. Structmally it is neither more nor less than a piee of aberrant skin, supplied with hairs and sebaceons and surlorific glands. Associated with it we often find malformation of the lids, iris, ote.

In remoring the tumor great are is necessary to avoid making an opening in the cornea. 


\section{Plate I 8.}

a. Marginal eczema-pustule in a scrofulous boy, 12 years old; three days after the beginning of the disease.

$b$. Epithelioma involving both cornea and conjunctiva, in a man, aged 36 years. The tumor has been growing steadily for three years : but the patient felt no inconvenience until quite recently, when it began to cause itching and stabbing-pains and some diminntion of vision. The growth is not painful on pressure. The adjacent portion of the eornea is thick and opaque, its surface rongh and uneven; the rest of the eorncat is corered with a cloudy and highly vascular film, so that direct inspection of the eye is impossible. Vision is pratically abolished, the movements of the hand being discerned only at a very short distance. Enucleation. Examination shows that the cornea is largely iuvolved, and even the sclera has been attacked by the tumor.

Simple polypi (small fibromas) oceur rarely; their favorite seat is the inner canthus. Papillomita are occasionally seen in the same situation.

Malignant tumors include corrinome (epithelioma) and sarcomn. Both tumors preferably begin at the corneal margin. Epithelioma originates as a small, non-pigmented, flat elevation, not unlike an erzema-pustule, which for a long time retains its superficial character. but eventually becomes larger and penetrates more deeply into the subconjunctival ti--ue (Plate 18, b). While ancerous growths are seated on a broad base and tend to spread superficially, the tendeney of a sareoma is rather to grow in height, overhanging the cornea without involving its structure. Sireoma is usually pigmented.

Both "arcinoma and sareoma are exceedingly malignant and demand immediate radical exeision, to protect both the eye and the life of the patient. If the tumor is firmly embedded in the tisues of the eye, enucleation is unavoidable. 
Tab 18.

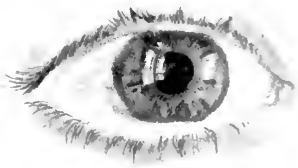

a

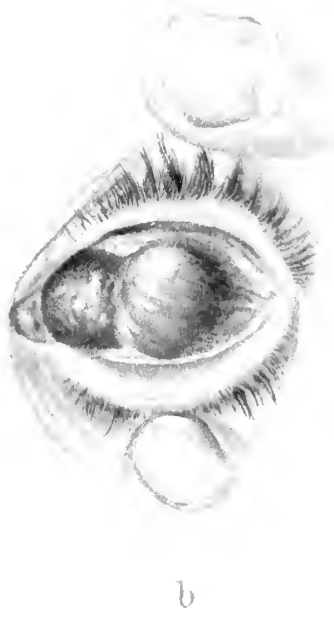





\section{DISEASES OF THE CORNEA.}

\section{A. DIFFUSE INFLAMMATIONS.}

\section{Parenchymatous Keratitis (Interstitial or Diffuse Keratitis .}

This disease is important, not so much on account of its frequency as of the grave srmptoms to which it gives rise. The great majority of cases (90 per cent.) oecorr in children between the ages of five and sixteen. The course of the disease has been so armirably described by Horner ${ }^{1}$ that it seems to us we eamnot do better than quote hiexact words :

"In these children a faint, gray haze, accompanied hy slight ciliary congestion, slowly creeps into the periphery of the comea. It first it aecipies a narrow band along the margin; but gradually it includes wider portions of the periphery and sends out tongue-like processes toward the center (-ce Plate 28, (*), which som coalesce and cover the entire marginal zone with a clondy film, leaving only the central portion free. The lisls are spasmodically closed, and when we foree them apart we observe that the surface of the cornea is clondy and the cpithelium las a steamy, stippled appearance (in lare case- it is puckered into folds), as in eases of increased intracular pressure. Writh lateral illmmination the stripe-like and net-like opacities are seen to oceupy the deeper layers of the membrane. The film gradually adrances form all directions toward the center, where it contracts and increases more and more in density, forming a serious obstacle to vision, while pari pason the marerinal zone begins to regain its transparency. Now the central opacity gradually legins to change, and the surface relaxes and breaks up, showing areas of greater transparency among the gray spots. The vascular changes vary widely during this process of migration. In some cases the centripetal migration is not followed by any pathologic changes in the blood-ressels;

'Horner, "Die Krankheiten des Anges im Kindesalter," Handb. der Kinderkrankheiten, 5 Bd., ii. Abt., p. 320. 


\section{Plate 19.}

a. Lime-burn of the conjunctiva and cornea, recent, in a boy, 13 years old. The injury was caused by the explosion of a bottle which the patient was filling with water and unslaked line. The skin of the lids, on the right, shows the marks of glass fragments. The conjunctiva of the upper and lower lid is badly excoriated; also the bulbar conjunctiva below the cornea and the lower segment of the cornea itself, which is dim and bluish-white. Satisfactory cure was obtained with practically normal vision, although a rather dense cicatricial opacity remained about the lower corneal margin and the conjunctiva covering the lower retrotarsal fold was somewhat shortened.

b. Lime-burn of the conjunctiva and cornea, of longer standing than the preceding, in a mison, 18 years old. A week ago, while the patient was mixing mortar with lime that had been slaked two days before, some of the material entered the left eye. The eschar is seen in process of separation, and the corresponding spot on the cornea has lost its epithelium and is surrounded by a gray border. The center of the injured spot is slightly depressed from the loss of tissue. Healing was followed by ouly slight sear-formation and vision was not diminished.

in others a few small vessels appear in the deeper lavers of the cornea, but not until some time after the formation of the central opacity. In a few rare cases, however, a very characteristic vessel-formation is observed to accompany the advance of the process from the sclera into the cornea. Short, densely packed bloml-vessels, terminating abruptly at the center, appear to push the oparity before them and in a sense constrict the comeal field. These ressels are sometimes so thickly crowded that they look like an ecehymosis.

"The corneal disease does not ond with the completion of the centripetal migration and breaking up of the central opacity. Irregular gray spots and nebula make their appearance in the substance of the cornea and combine with the resolution of the central opacity to give the membrame a speckled appearance. This secondiury stage is sometimes interpreted as a primary corneal lesion, and the special name lieratitis punctate is given to it. The cror is readily explained by the fact that the patients do not 


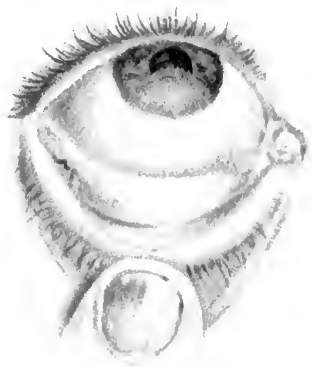

i)

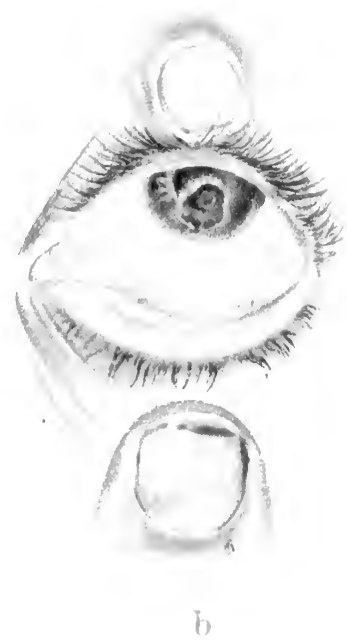



usually present themselves for treatment mutil after the centripetal migration is completed.

"When iritis oecoms as a complieation the precipitates on the posterior lamina of the eornea and the secondary changes in the more anterior portions of the membranc tend to alecentuate the punctate alplealame of the opacity and thus form another somere of error. In about 30 pere cont. of all cases of interstitial keratitis the deep structures of the eye beeome involved arly in the course of the disease; but in most cases this complication appears much later. Iritis msully takes the serous form; it is attended with the deposition of heary precipitates on the posterior lamina of the cornea and ligamentum pectinatum, slight exudation into the pupil, and variable presinlesymptoms-msually subnormal tension. As semols iritis itself is a form of "reeitis, we are often able, after the conter of the cornea has cleared up, to establish the existence of opateities in the vitreons, equatorial foce of choroiditis, and moal nenritis; we may find polar and posterior cortical eataract-in short, all the signs of a diffinse morbid process, which from its conspienous feature has been called diffise keratitis, but is very often a panophthalmial.

"The disease usually affects both eyes, the second beine attacked days, weeks, or even months after its fellow. I myself have been able to establish bilateral involvement in 80 per eent. of my alses, in spite of the obvious fact that the patient hails the appearanee of disease in the second eye at a proof of inefficient treatment and seeks advice elsewhere. It is always alvisable to predict the probable oceurence of the disorder in the other eye, and to warn the patient that it is very apt to run a slow and terlious course. The most favorable cases last from six to eight weeks; secondary opacities, iritic complications, and their consequences protract the duration of the disease to months and yoars. Relapses are frequent, even after long intervals of freedom from the discase. These relapses do not, as a rule, exhibit the same character as the original 
attack ; the participation of the sclera is more pronounced or a true seleritis derelops; and the eorneal haze is not so diffuse, but appears in patches, while the vascular changes in the superficial and deep layers are more irregular."

The ultimate fate of the corneal maeulae varies widely. In some ases transparency is completely regained; in others, marked by frequent relapses, the center is irremediably obsenred by fine, nebular opacities and vision is permanently injured. In almost every ase of interstitial keratitis minute vessels can be detected with a loupe and lateral illumination, or with the ophthalmoscope and direct light. They can be seen twenty years after an attack, and may be utilized as a diagnostic sign of syphilis.

The cause in two-thirds of the cases is hereditary syphilis, and the elassical signs of this condition should always be looked for ; ther are: Flat uper jaws, smonen nasil bridge, scalrs at the angles of the mouth, and Hutehinson's teeth, characterized by diminished size with fairly good enamel and shapely outline, and, usually, wide interrals, especially between the incisors. The central incisors of the upper jaw are wedge-shaperl at the expense of the free cutting-surface, which is often marked with a small circular noteh. The signitiance of the deformity is limited to the permanent teeth. We also look for ulcers or scars in the palate, for tis-ue-destruction of the pillars of the fauces, or athesions of these structures to the pharyngeal wall. Deafness not infrequently develops in the later stages of the disease; the cervical glands are enlarged ; there are chronie periostitis of the tibia and painless synovial effusions in the knee-joint. Tpon inquiring into the family history we learn of a large mortality amone the children, and of abortions and stillborn infants. In some cases, if the refracting media are not too much obseured hy the opacity, it may be possible, during the healing-staige, to make ont minute light or dark blotehes on the eycompomel, which I have illustrated in my dths of ()phthalmoseop!y, vol. vii. of this series, and which I consider positive signs of hereditary lues. The larger foei of 
choroiditis which sometimes appear during the later stages of the disease have no signiffeance.

The diagnosis is materially simplified by the face that parenchymatons keratitis never underegoes nileration, differing in this respect from eezematous inflammation of the cornea. It is of the highest inportance to be able to distinguish the disease from glaueoma, which in lare instances oceurs in childhood; an crror in this respect might entail fatal consequences. In both discases there is a faint cloudiness of the cornea; but in keratitis the opacity is irregularly distributed in spots, while the haze of glaneoma is uniform and diffises, and usually leser marked than in keratitis. Definite information cain be obtrined by testing the tension, if necessary under anctheria.

Prognosis. - This is unfarorable in so far als we are unable to remove the inflammation or prevent it- acenrrence in the other eve. The prospect of rision being eventually restored is, however, fitirly good, recovery is practically perfect in many cases, and almost always a serviceable degree of visual acuity is regained.

Treatment. -This, in the first place and in all eases, must include a tonic regimen; in the secoml place, provided they do not interfere with dige-tion, the milder iodids, and finally the careful use of mereory ; the latter drug, however, is not so efficacions as in the inflammations of acquired syphilis. The local treatment in the early stages should eonsist of atropin and dark glases to relieve the irritative smonptoms. Later hot fomentations are to be applied; and if it is tolerated, after a time yellow oxid of mereury salse may be rubbed into the eye. The oxid ean be incorporated with mot. anylo-glycerin, $0.1-0.2$ in 10.0, or with varelin, $0.2-0.5$ in 10.0 , applied with a glass rod and well rubbed over the surfice of the eornea with the elosed lid, once a day or every other day. It may not be borne until late in the discase, but its continued use materially hastens the elearing of the opacity. [In addition to the tonie regimen, which should include cod-liver oil, arsenic, iron, ete., aceording to the 


\section{Plate 20.}

Herpes zoster ophthalmicus, taken on the sixth day of the disease. The patient, a healthy man, of 48 years, at that time complained of pain and the sensation of a foreign body in the left eye. The next day he had a slight ehill, followed ly nausea and lassitude, so that he went to bed. When he woke up the following morning forehead and nose were covered with an eruption which caused burning pain. The left eye also became violently inflaned and he could not sce well with it. The doctor ordered lead-water compresses (a mistake, on account of the corneal affection), wherempon vision beame worse. At the time of admission the vesicles had already dried up and formed crusts, as seen in the pirture. The lids are somewhat edematous: conjunctiva vers red and swollen. and covered with secretion: the entire cornea, with the exception of the periphery, is denuded of epithelium, and where any exists it is grayish-white and opraque. The corneal tissue shows diffuse turhidity, and the pupil. which is moderately dilated, is barely visible. Sensibility is diminished in the distribution of the ophthalmic branch of the fiftl nerve and entirely lost in the cornea except at the periphery. Under a bandage the corneal epithelium gradually regenerated in two weeks and the surface cleared somewhat. When the patient was dismissed, six weeks after the beginning of the attack, sellsibility had not been restored in the cornea; the surface was uneven, though capable of reflection, but the tissues were obscured by macula, so that the pupil was barely visible. In this case the cornea was attacked primarily, at the sane time as the skin.

indication-, suitable dict, regular excreise, massage, ete, the Flitor has much faith in the daily inunction of mercurial ointment, which may be kept up for weeks at a time.]

In rare instances parenchrmatons keratitis is met with in arequired sphilis, mslally in association with iritis. It is somewhat nore aommon in shemmatir subjects, forming in snch atses part of a ceneral selfritix. Portions of the cornea near the seleritic focus beeome opaque and, in the (onse of time, as white as the selera (sclerotizing lieratitis); the cornea loses its eiroular ontline and appears to be cucoached upon hy the solera (Plate 29, b). [The discas is also attributed to rachitis, scrofula, malaria. and deporsol nutrition. Raroly it may begin in utero.-Eus] Slight injuries may grive rise to extensive parenchyma- 


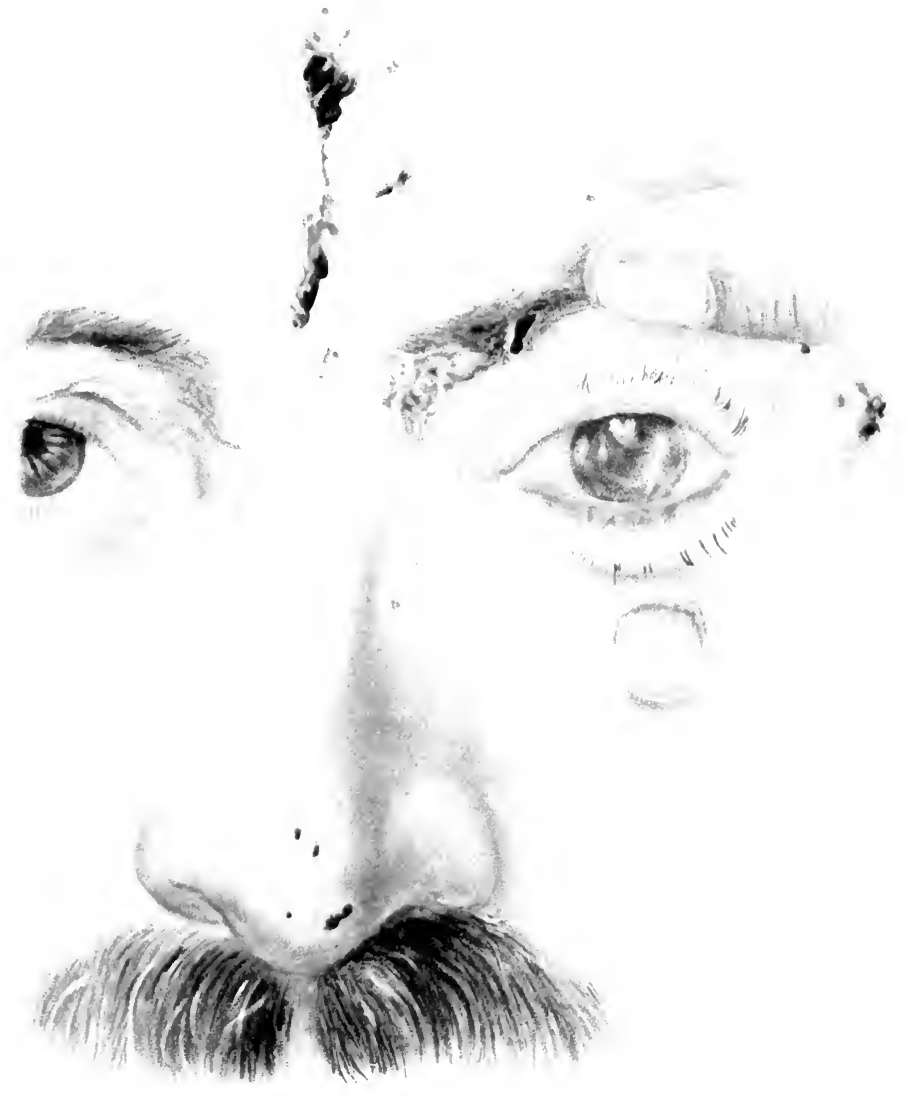



tous infiltration of the rornea, which usually disappears rapidly, but oceasionally perwists for some time and only partially disappears. It is therefore important to observe the greatest are in the treatment of slight injuries, either from scratches or the entrance of foreign bodies; often it may be necessary to use protecting bandages. Deep diffuse infiltration of the cornea may also be caused by iridoerelitis.

\section{B. CIRCUMSCRIBED INFLAMMATIONS OF THE CORNEA.}

These forms are more frequent than the diffise, and the most frequent of them is

\section{Eczematous Keratitis,}

also called phlyctemular or serofulous liciratitis [phlyctenular keratoconjunetivitis.] The corneal affection may oceur independently or in combination with eczema of the conjunctira, the predisposing causes being the same for both forms.

The pustules vary quite as much in size and number in the independent corneal disease as in conjunctival eczena; but here also each individual focus has a distinctly circular contour. The smaller vesieles, which appear as minute grarish elevations and are rapidly converted into small, superficial depressions by the loss of their epithelial covering, heal in from eight to ten days, without causing congestion or leaving any appreciable permanent opacity. The healing of larger ulcess takes place much more slowly and involves a greater loss of substance; ulcers with purulent floors are formed; a few thickened blood-ressels alppear at the erlge of the cornea and gradually work their way toward the ulcer, underneath the epithelium. Unlesis secondary infection takes place, the ulcer clears up and regenerates under its fresh epithelial covering, as may be seen by its reflective properties and failure to stain with fluorescin. The normal transparency is not completely restored, but a permanent 


\section{Plate 21.}

Foreign Body on the Cornea and Dermoid Cyst of the Orbit.--An Italian marble-cutter, 1- years olel, yesterday received a splinter in his left eye, which appears as a small hown particle -momnded hy a yellow infiltration, a little to the temporal sidr of the center. Patient refuses to have the dermod cyst removed. The swelling above the left lichrymal sar has existed since ehiltheol, and has increased very little in the last few yoast.

moremle remains, especially after a centrally situated nleer

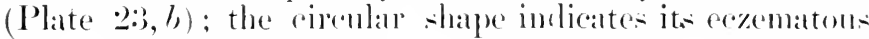
origin. Iarge putules may penctiate deeply into the corneal tisine and eventually cance a perforation, n-mally after the derelopment of iritis and turbidity in the anterior chamber. I alroe single nleers near the corneal maroin are more apt to perforate than eentral ulcers. Perforation is ustally followed he attachment of the iris to the wound, where it becomes incarcerated in the healing process (Plate 2:3, "1).

If the perforation is very large the iris is apt to slip through the opening (polopse of the irix), and if there is rstensive purulent infiltration from seemdary infection, the corneal tissues may break down and a strephyloma result. This is formed as follows: The iris which closes the perforation, although reinfored by granulation-and sar-tisue, is mable to with-tand the intracular pressure, which is msually increased by secomdary glaneoma, and gratually bulges forward. In a few works or months the staphyloma is completed-a hemispherical, grayish-white or bluish protmoion, which canses a marked deformity. Vision is nstally destroyed much arlier.

If the diseatse is protracted and the eptpptions constantly recur, acoompanied by vascularization, so-called eswemotoris

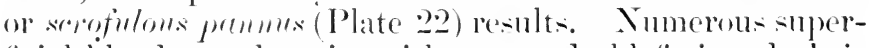
ficial bloof-resols mite with new and old foci and their maculæe to form a grarish-led coating over the fice of the cornea and, of compe, interfere erreatly with vision. If the conlition persists for any length of time an extensive 
0
0
0
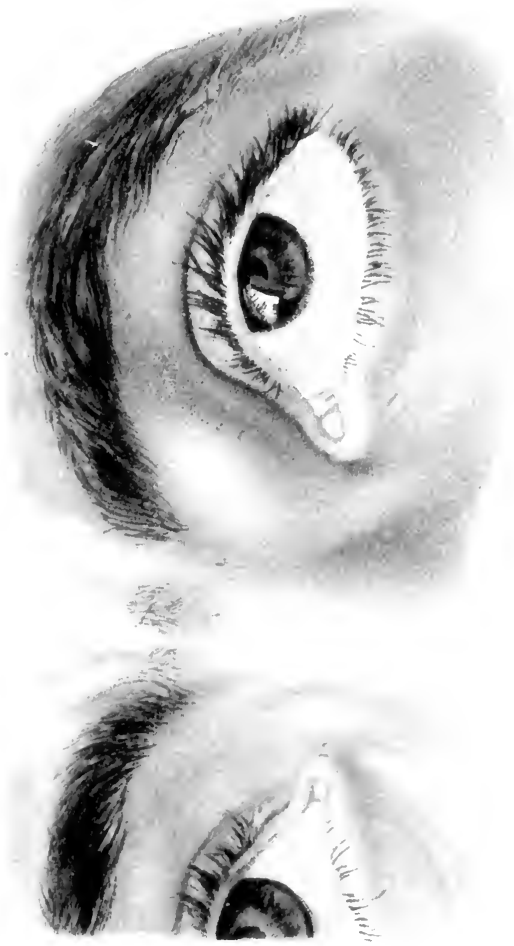

opacity may result and cause permanent diminution of visual acuity.

Corneal eczema very often oceurs secondarily to eezema of the conjunctiva. Pustules appear directly on the corneoscleral junction, partly on the cornea and partly on the conjunctiva. The adjacent comeal area becomes cloudy, and a few blood-ressels make their appearance. This is the so-called marginal lieratitis. If the marginal phlyctenulæ are large $(1.5-2 \mathrm{~mm}$.) the eorneal half is often converted into a deep (exeavated) uleer, with strong tendency to perforation (Plate 23, a); or the phlyetenular ulcer may leave the periphery and creep toward the center of the cornea, forming the so-called migratory pustule or fascicular lieratitiv. Thie mechanism of this process is not well understood. Most cases do not come under observation until after the process is completed, wecks or months after the beginning of the inflammation, when the following picture is seen: A bundle of minute blondressels, from 1 to $2 \mathrm{~mm}$. hroad, extends from some portion of the periphery toward the center of the eornea, running beneath the surface in a straight or slightly curved line and terminating in a erescentic, grayish elevation. When the process is kept under obscrvation for some time the blool-vessels appear to puth before them the erescentic infiltration in which they end; the latter gradually wanders toward the center or across the face of the eornea, between the center and the periphery, its eonvex borler presenting toward the center. The process is attended with severe irritation and blepharospasm; children evince a constant desire to bury their heads in pillows or ereep into dark corners. Whenever the disease is seen at its inception, the original cause is always found to be a marginal pustule. Occasionally several fascicula are seen in the same cornea, or one in each eye. The entire course of the fascicular keratitis across the eornea is marked bra stripe-like opacity, which remains for years as evidence of the disease, and usually produces permanent diminution of vision, as it preferably affects the pupillary region. 


\section{Plate 22.}

Eczema of the Cornea and Conjunctiva on Both Sides, with Eczema of the Hairy Scalp, Nose, and Mouth.-The patient, a delicate, undersized boy of 11 years, very pale, has suffered from inflamed eyes for the past two gears. There is conjunctivitis of both eyes, with copious secretion ant eczematous pannus orer both cornex, which are covered with infiltrates of various sizes, fresh pustules, and maenles of long standing. A recent pustule is to be scen in the nasal half of the cornea in the left eyc: in the right eye a crescentic opacity in the lower segment betrays the former ocenrence of fascicular keratitis. The eutaneons eczema proves the common origin of the varions manifestations.

Marginal phlyetenulie sometimes lead to the derelopment of ecyematons, mareinal pannus, or, which is worse, to a long marginal nlcer, by the coalescence of several adjacent pustules. The adjicent portions of the cornea beenne the seat of extensive infiltration, and perforation is rery apt to result.

While in the conjunctiva the process is attended with only a moderate degree of irritation, eczema of the cornea gives rise to marked subjective symptoms, pain. a feeling of grittiness, as if the ere contained a foreign body, difficulty in opening the lids, or even blepharospasm, and excerive lachrymation. Vision is affected as soon as the proces- invades the pupillary region.

Diagnosis. - The circular shipe of the individual pustules and the presence of eczema in other parts of the borly are the chief diagnostic points (Plate 22). In addition much information may be gained by observing the riliars eongestion and the refleeting properties of the corneal infuce. If many old and recent opacities are pressnt, a--irciated with pronomeed vascularization, the picture of paremehrmatoms keratitis may be simulated. The latter condition, howerer, is never productive of tisue-destruetion, and the cirenlar opacities which sometimes develop in the later stages are less shaply defined than are the macule of ecz'ma, which, in addition, are characterized by a comstant central depresion.

The prognosis is influenced by the unfortunate ten- 
Tab. 22.
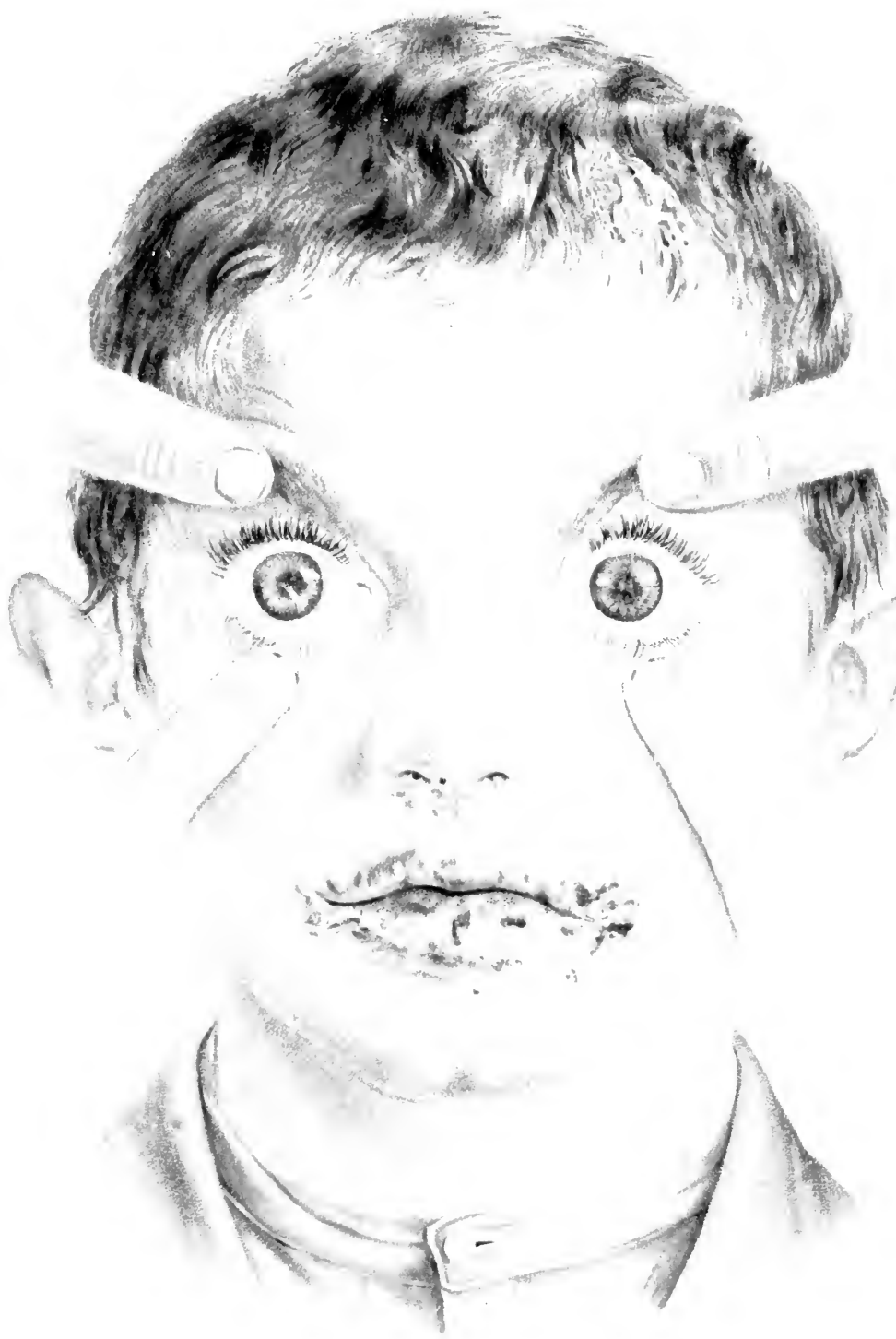

dencr to relapses, which threaten to protract the disease indefinitely. If a large pustule develops in the center of the pupil, permanent impairment of vision is the unaroidable result. In strumous subjects external conditions, such as food, living-quarters, cleanliness, ete, have a marked effect on the onteome of the disease.

Treatment.-General measures to neutralize the evil effects of the strumous habit alre the first requisite. If the patient's surroundings as to food, lodging, and cleanliness are unsatisfactory, crery effort should be made to get him into a hospital, where his diet can be carcfully regulated. Iron (ferr. sacch. solub. [the Eulitor prefers the iodids of iron, to which Fowler's solution may be added]) has a stimulating effect on the appetite, especially for meats, and acts as a general tonic. This should be supplemented by saline baths, and during the winter with colliver oil; in obstinate cases good results are sometimes obtained by a course of sweating.

Locally, atropin in sufficient quantities (3-8 drops of a sterile 1 per cent. solution or several applications of atropin-raselin) to check the pain is indicated. A compres-bandage, which in itself tends to allay the pain, is then applied to guard against secondary infection and purulent infiltration of the abrasions, which are very apt to ocenr in erzema. The best form of bandage consists of one wound over a parl of eotton, which is kept moist with a $1: 5000$ solution of mercuric chlorid, more particularly if there is catarrh. The dresing must not be removed until every single abrasion is sufficiently covered with epithelium. To check the catarrhal secretion, which does not contraindieate the bandage, the tarsal conjunctiva should be painterl once every day with a 1 to 2 per cent. solution of silver nitrate.

If purulent infiltration has set in around the pustules, near the corneal margin, for instance, the handage should be tightly drawn. This is the only condition in which presiure is desirable in the application of the dresings.

Before the caustic treatment of fascicular keratitis was 


\section{Plate 23.}

14. Perforation of the Cornea by an Eczematous Ulcer, with Adhesion of the Iris.-Patient is a scrofulous boy, 10 years old, who had been treated outside of the hospital for the past four weeks, and was admitted at the time of this recent perforation. It is evident from the shape of the perforation that it is due to an eczema-pustule, even without the evidence of eczema in the other eye. There is typical ciliary congestion. The pupil, owing to the adhesion of the iris, is displaced toward the temporal side. A compressing bandage was applied for two weeks, and the pertoration healed, leaving a smooth, slightly pigmented scar. The pupillary distortion is permanent. After a tew weeks vision was practi(ally restored.

b. Macula of the cornea of long standing, the remains of an eczematous ulcer. The circular ontliue of the sear and the loss of cilia indicate that eczema is the causal agent. The eye at the present time is riee from irritation.

introrluced, the malady was most distresing to the patient and a great trial to the phrsician. Now we resort to (anterization, usually with the mitigated stick, well drawn out to a point, moler local anesthesia with cocain. It is important to have the patient under good control, so as to aroid injuring the healthy tissues, henee the services of a apable asistant are indi-pensable. If the first applieation fails to arrest the process a second should be tried. The elestruction of the advancing erescent is speedily followed hy eure, as the rich vasuluarity of the tissues is most farorable to regenelation.

It is most important in all forms of eczematons keratitis to apply a stimulating remedy at the most favorable moment for hastening the reparative proces.s. For this purpuse a 1 to 2 per cent. sal ve of yellow oxid of merenry (woll mixed and comminuted) nowally suffices. Its nise is indicated ats som as the inflammation hat begun to subside, when the ulcer's are n-mally clean and ressel-formation has begun. The salve fulfils the double purpose of clearing up the opacities and preventing relapses, and its application mu-t be preserered in for some time.

[The treatment of the rhinopharrax is escential in all these eases, and always there will be found rhinitis, hyper- 

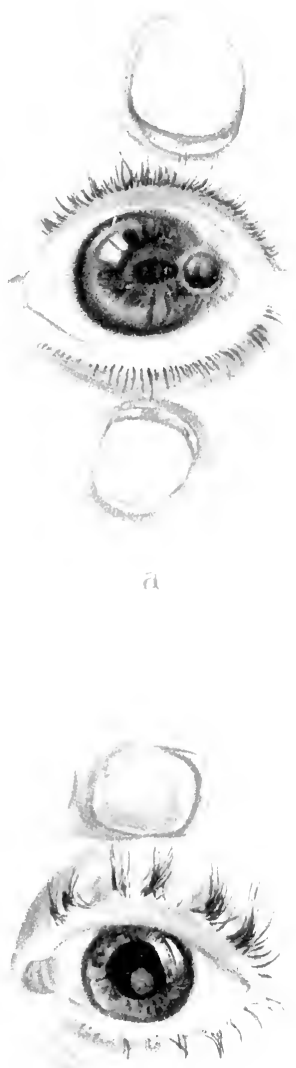

trophied turbinals, adenoid regetations, etc. The lachrymonasal duct should be kept patulons. Severe corneal uleers are managed on gencral principles.-En.]

\section{Herpes Cornea.}

Herpes is another for'm of keratitis of a dermoid character and oecurs as herpes zoster or as herpes febrilis.

Herpes zoster (see p. 92) produees valrions lesions in the eornea:

1. The resicular eruption may appear primarily in the eorneat at the same time as on the skin (Plate 20). The vesicles appear in groups, rapidly break down, and form an irregular, shallow ulcer, which sometimes becomes deeper and gives rise to extensive purulent infiltration of the cornea. In the mildest anses the site of the resicular eruption is marked by a more or less permanent opacity (Plate 20). Iritis ocours in some instances as a complieation. The most conspicuons symptom in this and in the following forms of herpes zoster is lessening or abolition of the sensibility, which is determined by tonching the eye with a twist of cotton.

2. In some cases anestheria oceurs in cireumscribed areas, and upon eareful examination delicate nebule, often composed of numerons, small round dots, are seen in these areas and sometimes profluce shallow ulcers, but in most cases persist for some time without breaking down and eventually disappear entirely. These opanue spots appear to be direetly dependent upon the anesthesia or disease of the trifacial, which is the original cause of herpes.

3. Paralysis of the trifacial may give rise to neuroparalytic leratitis, a dangerous form of inflammation eansed by pyogenic microcoeci, which may lead to extensive nleeration or purulent (colliquative) necrosis of the corneal tissues.

The treatment of herpes zoster consists in the areful and continned applieation of a protective (sealed) bandage, which, if persevered in, may possibly ward off' neuroparalytic keratitis. For this reason it should be employed 


\section{Plate 24.}

Herpes Corneæ Febrilis.-These eighteen outline drawings show varions shapes and positions of herpes-ulcers, taken from thirteen cases under my observation during the epidemic of influenza in 1 1 90-91. (They are also to be found in the work of 1)r. Hagnauer, who was at that time $1 n y$ assistant. ${ }^{1}$ ) In Figs. 1, 5, 6. 7,13 , and 17 we see macules from former attacks of herpes. recognized by their irregular ontline, resembling a geographical map. Figs. 10 and 15 show the macules which resulted from the uleers seen in $i$ and in 9 and 12. Figs. 12 and 14 illustrate the coalescence of a discrete eruption, and Fig. 1\% a magnified picture of the original ulcer. In Figs. 11 and 12 slight vascularization is begiming to show itself.

even when anesthesia is the only symptom, and is imperatively demanded when there is destruction of the corneal tissue.

Herpes corneæ febrilis (Horner) should engalge our interest if only becanse it proves conclusively that processes can oceni in the cornea in every respect analogons to cutaneous diseases, and that the individual foci possess the same shape, on a very much reduced scale, as in the skin.

It is important to note that the resicles on the cornea are much more lelicate in structure, and therefore break down and disappear more rapidly than on the skin ; henee the diagnosis is msully made from the characteristic shape of the subsequent loss of substance, the herpetic ulcer and its peenliarities. Ifter the resicles burst (in from onc to two dars) the cornea for the next week or two look: as if it had been scratched with a sharp splinter. The irritation is moderate, and the injured spot as well as its immediate surroundings, only slightly opacpue. In a week, or firom one to two weeks after the first appearance of the eruption, the last shreds of the vesicle-walls separate and the uleers present their typical simuous ontline and clearcul edges. The contour ean be very elearly brought out by staining with fluorescin, a procedure of the greatest

1 Ihe Mistentungen des Herpes Corner Febrilis, Inaug. Dissert. Zürich, 1891 . 
Tab. 24.

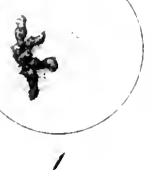

$x$
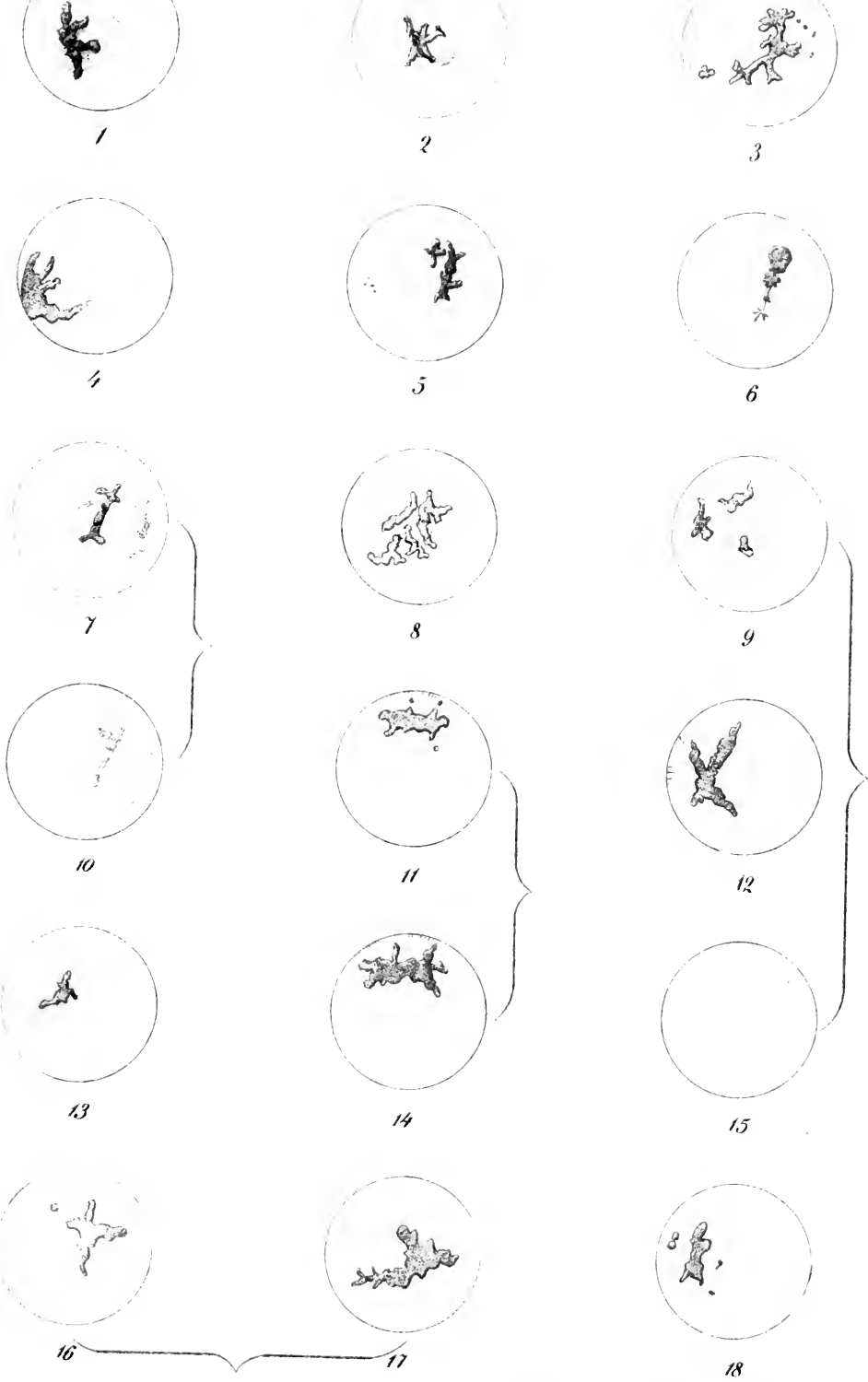

lith. Anss Fi Reichhold. Wünchen 
$\$$ 
diagnontic value in doubtful cases. [As pointed ont by Vasey, toluidin-blue will also stain the cornea when it is deprived of epithelium.-ED.] Bofore the stain is introduced, a few drops of a 2 per eent. solution of conain are instilled into the eye, which hats the incidental advantage of inten-ifying the color. One lrop of an alkaline solution of Huorescin (fluorescin, 0.2 ; sorl. carb., 0.3 ; anqua destill., 10.0) is then applied to the cornea and the eye kept closed for half a minute, after which it is thoroughly wished with a 1 :5000 bichlorid solution. The peculiar shape of the ulcer at once becomes manifest (Plates 24 and 2.5, a). Oceasionally more than one uleer is to be seen. As a rule, the original outline is rotained throughout the course of the disease ; in exceptional eases, however, small extensions make their alpearance after a few days, due to deeper-lying uleers whose epithelial covering has just separated. Of conse, if recondary infection and infiltration of the surrounding tisue supervene, the uleer may asime any size, and may even result in a true hypopyon. The distinguishing feature of herpetic ulcer is the exceedingly slow healing proces-s, requiring from four to eight weeks for its eompletion, which is probably due to the seant and sluggish vessel-formation.

The explanation may be found in the faet that the norves are diseased in herpes febrilis as well as in herpes zoster; this is shown by the diminished sensibility of the cornea observed in many eases. As in all forms of eorneal ulcer, regeneration begins at the edges; a new epithelial covering oversprearls the floor of the ulcer, so that it recovers its reflecting power and does not stain with fluoresin. The original level is very gradually restored, although a more or les pronounced macula alwars remains and for years afterward retains the shape of the original ulcer (Plate 24).

Herpes cornese does not appear in successive (rops, like eczema; lut it is prone to recur in the same eye, or, by way of variety, in the other eye, whenever the individual happens to have fever. An ordinary cold or a short attack 


\section{Plate 25.}

a. Herpes corneæ febrilis, three weeks after the beginning of the dis(ase, stained with fluorescin, showing a green ulcer, of irregular, sinuous shape, in the temporal half of the cornea. IThe green color is a little too light in the figure.) A slight degree of vessel-formation may be seen at the temporal margin of the corneat. The conjunctiva is stained yellow by the fluorescin and, in addition, shows marked eiliary congestion. The pupil is dilated with atropin.

b. Hypopyon-keratitis. - I ust below the center of the cornea is a purulent infiltration which developed in the course of a few days. The limit of the infiltration remains stationary. The hyopyon in the anterior chamber is ? mm. high. No history of traumatism. There are moderate dacryostenosis and thronic conjunctival eatarh. Satisfactors cure after several applications of pure earbolic acid. Visual acuity $\frac{6}{8}$.

of gastric fever suffices to bring it out. The malady is particularly common after influenza. In spite of the long duration of the process, the iris rarely becomes involved, unlers a secondary infection takes place.

The diagnosis is readily made from the rmmptoms described, and especially from the color obtained with fluorescin. Sometimes a herpetic ulcer fails to show the typical sinuous contour (resembling a geographical map), in which ease we base our diagnosis on the slow process of repair. It first the diseased spots may easily be mistaken for scratches, except for the absence of a history of tranmatism. It is often difficult to determine the febrile nature of the disease, becanse the patients msually present themselves long after they have forgotten any fererish srmptoms they may have had. Oceasionally al herpetic marula from a former attack is deteeted and helps to elear 11) the diagnosis.

Prognosis.- $\mathrm{IT}^{\mathrm{T}}$ should emphasize the probability of a long duration, and, if the levion is ecentrally situated, the mavoidable permanent impaiment of vision. On the other hand, if the uleer is properly treated there is little danger of its spreading. Relapses are not infrequent, and little or nothing ean be done to prevent their occurrence. 
Tab. 25.

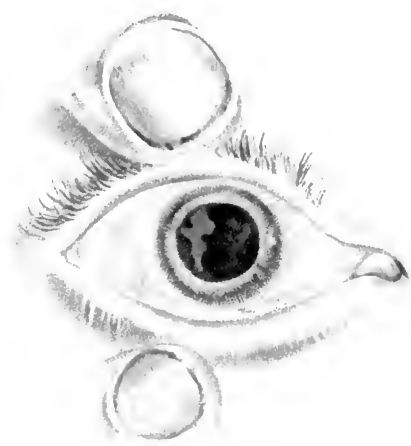

a

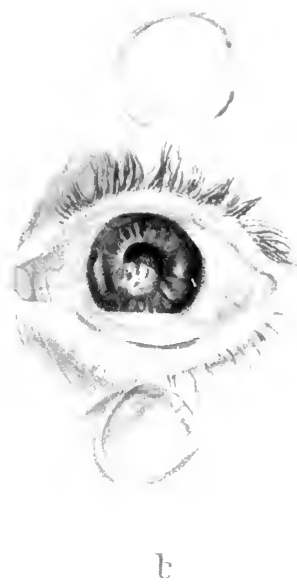



The treatment is the same as for corneal ulcer; it consists in atropin and the eonstant use of a bandage, to be worn until the reflex is restored in every part of the uleer (for its chief oljeet is to guard the ulcer agatinst contamination of any kind, especially of an infections nature). The bandage also serves to diminish the pain by keeping the lids quiet, and allows the process of tissue-repair to $(20$ on undisturbed. When at last a firm epithelial covering has been formed, the bandage may be dispensed with, and yellow oxid of mereury salve (see p. 147) may then be used for from three to four weeks, to eomplete the anre. In the begimning of the disease one or two alpplications of sublimate solution with a cotton pledget (under cocain anesthesia) are of advantage.

\section{Hypopyon=keratitis, or Purulent Ulcer of the Cornea.}

The slightest abrasion on the eorneal surface maty open a way for the entrance of progenic microörganioms, providing some infections material containing them is present and the cornea at the time affords a farorable culturemedium. The second eondition is satisfied in individuals weakened by diseate, barl food, or senile decar. The diseases which produce -ueh a condition are meatles, searlet fever, typhoid fever, whooping-comgh, variola, ete. Infections material is especially abundant in catarth of the lachrymal sac or of the conjunctiva. Farmers often - uffer from purnlent keratitis, probably because their hands are soiled with eath, although the unhrgienic conditions under which they live are no doubt partly responsible. I have often found a pereeptible reduction of the hemoglobin in patients of this class. Then, too, the heat which prevails at harvest-time probably favors the oecurrence of infection.

The le-ions- are usually of a traumatic nature, -ometimes only slight abrasions made by a straw, a finger-nail, or a twig, which create entering points for infection. These may be established by foreign bodies. Sometimes the 


\section{Plate 26.}

a. Serpiginous Ulcer of the Cornea ; Pterygium. I I borer, (6.5 yearsold. Five days ago, while patient was chopping wood, a twig struck him in the left eye. He now presents a large growing ulcer. with suppurating edges, while the center is already in precess of regenration. He says he has been trombled with excessive latehromation in beth eyes for six or seven years. The lachrymal canalieuli are oceluted. A fairly large pteryium has been present for some time. Below the cornea the ocular ronjunctiva shows a molerate degree of elema. An liypopou, 1 mm. in depth. increased during the next few days in spite of repeated eleansing of the ulcer with pure carbolic acid, and finaliy filled two-thirds of the anterior chambere, so that it was derided to evaluate the pus by pumeture. The ulcer eventually healed eompletely. A large central lenkoma remained. Visual acuity: morements of the hand.

b. Serpiginous ulcer of the cornea, in all adrinced stage. The pattient is a farmer, $\pi$ years gld. He has felt stabbing-and burning-pains in the eye for two weeks; his friends noticed a spot and inflammation. Three days ago he consulted a doctor, who selit him to the elinic. llarked senile symptoms; hemoglobin, -n per ent. The eye has watered for some time: eanalieuli are impervions. The eye is very red: in the upper nasal portion of the cornea is a large uleer with broal, greenish-yellow edges and attemated. hulging center, through which the dark anterior ehamber is dimly seen. Hypopyon ? mm. decp: the affucous humor is turbid. The use of the thermocantery is followed by perforation of the uleer and evacuation of the hypopyen. Two days later the edges again suppurate, especially ahent the lower portion of the uleer. Canterization with "arbolie acid. On the next day the uleer had proglessed. especially below. At this time the picture was taken. Another application of the galvanocautrey arresterl the proess. In fire days the ulcer cleared up. Core after ome month, with the formation of a smootle scar, but no staphyloma. $V={ }_{50}^{1}$.

offending object is the direot allse of the infertion, if it happen- to be eontaminated.

I-eptic wombls of the eornea, eren if quite large, has rapidly and take on a new (overing of epithelium in a very short time; but if they berome infereted, they first turn erray and then rellow, and the discoloration spreats to the immediate surromelings; an infiltration develogs he the mierration of lenkereytes toward the injured spot, where they areromulate in the armeal sul)stance in ever-increasing mumbers. The purulent nature 
Tab. 26.

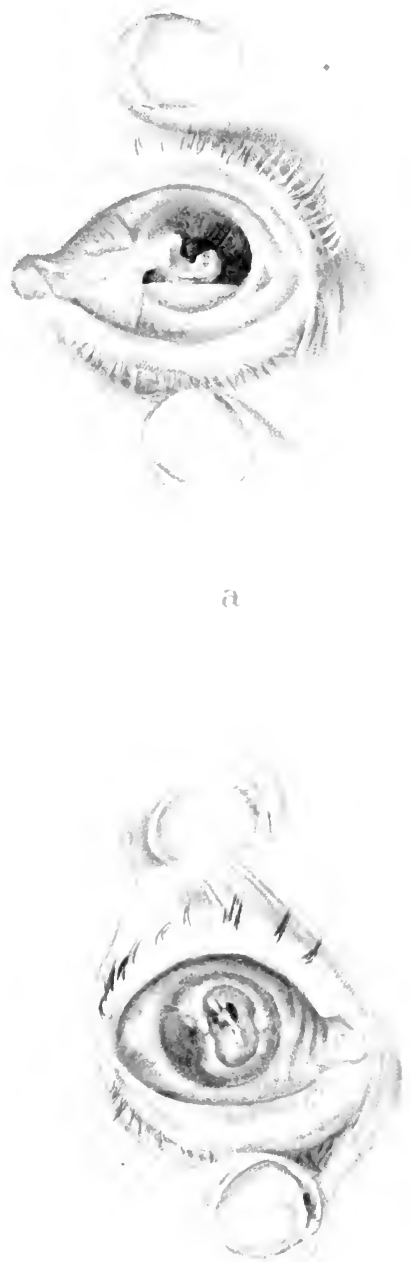



of the infiltration betrays itself in the yellow discoloration. Now, the same procesm may take place if a simple ulcer-caused by eczenal or herpes, for instance-beeones infected. In proportion as the inflammation and the eonsequent ancumulation of lenkenertes increase, the rest of the cornea becomes covered with a delicate, diffuse cloudiness and its reflex is lost. Is soon as the purulent foens attains a certain size, iritis supervenes; the ayneons humor beromes turbid, symechie are formed around the pupillary margin, and pus collects in the anterior chamber, at first a mere yellow line along the lower margin of the chamber, latter increasing to a regment (Plates 25, l, and 26, a). which may oceme onc-half or three-fourth- of the anterior chamber.

This purulent iritis is calued by a toxin, elaborated by the microogrganioms in the corneal, finding its way into the anterior chamber (just as atropin loes, for instance) and setting up an inflammatory process. The pathogenic bacteria themeclves are not likely to penetrate so far, unless there has becon a very decp-reaching infiltration and perforation into the anterior chamber ; hence a hypopron is nwally free from bacteria.

As the purulent inflammation increases, inflammatory edema develops in the bulbar conjunctiva and eventually in the lids. The edema beeomes rery marked and involves the orbital eontents (giving rise to protrusion) ; if extensive destruction of the corneal substance takes place, the suppurative process, penctrating into the iris and deeper coats of the cye, gives rise to panophthalmitis (Plate 27).

It must be remembered that a purulent infiltration of the cornea is very likely to result in general sloughing; the primary focus, which is usually circular in shape, breaks down in the center and an ulcer is formerl, the floor and margins of which exhibit a gravish-yellow discoloration. The patient nstally complainis of pain in the eye, headache, and dimness of vision, if the uleer is situated within the pupillary region, There are, however, 


\section{Plate 27.}

Suppuration of the Cornea from Serpiginous Ulcer; Panophthalmitis. -The patient, who is 73 years old and a farmer by oceupation, was treated in this clinic a year ago for conjunctival catarrh, which is now present, as may be seen by the dried seeretion at the inner canthus of the left eye. The tear-duct is patulous on both sides. Four days ago the patient noticed a burning sensation in the right eye, but paid no attention to it until yesterday, when he found that he could not see clearly. He does not know of any injury. In the right eye the lids are glued fast with secretion, the conjunctiva is red and swollen, and there is ciliary congestion; the cornea is clear except at the center, which is occupied by a circular, shallow ulcer, $2 \mathrm{~mm}$. in diameter, not serpiginous, but of a uniform greenish or yellow color. Small hypopyon. Behind and a little below the ulcer in the anterior chamber a strip of purulent exudate is adherent to the cornea. Aqueous humor turbid. The ulcer was immediately incised after the method of saemiseh. The exudate behind the ulcer was extracted, and brought with it a membrane which lined almost the entire anterior chamber. The next day the slonghing of the cornea had increased, and the incision was opened once more. On the following day the purulent ulcer was much larger, a large amount of pus had collected in the anterior chamber, and there was incipient panophthahmitis. with edema of the lids and copions purulent discharge from the conjunctiva see Plate). On the fifth day after treatment was begun the entire cornea was converted into a greenish-yellow purulent infiltrate, and in the course of the next few days slonghed away more and more, while panophthalmia increased pari pussu.

so-called torpir ulcers of this kind, which give little pain (perhaps becanse the sensitive fibers are paralyzed by the toxin), but are none the less serious.

The most frequent, as well as the most dangerous, trpe of hypopyon-keratitis is the seppigimous meer, one of the most malignant form of corneal discase, which is attended with great danger to the everight from the fact that it preferably affects the central portions of the cornea. The nleer spreads rapidly by one or more of its margins advatucing in the form of "an clevated curve of vellow infiltration (see Plate 26), while the parts of the uleer lying behime this propagating are, as it is ealled, show more or lese tendency to repair. Hypopyon som develops. Left to itself, the lesion at first produces extensive destruction 
N
है
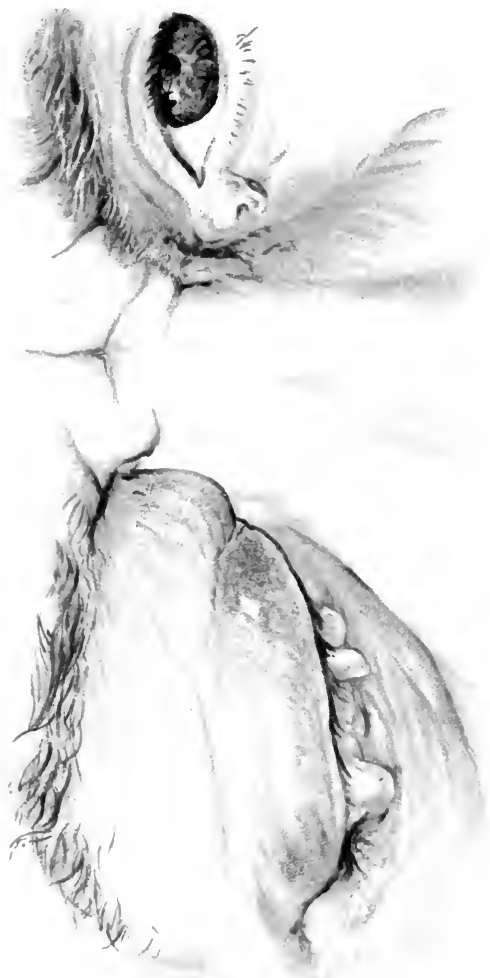

of the superficial tissues, and later penetrates more deeply, so that perforation often oceur's, followed by prolapse of the iris and, finally, panophthahmiti..

It appears from the investigations of ' ththoff', Axenfeld, and others that the serpiginous ulcer is almost

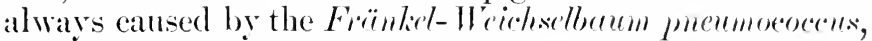
while the other purulent ulcers of the cornea are due to the action of staphylocoecei and stieptocoece (much less fiequently to aspergillus), and only in rare instances to pnenmoeocei.

Among these other forms of hypopyon-keratitis we inelude the purulent ulcerations which oceur in the course of gonorrheal and diphtheritic eonjunctivitis, and in marasmic infants who are aftlicterl with, and eventually dice of, grave digestive disturbances; aloo kerectitis nemoporolytice, cansed by paralysis of the trifacial nerve. These forms of purulent keratitis are capable of causing guite as extensive destruction in the eye as the rerpiginoms ulcer.

The invariable termination of all purulent ulcers, be they large or small, is a dense, clondy scar or lentioma, which n-inally produces a permanent visual disturbance, as it is situated wholly or partly within the pupillary region. If the perforation is small, the result is a mere adlesion of the iris (adhorent lenkoma); on the other hand, the scar of a large perforation may beeome distended and even give rise to a partial or total armeal staphyloma. Small ulcers sometimes leare a membrane of inflammatory exulate in the pupil, which interferes with vision. If adhesion of the iris to the alpsule takes place along the entire pupillary margin, serouder!" glencomen is apt to develop and iridectomy beeomes necessary ; in fact, any adherent lenkoma may give rise sooner or later to seconidary glancoma. Slonghing of the entire cornea is usually followed by prolapse of the lens, panophthalmitis and, finally, phithisis bulbi.

The prognosis in all forms of hypopyon-keratitis, and especially in serpiginous ulcer, is always execedingly grave, 
since the entire cornea is threatened with destruction. Cnless appropriate measures are taken at the proper time, the process nsually leads to total or virtual hlindness.

Treatment. - As a prophylactic measure, lacryostenosis and conjunetival catarh oecurring in elderly people should be treated with special care, and the subjects warned of the danger that threatens them. Most eases are presented too late for general treatment to have much effect; but for all that it must not be neglected in protracted ases. The chief aim in the management of the disease should be the thorongh destruction of the pathogenic colonies in the cornea-in other words, disinfection. At the same time the gratest care should be exercised not to destroy any more corncal tiscue than is needful, because extensive corneal cicatrices, even if they do perforate, are very apt to undergo distention. The first step in this procerlure is direct disinfection of the ulcer itself; the second, the injection of a saline solution under the enjumetiva, cauterization of the retrotarsal folds, ete., for such is the rapidity with which the ulcer tends to spread that the most energetic measures are demanded. Still, crery case must be treated on its individual merits. If the ease is seen at the very beginning of hypopron-keratitis and prescuts no more than a yellowidi infiltration with a slight tendener to ulceration at the center, painting with carbolic acill is usually sufficient. or even when there is a somewhat more extensive infiltration, about as large, say, as the one represented on Plate 2.5, b, which had already produced hypopron. The eve is cocainized for this purpose, and the carbolic acid, after being slightly warmed in order to melt it, applied to the corneal focus by means of a sharp probe wrapperl with cotton. until a whitish eschar is formed, limited strictly to the discased area. The eye is then treated with atmpin and covered with a sealed liandage. If after one or two days the infiltration is still found to be progresinge, the arustic agent must again be applied.

If the infiltration is larger than the one shown in the 
figure, it is fair to assume that the bacteria have penetrated into the deeper layers of the corneal tisine, where they cannot be reached by the carbolic acid, which only acts on the surface. A galvanocautery, drawn out to a point, affords the best means of cauterizing in this case, or a heated knitting-needle will answer the purpose in an emergency. If one margin of the ulcer has alrealy progressed further than the others, cauterization should be partienlarly vigorous at that point. If the situation of the uleer or of the are of propagation is such as to justify somewhat less heroie measures, the infiltrated tissue may be scraped out as thoroughly with a sharp-pointed knifi, or a small sharp curette, and the site touched with carbolic acid; but if on the next or on the third day any part of the infiltration is found to have progressed, the thermocantery must be brought into requicition after all. This procedure may he employed in such cases as are illustrated on Plate 26, for example. [Other antiseptic and caustic substances which may be applied to check the spreal of purulent ulcers are: silver nitrate ( 2 per cent.), tincture of iodin, formaldehyd $(1: 50)$. Ifter curetting an ulcer an excellent practice is to lust iodoform upon its surface and apply a dry sterile bandage.-En.]

Another method of treating these eases is that advocated by Saemisch, which consists in splitting the ulcer. The eve is first thoroughly cocainized and securedy fixed with the forecps ; a Graefe knife is inserted into the somd tissite on one side of the ulcer, with its eutting-edge directed forward, carried across the anterior chamber behind the ulcer, and brought out on the other side of the ulcer in the sound tisine, so ats to divide it from behind forward. The incision should pass through the center of the propagating are. Thus in the case illustrated in Plate 26, ", the section would be made from the outer and lower, to the inner and upper side of the cornea, dividing both propagating ares. As soon as the aqueous humor, and with it the hypopyon, is evacuated, the greatly inflamed iris comes in contact with the posterior surface of the 
cornea and causes violent pain, which last- for some time. If the hypopyon is tenaeions and does not eome away entirely of its own accord, it must be remored with a pair of forceps. If pus remains in the anterior chamber, it need not be removed, as it is usmally free from germs. In performing this operation the greatest care is necessary to aroid jnjuring the lens with the knife. Ifter the first incision the wound must be reopened every day with a blunt, slender probe, until the nlcer begins to heal. The alvantage of this method is that good results are often obtained at the smallest possible sacrifice of corneal tissue ; on the other hand, it camnot be denied that the operation is almost always followed by extensive anterior syechia of the iris, which in turn may give rise to secondary glaueoma. Even Saemiseh's section is inalequate in malignant cases and when the ulcer has reached a large size (see Plate 27 ).

This operation is entirely analogons to a seetion carried through a phlegmon or furuncle, from sound tissue on one side to sound tissue on the other, and depends for its good effects on the same conditions, namely, relaxation of the tissues and the opening of a channel for the lymph-stream to reach the wound and check the further progress of mieroörganisms-in other words, self-drainage.

The treatment may be supplemented by injecting from $\stackrel{1}{2}$ to 1 c.c. of a 2 to 5 per cent. saline solution under the conjunctiva, every day or every few days-a procedure which is supposed to have a stimulating effect on the lymph-stream. Above all, dacryostenosis and conjunctival catarh must receive careful treatment, the latter by means of daily applications of a 2 per cent. solution of silver nitrate; the former hy daily irrigation of the tearsac with a $1: 1000$ sublimate solution, and, if necessary, by pasing a sound or extirpating the sac. Atropin is also indicated to combat as soon and as vigoromsly as possible the iritis which is usmally present. [ $\mathrm{f}$ collyrium of mercurie chlorid $(1: 1000)$ is, in the julgment of the 
Editor, too strong; 1:5000 is sufficient. Formaldehyd $(1: 3000)$ is nseful.]

\section{The Catarrhal Ulcer.}

This is the most important represcntative of the nonpurulent group of uleers, and is of interest on aceount of its comparative frequency. As its name indicates, it is a sequel of conjunctival catarrh, and usually oceurs in old people. It occupies the peripheral portion of the cornea, forming a shallow suleus of variable length along the eorneal margin. As the ulcer presents very little infiltration, either at the base or along the edges, its position and extent are often difficult to determine without an examination of the reflecting properties of the corneal surface or the behavior with fluoresein staining. Pain is usually moderate, the flow of tears and circumeorneal redness are not excessive, and the ulcer on the whole shows a tendeney to heal of itself. On the other hand, if there is much purulent secretion, a neglected ulcer may develop into one of a purulent type and threaten perforation. This is a grave complication on account of the large extent and peripheral position of the ulcer, and is very apt to be followed by extensive prolape of the iris.

The diagnosis is suggested by the presence of ciliary congestion. The discovery of this trpe of congestion during an attack of catarrh should be immediately followed by a close serutiny of the cornea for the presence of such eatarrhal ulcers. To this end the reflecting power of the mombrane is tested and an examination made by lateral illumination, which affords the surest means of detecting the grayish opacity (of the diseased cornea) during the initial stage.

The prognosis is farorable. The ulcer heals rapidly with appropriate treatment, and, owing to its peripheral position, does not affect the evesight.

Treatment.-This is usially limited to the conjunctiva. If infiltration makes its appearance, loeal disinfect- 
ants are indieated, one application of sublimate being usually sufficient.

\section{INJURIES OF THE CORNEA.}

Injuries of the cornea demand the most careful consideration, not so much on account of their frequency as of the vital consequences which they may entail. The slightest abrasion of the surface may open the way to infection and set up a morbid proeess which the surgeon is afterward unable to control. Foreign bodies frequently become embedded in the corneal surface. They may be so minute as to be detected with great difficulty, and yet set up an inflammation which by surrounding it with an area of grayish discoloration betrays the site of the foreign borly. When this is a spicule of iron it has a brown or brownish-black color. If the iris is brown, such a body is at first difficult to detect; later it is brought out more clearly by the area of infiltration, before described, which surrounds it. Similarly a white substance (grain of sand, ete.) where the iris is light colored can at first only be detected by testing the reflection of the corneal surface or with the aid of lateral illumination.

Occasionally a non-irritant body, such as a grain of powder, for example, which has penetrated bolow the surface, may become permanently embedded.

Stab- and cut-wounds, if deep enough, lead to perforation and prolapse of the iris, or at least to adhesion of the iris to the scar.

The treatment in all injuries of the cornea consists in gnarling aganst infection by means of a compressing bandage. Foreign bodlies are carefully removed with a sharp instrument, a cataract-needle, etc., or with a cotton pledget dipped in a sublimate solution, if they are situated on the surfice.

Ifter the removal of a foreign body the cornea should be carefully examined with a loupe and lateral illumination for any stray particles that may have been over- 
looked. If the intruder wats a spicule of hot iron, the brown spot which often remains (see Plate 21) must be arefully scraped out (a matter of some difficulty during the first few days, as the substance clings tenacions]y). Atropin is not necessary in fresh, non-inflammatory calses; but a compressing handage is always to be applied and kept on until the reflex har beeome normal, or at least mntil the site of the injury becomes eovered with epithelium and faik to take the fluorescin stain. If this precaution is neglected, a protracted case of diffise or hypopron-keratitis is apt to result.

Large wounds of the cornea, especially perforating wounds, must also be dressed with a compresing bandage, and the patient must be put to bed. In aser of prolapse of the iris, if the injury is quite fresh, replacement with a suitable instrument (spatula) may be attempted, after disinfecting with a $1: 5000$ sublimate solution. The operation is ustally a failure. If the prolapse is one or two days olk, infection has very probably taken place, and replacement would be followed by a dangerous iritis which wonld imperil the other eye. In such a case it is better, therefore, to excise the prolapsed irio, replacing only the ciliary attachments, so as to leave as little iris-tissue as posible in the womel and relieve the tension of the pupil.

\section{MALFORMATIONS OF THE CORNEA.}

These are of interest beanse they interfere with vision. The most frequent anomaly is unequal horizontal and vertical curvature, and forms one of the causes of astigmatism.

Megalocornea (cornec globosu) may be congenital and sometimes hereditary ; the cornea may retain its transparener thronghout the life of the individual. A similan anomaly ocen's after infantile glancoma; but the cornea in this form early presents the characteristic glancomatous haze and later becomes covered with irregular opacities which materially impair its transpareney. The bulb 


\section{Plate 28.}

a. Trachoma, with Pannus of the Cornea.-The patient, an Italian woman, 37 years old, has suffered for years from inflammation of both eyes. One eye shows incipient cicatricial trachoma, with a number of papillary granulations on the upper lid. (The patient nufortunately declined to sit any longer after the first illustration, ant it was impossible to obtain a picture of the inner surface of the upper lit, as had leen inteuded.)

\section{b. Phthisis Bulbi Anterior; Calcareous Degeneration of the Cornea.} -The woman, who is : 26 years old, sustained a stab-wound in the right eyc when she was five years old; the sear is plainly seen, running whigurly toward the corneal margin. She does not remember ever to have been able to see with this eye. The contraction of the anterior' portion of the eyeball suggests that traumatic cyclitis oceured at the time. As the remains of iritis are to be seen in the other eye, it is quite likely that there was also sympathetic iritis, which, strangely enough, appears to have healed spontaneously, for the patient does not remember to hare sutfered from inflammation in the left "ye. The cornea of the right ere was shrunken, and badly disfigured with whitish epithelial seales. Tattooing was emplosed with very good results and without doing any damage.

c. Parenchymatous Keratitis.-The inflammation began three weeks ago, and the cornea is already to a large extent covered with an opacity which began at the upper and outer margin. The opacity was soon followed by marked vascularization. That the keratitis is diffuse is recognized by the ill-defined delimitation of the infiltrated area. Cause, luereditary syphilis.

eraulually rields to the increased tension, and unless the latter is relieved the condition usually ends in hlindness.

Keratoconus is an acquired anomaly, in which the cornea as-lmes a conical shape. The ecnter of the cornea becomes thimner and is gradually bulged forward by the intracoular presure. I severe grade of keratoconims is at once recounized by the altered reflex, which lends a peruliar flathing-look to the eye. The light is concentrated on the alpex of the eone; the reflex is smaller and brighter than in the normal eye, and surrounded he a halo. I multful wase ale best examined with a Plaredelodise, the blark and white eoncentric rings of which show a poruliar distortion. Similar distortions and illusive movements are also observed in the ophthal- 
Tah 28.

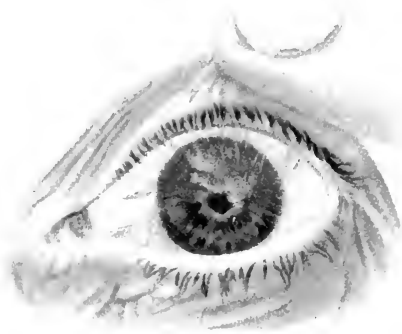

i)

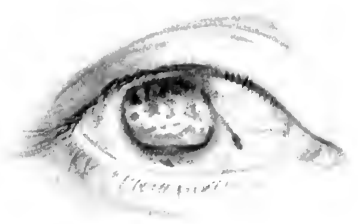

b)
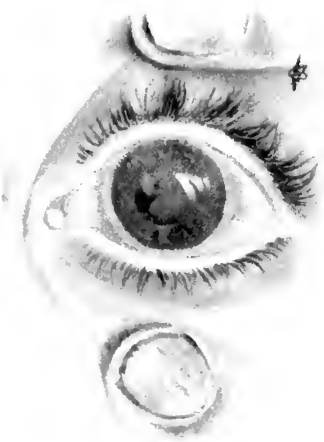

C 

moseopic image. In adranced ases of keratoconus the apex becomes opaque and another disturhing element is alded to the abnomal refractive phenomena. Both eyes are nsually affected, and the condition is met with nost frequently among women. It is rarely posibible to correet the optical error with glasses. I once saw the process arrested by scleiotomy, supported hy general eonstitutional treatment. [High grades of conical cornea canmot be helped much if at all with glasses; but intermediate grarles, and even cases of comsiderable conicity, may be markedly benefited and vision greatly improred with high eylinders or spherocrlindrieal combinations. The best operative procedure is anterization of the apex of the cone with the galvanowatery and later, if necesing, an optical iridectomy. Ens.]

Staphyloma may develop in consequence of extensive ulceration of the cornea and lead to grave impaiment of the visual power. The deformity is eaused by the distention of sour-tissme and is almost always associated with heightened intraocular tension-secondary glancoma. Irremediable blindne-s is the usual result, and the only treatment is a surgical operation.

\section{DISEASES OF THE SCLERA.}

\section{Inflammation of the Sclera.}

Inflammatory procesies are much less common in the sclera than in the cornea, and are alwars localized in the anterior segment. Two forms are distinguished : superficial, or episcleritis, and deep seleritis. Many transitional forms are also met with, and it is often difficult to determine to what depth the inflammation has penetrated. Both forms are characterized by the formation of circular, hypertroplic nodules; in deep scleritis, howeror, the inflammatory process is prone to diffuse itself over a larerer area, surrounding the cornea on all sides and producing 


\section{Plate 29.}

a. Scleritis, recent-i.e., three weeks old. The back-shaped elevation, which is jlainly visible to the temporal side of the cornea, is very sensitive to pressure. 'The disease was probably rhemmatic in character and took two months to heal, leaving a slaty discoloration at the site of the elevation, which may be seen over the cornea in the next figure.

b. Sequelæ of Scleritis and Sclerotizing Keratitis.-It is quite evident, from the prounduced slaty discoloration and reluecd density of the. sclera above the tornea, that the patient (a woman, 3 r years old) has suffered for years from seleritis. The actual presence of seleritis at that point and to the temporal side of the cornea may be inferred from the inflammatory opacity in the cornea and corresponding ciliary congestion. It is also evident from the haziness of the corneal margin that the cornea has suffered frequent encroachments during former attacks of scleritis (sclerotizing keratitis). Finally, we see signs of a former plastic iritis in the irregular outline of the pupil, which is attached to the lens by numerous synechia. The only abnormality in the other eye is a broad synechia in the inner and lower portion. The cause of the process is dificult to determine. The irritative symptoms began when the patient was fourteen rears old. She has eight healthy children; two of her wothers died of phthisis. Eleven vears ago she had a short attack of articular rheumatism without fever. Her eyes had not troubled her for the past three years; the present inflammation began six weeks ago after confinement. Not a trace of albumin in the urine. Iridectomy. Discharged with visual aeuity of the left eye equal to $\frac{3}{60}$.

first a blui-h-red. and later a pale violet, porcelain-like discoloration (Plate 29, b). A reep seleritis often encroaches on the aromea, where it produces infiltrations in the drepere larers which do not break down, but usmally leave a permanent oparoity (solerotizing lievertitis). Besides the cornea, the iris and choroid coat are very liable to become involved; opacities are formed in the vitreons body and threaten to destroy the evesight. Finally, not to montion iritic exulates, cireular synechice, or pupillary membranes, the process may eventrially lead to eataract and ectasia sololie, when the membrame is weakened by a prolonged attack of the discaice.

The speali of a sclenal strphlylome. This form of scleriti- nsually attacks both eyes, preferably those of yomng individuals of the female sex. Such jatients are often 


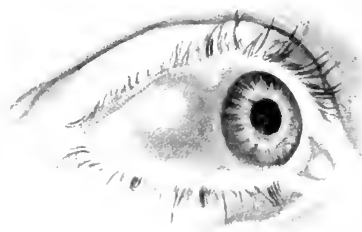

a

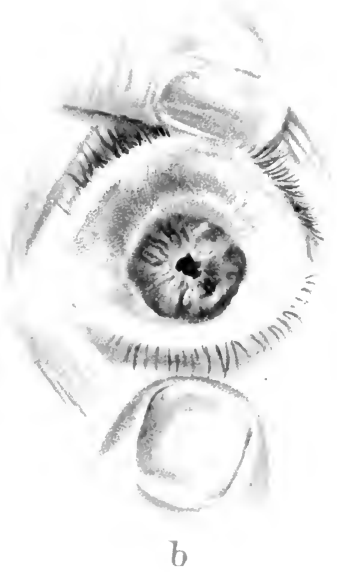

lith. Anst Fi Rewhhold, Wunchen. 

tubereulous or the subjects of hereditary or accunired syphilis. The disease, which usually last for years, is rarely amenable to treatment.

Episcleritis is more eommon than the deep form, and is characterized by the scleritic hump (Plate 29, a) which betrays its site by a deep, bluish-red injection underneatl, which is not movable with the conjunctiva. The inflammatory foci never ulcerate, but gradually disappear in from five to ten weeks or later, leaving a dull gray spot due to the attenuation of the scleral tisme. Episcleritis is also refractory to treatment, especially the migrating form, which tends to encircle the cornea wholly or partiallyscleritis migrans.

The elevations in the sclera, which represent a true round-cell infiltration, vary in size from 3 to $8 \mathrm{~mm}$.; several may be present in the same eye. They are usually very sensitive to pressure, but not painful if undisturbed, except in a few cases, when the pain is said to be rery distressing. The process is rery apt to recur, and, in course of time, attacks both eves. Episcleritis is, on the whole, less dangerous than the deep form, and is followed by fewer complications.

Tuberculosis and spphilis are predisposing causes; but the affection is more often observed in eonnection with the rheumatic diathesis, and the treatment in most cases should consist of active antirhemmatic remedies: sweating and a long-eontinued use of sodium salicylate.

\section{Injuries of the Sclera.}

In addition to stab- and cut-womds, which are quite common, we oceasionally see the more serions injury of rupture of the sclera, caused by the application of violent external forec-a blow with the fist or a stick, or a cow's hom, or collision with any blunt object. Rupture of the sclera is, of course, a perforating wound, and therefore endangers the contents of the globe; the same is true, however, of most stab- and cut-wounds. Besides causing 
the loss of more or less vitreous body, such perforating wounds are the means of introducing infections material into the interior of the globe, and as the latter is an excellent culture-medium, the purulent inflammation rapidly spreads to the retina and uveal tract. In exceptional cases rupture of the sclera takes place without tearing the eonjunetiva, so that the rent does not communicate with the outside. In such cases the lens, instead of being forced completely through the rent, as it nsually is may only prolape ats far as the conjunctiva (Plate $34, b$ ). Rupture usually takes place above the cornea, in a line parallel to the margin; sometimes to one side of the cornea (Plate $34, b)$. The accilent is very often followed by a large hemorrhage into the vitreous-hemoplithalnos-the retina beeomes serionsly involved (retinitis proliferans), and total or partial blindness nsually results. A large escape of vitreous, especially if mixed with blood, is followed sooner or later by separation of the retina and total blindness.

Wounds intlieted with a knife, scisors, or broken glass may heal satisfactorily, if they do not beeme septic; they are not attended with as great a lo-s of vitreous as is a rupture callsed by compression of the bull).

A foreign borly is not as likely to bury itself in the sclera as it is in the cornea; it usially penetrates into the globe and lodges in the vitreous or on the retina. This is particularly the case with pieces of iron, which aeguire sufficient imomentum to pierce the tissnes of the selera. Pieces of enpler also, from exploding dynamite caps, chips of stone scattered by powder or drnamite blasting. and glass splinters from the explosion of glase resects in laboratory work, ate, often penetrate the releria. If the splinter is larewe, it may inflint a considerable womm without remaning in the grobe; these eases are rare, however, compared with thow in which the splinter penetrates into the interior of the ghobe ; and the latter event is always to be eonsidered the mo-t likely in making a diagnosis.

A perforating womb of the selera, if extensive and before the edges have beeome united, reveals itself by re- 
duction in the tension of the globe. The ophthalmoserpe shows more or less hemorrhage and inflammatory turbidity in the vitreous body. If the wound is situated along the equator, a bright bind may be seen in the ophthalmo-copic image, indicating a lesion of the ehoroid. The presence of a foreign body in the interior of the globe demands a thorough ophthalmoseopic examination. If the snspected substance is iron, it is advisable to we the sideroscope, a very delicate magnetic needle provided with a device which permits its deviations to be read off with a telescope, or the large electromagnet, proposed by me, which either attracts the splinter toward the iris or at least indicates the presence of iron by the pain it produces. [The Röntgen rays furnish a means by which the presence and position of a foreign body in the eye can be determined with accuracy. Of the niany methods suggested for enploying the $Y$-rays under these circumstances, that one proposed by II. II. Sweet seems to the Editor, who speaks from experience, to be the best.]

Never explore a wound in the salere with a probe, either for the purpose of detecting a suspected foreign body or to determine whether the wound is really a perforating one. For in doing so there is great danger of introducing pathogenic germs, which may be present on the exterior of the wound, into the ritreous body and setting up a fatal inflammatory process in the interior of the globe.

The treutiment of scleral wounds demands absolute rest in bed, at least for some time. If the wound is large, both eves must be bandaged. If the wound is already closed, it is better not to disturb it ; gaping wounds may be carefully closed with sutures passing through the conjunctiva and episcleral tisue; it is not usually advisable to inclucle the sclera itself in the sutures.

Only when the piece of iron which has penetrated the selera is very large should the attempt be made to extract it through the scleral wound with an electromagnet; small splinters should be drawn into the anterior chamber and 


\section{Plate 30.}

1. Sarcoma of the Iris.-I am indebted for this picture to the kindness of my colleague, Dr. Mayweg, of Hagen, who made the following report of the case before the Ophthalmologic society of Heidelberg, at the mecting of the society in 189\%. As long ano as $18 \% 0$ the patient. a factory-hand, 53 years old, had his attention called to a small yellowishbrown elevation, as large as a pinhead, in the temporal third of the iris, near the outer rim. A year later he noticed a change in the spot; it gradnally became larger, withomt eausing diminution of vision, which at the time of his admission was perfectly normal. The tumor was completely removed in two sittings and the wound healed in three weeks. Examination of the tumor revealed a moderately pigmented, spindlecell sarcoma. The pigment-spots on the lower portion of the iris are not pathologie; such spots are often seen on the iris; occasionally. however, they develop into sareoma.

b. Syphilitic Iritis.-There is marked ciliary congestion. The hyperemia in the iris has changed the original blue-gray color (as seen in the other eye in Fig. (') to a greenish tint. The pupil is dilated with atropin and shows the projecting synechice. The patient eomplains of pain and a moderate degree of photophobia; he was infected a few years ago.

removed through an incision in the cormea. When the eye is brought near the electromagnet, if there is a loose piece of iron in any part of the vitreons body it will be drawn aromel the lens against the iris and ause it to bulge forwarl. As soon as this is observed the patient's head is at once thrown back, or the electric eurrent interrupted, lest the substance become fixed in the posterior surface of the iris. If the eye $\mathrm{i}$ now turned toward the site of the intruder, it can usually he drawn through the pupillary opening into the anterior chamber, if the preeaution hat been taken to dilate the pupil hefore begimning the operation. If the substance is lodged in the retina or choroid coat, some time may elapse before the magnet beeomes effective, hence the attrmpt must not be abandoned too soon and may be repeated if necessary. The smaller the particle of iron the greater must be the power of the magnet, and rive resese. If there is no larege magnet at hand, an attempt must be made to find and extract the foreign body with the small magnetic probe, either through the original seleral wound, or through a fiesh in- 


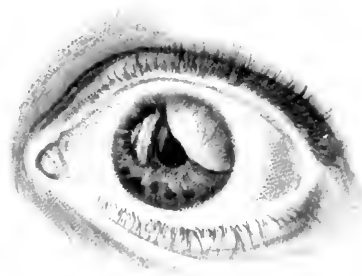

a
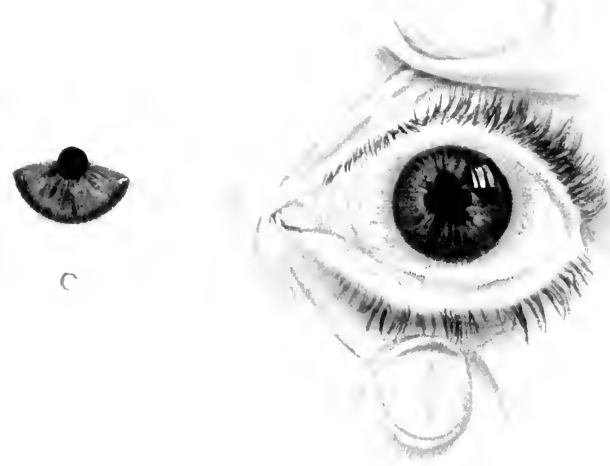

b 

cision. [If the foreign substance, steel or iron, is proporly loeated by means of skiagraphie examination, the Editor believes that its extraction through a suitahly plated incision by means of the extension point of a Hirschberer or similar magnet is an eminently preper surgical procedure.]

\section{DISEASES OF THE IRIS AND CILIARY BODY.}

\section{Inflammation.}

Is a lule, the anterior segments of the urea, the iris, and the ciliary body all partieipate in the inflammatory process, so that inflimmation of the iris alone (iritis) or of the ciliary bods ( grades of inflammation even the choroid becomes involved, and we speak of necitis.

The symptoms of iritis are very characteristic. 'There is perionrneal injection, and the pain, lachrymation, and photophobia are so severe that the patient finds it eliffienlt or imposible to open his eyes in a bright light. Hyperemia is a conspicuons symptom, which manifests itself in chromatic alterations in the iris; a blue iris becomes green, gray changes to a redelish tint, a light brown or green color is somewhat darker and more mully than that of the normal eye (Plate $3(0), b)$. The striations are partially obsemed ; the tissues are somewhat turbid and puckered or thickened from the inflammatory infiltration. The increase in the rolume of the iris callises shrinking and partial los of mobility in the pupil. The latter smptom is aderavated by the inflammatory irritation in the musclefibers, and eventually the pupil fails to react promptly to light on account of attachments between the pupiliary margin and the lens apsule. At first certain portions only of the pupillaty margin beeme attaclued, which, after dilatation of the pupil with a mydriatic (atropin, hyoscin, cocain, homatropin), appear as tongue-shaped 
projections of varying width (Plate 30,6$)$ and mar the eircular outline of the pupil. These attarhments are ealled posterior symechice, to distinguish them from anterior synechic between the iris and the cornea, which oorur in perforations of the cornca. If the ease is seculate, the entire pupillary marein may be bound down and the pippil mar fail to dilate altogether under the influence of a mralriatic. Sometimes the pupil begins to dilate at various points after a long application of the drug, by the freshly formed swnechice giving way, and if the attachments are not too old it is sometimes possible to loosen them all in this war and restore the contomr of the pupil. The attachment of the whole pupilary marem by an ammular srnechia is termed exchxiom of the pmpil (scelnsio pupilla), beeanse the space behind the iris, the posterior chamber, is exeluded from the anterior chamber.

If numerous srnechice are formed, they are $11-11$ all $y$ asiociated with exudation into the pupillary region and the formation of a false membrane which completely oceludes the pupil; this is called ocolusion of the pupil (ocelusio pupillae). The interference with vision is directly proportional to the thickness of the membrane. At the same time a similar exulation takes place in the aqueons humor, which beomes tmolid with lenkocrtes and fibrin, and leads to still ereater obscmation of the iris and pupil. In severe grades the lenkocrtes mav collect at the hottom of the anterior chamber, forming a hypopyom and thos indieating the purulent nature of the iritis. In other eases the exudate comsists principally of filmin and forms a semitransparent gravish opacity in the anterior chamber. High grates of iritis mally give rise to a diffise haziness of the cornea, due partly to fine deposits on its posterior surfare, and partly to direct participation in the inflammatory procesin the form of an infiltration of migratorr lenkorover.

The pain in sovere iritis is often veryereat, and spreats from the eye to the hrow and temple; it beemes almost mobarahle if the "re is exposed to the light: but ma! 
also be very severe at night, whon it gives rise to excessive lachrymation.

On the other hand, there are insidious cases of iritis, in which the patient is harlly conscious of inflammation; persons are sometimes found to have synechice who do not remember ever to have had inflamed eves.

Iritis may be present in one eye only ; and, if it recurs, attacks the same ere; or it may show a tendency to affect both eyes, so that the second aye becomes involved sooner or later.

C'yclitis presents other manifestations of inflammatory exuflation :

1. Precipitates on the posterior lamina of the cornea, ranging in size from a mere point to $2 \mathrm{~mm}$, consisting of circular aecumulations of round cells, mixed with pigment or fibrin, gray or hrown in color, acoording to the nature of the pigment. They are seen chiefly on the lower jortion of the eornea and may he so minute as to be detected only with the aid of a lompe and lateral illumination, or with the ophthalmoseope under direct light. They are often limited to the inferior cyudrant of the cornea-i.e., to a triangular area, the apex of which lies in the pupil. The exudation in cyclitis may also take the form of hypopyon or deposit grayish-white mases which appear floating, in the inferior and lateral portions of the anterior chamber.

2. The exulation may be principally into the posterior chamber and produce a general attachnient of the surface of the iris to the lens-capsule by a complete posterior srnechia. This is recognized by the gradual retraction of the iris against the border of the lens as the exudate contracts, and the deepening of the anterior chamber at it: periphery. In this form of ciliary attachment dilatation of the pipil is complete, or absent altogether.

3. The exulate may ocoupy the vitreous chamber, expecially the anterior portion, and, if extensive, produce more or less marked impaiment of the visual power. The exudate behind the lens in course of time becomes 
organized into masies of inflammatory tissue which gradually contract, while the continuous irritation of the ciliary body and progressive obscuration of the vitreous finally lead to atrophy of the eychall (phthisis bulbi).

In severe grades of crolitis the three forms of exudation may be combined, and severe inflammatory symptoms-, especially pain and congestion, are present. in the other hand, a simple crelitis may run its course without giving rise to pain and congestion, being recognized only by the presence of precipitates and turbidity of the vitreous and by the interference with vision which these alterations produce. The term serous iritis was formerly given to this variety; but the name is incorrect and now obsolete.

Alteration of the intracoular pressme is an important symptom of eyclitis. It may be abmormally high, in the form characterized by the deposition of precipitates, or it may fall below the normal, especially in severe grades of the disease and in the later stages. Associated with abnormally diminished tension we often have the important subjective srmptom of extreme sensitiveness to pressure in the ciliary region, the patient immediately drawing his heal back when we attempt to touch this recion. Another ominous symptom of eyclitis is edema of the upper lid.

Iridecyclitis, or the association of reclitis and iritis, constitutes a dangerous and very intratable disease, owing to the permanent injuries to the eve inflicted by the eyclitic exurates in the posterior chamber and in the vitreous, which are absorlsed with croat difficulty and eamot be removed hy strenical means. The cyolitis shows a decided disinclination to heal, and may torture the pationt for montls am rours. But eren a simple, chronic cyclitis, produring more punctiform precipitates on the cornea and a molerato dogree of turbidity in the vitreous, may run a slow and tedions course. ilhen primary it ustally attacks both eyes. In cases of long duration the choroid usmally heomenes involved.

While, therefore, "ren an arente iritis or iridocyclitis may be protracted for weeks, the duration of the 
chronic form must be expressed in months or years, and the final result is but too often practical or total blindners, the more so if the disease shows a tendency to relapese, ats it often does. ('hronie iritis and iridoevelitis eventually lead to atrophy of the iris, cataract, atrophy of the bulb, either of its anterior portion (phthisis anterior) or of its entire volume (phthisis bulbi).

The causes of iritis and iridocyclitis are manifold. We distinguish between primary and secomdary iritis. The latter oceurs in keratitis, especially in the purnlent form, and after scleritis, choroiditis, retinal detachments, intraocular tumors, ete.

The primary form may follow in the train of various constitutional iliseases, or it may oecur as a loealized disorder, as in trammatim. Syphilis is by far the commonest canse of iritis and iridoeyclitis (in about one-half of all the cases).

Syphilitic iritis may assume the form of a simple iritis with syneehixe (Ilate $30, b)$; or it may be attended with more or less extensive deposits on the cornea, or both these forms may be combined. Sot uncommonly the discase presents a characteristic picture by the formation of nodules in the tiswes of the iris (Plate 31). The color of these nodules when they are small $(1 \mathrm{~mm}$.) is grayish-red; when they are large (3) $4 \mathrm{~mm}$.) yellowish-red, and the surromdling portion of the iris is usually congested and reddened. Ther preferably solect the pupillary, more rarely the ciliary, margin, and grow quite rapidly. Occasionally several alpear together, and by coalescing convert portions of the pupillary margin into a thick fold. The site of such a spphiloma is invariably marked by a synechia, which persists even after the nodules have become absorbed. Any marked thickening of the pupillary margin, associated with an extensive synechire, should aronse a suspicion of the specific nature of the inflammation, even if the norlules are not plainly visible, as they often require the mieroscope for their detection.

Iritis, with or without the formation of nodules, usually 


\section{Plate 3I.}

Syphilitic Condylomatous Iritis.-L. P., 2:3 years old, footman. The patient conplains of pains in the right temporal region and in the right eye for the past five days. Ciliary injeetion: rornea and aqueous humon normal p pupil dilates in the form of a kidney upon instillation of at ropin, wing to a syneelia at the outer lower portion. At this point a redelish tmmor as large as a hemp-seed projects into the pupil. On the raphe of the penis, about the minlelle of the pendulons portion. is a mod"rately infiltrated, pigmented sar of a livid coppery lume, ahont as large ats a bean. Ingninal, cervical, and axillary glands swollen. Difluse pustular syplilide.

cured with inunctions and subconjunctival injections of sublimate.

appear- in the secomdary stage of syphilis, so that the

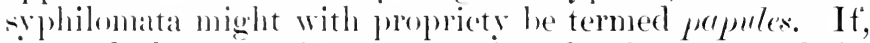
as rarely happens, it alpears aftor the first rear of the disease, the norlules mar be wanting, or they mas appear during the tertiary stage, when they should be diongrnated as gmmmeto. Ther mar attain to a comsiderable size and involve the cilian hom

In the comses of a spluilitic infection iritis is very apt to elevelop in both eyes: it is prone to recur, and is often aceompanied hy discase of the choroid, retina, and optic nerve.

Iritis may he attributable to hereditarysphilis. Chronic, bilateral iritis, ocemring in a child, always sugesets hereditary syphilis.

Rhemmatic iritis is quite ammon in certain districts. It present- no rharacteristic smotoms, and the diagnosis must be based on evidenoes of pheumatic disease in other parts of the hody, on the history, and on the effect of druess. Relapuse ane frequent ; they often follow relapses of artieular rhemmati-m.

Gomorrheal iritis, oenerime as it does in gonorrheal subjects who are apt to suffer from so-called gomorrheal rheumatism, is often difficult to distinguish from the rheumatic form. The same tendencr to appear in association with articular rhematiom, or with relapses of the same, is observed in this type. It often proves very intractable. 


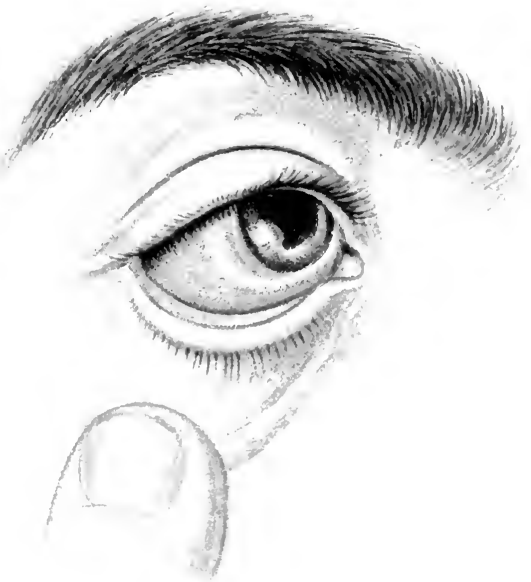



Among the rarer forms of iritis may be mentioned tuberculous and scrofulous iritis, which occurs in tubereulous subjects either as a simple iritis with posterior precipitates, or as a chronic tubercular process with the formation of nodules in the tissnes of the iris. The latter somewhat resemble syphilomata; but they are situated at the periphery, instead of at the pupillary margin, and their color is more gray or grayish-red. Their growth is less rapid than that of syphilomata and is attended with less inflammatory symptoms; usually they are asociated with large precipitates on the posterior layer of the cornea. 1 number of smaller nodules often coalesce and form an irregular, lumpy mass, which partially fills the anterior chamber. The process preferably begins in the lower portion of the anterior chamber. The presence of miliary tubercles among the larger spherieal proliferations in the iris sometimes helps to clear up the diagnosis. Small nodules resembling tubercles may also be caused by the entrance of cilia into the anterior ehamber and, rarely, by leukemia and pseudoleukemia.

Iritis is occasionally met with in dichetes and allonminuria, or in connection with recurent ferer.

Irliopathic iritis, or one in which no primary discase can be diseovered, is not attended with marked inflammatory symptoms. It oecurs usually in the form of a chronic iridochoroiditis with synechice, deposits, and disease of the deep layers of the ritreous, which becomes more and more turbid. It leads to obscuration of the lens and atrophy of the choroid and retina, and may in the course of years result in romplete blindness. Idlopathic iritis is" a grave diseane, which usually affects both eyes, although at first one ere may be more serionsly involved than the other.

The most important of those forms not due to a constitutional disease is traumatic iridocyclitis, because it is apt to be followed by sympathetic ophithalmitis of the other eye. Destruction of the affected eye at least is the usmal outcome. Traumatic iridocyclitis oceurs when a perforat- 
ing wound becomes infected; aseptic wounds of the iris and ciliars bodr heal without inflammation. The complication may be cansed by operative (as in cataract(xtraction, for example), as well as by accidental injuries. Whenerer a wound penetrates to the ciliary body, or a forcign body is allowed to remain in the eve, there is danger of iridocyclitis and inflammation of the other ere.

Sympathetic ophthalmitis sometimes follows an acute purulent iridocyclitis, which will eventuate in panophthalmitis, but is mich more likely to derelop into the chronic, insidions form of iridocrelitis, which at first does not appear to be at all alarming. The visual acuity of the injured eye may not be materially affected, and no more serions simptoms may be noted than a slight congestion, diminished tension, and a few punctate precipitates on the posterior surface of the cornea, so that the surgeon hesitates to sacrifice the eve. On the other hand, if a phthisical bulb, in which the primary inflammation has already subsided, again becomes inflamed, either spontaneously or as the result of a second traumatism, sympathetic ophthalmitis may develop, while non-inflammatory, painless atrophy of the globe is unable to produce the condition. In most cases the sympathetic inflammation makes its appearance while the primary iridocyclitis is still active, say from four to eight weeks after the injury. Its coming is heralded by prodromata which are designated symprithetic iritation, because they are not actually inflammatory in character; they are defective accommodation, photophobia, and heginning eiliary congestion. These are soon followed by the oljective inflammatory symptoms, distinct ciliary congestion, pupillary contraction and synechixe, opacitics on the posterior sirface of the cornca, and all the other signs of iridocrelitis. Srmpathetic iritis is one of the most malignant forms of inflammation and often goes on to total hlindues. The route of transmission fiom the affected to the maffected eye has not as yet been discovered. [Sympathetic ophthalmitis may sometimes arise in the wake of an attack of sympathetic irritation, 
may sometimes coexist with it, but frequently, indeer usually, develops withont any premonition or association of this character. Therefore it would seem to be safer to regard sympathetic irritation and sympathetic inflammation as two essentially different conditions.-ED.]

Diagnosis of Iritis.-It is of vital importance to be able to distinguish iritis and iridocyclitis from glaneoma, because remedies appropriate for the treatment of iritihave the most disastrous effects in glancona, and the error might easily lead to total blindness. In iritis the pupil is contracted; in glancoma dilated. The intraocular tension (which is markedly clevated in glancoma) aftords valuable information, and its investigation must not be neglected in any case declared to be iritis. The former occurrence of iritis may have an important bearing on the diagnosis, as it throws light on the question of sphilitic disease; hence a persistent pupillary membrane must not be mistaken for the remains of srnechire A persistent pupillary membrane is not infrequently seen in the form of gray dots or threads in the pupilliry region, passing from the iris to the lens-(ap)sule. But while the remains of senechice originate at the pupillary margin and form a wreath or wreath-like patches, the threads of a persistent pupillary membrane are attached to the small circle of the iris and appear in the form of irregular groups.

The treatment of iritis and iridocyclitis includes local remedies and general constitutional medication for the removal of the primary disease. In every case mydriasis must be maintained with atropin or hyosein, sipplemented with a few drops of cocain in refractory pupils. If intraoenlar tension is increased, atropin must be withdrawn for a time. The eye must be protected from light, either with dark glasses or by keeping the patient in a dark room, according to the severity of the iridocyelitis. Atropin and dark glasses not only diminish the pain by keeping the iris quiet, but also tend to check the inflammatory process by lessening the entrance of blood into the contracted iris. Mydriasis also renders the 
formation of synechie difficult. In simple iritis, showing mere punctate opacities, one to two drops of a 1 per cent. solution are usually sufficient ; in arute iritis five to eight drops per day, with, if neecsiny, the sime dose of a 2 per cent. solution of cocain. Mbsolute rest for the eyes and abstinence from alcohol in any form shonld be strictly enforced in acute iritis.

Syphilitic iritis demands rigorous antispecific treatment in the form of inmetions, 2 to $4 \mathrm{gm}$. per day, and potassium iorlid, 2 to $5 \mathrm{gm}$. per day. In obstinate cases a course of sweating is recommended, which, with sodium salicylate internally, is also applicable to the rheumatic form.

Tubercular iritis can only be treated by general constitutional medication; excision of the nodules is not of much arail. On the other hand, I have seen good results in several instances follow the introduction of sterilized ioloform into the anterior chamber.

In traumatic iritis prophylaxis plays an important part. The strictest atepsis is to be observed in all operations within the eveball; infected wounds should be sterilized as well as posible with carbolic acid, with the thermocautery, or in any other appropriate way. For this purpose iodoform may be again recommended; I once saw, in the ease of a suppurating eataract-wound, an apparently hopelese cye ared by the introduction of iodoform into the wound and into the anterior chamber. Cold compresice, so popular among the laity, are to be absolutely forbidilen in all womnds of the eveloall, on account of their great liability to infection. "The Eclitor has the greatest conticlence in sterilized ice compreses in noninfected womnds of the eveball. Naturally great care is exercised that the empresies themselves shall not carry infertion.] If the wound is already infected. cold conipreses, as well as leeches, are as nseles- as would be the "singing of hrmn- at a fire" (Hirschberg).

Most important is the prophylaxis of so dangerons a disease as smpathetic iriti... Therefore, all injuries likely 
to produce this affection mu-t be treated and watched with the utmost care, and such cyes must be enucleated which threaten sympathetie iritio, especially such at have badly healing wounds in the ciliary region. If the sear's in such eyes begin to contract, they usually are rearly for enucleation, especially if to other indieations atre added abmormally low tension, persistent ciliary congestion, and tenderness on pressure. The prevention and cure of tranmatic iritis demand the removal of any foreign body which may be within the globe, a prencedure still more armestly ilemanded if smpathetic iritis threatens.

If s'rmpathetic inflammation has already set in, inmediate enteleation of the ero originally affected is namally indieated. This is to be followed by long-continned my idriasis (with atropin) in a dauk room and a course of ${ }^{\circ}$ inunetions with blue sintment.

In order to guard against the oecurrence of traumatic, and especially smmathetic iritis, it is well never to operate on an inflamed eye except for the removal of a foreign body or for other imperative reasons. Operation on a simpathetieally affected cye is never arlvisable until some time after the subsidence of all inflammatory symptoms, when an attempt may be made to improve the visial power by an iridectomy.

If ocelusion takes place after iritis, iridectomy must be performed early, to prevent the occurrence of glancoma.

\section{Injuries of the Iris.}

Injuries of medieolegal significance, caused by violent external force are sometimes met with in the iris. Such are fissures in the pupillary margin and rupture of the sphincter, which destroy the circular ontline of the pupil, and, by producing partial or total paralysis, give rise to tianmatic mydriasis, although the latter is also cansed by simple contusion of the nerves. Iridodialysis is the term applied to a rupture of the eiliary attachment, in which a dark cresentic opening is formed in the periphery of the 
anterior chamber ; the pupillary margin at this point is straight instead of colrenlar and does not react. The iris mar he completely or partially detarhed in ruptures of the selerotic coat, a comblition terined trommatir irideremia of aniridie; or the iri- may le folded hack on itself (Plate 34, b). All thes injuries of the iris mas be attended with hemorrlage into the anterior chamber and disloration of the len-.

\section{Tumors of the Iris and Ciliary Body.}

Cysts m-mally develop after perforating wounds of the anterior dhamber. Ther are generally benign, thomgh somewhat difficult to remove. "( )peration should not be delaved, because there is danger of glancoma amel romsesquenit losis of vision.

Sarcoma oecasionally ocemrs in the iris and riliars body. It is usmally pigmented, the rolor ranging firom eraly to dark-bown or black, amd very malignamt. A salromal sometimes develops finm small pigment-pots in the iris which lase lesen present a long time; the growth is at first rely sow. hut gradually a largere mass is formed (llate :30, 1), which, if loft to itsolt, hraks through the onter coat. Sareomal of the ciliarr boly may escape detortion a long time, mutil tinally it amereses on the periphare of the anterior ahambere. It the sareoma is limited to the iris and is verv-mall, it mav he exeosed ; but if the sal-

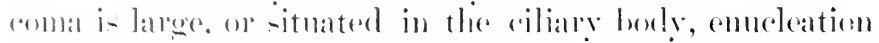

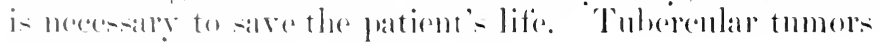

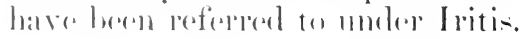

\section{DISEASES OF THE LENS.}

The orystalline lons, hoing a nom-vasenlalr structure, is mot subjeret to inflammation; at the most it may be in-

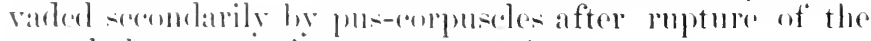
(a) 
Cataract is practically the only clisease, whether primary or secondary to other disease or injury of the eye, that oceurs in the lens.

The color of the opacity is gray or bluish-white by direct light, and black on a red backgrouml by transmitted light (Plates 32 and 33). As the opacity is often situated at the periphery of the lens, it is necessary to rilate the pupil to bring it clearly into view. If this is done and the eye is examined by lateral illumination, the position of the opacities is readily seen. Depending on the arrangement of the lens-fibers, an incipient cataract appears in the form of ralial lines, streaks, or wedgeshaped opacities (Plate :3:), b and c) rumning from the anterior or posterior cortical layer toward the anterior or posterior pole, and, if long cinongh, encroaching on the pupillary region. In adilition a number of punctate opacities are seattered here and there. The opacities are always in the fibers of the lens or in the epithelium covering the posterior surface of the anterior lens-capsule, never in the eapsule it-elf. When we speak of capsulut" cataract we mean opacities due to proliferation of the calpsular epithelium, which are found exclusively in the central portions of the anterior lens-surface, are sometimes bright yellow, sharply defined, and in sone calses projecting (Plate 34). This form ronsist of a dense acemunlation of epithelial cells, while the other varieties of cataract are due to degenerative changes, being produced by the lens-fibers between the nucleus and the cortex in the region of the equator separating and learing open spaces, which beeome filled with transparent granular matses. The fibers in the equatorial region swell up and become turbid, and eventually break down, forming a viscid maks containing fat-granules, droplets of myelin, cholesterinerystals, and débris. The distinet swelling which oceurs in the lens during the formation of a cataract would appear to indicate that the degenerative process is asiociated with an increased amount of fluid in the lenticular substance. The swelling can be recognized by the less- 


\section{Plate 32.}

a. Senile cataract, mature-i. e., the opacity has extended as far as the eapsule, and therefore the pupillary margin. The patient, a woman of i2 years, is otherwise in good health.

b. Traumatic Cataract.-The patient, a boy of 14 years, stepped into a large box with one foot and struck his left eye against the edge. The eye was probably injured by a nail or a sharp splinter, for we see in the lower portion of the cornea (a little to the masal side of the center) a freshly healed wound about $? \mathrm{~mm}$. long, appearing as a grarish streak, with a corresponding wound in the nasal half of the iris and in the anterior lens-capsule. The opacity has spread from the anterior cortex, where it surromes the wound in the capsule, to the posterior cortex, forming a delicate rosette, which is only seen by transmitted light. There is some ciliary injection. Visnal atuity, $\frac{6}{36}$. Two weeks later the opacity in the posterior cortex had diminished, while that in the anterior was more pronounced, and the lens began to swell. In the course of the next two weeks the entire lens became opaque. The unabsorbed portion of the catarate was then removed by repeated discission, and after a few months the risual acuity was found to be $\frac{6}{6}$, with a hypermetropia of $12 \mathrm{D}$.

ened depth of the anterior chamber from forward dislocation of the iris. The entrance of anueous humor into the lens from any cause, such as injury to the anterior capsule, is followed by swelling and turbidity of the lens, and what is known as trammatic cataract (Plite 32, $b$ ).

Subjective symptoms-that is to say, impairment of rision-are present only when the cataract affects the axis of the lens; a peripheral opacity may be present a Iong time withont being discovered." A rentral eatarict soon betray itself by the appearance of dark spots and strealis. " muncee," in the field of vision, and ly diplopia, which is particularly noticeable when the patient looks at at light. If the entire surfice of the lens beemes turbid, the visual deterionation i-, of conr-e, greater than it is when a few rays of light can still find their way through streak: of opacity. As the "atanant progreseses the vismal acuity decreases more and more, althongh in an otherwise healthr ere some degree of vision i- alway- preserved in simple cataract, conabling the patient to discern mosements of the hand at 20 to $: 30 \mathrm{~cm}$. and to locate a candle in the dark 

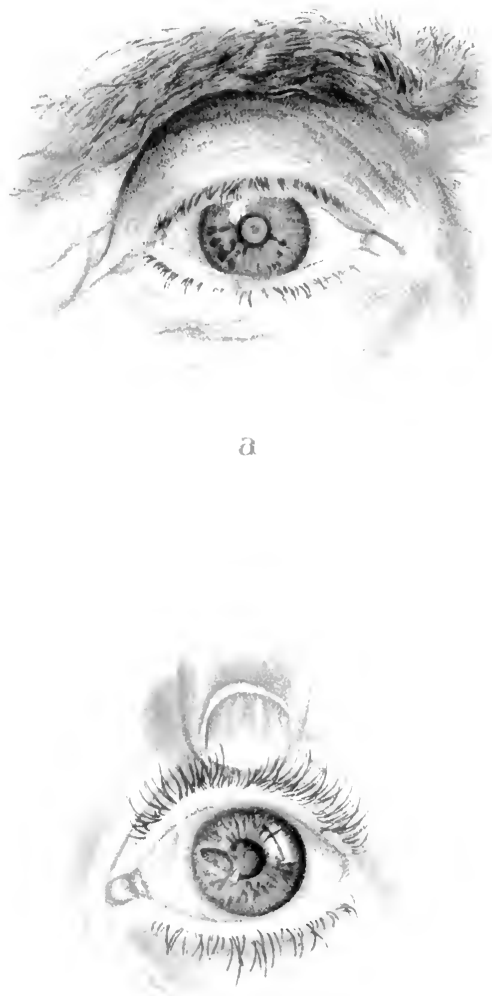

b 

correctly in any direction (see p. 43). The flame of a candle can always be seen in a dark room at a distance of 3 meters at least. If even this power is lost, we must assume the existence of morbid changes in the deeper coats of the eye, retinal detachments, atrophy of the optic nerve, diffuse choroiditis, etc. Sometimes the heginning of senile cataract ean be inferred from the derelopment of myopia or from the inerease in an already existing myopia, due to the fact that the swelling of the lens increases its rofractive power. The various forms of cataract are classified clinically as follows:

\section{(1. Partial Stationary Cataract.}

Under this head are incluted:

r. Anterior Polar Cataract._- s small white spot or prramidal mass is formed at the anterior pole of the lens, and sometimes drawn out to a point (Plate :3, a). It is a so-called capsular cataract-i.e., the opacity consists of proliferating capsular epithelium. It may be congenital, and is in that ease unally bilateral ; or it may be acquired. A central corneal illeer perforates, the aqueous humor escapes, and the lens is bronght against the site of the ulcer, exciting proliferation of the capsular epithelium. Hence a macnle is always seen in the center of the cornea in such cuses. The process just described occurs only in childhool, ustally after gonoriheal conjunctivitis. An anterior polar eatalact is always behind the lens-capsule, and cannot therefore be detached from the lens without opening the capsule and producing trammatic cataract. If the opacity is small, the visnal disturbance is slight, but increases in a strong light with the contraction of the pupil.

2. Posterior polar cataract forms an opacity on the posterior pole, and may be congenital (rarely), when it is eansed by remains of the fotal tunica rasculosa lentis and of the hyaloid artery; or aequired, after pigmentary degeneration of the retina, choroiditis, or degeneration of 


\section{Plate 33 .}

1. Zonular Cataract.-The patient is i years old, and has had lamellar cataract in hoth eses since infancy. His visual acuity. which was never quite normal, is now $\frac{1}{4}$ in the eye represented in the plate, the defect becoming more noticeable on his being sent to school. The leus was remosed, is the eyes are in other respeets normal.

b. The same eye by transwitted light. The pupil is dilated, showing fine, radiating lines surrounding the central opacity (an unusual condition).

c. Incipient senile cataract in transmitted light, showing the radiating streaks of opacity to the best advantage, after dilatation of the pupil. In other respect the ere is normal. The slight degree of ciliary congestion is cansed by a trifling abrasion of the corneal, not shown in the picture.

the vitreons. The last two disease- usmally produce -omewhat erreater opacity on the posterior cortex, and, with the exeeption of the congenital form, thi- posterior catarat show: a tendeney to progers.s. The opacity antsed by pigmentary degeneration, on the other hand, remains -taitionary for a long time. It can be detected only with the ophthalmoseope hy transmitted light, and is one of the sign of this retinal diseato.

3. Perinuclear, zonular, or lamellar cataract, is the most frequent form of catalaret in childhood, and is sllpposel to have something to do with rhachitis

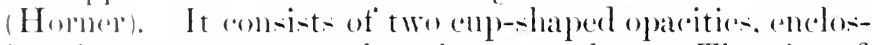
ing the tran-falment nuclens between them. The size of the morelen- and of the altalaet varies; the one shown in Plate :3:)." for example, is quite small. It is n-mally"

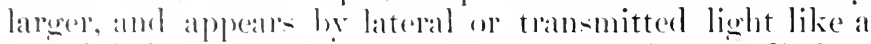
romel di-k. whinh by lateral illumination shows a distinct convexit? : and if the light (in lateral illumination) is thrown in the posterios half of the lests the posterior opacity is - times the malerin of a lamellall eatallatet is seen hy transmitted light to be arrered with small projections, eor-

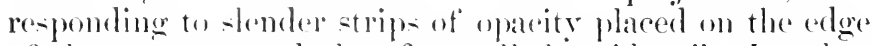
of the rataract, and therefore atled "rider.." In other 
Tab. 33:3

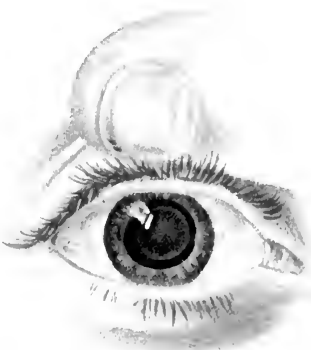

il

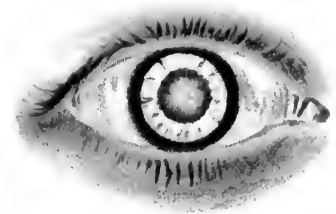

b)

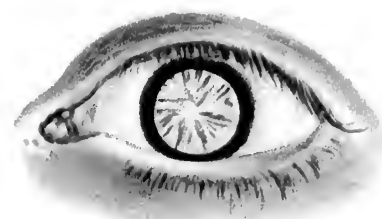



cases short streaks are seen nearer the periphery (Ilate 33,6 ). Occasionally we meet with a case in which the lamellar eataract remains rudimentary and the disks are represented by fine disseminated dots. The visual disturbance is, of course, eorrespondingly slight, while in severe cases it is extreme, esprecially when the pupil is contracted, not a ray of light being able to get past the cataract and reach the retina. Lamellar cataraet is usually bilateral and stationary, but later in life may become complete.

In the treatment of the first-named varieties of cataract operative interference is indicated only when the cataract is extensive; lameliar eataract, however, ustually requires operative removal soner or later. Simple iridectomy (at the lower, inner angle) may allow some light to enter past the cataract in mild ease-; but, as a rule, removal of the lens by discission is indicated.

\section{b. Progressive Cataracts.}

This group eomprises the more frequent forms of cataract, the most important of which is

I. Senile Cataract. - It begins as a spoke-like arrangement of lines, streaks, or wedges, radiating from the pole of the lens, incipient cotaract, goes on developing as returacta intumescens, and becomes romplete, cutroratu matura, when the opacity reaches the eapsule, so that the iris does not throw a shadow on the opacity by lateral illumination (Plate 32, a). The cataract is called "ripe" at this stage, becanse it is in the best condition for operative removal, the soft consistency of the cortex permitting its complete separation from the capsule. In a strong light the rellowish nucleus may be seen shining through the grayish cortical layers. The nucleus may be colorless. Senile eataract is caused by the phrsiologie sclerosis of the lens due to age, which is the canse of diminished areommorlation (see p. 53) and serves to protect the nuclens from cataractons ehange, as shown by the fact that it retains its 


\section{Plate 34.}

a. Anterior polar cataract, so-called pyramidal eataract. The bor, who is 15 years oll, did not have any purulent discharge at birth; but six months later he was seized with convulsions. The physician who was ealled at the time eliscorered a spot in the eye. Hereditary syphilis is suspected, as there were two premature births in the family and eight children died at ages ranging from eight to ten weeks. There are only three children living. No other signs of syphilis are to be found; the cornea is perfectly transparent and the fundus of both eyes normal. Visual acuity on both sides is only $\frac{1}{4}$, as the centrally situated opacity, of course, profluces marked disturbance, especially with contracted pupil. On both sides a small pointed eone is seen on a round, grayishwhite base $2.5 \mathrm{~mm}$. in diameter, projecting int o the anterior ehamber. The remaining portions of the lens are clear. In performing discission a circular section was male around the polar opacity and the latter extracted. Nieruscopie examination shows it to be a so-called capsular cataract, situated under the capsule. The operative removal of the lens was successful, and resulted in a visual acuity on both sides of $\frac{1}{2}$, with hrpermetropia of $1: 3 \mathrm{D}$.

b. Subconjunctival Displacement of the Lens.-Three months and a half ago the patient. a man of ji sears, struck his eye against the limb of a tree. The accident was immediately followed by marked reduction of visual acuity ; at present the patient is just able to comnt fingers at 21 meters. Courex glasses have no effect; the left ere is normal. The sear in the sclera, through which the lens escaped, is plainly seen on the temporal side of the cornea. The pupil is displaced ontward, having (evidently becon turned barkward by the force of the blow. Streaks of injected vitreous are seen running toward the seat of rupture. The posterior layers are so turbid with blood that the fundus is barely risible; but a rent in the choroid coat can be seen on the temporal side. The conjunctiva was divided and the lens, which had become adherent and annoyed the patient. removed without injury to the original rupture or escape of the vitreous. Complete cure in ten dass.

transparencr more or less perfectly within the turbid artex. Ifter the serenticth rear the sclerosis extends almost to the capsule, the rewal gray alor of the opacity is wanting, aml it may happen that the lens remains semitran-parent, with a daik reflex due to the absence of cortieal substance and the rollowi-h-brown discoloration of

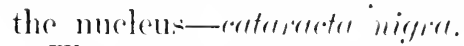

The stage of maturity is followed by that of "orerripeness," during which the rolume of the lens gradually 
Tab. 34

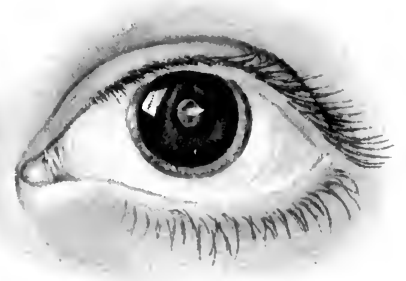

a

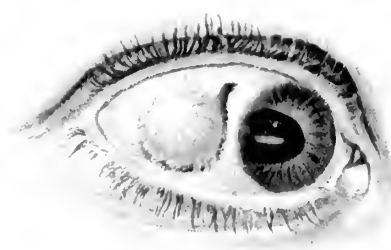

b) 

diminishes, the anterior chamber becomes abnormally deep, and an anterior capsular cataract not infrequently appears in the shape of small white dot. Shining cholesterin-crystals are seen suspended in the liquefied cataract. As the cataract continues to shrink, it beeomes tremulous, and, finally, the zonula may give way and produce luxation of the eataract.

2. Congenital cataract is much less frequent than the senile form ; it is usually bilateral and soft, as there is no nucleus. In very exceptional cares congenital total eataract is hard, for reasons that are not understood as yet.

3. Traumatic Cataract. - This is nearly always progressive. Any laceration of the lens-capsule, which admits the arucous hmmor or vitreous body to the substance of the lens, is followed by eataract. The injury may be direct, caused by some perforating instrument (knife, scissors, foreign bodly, etc.) ; or indirect, from contusion of the entire globe, the capsule probably becoming ruptured at the equator. In rare instances cataract may be produced by mere concusion of the lens without solution of eontinuity in the capsular structures. In large wounds of the anterior capsule the greater part of the lens may become turbid within twenty-forr hours; in smaller woinds the cataract develops more gradually. A grayish or bluish-white discoloration at first appears about the injured spot (Plate 32, b) ; the lens-substanee swells and projects into the anterior chamber in the form of a cone. Particles of the lens-substanee separate and sink to the bottom. In small wounds the swelling is incomsiderable, and absorption of the cataract in the anterior chamber, which is nomally quite rapid in young people, takes place more slowly in consequence. If the communication between the aqueons humor and the lens is maintained, swelling and alworption continue until all of the lens-substance except the capsule is removed. A small rent in the capsule may be enlarged by the swelling of the eataract; $\mathrm{or}$, if it is very small, it may be closed, either by the proliferation of capsular epithelium or by adhesion of the iris. 
Such minute lacerations often produce a delicate rosettelike opacity (seen by transmitted light) in the posterior cortex of the lens, and the cataract mar remain stationary for a time, or eren diminish; but, as a rule, it becomes progressive and goes on to total ipacity.

secondary glaucome is an important eomplication of traumatic catarat. As som as the swelling of the lens beeomes excessive there is danger of glaturoma, esperially in old people. The increase in tension is at once indicated by clondiness of the cornea, and, muless the pressure is relieved by paracentesis connese and evacuation of the cataractons mass, vision is gradually destroved.

Cataract is sometimes attended with inflammation, the anterior chamber hecoming contaminated at the time of the injury and setting up an iritis or iridoerclitis. Adhesions are formed between the lens and the iris or ciliary body, giving rise to cataracte acereta, which does not lend itself readily to operation.

4. Complicated cataract ocours in conseyuence of other diseases of the ere, such as acnte iritis and iridocrelitis, especially the purulent forms (creeping ulcer); chronic iridochoroditis with opacities in the vitreons, separation and pigmentary degeneration of the retina, and the end-stage of glancoma. Persons with a high degree of myopia show a certain tencleney to eataract, especially in advanced life. Complieated cataract is reeognized liy its abnormal, dirtr-vellow or, if ealcifieation has taken place, chalky color, hy atherence of the iris. by thickening of the rapsile, tremulomess, ete., and epecially ly the loss of function. In normal cataract, as has been stated (see p. 57), the power of locating a candle in the dark is alwars retained.

In addition to the causes of cataract which have heen mentioned (senility, trammatiom, cte.), we reoognize diabetes and albuminuria and hereditary disposition.

In the diagnosis the following point are to be borne in mind: Incipient ataract must never be diagnosed until the eye has been examined by transmitted light. 
The sclerosis ineident to oll age often produces an intense gray reflex in the pupil, which may be mistaken for a cataractons lens. By transmitted light, howerer, the pupil exhibits a beantiful red reflex, and the streaks of opacity which characterize incipient catalact are absent (Plate 33, (c). In traumatic cataract, if the lens becomes opaque rapidly, a bright metallic reflex is sometimes seen in the posterior lavers by lateral illumination; and must not be mistaken for a foreign hody. The latter appears black by transmitted light, which is not the case with the reflex referred to.

The treatment of all forms of cataract, except the complicated, is essentially surgical. Partial juvenile cataracts are treated by discission, and the semifluid mass is cracuated through an incision in the cornea. ('omplete soft eataracts ean alio be removed by means of a short incision through the cornea and capsile. To remove a senile nuclear cataract a semicircular incision must be made concentric with the corncal margin and involving more than one-third of the circumference. If, after the delivery of the cataract thromgh the pupil and corneal wound, it is found diffieult to replace the iris, a small scetion must be removed by means of iridectony. It is sometimes advisable in slowly ripening cataracts to operate before the stage of maturity has been reached. In such eases iridectomy is performed hefore the cataract is delivered, in order to make more room for the egress of the lens-substance and prevent an increase in tension from swelling of the cortical remains.

In trammatic cataract the intraocular tension must be carefully watehed and a part of the lens-substance removed by paracentesis of the cornea, if the presure rises. If the swelling is great, the pupil must be well dilated to allow the cataractou: mas free access to the anterior chamber.

\section{Dislocation of the Lens.}

This is due to anomalies in the zonula. Owing to congenital unequal development, decentration of the lens to- 
ward the shorter zonula take- place: Eretopialentiscongenita. If the upper zonula is shorter than the lower, the lens is displaced upward and the dislocation inereases as the lower zonula gradually atrophies and disappears. Snch a disheation upwarl results in diminution of the upper angle of the anterior chamber and tremulousness of the iri-s, which loses the support of the lens. The same phenomena are observed after rupture of the zonula by a blow on the ere, a not infiequent accident. The lens may suffer only partial dislocation to one side, so that the margin is seen as a sharp cireular line within the pupil (subluretio lentis), or it may be thrown into the vitreous boly (luretio lentix). In the latter case the normal gray color of the pupillarr reflex is changed to black, the entire iris is tremuloms, and the lens is seen, br lateral illumination or with the ophthalmosene, as a spherical body freely movable within the vitreous. In farorable cases it beeomes fixed after a time by adhesions, cataract develops, and the lens contracts; usially, howerer, a movable lens gives rise to glancome, probably by irritating the eiliary procesces which secrete the aqueous humor. Even subluxation may have this effect.

I partial diskoation, whether eongenital or trammatic, is very apt to become complete. Complete luxation may be anterior (although rarely), and a shrunken and turbid, or a semitransparent, lens is sometimes fomd in the anterior chamber. If the lens is transparent, the yellowish luster of its margin gives the impression of a large drop of oil in the anterior chamber. In violent contusions with rupture of the selera the lens is sometimes bolily reverel form the eye, and the sme acedent may occur in ferforation of the cornea hy extensive uleerations if the patient strains during the examination.

spontanens luxation into the vitreous chamber is ansed by atrophy of the zomula in eonseguence of liquefartion of the ritrous humm oceurring in severe my topia, antorior choroiditis, or retinal separation. Itrophy of the zonula sonetime- aceurs through the shrinking of an 
over-ripe cataract, and luxation may be induced by the slightest shock, a blow, or the momentary congestion caused by bending over or sneezing.

The greater the dislocation of the lens, the greater the risual disturbance. Subluxation gives rise to myopia and astigmatism, and, later, to more marked disturbances from obscuration of the lens. Complete dislocation of the lens from the pupillary area has the same effect on vision as absence of the lens, or "phatian, and causes a reduction in the refractive power, which in emmetropic eyes amounts to $10 \mathrm{D}$. If the lens beromes fixerl in the vitreous body and causes no further disturbance, the patient ean see quite well with cataract-glasses. Such cases are, however, exceptional. Usually the eondition is very painful and gradually leads to glanconia and total blindness.

The prognosis in dislocation of the lens is very grave. The eye is always in great danger and in many cases its loss is unaroidable.

Treatment.- In a rery few cass the aphakia may be corrected by the use of suitalle convex glasses. In partial dislocations, especially in roung persons, the lens should be removed by discission; in fresh luxations into the vitreous chamber an attempt mar be made to induce fixation by rest in bed, any intercurrent rise in tension to be met by the instillation of myotics (physostigmin, pilocarpin), or the glancoma may be checked by repeated sclerotomy. Extraction of the lens is nsually attended with a diangarous eseape of vitreous humor. Glancoma not infrequently necessitates removal of the globe.

\section{DISEASES OF THE VITREOUS BODY.}

Disease of the vitreous, in the large majority of eases, is seeondary to inflammation of the ciliary body, ehoroid, and retina, and manifests itself in turbility, ilue to the entrance of inflammatory material, and in ilegeneration, 


\section{Plate 35 .}

a. Suppuration in the Vitreous, Caused by a Piece of Iron.-B. H., aged 9 years, while digging with a small hoe on April 1\%, 1-97, suddenly felt something entex her left eye. On April :o she was admitted to the elinic, the eye having meanwhil. become inflamed and vision impared. 'The cornea was covered with a diffuse haze, and by lateral illumination a fine gray sear, about $1.5 \mathrm{~mm}$. in length, wasten in the inner upper quadrant where the substance had entered the eye. There was a broad adhesion between the lens and the iris. Hypopon of $: 2 \mathrm{~mm}$. in the anterior chamber: large exndate in the pupil, making it difficult to determine the condition of the lens. It was found imposible to extract the piece of iron with the large electromagnet. Six days later (when the picture was taken) the edema and redness of the conjunctira had subsided, the anterior chamber was clear, and the pupillary exudate had shrunk to a mere shred. The lens was not distinctly cataractous. but displayed a greenish-sellow reflex, indicating suppuration in the vitreous. Visual acuity reduced to light-perception at $20 \mathrm{~cm}$. On May 12 enucleation was performed. The piece of iron was found embedded in the nasal portion of the vitreous. surromided hy pus. Normal recovery.

\section{b. Panophthalmitis from the Entrance of a Piece of Iron into the} Vitreous.-B. II, a peasant-woman, 41 years old, got something in her right eye while hoeing potatoes. At first she felt only a sensation of grittiness: hut vision at once became dim, and during the night she had violent pains in the eye and on the right side of the brow. The next day the lids were swollen and somewhat inflamed. the eyeball protruding and less movable than normal, and moderate chemosis developed. No dacryostenosis or conjunctivitis. Cornea uniformly opaque, with a sharp linear wound. $1.5 \mathrm{~mm}$. in length, in the onter upper quadrant. The iris was harely visible. Small hypopsom and exudate in the pupil. No reflex could be observed. When the eye was bromght near the large electromagnet, the piece of iron at once emerged through the opening. The panophthalmitis, bowever, continurd and the condition seen in the picture developed: Iarked exoplnthalmos, colema of the eonjunetiva (chemosis), and grayish-green discoloration of the eornea. A shred of necrotic tissue adheres to the wound, evidently a portion of vitrous which has undergone liquefactionnecrosis and escaped through the wound, as it is fonnd impossible to wipe it off. Enucleation was performed twelve dass after the aceident, complete panophtlahnitis having develoged. The globe was filled with a yellowish-brown lardaceons mass, from which three colomies of streptococei and one colomy of multiartienlar. vacuolated barilli, resembling the "Wurzell bacillus," were olstained. The wound healed without further complications. 


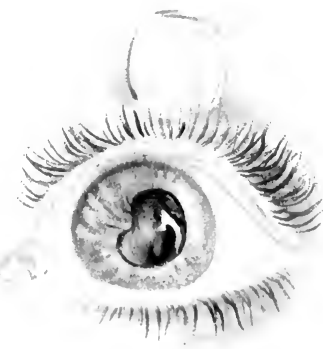

a

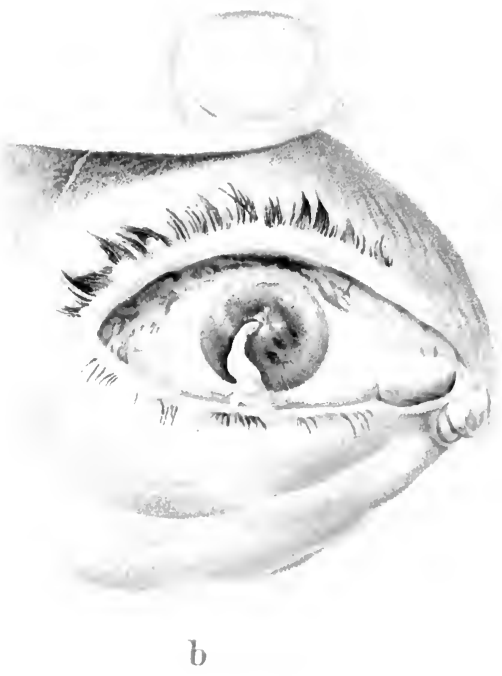

Lilth. Anst F' Reuchfiald, München 

leading to liquefaction or to the formation of fibrillar, flake-like opacities. As the vitreons posserses a feebler regenerative power than any other tissne in the borly, the slightest escape of vitreous humor through a tramatic operative wound, or any interference with its structure by the introduction of instruments, is likely to produce opacity and separation of the retina.

The suppuration caused by the entrance of a foreign body deserves special mention. What has been said in this connection about injuries of the sclera may be supplemented by the following: A foreign body which penetrates as far as the vitreons and retina is more likely to enter through the cornea than through the selera; it may pass through the iris and the lens (Plate 36, b), or throngh the lens only, and sink to the bottom or continue its flight to the retina, depending upon the amount of momentum it has acquired. Having reached the retina the intruder either buries itself in its tis-nes or reeoils and lodges somewhere in the lower anterior part of the vitreons, where it cannot well be detected even with the ophthalmoscope, so that its presence has to be inferred from the lesion in the retina.

If traumatic cataract develops, detection is even more difficult, although its probable course can be approximately determined by the position of the wound in the cornea, iris, and lens. [The Röntgen rays may always be utilized to locate foreign bodies within the eveball._ED.] If the wound remains aseptic, the piee of iron can nisully be extracted by means of the large electromagnet (see p. 175), which may also be ntilized to determine the nature of the foreign borly. Unfortunately, however, such particles of iron usually set up a violent suppurative inflammation, which results either in suppuration of the vitreons (Plate 35, a) or in panophthalmitis (Plate 35, b). This is particularly the case when the particle of iron is derived from a hoe or similar digging tool. Panophthalmitis may declare itself within forty-eight hours. The infection is probably carried by the substance itself, since 
a piece of a hoe, which is eontaminated with dirt, is more likely to produce a severe purulent inflammation than a spicule of forged iron, a glass splinter, grain of powrler, or other forcign bodr. It may be that in some ases infection oecurs secondiarily through the wound.

Ocasionally the entrance of a foreign bodr into the vitroons chanber gives rise to an incieliens attack of iridocrelitis, which is no less dangerous to the life of the (xe than an acute, purulent inflammation. Enueleation is n-ually necesiry to save the other cre, for srmpathetic ophthalmitis is particularly apt to develop in such cases. Even if no inflammatory process of any kind develops after the entrance of a sionle of iron, the evesight may eventually be destrored by sideroxis-i. c., gradual ehemical solution of the iron which is deposited on the retina. In a few rare instances the presence of iron-particles has been tolerated without detriment to the ere. Aseptic particles of copper are at first tolerated, but eventually injure the retina; although, if they become eneapsuled in the anterior portion of the vitreous, a serviceable degree of rismal acuity may be retained for some time.

Enucluation is indicated in most cases of suppuration in the vitreous and of panophthalmitis. The latter is recognized hy edema of the lidis, the eonjunetiva, Tenon's space, and the aljacent orbital tissue, which produces exophthalmos. The inflammatory elema in the orbit is caused by the toxins elaborated by the progenie microörganisms in the interior of the hulb, and not by the microbes themsclves, since ther camot well penetrate beyond the hulb. For this reason enueleation mar he performed during the hright of the panophthalmitis without tanger of the inflammation sprealing downwel and to the brain, providine the eroball does not become infected during the operation by soiled fingersor instruments.

In these eases of injury to the eye by a particle of iron, slstained while the patient is hoeing in the fields or doing any work in which iron is male to strike iron, as in entting with a chisel, for example, the surgeon should not allow 
himself to be influenced by the statement that the substance merely hit the eye without entering. It is quite common to be told by the patient that he salw a stone as loig as his fist strike lim on the eye and Hy off, and then to find a piece of iron in the depths of the evelall. The illusion may be explained by the fact that the patient sees the foreign body entoptrically magnified during its passage through the vitreous, and projects its Hight outward. In all such eases, therefore, it is of the utmost importance to make a thorough scareh for particles of iron, and to remove the intruder as quickly as posible. By prompt removal the eye may be saved even when the partiele of irom is from a hoe ; but every minute of delay makes the prognosis more doubtful. "The best method to pursue is the one described on p. 175 .

\section{GLAUCOMA.}

Inereased intraocular tension, increased hardness of the eyeball, or glaneoma, is one of the most important diseases of the eve, and every practising physician should be perfectly familiar with its symptoms, as the integrity of the affeeted eye depends on prompt application of the proper treatment

There are two varieties: primery and secondery glencomat.

\section{Primary Glaucoma.}

Primary glancoma is spontaneous, usually bilateral, and may be acute or chronic, with a varying increase of intraocular tension. In the acute form we have all the external signs of inflammation: Redness, pain, elema of the conjunctiva and iris; in the chronic form these are ahsont most or all of the time. Primary glancoma is therefore subdivided into infammatory and non-inflammatory or simple glauroma, although the latter may at any time change to the inflammatory form. 
a. Inflammatory Glaucoma.-We subdivide this again into acute and chronic inflanmatory glancoma, bearing in mind that the acute form often changes to the chronie.

Inflammatory glancoma is usually preceded by prodromata, such as healache, dragging and pain in the temple, and oecipital neuralgia ; the visual acuity is variable, and the patient complains of a haziness before his eves, as if he were surrounded by smoke or fog. If he looks at a light during one of these prodromal attacks, it appears to him surrounded by an iridescent halo, the canse of which is found, on examination, to be a slight haziness of the corneal surface. The cloudiness is most pronounced in the rentral portion, which resembles the appearance of glass the surface of whieh has been breathed upon. There is also some shallowing of the anterior chamberi. $c$, the iris and lens are displaced forward; the pupil is somewhat dilated and reacts slowly to light. Sometimes there is ciliary congestion. A prodromal attack of this kind may last several hours, the eye becoming quite normal again afterward. The intervals between the attacks become progressively shorter. They may be induced in varions wass, by emotional excitement of any kind, pleasurable or painful, by a hearty meal, by bending over, ete.; or they may oceur without any demonstrable canse. The prodromal stage may be protracted for weeks, months, or even years; but in the last case permanent alterations result-congestion of the anterior eiliary ressels, excavation of the nerve-head, and impaired vision.

An outbreak of fully developed glaneoma (glancoma crolutume is charaterized by the following symptons: Violent pain in the ere and headarhe, whicli soon become unbearable and rob the sufferer of sleep and appetite, aceompanied by intence congestion of the eveball. Edema of the lids occurs, and in severe cases of the bulbar conjunctiva. There is rapid lose of vision, which is almost absolute in the affected eve. If the attack is a serere one, 
the patient romits as long as it lasts and usually takes to his bed, with every appearance of severe illness. The characteristic objective signs are diffuse haziness of the cornea ; shallowing of the anterior chamber ; alteration in the shape of the pupil, which is dilaterl and may be irregular, oval with its long axis vertieal or ol)liquely placed, or deeentered; reaction to light imperfeet or absent. I greenish reflex is seen in the depths of the pupil (Plate 36, 1), from which the name of the discalse is taken (green eataract), although there is nothing charaeteristie alout it, inee it is observed in most elderly people when the pupil is dilated. Its presence in glancoma beeomes apparent on aceount of the dilatation ineident to the diseatse, and is due chiefly to sclerosis of the lens, complicated in some eases with a slight turbidity of the vitreous. Upon inspection with the ophthalmosope the eye-ground is seen imperfeetly or not at all, owing to the opacity of the comea and the turbidity of the vitreons referred to. Upon palpation the tension of the eveball is found to be increated.

If treatment is delaved, an attaek of this kind may last for days and weeks, and subside very gradually, leaving the risual aenity permanently impaired and followed by chronic congestion of the anterior eiliary reins, dilatation of the pupil, immobility and atrophy of the iris, and reduction in the depth of the anterior ehamber (Plate 36, "1). In many cases the visnal field shows marked restrietion on the nasil sille. The optic nerve is more or less exeavated and discolored from atrophy, particularly in the temporal laalf.

Hemorrhagic glaneoma, a most malignant form of the disease, gives rise to hemorrhages in the retina, which are detected with the ophthalmoserpe, and sometimes into the anterior chamber and into the vitreous.

When the glaueomatons habit is once cstablished, the attacks oceur again and again in slightly deereasing severity. Each snceessive attack inereases the deterioration of vision and damage to the optie nerve, until finally perma- 


\section{Plate 36.}

a. Acute Glaucoma.-E. B., a woman of 71 years, underwent an oleration for cataract in the left exe seven years ago (without iridectomy). and since that time enjoyed perfectly good vision, the posterior eapsule having been removed by discission shortly after the operation. The pupil was round and movable. Tro days ago she was suddenly seized with pain in the exe and dimness of vision, without apparent eause. Her condition improved at first after the administration of myotics, and visual acuity returned to $\stackrel{3}{2}$. Another acute attack occured in the elinic, with tension of $T$. $:$, redness of the ere, and dilatation of the pupil see illustration), which was displaced slightly upward, as frequently happens in glaucoma. The surface of the eycluall was cloudy, and a grayish-green reflex was observed in the deep portions of the eye. Sclerotomy and thorough discission were performed, and by continued use of physostigmin and pilocarpin the patient was finally cured, with a visual acuity of $\frac{1}{3}$.

\section{b. Spicule of Iron in the Vitreous (Extracted); Laceration of the Iris,} Traumatic Cataract, and Turbidity of the Vitreous. - V. Sch.. a peasant woman, 60 years old, got a piece of iron in her left eye while hoeing potatoes on June 14. 1-97. The next day she went to a doctor, who pronounced the wound superficial and of no consequence. The patient did not feel pain at any time. but complained of a thick haziness immediately after the injury. When she was admitted to my private hospital, on the 17th, the ere was inflaned and the channel of the wound plainly seen (see figure). The wound consisted of a rent in the comea (where the foreign body had entered), a little below the enter, appearing as a fine, gray line $1.5 \mathrm{~mm}$. in length: a laceration in the iris, trammatic cataract. and a triangular wound in the pusterior eapsule. The iris was adherent to the wound in the anterior capsule. The pupillary reflex was greenish, and by lateral illumination a metallic luster was seen in the opacity of the posterior cortex. The foreign body was not visible, although undoubtedly present in the vitreons. On approaching the large electromagnet it was at once drawn into the anterior chamber, from which it was remored though the original point of entrance (.Jume 1\%). On the :ith the inflammation had practically disappeared, and on the gith the woman was discharged. All inflammatory symptoms had subsided and the patient was able to comnt fingers at 2 meters. On July 9 the risnal acuity was still the same and the eataract had not progressed; the fundus also was plainly visible.

nent, alsolute blinduess supervenes and the eye presents

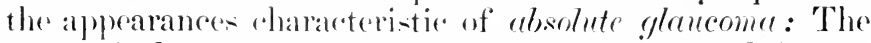
colnea is less opangue than in the carly stages, and is surrounded by a wrath of dilated blood-vessels; the anterior 
Tab. 3(i.

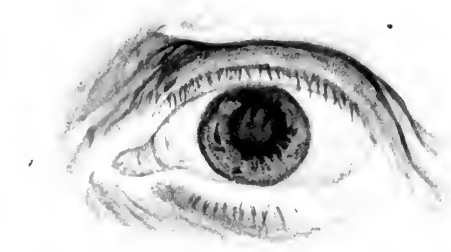

i)

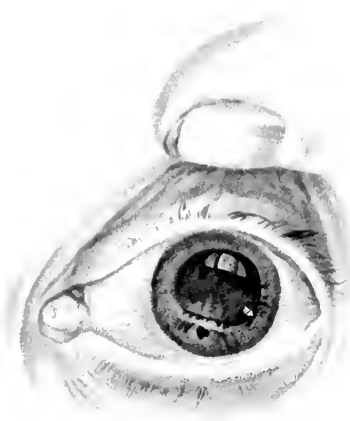

b 

chamber is excessively shallow; the iris reduced to a narrow ribbon or completely obliterated in places (Plate 40). The pupil is widely dilated and immovable, and shows a greenish reflex shining through. The papilla of the optic nerve is deeply excavated in its entire cireumference and the eyeball is ats hard as stone. From time to time the eye is quite painful, and eventually degenerates, while the cornea becomes permanently obsecured and covered with glassy deposits and hypertrophied folds. The sclera may exhibit ectasia about the eornea or in the equatorial region. The lens beeomes eataractous.

The course of ehronie inflammatory glaucoma is slower than that of the acute variety, which sometimes takes the form of fielminating glancome and utterly destroys the eyesight in a few hours.

\section{b. Non-inflammatory or Simple Glaucoma.-} In this treacherous form of glaucoma the risual deterioration impereeptibly goes on to complete blindness withont the patient's being aware of distinct attacks or of pain and inflammation. The examining surgeon often finds one eye irremediably injured or absolutely blind, and the other more or less amblyopic; rise in tension is barely pereeptible or even alsent; but the optic nerve is found to be excavated. By testing the tension repeatedly at varions times of the day, however, especially early in the morning, the cardinal symptom ean usually be obtained, and on eareful inquiry the patient admits that he has had slight pain and dimness of vision. The loss of vision usually begins at the circumference of the field of vision, the restriction being most noticeable at first on the nasal side. Central vision is also affeeted to a corresponding extent, although it is relatively better up to a certain period in the disease. The disease always affects both eyes, and may be protracted for years, eventually pas-ing into the inflammatory or the hemorrhagic form. "In cone cases of simple glaucoma the degeneration of the optic nerve is probably hastened by the abnormal loss of rigidity of the lamina cribrosa. 
(renerally speaking, glaneoma is a disease of arlvanced life. Inflammatory glaucoma is rare before the fiftieth rear ; simple glaucoma sometimes oceurs before that age. ()casionally the process is met with in children.

Infantile Glaucoma.- The changes produced by glancomia in the growing eye inclute abnormal enlargement, which is never observed in the adult (if we except the ectasize which occur in the degenerative stage), no matter how long the rise in tension continues. Buphthatmos or hydiophthatmos develops if the process is not arrested. The first srmptom observed is the characteristic clondiness of the surface of the cornea, followed shortly by diffuse opacity of the entire membrane, which becomes enlarged and covered with spots. Upon careful examination a peculiar network of ribbon-like streaks is seen in the repth of the corneal tissue. This phenomenon persists after the tension has returned to the normal, and furnishes, in the writer's opinion, an important. albeit somewhat tardy, support to the diagnosis. The dilatation of the pupil and shallowing of the anterior chamber are less marked than in the adult form, and, if the cornea has become enlarged, the anterior chamber will apprar abnormally deep. Excaration of the optic nerve is not sow to develop in most cases. The disease usually affects both eyes. The children exhibit photophobia and usually appear to feel some pain, so that considerable difficulty is experienced in making an examination. $I$ s it is quite imposible to make a satisfactory test of the ten-ion if the infunt struggles and cries, anesthesia is nsually employed for the entire examination, inchuling inspection with the ophthalmoseope. In rare instances the disease tends to spontaneons cure; but, as a rule, it goes on to complete destruction if not checked by the proper treatment. Sooner or later the child strike against some object in his surroundings, and the weakenod membranes burst and shrivel up.

Glaucoma orenrs shortly after birth or during the first few years of life. It is inknown in later childhood. 
It may be stated, in general, that myopie eyes almont never beeome affected with inflammatory glancoma, but mar be attacked by the simple form. Arterial selerosis and cardiac weakness are predisposing canses. The mechanism of glancoma is not well understoed. The rise in tension is thought to be caused by increased secretion of fluid within the eve (ron Gracfe's serous choroiditi-) and by obstruetion to the normal outflow from changes in the ere (obstruction to the ontflow in the anterior chamber in the form of circular adhesions between the periphery of the iris and the cornea, Knies and Webor theory).

IDiatation of the pupil with atropin is poritively known to bring on glancoma if the eye is predisposed to the discase or has alrearly suffered an attack.

Diagnosis. - Inflammatory glaucoma is rery apt to be confounderl with iritis; and the differential diagnosis is of the highest importance, as the two conditions demand radically different treatment. It should be made a rule of practice never to use atropin until the tension has been aceurately determined. In iritis the pupil is contracted; in inflammatory glaucoma, dilated. The recognition of simple glancoma depends on an ophthalmoscopic examination. A fatal error is to mistake infantile glancoma for parenchymatoms keratitis; the two conditions are very similar in their external appearances during the initial stage. The distinction is made by observing the tension.

The prognosis is always grave. Simple glancoma is more difficult to eure than the inflammatory variety; but the hemorrhagie form is the most hopeless of all. The more precarions the eondition of the heart and bloodressels, the more dubious will be the prognosis in a given case of glaucoma.

The treatment consists in the local use of myotics, physostigmin or pilocarpin, and in most cases surgical operation. Medicinal treatment must be begun at once : 3 to 5 drops of a $\frac{1}{2}$ per cent. solution of physostigmin (eserin), or 5 to 10 drops of a 2 per cent. solution of pilocarpin, 


\section{Plate 37.}

Sarcoma of the choroid, which has ruptured anteriorly. The patient, who is 53 years old, says he received a severe blow on the left eye eleven years ago, by rumning against a beam, and that since then vision gradually deteriorated and the eye sometimes gave him pain. About six months ago the eye began to increase in size. A large conital tumor projects through the palpebral fissure, and is seen to be covered with a number of smaller nodules (hidden in part moder the upper lid). A small, bluish seguent of the cornea is seen below. The growth is impervious to sunlight even when a lens is used. In places it feels hard to the touch. No pulsation in the tumor. No glandular swelling on the left side of the head. The whole contents of the orbit were inmediately extirpated and the diagnosis of sareoma confirmed by examination of the specimen (moderately pigmented spindle-cell sareoma) and by the subsequent course, for the man died a year later of a large sarcoma involving the left half of the pelvis and the inguinal glands on both sides, and of a sareorua in the right deltoid musele. The tumor did not recur in situ.

instilled into the eve every day. Pilocarpin is the milder of the two, and is well adipted for long-continned nse and after an operation. This is supplemented by subeutancoms injections of morphin, which has the domble advantage of inducing sleep and assisting in the production of myosis. Atropin is to be strictly aroided in glatucoma.

The success of an operation for glaueoma depends altogether on its being performed early in the disease. Iridectomy is the best operation in inflammatory, and sclerotomy in simple, glancoma in an advanced stage. In the early stages of simple glaucoma iridectomy may also be employed. It is often adrisable to combine the two operations, and many alses require repeated sclerotomies at varying intervals, the myosis meanwhile being steadily maintained. The comses of the discase is in most cases marked hy frequent relapses, which readily yicled to proper tratment. But in no aise shombl a pationt be left to himself withont oh-ervation after the performance of an iridectomy. In hemorlhagic glancoma, not iridectomy, but scleprome is indiraterl, enmbined with aetire mosis amd areliac stimulant-. Infintile glancomal can be eured by repeated sclemomy, if begun early enomeh. 
Tab. 37
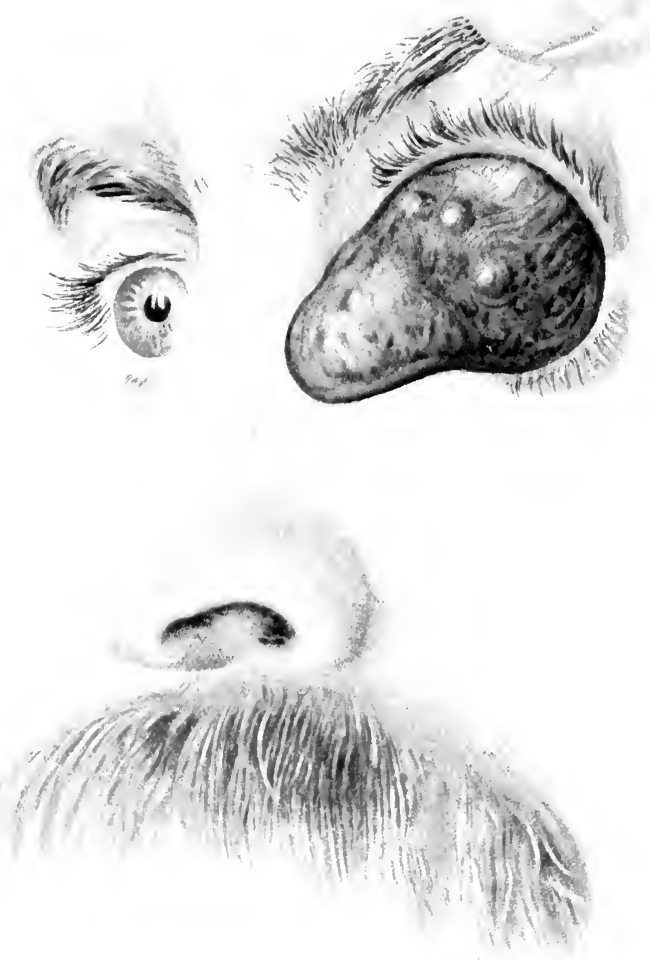



\section{Secondary Glaucoma.}

This form of glaueoma may oceur at any age and as a complication of various diseases. It manifests itsolf by cloudiness of the cornea, dilatation of the pupil (unless there are annular adhesions), and pain. Like the primary form, it may lead to loss of vision through excavation of the nerve-head.

Secondary glaucoma is induced by the following conditions :

1. Any condition tending to draw or push the iris forward; anterior synechie with corneal wounds, espectally. such as bulge forward, or pressure by swelling or subluxition of the lens.

2. Posterior displacement of the iris by a lens which has entered the anterior chamber.

2. Pupillary oeclusion.

4. Iriclocyclitis with preeipitates on the posterior strface of the cornea.

5. Mechanical irritation of the ciliary body by a lens in luxation or subluxation.

6. Intraocular tumors, sarcoma and glioma in the sacond stage (before rupture ontward has oecurred).

The treatment of seeondary glaneoma is chicfly directed to the relief of the condition which produced the rise in tension. Anterior synechia must bo separated or the attached portion of the iris exeised (iridectomy). A dislocated lens in the anterior chamber is to be removed. Ocelnsion of the pupil demands an iridectomy to restore communication between the anterior and fosterior chambers. In iritis combined with increased tension sclerotomy is indicated and often suffices to restore the normal pressure.

\section{DISEASES OF THE ORBIT.}

\section{Inflammations.}

Inflammation may originate in the periostem of the orbit, or it may attack the eontents of the orbit primarily. 


\section{Plate 38.}

$a$ and $b$. Glioma of the Retina.-The infant was quite well up to the sixth month of its existence, at which time she began to squint with the left eye. When she was one sear old her mother noticed a yellowish reflex in the pupil, which appeared more and more distinct as the pupil dilated. A few weeks ago (the child is now twenty months old) the right eye began to show signs of failing vision. The left eye was some what inflamed, hard ( $T+1$ ), and larger than the right. The left iris brown, the right blue. Left pupil dilated and rigid, transmitting a bright reflex (see Fig. a) corresponding to several nodules which appeared to occupy the greater portion of the vitreous. The surface of the tumor streaked with red, partly blood-ressels and partly, no doubt, hemorrhages. In the right eye, in which tension was normal, the pupil was dilated and there was a complete, funnel-shaped retinal separation; the eye appeared to be nearly blind. Enucleation of both eyeballs was proposed and refused; but the child was brought back one year later to have the operations performed. At this time there was marked protrusion of the left eye; the cornea was increased to twice its nornal size and was opaque; two days after admission it ruptured and large masses of the tumor protruded through the opening (Fig. $b$ ). Four days after admission, enueleation on the right side and extirpation of the contents of the orbit on the left were performed. On acconnt of severe lemorrhage, however, it was impossible to sterilize the orbit thoroughly in the region of the optic foramen; on the next day ferer set in, and on the day following, scurlet ferer. Death two weeks after the oferation, from purulent meningitis.

Periostitis of the orbit is quite frequently met with. It: usual seat is the margin, where it protuces thickening and temlerness on pressure. The thickened masses of bone are not movable. (Often there is edematous swelling of the lids. An inflammation situated in the posterior portion of the orbit is less easily recognized and often very difficult to distinguish from orbital cellulitis. It manifests itsolf by protrusion, with more or less pain, and lessened mobility of the eveball (Plate 39). Sometimes the nature of the process is not recognized until a deep-seated periostitis leads to suppuration and the abscess ruptures anteriorly, when the romghnes of the bone is felt with the probe. The suppurative process may spread to the cranium and cause meningitis or eerebral absecss. This complication is particularly apt to follow periostitis of the 

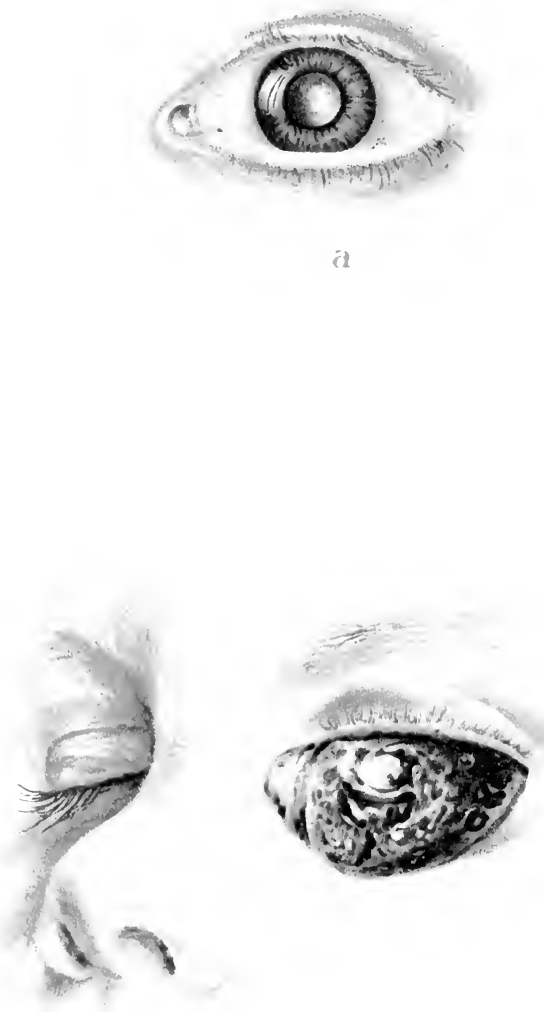

roof of the orbit. A periostitic abseess at the orbital margin produces marked swolling and redness of the superjacent area, and ruptures externally. A fistula is often formed, through which the roughened bone an be felt with a sound; after discharging pus for some time the fistula becomes closed by the characteristically contracted adherent scar seen in bone-suppuration. There is usually a defect at the corresponding point on the bone, caused hy the caries. Eetropion of the upper or lower lid sometimes develops from adhesion with the fistula.

(O)hital periostitis develops after injuries and in the conrse of tuberenlosis, the immediate cause of the process being usually trammatic, hence the upper outer and lower inner margins of the orbit are most liable to be attacked by tuberculons earies. Children commonly suffer from this form, which is comparatively frequent; while in adult syphilis is more likely to be the causal factor. In the tertiary stage the bones become thickened from periostitis; suppuration is less common.

The treatment of suppurative forms of inflammation hats for its first object to provide evacuation of the pus through the skin. This is best accomplished by making an incision 2 to $3 \mathrm{~cm}$. long throngh the periosteim to the bony margin, at the point of greatest swelling. The periosterm is then separated from the bone by means of a curct and the wound extended between the periosteum and the bone, so as to afford a good view of the injury. A drainage-tube or strip of iodoform-gauze is then introduced into the wound to allow the pus to discharge frecly. Caries of the orbital margin requires general supporting treatment and, if necessary, removal of the necrotic bone with a sharp curet.

Syphilitic periostitis can usually be made to disappear by a vigorous course of blue ointment and potassium iodid.

Inflammation of the cellular tissue of the orbit lead- to phlegmon of the orbit, or retrobulbar abscess, and manifests itself by severe external symptoms, as 


\section{Plate 39.}

Exophthalmos of the right ere, probably due to periostitis of the orbit. Patient is a baker, :o years old, and was adnitted to the elinic on account of grave symptoms in the right eye. which he first noticed two weeks ago. After riolent cold and headache the ere beeame so swollen that he eonld not open it. On raising the lid with the finger he fond that he saw double. The swelling soon subsided, but the diplopia renajued, and the patient has to keep the right eye elosed when he walks. The eyelall is displated forwatel and downward, abont - mm. in "ach direction. The movements are much restricted in every direction, especially mowal. When the eye is turned to the right, there is right diplopia: when to the lefte erosiced diplopia diminished abduction and adfuction). When the gaze is directed upwarel the image of the right eye is also displated upward. Vismal acuity and eye-gromud normal. (In palpating between the orbital margin and the globe a tumor-like resistance is folt. The rhinopharynx is normal. No signs of syphilis.

The patient is condition continued for two weeks without change, and then elisalpeared entirely without treatment, first the protrusion and then the dislocation downward. The cause is probably to be sought in a promtitis, secondary to catary of the frontal sinus.

marked eflematoms swelling of the lids and ocular conjunctiva (chemosis) and exuphthalmos. The movements of the ereball sonn suffer pestriation and vision is often impaired or uttery dextrovel. The -ubjective srmptoms are even more seve thain in periostitis: Violent pain, romiting, prostration, and slow pulse-altogether a very alaming clinical pieture. The abscess may rupture and dischalege its contents through a point on the lids, marked by intense redness and swelling and by fluctuation. After the pus is evacuated the inflammatory srmptoms may subside rapidly; but a permanent visual deterioration usually remains, hecante orhital phlegmons are very apt to produce inflammation and atrophy of the optic nerve. The bulbus itself may suffer permanent injury in the form of retinal separation. If the inflammation is very screre, panophthalmitis maty result, and, as in the case of periostitis, lead to fatal purulent meningitis and cerebral abseess.

Among the causes of orbital abscess may be mentioned : 


$$
\text { लें }
$$
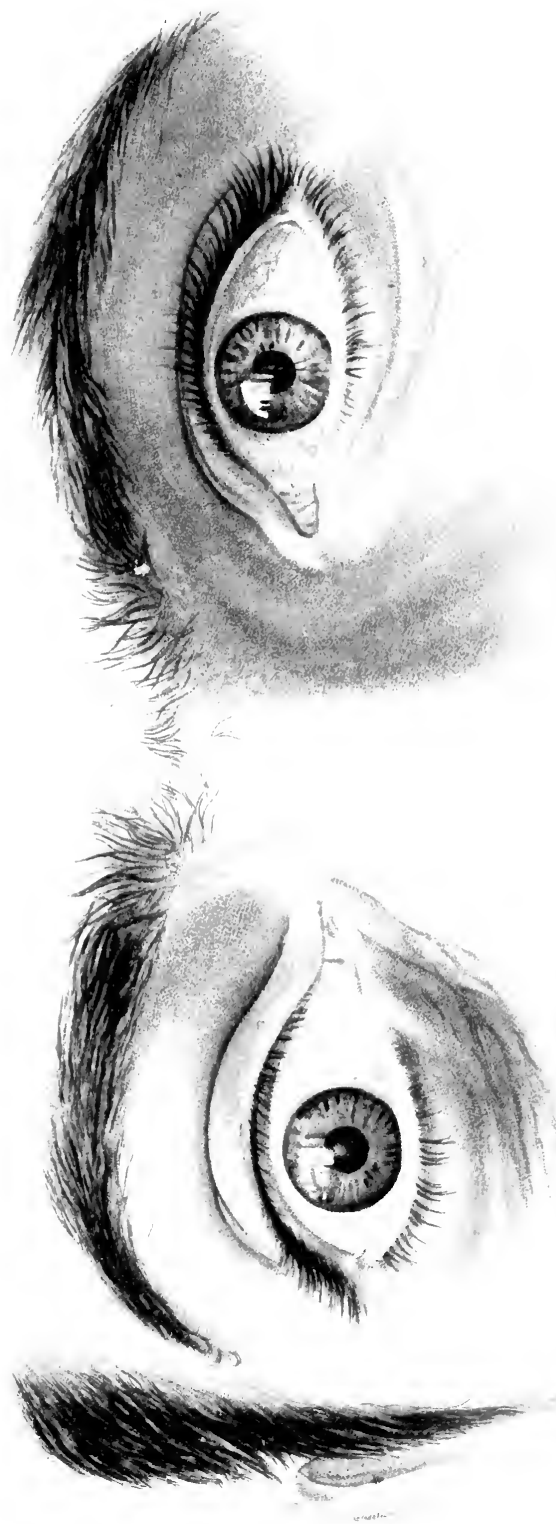

1. Wounds which have become secondarily infected (traumatic or operative) and foreign bodies in the orbit.

2. Purulent catarrh of the bony cavities communicating with the orbit (frontal sinus, nasal cavities, ethmoid cells, antrum). Periostitis of the orkit first develops and transmits the infection to the orbital contents.

3. Erysipelas of the face, by the inflammatory poison penctrating to the deeper structure and setting up an inflammation in the cellular tissue of the orbit.

4. Metastasis in pyemia, typhoid, scarlet fever, influenza, ete.

The treatment consists in removing the pus in the depths of the orbit, which may cndanger the eye and even the life of the patient. Access is obtained by the same mothod as that described in periostitis, and after the periosteum has been separated from the bone an incision is made in it from behind forward, over the point where the pus is supposed to be, and a drainage-tube introduced.

\section{Injuries of the Orbit.}

Either the soft parts or the bone may be injured. Fracture of the bone under ecrtain ciremetances gives rise to emphysema of the lick (see p. 107) and of the collular tis-an in the orbit, showing itself in protrusion of the eyehall. The latter can be replaced, but exophthalmos reappears as soon as the patient blows his nowe. The partial or total loss of vision following a blow on the bones of the orbit or the entire cranium is important from a practical and medicolegal standpoint. Holder and Berlin have shown, by their valuable investigations, that a fracture of the base of the skull, even when the blow is received on the back or side of the head, is capable of producing fisimres in the roof of the orbit and optic canal. The corresponding nerve is often so badly damaged by contusion or hemorrhage that the nervous pathway is interrupted and total loss of vision results. The patient on recovering consciousness is blind in one or both eyes, and 


\section{Fig. C.}

Dermoid Cyst of the orbit.-S. MI., 5o years old. In her twentyeighth rear a tumor developed in the inner canthus of the left eve, attaining a considerable size within three months and then diminishing again. The growth of the tumor was attended with moderate pain and inflammation. Two months ago the neoplasm again began to grow, and hat inereased rapidy in size during the past three weeks, so that the globe is now displaced far to the temporal side, and the woman often complains of (crossed) diplopia. The tumor is smooth, the size of a pigron's egg. and resilient to the tonch; the lower portion is visible in the palpebral fissure under the bulbar conjunctiva, and can be felt for some listanes backward along the bulb. It is freely movable, not adherent to the bone. Joes not diminish on presure. and shows no pulsation. Left lachrymal duet patulons. Nasal cavity normal. Ophthalmoscopic examination: On the nasal side the wall of the globe is turned in so as to simulate a slight retinal separation; at the periphery the posterior portion of the ciliary body is seen (large, dark-brown projections). The diagnosis of dermoid eyst was confirmed after extirpation. The crst extended along the nasal wall to the posterior pole of the orbit, and contained the characteristic mushy material, with numbers of cilia. The epeball returned to its normal position and movement was restored. ('ure in seventeen dars.

a few weeks later the atrophy of the nerve is demonstrable with the ophthalmoseope. Fracture of the orbital roof ant optic canal may also be eaused by a severe blow on the upper or outer portion of the orbital margin. The resulting blindness in these cases is incurable.

\section{Tumors of the Orbit.}

Orbital tumors sonner or later have the effect of risplating the eve forwart. I tumor situated within the ane of the recti muscles, surpomding the optic nerve, anses a displacement in the direction of the ophital axis; the movements of the ere are somewhat restricted, but appally strong in all directions, if the tumor is benign (Fig. F), whereas malignant tumors very ary interfere with the action of the muscles. If a tumor alevelops ontsirle the eome of the museles from one of the orbital walls, the ereball will be di-placed toward the opposite side. 'Thus, a tumor beginning on the floor of the orbit causes 
protrusion and upward di-placement (Fig. F); one in the nasal portion of the orbit, protrusion and outward displacement (Figs. ( $C$ and D). A deep-seaterl tumor can sometines be located by palpation with the little finger between the globe and the orbital margin. The nature of

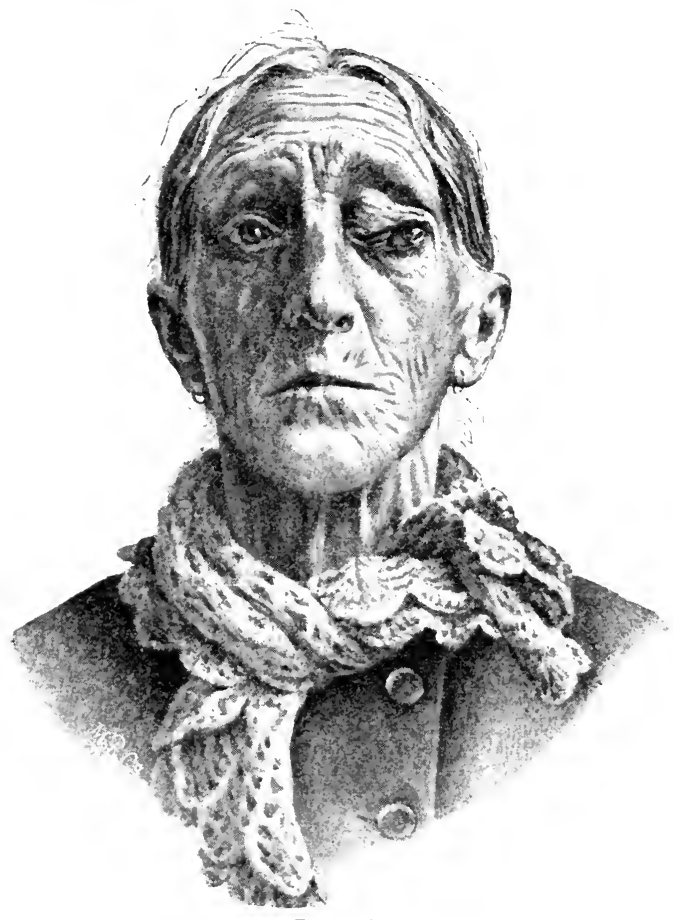

FIG. C.

the tumor in most ases can only be surmised; but it may be assumed that a tumor which grows slowly and causes little pain and limitation of movement is benign ; while malignant growths develop more rapidly and occalsion a higher degree of pain and functional disturbance. Dermoid cyst (Plate 21 and Fig. () is one of the more 


\section{Fig. D.}

Bone-cyst Due to Ectasia of the Ethmoid Cells, the Frontal sinus, and the Nasal Cavity.-M. F., carpenter, 24 years old. The tumor first made its appearance seven years ago, above the inner canthus of the left eye, and increased gradually, attaining its present size two rears ago. No pain at any time; but last winter there was excessive lachrymation from time to time.

At present there are no sigus of inflammation and the left lachrsmal duct is patulous. The tumor is about the size of a pigeon's egg, the greater portion situated above the internal lateral ligament, which forms a slight constriction in its lower portion. In the region of the root of the nose it is imposible to differentiate by palpation between the supraorbital margin and the tumor; but along the npper onter border the tumor can be felt extending some distance into the orbit. The tumor is tense, elastic, and fluctuating; no pulsation. Crossed diplopia. Visual acnity and fundus normal. Cpon extirpation of what was thought to be a dermoid cyst, a fibrous sac of connective tissue was found, which conld not be dissected out, being firmly adherent to the bone on its upper and nasal sides, and limited on the onter side by a thin plate of bome, the nasal wall of the orbit. The bony plate is displaced toward the orbit and is slightly movable. The sac contained a mass of thick, greenish or brownish gelatinous material. After this was removed, a cavity the size of a pigeon's egg was exposed, communicating above with the frontal sinus and below with the nasal cavity, and limited on the orbital side partly by the plate of bone and partly by connective tissue. cure was effected in three weeks. The plate of bone and the eveball gradually assumed a more nasal position.

frequent benign tumors. The disposition to dermoid erst is congenital, but the growth usually does not develop sufficiently to ineonvenience the patient until quite late in life. Its favorite seat is the anterior portion of the orbit, a little above either the inner or the outer canthus; but a laree erst mar fill the greater part of the orlit and canse lateral displacement of the bulb. Care must be exercised not to incise the eyst during the operation. In exeeptional cases I have done this purposely, when the erst was very laree and partly situated behind the gholse. I marle a small incision in the anterior pole and closed it again after part of the contents har escaped, so that the crst, while retaining a moderate degree of tension, was quite asily removed in toto from behind the bulb. 
A dermoid eyst may be diffieult to distinguish firom a cystoid dilatation of the ethmoid cells, the frontal sinus, or the nasal cavity, an example of which is shown in Fig. I). The differential diagnosis is based on the presence of a thin plate of bone between the erst and the globe, corresponding to the nawal wall of the orbit.

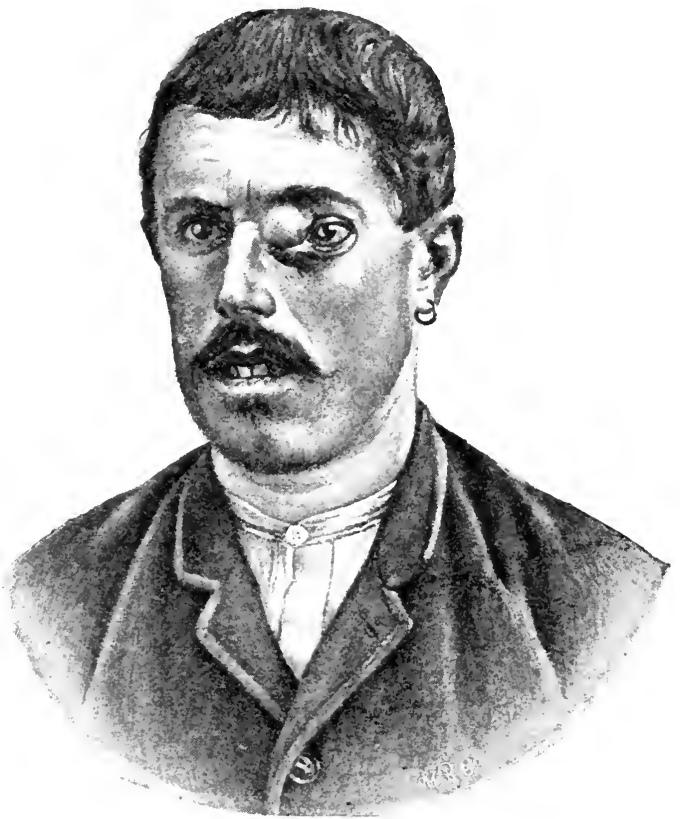

Fig. D.

An orbital cyst appearing shortly after birth should always suggest encephulocele or meningocele, which consists of a hernia-like protrusion of the dura mater into the orbit. If the sac contains brain-tissue, it is called encephalocele; if only cerebrospinal fluid, meningocele. The lesion usually develops along the line of a bone-suture. The most frequent seat in the orbit is the suture between 


\section{Fig. E.}

Angioma of the Orbit.- This tumor developed in the course of ten years, without giving rise to pain or inflammation, in the center of the orbit, and caused such enormous protrusion of the eyeball that the woman, who was then 41 years old, finally consented to have it removed. Unfortunately the tumor, which was evidently benign, had hy this time (1-91) become so large that enucleation of the globe had to be performed at the same time. The visual acuity of the affected eye had been diminishing for some time and was then redueed to $\frac{2}{5}$. This visual deterioration was chiefly due to a macula, which I observed in its initial stages, six months after the first appearante of protrusion, and which is illustrated in Fig. 52, a. Lehmann's Itlases. vel. vii., second edition, whieh shows the ophthalmoseopic image as it appeared in 10-5, and in Fig. 4-, $u$, showing a transverse section of the macula. In addition there existed for some time a moderate degree of papillitis thoked disk , which eventually passed into optic-nerve atropher. At the time of operation the lids could not be elosed, the palpebral fissure remaining open to the extent of $3 \mathrm{~mm}$. Eetropion had begun in the lower lid. To the outer aud lower side of the globe a moderately hard, lobulated tumor was felt, not fluctuating and not sensitive on pressure.

the ethmoid and frontal bones, hence the anomaly is found nstally in the upper inner portion of the orbit. The tumor is covered with normal skin, diminishes on presine, -ometimes with smptoms of cerebral tension, and may exhibit both circulatory and respiratory puliation, transmitted by the brain. It is firmly attached to the bone.

lasculer tumors are occasionally seen in the orbit, sometimes they take the form of an angioma, less frequently that of aneurrom. A cavernou: tumor may attain a considerable size (Figr. E).

Mnlignumt tnimors of the orbit are of the greatest importance, as they threaten the patient's life. Sarcoma in it sarion- formo is the tumor that orecurs most fiecuently. It may originate in the bone, the periostemm,

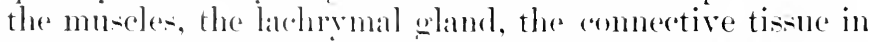
the orbit, or the sheath of the optic nerve. A sareoma in the choroid may break throngh into the orbit and eontimue to grow towird the front of the eve (Plate:37).

The ratre eases of primatry orbital careinema nisually begin in the larhrymal glamil. ( )n the other hand, earei- 
noma of the lids or of the eonjunctiva mar extend into the orbit, or it may break through from the arljacent bony cavities, especially the antrum of Highmore (Fig. F). Early recognition of the last-named condition is most important, as operation very soon becomes imposible if the cancer is allowed to grow for any length of time. The nasal cavity should alio be carefully examined, in

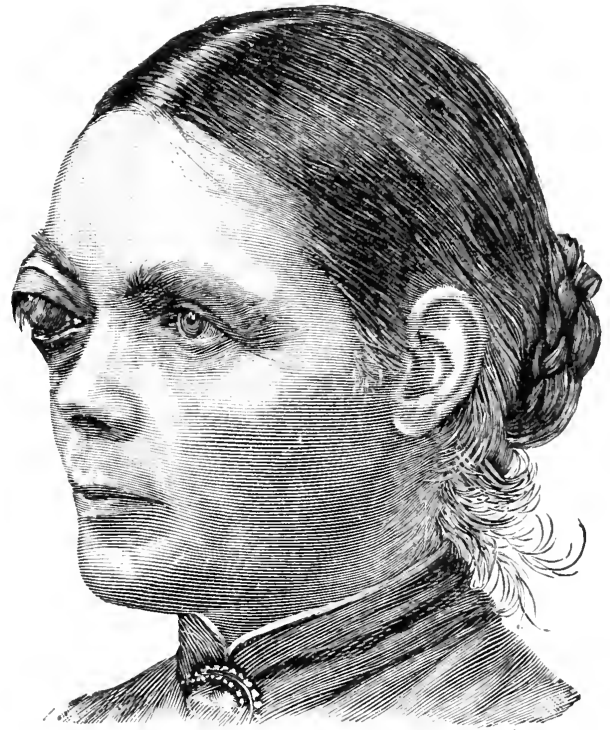

FIfi. E.

such eases, for possible exostose- below the lachrymal sac or the lower orbital margin and in the temporal region (see Fig. F). If the antrum of Highmore is filled with eancerous tissue, the respiratory murmur will be heard much better with the stethoscope at that point than orer the somond side.

Malignant tumors must be extirpated as soon as posilule. Krönlein's method, which consists in temporary resection 
Fig. F.

Cancer of the Upper Maxilla and Orbit.-Mrs. 1. W., 5:3 years old. Four months before her first visit to the clinic the patient had violent toothache on the right side, and although she had several teeth extracted the pains increased in severity and spread to the right eye and temple. As we see in the pieture, there was even at that tine a slight swelling in the region of the right upper jaw and temple, and the right eyeball was displaced forward and upward. The movements of the eye were restricted in every direction, but especially downward. The patient was referred to the snrgieal clinie, and extirpation of the tumor was performed by my colleague, Dr. Krönlein. The whole uluer jaw, with the exception of part of the palatine process. and the greater part of the zygoma were resected. It was then found that the growth was much more extensive than was to be expected; it extended some distance backward on the base of the skull and was laid bare as far as the middle meningeal artery. The eyeball had to be removed, as it was in close relation with the cancerous tissue. Exterually the tumor had broken through the bone and invaded the masseter muscle. On microscopic examination it proved to be a squanous epithelioma. The woman becane extremely emaciated and died three months later in collapse. There was no recurrence of the tumor.

of the temporal wall of the orbit, atforks the best meams of alceess. The flap of bone and soft tissues is replaced after the tumor has been removed and secured with sutures. A small tmmor in the temporal portion of the orbit can often be removed by this method without sacrifieing the globe. In extensive malignant growths the entire contents of the orbit must be extirpated.

An interesting and not very common affection of the orlit has received the name pulsating exophthalmos (Plate 4)). It may develop spontaneously (rarely) or after a severe blow on the skull. Pulsation ean be felt at the immer npere portion of the bulb, and the patient complains of a noive in hi- head like the poumeling of a steam-chgine. I hruit eam be distinctly heard on ansenltation in the region about the ere and more faintly as far back as the aeriput, on both the affected and the matfeeted sides. It is a characteristir sien that the noise and pulsation disappear on eompresion uf the carritil. Tpon close inspection a large pulsating vein is nsually detected in the 
inner "lpyer portion of the bulb. The protrusion can be slightly reduced by continned pressure. If the condition is neglected, the conjunctiva eventually becomes puckered into large, edematous folds, the superfieial ressels in the anterior portion of the globe become more and more dilated, until finally the lids are unable to close and the

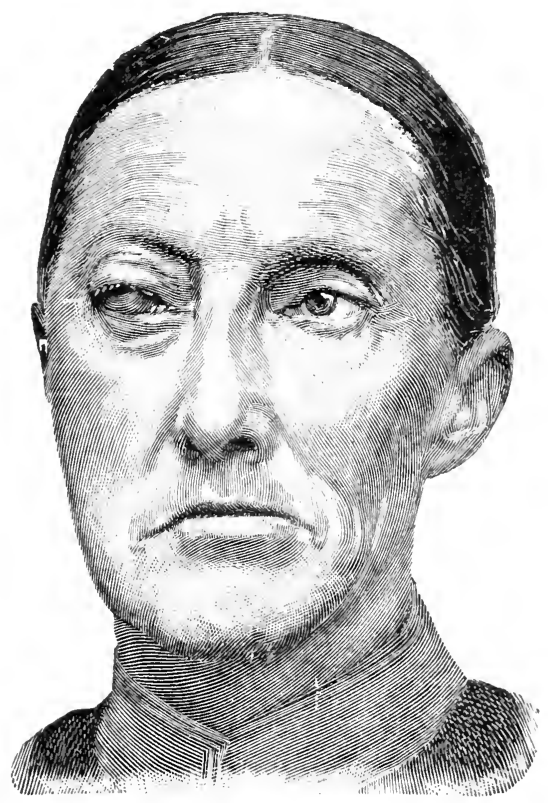

FIG. F. .

cornea is endangered. The disease is camed by trammatic frature of the base of the skull or spontaneous rupture of the internal carotid within the carernoms sinns. The veins which carry the blood from the orbit into the simus thus beeome engorged with arterial blood from the carotid and pulsate.

The surest treatment is ligation of the common carotid 


\section{Plate 40.}

Pulsating Exophthalmos and Glaucoma of the Left Eye.-The patient is 3- years old, and a farmer by occupation. On August 14, 1596, he fell from a load of grain; did not lose conscionsness, but bled freely from the nose and at once became stone-deaf. On september 13 the left eyeball began to protrude. visual acuity and mobility diminished, and by the middle of Oetober. when he was admitted to the clinic. all the symptoms of pulsating exophthalmos had developed, except that the patient dis not complain of noise in the head. although a pulsating bruit could be heard with the stethoseope all over the head. The increasing protrusion of the globe. howerer. became more and more distressing lat one time a small corneal ulcer dereloped, and the patient consented to ligation of the carotid. which was performed by Dr. Krönlein on November 20 . At first the result appeared to he favorable; but in the course of the next six months marked exophthahmos again developed and became further complicated with glaucoma. The latter is responsible for the dilatation of the pupil and disappearance of the iris under the lower margin of the cornea, seen in the picture. The anterior chamber is shallow and contains a small hỵphema. Fundus not visible, only red light. $T-2 . \quad$ As the region of the supraorbital vein (above the inner (antluns) was much swollen and the rein itself exhihited pulsation and bruit. I advised the patient to have the other "arotid ligated, which was done by Dr. Krönlein on July 30. The exophthalunos subsided almost completely and the subjective eondition improved. although the glaucoma remained. The vision of the left eye and hearing are permamently destroved, but the man is able to work.

of the same, and if necessary of the olposite, sicle. In some arses digital compression of the carotid suffices to effect al curre. 

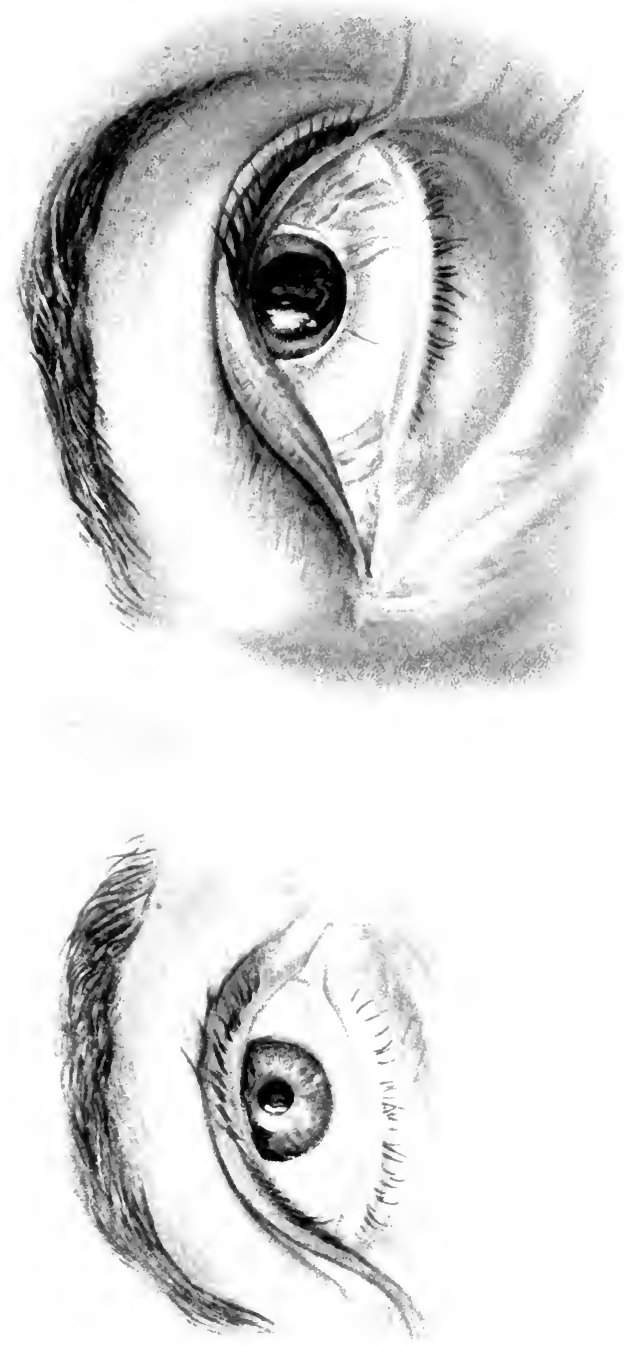



\section{N D E X.}

A Bscess of lachrymal sac, 86 retrobulbar, 213

Accommodation, method of measuring, 43,50 table of range of, 53

Acne of conjunctiva, 135

Acuteness of vision, 38

Amblyopia, it

Aniridia. 188

Ankyloblepharon, 107

Anterior chamber, examination of, 35

Aphakia, 199

A trophy of optic nerve, 59

BACTERIA in conjunctival sac, 110 in lachrymal sac, 80

Blennorrhea neonatorum, 113. See Conjunctivitis, gonorherl.

Blepharitis, eczematous, 94 ; Pls. 4, 6 squamous, 97

Blepharochalasis, 104 ; Pls. 8,9

Blepharophimosis, $10 \%$

Buphthalmos, 208

Cataract, 189

anterior polar, 191; Pl. 34

capsular, 114, 159; Pl. 34

complicated. 196

congenital, 19\%)

diagnosis of, 196

incipient, 193

partial stationary, 191

perinuclear, zomilar, or lamellar.

192: Pl. 33

posterior polar, 191

progressive, 19:3

senile, 193, 194; Pls. 32, 33

traumatic, 195 : Pls. 32,36

treatment of, $19 \%$

Cataracta accreta, 196

intumescens, 193

matura, 193

nigra, 194
Catarrh, eczematous, 131

Chalazion, 10: ; Pl. T

Chorvid, sarcoma of, Pl. 37

Ciliary body, diseases of, 177 gummata of, 182 tumors of, 188

Color-blindness, 60 detection of, 62

Color-sense, contrast-test for, 61 perimeter-test for, 57

Congestion, ciliary or circumcorneal, 27

conjunctiral, $2 \pi$

diagnostic value of, 30

localized ciliary, 30

Conjunctiva, acne of, 135

burns of, 139 ; Pl. 19

diseases of, 110

ecchymoses of, 139

eczema of, 129,132 ; Pls. 17,18

essential shrinking of, 134. See Pemphigus.

forejgn bodies in, 133

hrphæma conjunctive, Pl. 14

iehthyosis of, 134

in leprosy, 138

in scleritis, 13.5

in variola, 135

syphilomata of, 138

tuberculosis of, 136

tumors of, 141

uleers of, $110,114,132,136$

Conjunctivitis, diphtheritic, 119 ; Pl. 13

eczematous, 129,132

etiology of, 110

follicular, 112

gonorrheal, 113; Pl. 12

treatment of, $11 \%$

granular, 121, 123, 128

phlyetenular, 1:29

scrofulous, 129

simple catarrhal, 109, 111

spring-, 126, 13:; Pl. 15 
Cornea, burns of, Pl. 19

diseases of, 143

examination of, 31

injuries of, 165

leukomata of, 33,115

maculæ of, 34, 114; Pl. 23

malformations of, 169

milky opacity of. in spring-conjunctivitis, $12 \tau$

opacities of, 34,114

transparence of, 33

ulcers of, $159,16 \%$

Corneal deposits, 49, 179

loupe, 46

Credé's prophrlactic method, 113

Crelitis, $17 \%, 179$

('ysts, dermoid. $8 ., 150,21 \%$

prelachrsmal, st

DACRYOCYSTITIS. $93 ;$ Pls. 1, :

blemnorrhœica, 84

treatment of, os

Dacrostenosis, 78,79

srimptoms of, :2:

Deposits, cormeal, 49, 179

Diffusion-circles, 50

Diopter, 45

Diplopia, 63, $6 \tau$

Double images, 66, 7.2

ECT.sia of lachrymal sac, 83 ; Pl. 3

Ectopia leutis congenita, 195

Eetrolvion, 95, 105

Eezema, 21,94

marginal, 95, 128, 130

of conjunctiva, 130 ; Pls. 17,22

of cornea, 130; Pls. :2:, 2:3

of erelids, 94

pustule or phlyctenule, 131

Emmetropia $5: 2$

Encephalocele, 219

Entropion, 95, 1:2; Pl.9

Epicanthus, 104; Pls. 3, 9

Epiphora, is

hypopyon-keratitis, 8:

Episeleritis 173

Errsipelas of erelids, 9\% of lachrrmal sac, -ti

Eversion, :3, :4

Examination of anterior chamber. 35

of eye by lateral illumination. 46

by transmitted light.

Fxophthalmos, Pl. 39 pulsating, 2.): Fl. 10
Ereball, inspection of, 26

tension of, $: 36$

Evelids, anomalies of, 104

diseases of, 9:

eezema of, 94

erysipelas of, 92

eversion of, ?:;

herpes zoster of, 92

injuries of, $10 \tau$

seborrhea of, 97

tumors of, 100

FAcets in cornea, 32

False images, 70

Field of vision, 55. See Visual field.

Fistula, lachryma1, 83 ; Pl. 3

For'inn bodies in conjunctiva, 138 ; Pl. 16

in cornea, 33; Pl. 21

in sclera, 174

Fruejahr's catarrh, 1:6, 13:, See Comjunctiritis, spring-.

Glatcosat, 19s: Pl. 40

fulminating. $20 \%$

hemorrhagic, $: 05$

infantile, 169, 208

primarr, 203

absolute. 206

acute, $\mathrm{Pl} .36$

evolutum, :04

inflammatory, 204

secondars, $163,196,211$

simple, 2ir

Glioma of retina. Pl. 33

(iramulations, follicular, 121

papillary, 121

pavement or tessellated, $\mathbf{1 2 6}$

HFMIA TOPSIA, 55, 59

Herpes cornex febrilis, Pls. :4, 25

zoster cornex, 155

of eyelids, 92

ophthalmicus, Pl. 20

Hordeolum, 100; Pls. 5, 6

Hrdiophthalmos, 208

Hrpopyon, 35, 175

Hypopyon-keratitis, a2; Pl. 25

ICITHYosis of conjunctiva, 134

Images, double, in paralysis, 66, 7\% false, 70

Irideremia, 189

Iridocyclitis, 150 
Iridocyclitis, traumatic, 183 treatment of, 187

Iridolialysis, $18 \%$

Iris, adhesions of, 154

diseases of, $17 \tau$ injuries of, $18 \%$

lacerations of, $\mathrm{Pl} .36$

prolapse of, 150

tremor of, 35

tumors of, Pl. 30

Iritis, 117

diagnosis of, 155

gonorrheal, 18:

idiopathic, 183

rheumatic, 18:

serous, 1 -0

syphilitic, 176,$181 ; \mathrm{Pl} .31$

treatment of, 15.5

Keratitis, eczematous or phlyetenular, 149

fascicular, 13:2, 151

marginal, 128, 130, 151

neu roparalytic, $15 \overline{5}, 163$

parenchymatous, 143; Pl. 28

sclerotizing, 145, 172; Pl. 29

scrofulous, 149

Keratoconus, 32, 170

LACHRYMAL APPARATUS, diseases of, 79

sac, abscess of, 86

bacteria in, 80

ectasia of, 83 ; Pl. 3

furumcle of, 86

tumor, 83

Lens, abnormal coloration of, 36

diseases of, 188

dislocation of, 195 ; Pl. 34

subluxation of, 193

Leprosy of conjunctiva, 138

Lenkomata, 33

Light-perception, 43

Light-sense, 59

Lipomatosis, 104

Loupes, corneal, 46, 49

Luxatio lentis, 190

MALINGERERs, detection of, 74

Megalocornea, 169

Membrane, persistent pupillars, 18.5

Meningocele, 219

Meter-lens, 45

Migratory pustule, 132, 151. See Keratitis, fascicular.
Milium, 109

Mobility, disturbances of, 62

Molluscum contagiosum, 108; Pl. 6

Mucocele, 8?

Muscre, 190

Muscles, ocular, action of, 63 paralyses of, $62,68,69$

Mydriasis, traumatic, $18 \pi$

Myopia, 5:

Nictitatio, 112

Nyctalopia, 60

OPACITIES of cornea, 34,114

Ophthalmia, Egrptian or gramular, 121. See Trachoma.

neonatorum, 113. See Conjunctiritis, gonorrheal.

Ophthalmitis, sympathetic, 184

Optic-nerve atroply, 59

Orbit, abscess of, '21?

diseases of, 211

injuries of, $21 \overline{5}$

tumors of, $150,216,217,220$

Osteoma of ethmoid, 87

PANnUs, 122; Pl. 28

eczematous or scrofulous, 150

phlyctenular marginal, 132

treatment of, 126

Panophthalmitis, 114, 163, 201; Pl. 35

Papillomacular bundle, disease of, 59

Paralyses, 66, 68, 69

false images in, 66

Pemphigus of conjunctiva, 134

Perimeter, $5 \pi$

Plotometer, 60

Phtlisis bulbi, 163, 180, 181 ; Pl. 28

Pinguecula, 140

Pityriasis of conjunctiva, 134

Presbropia, 53

Protrusion, 22

Pseudopteryginm, 139

Psoriasis of conjunctiva, 134

Pterrgium, 140; Pls. 16, 26

Ptosis, 104

congenital, 106

Pupil, abnormal coloration of, 36 occlusion and exclusion of, 178 reaction of, to light, 48

Pupillary membrane, persistent, 185

ReACTION to light, 48 
Retina, detachments of, 59 glioma of, Pl. 38 pigmentary degeneration of, 59

Retrobulbar abscess, 213

SCLERA, diseases of, $\mathbf{1} \boldsymbol{1} \mathbf{1}$ foreign bodies in, 174 injuries of, 173

Scleritis, 132, 135, 171 ; Pl. 29

Scotomata, 55, 59

Seborrhea, 21 marginal, 98

Siderosis, 202

squint, 73 test for, 2:

Staphyloma, 114, 163, 171 scleral, 1\%:

Subluxatio lentis, 198

Symblepharon, 106, 139

Synechix, 17s

Syphilides, 96, 134

Syphilomata, 138
Texsion of ereball, 36

Tonometer, $3 \dot{7}$

Trachoma, 121, 123, 128; Pls. 14, 28

Transparency of cornea, 33

Trichiasis, $9 \overline{5}$

Type-cards, 39, 4:

ULCERs, marginal or catarrhal, 110 of conjunctiva, 136

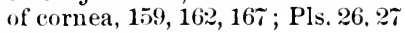
Uveitis, $17 \%$

VARIOLA of conjunctiva, 135

Visual acuity, test for, $3 ð$ field, abnormalities of, 59 methods of measuring, 55-57

Vitreous body, abnormal coloration of, 36

diseases of, 199

foreign bodies in, Pls. 35, 36 suppuration of, 201

turbidity of, $\mathrm{Pl} .36$ 


\section{Medical and Surgical Works}

PUBLISHED BY

\section{W. B. SAUNDERS, 925 Walnut Street, Philadelphia, Pa.}

American Pocket Medical Dictionary PAGE *American Text-Book of Applied Therapeutics

*American Text-Book of Chemistry . . 40

*American Text-Book of Diagnosis . . . 40

*American Text-Book of Dis. of Children . I

*An American Text-Book of Diseases of the Eye, Ear, Nose, and Throat .

*An American Text-Book of Genito-Urinary and Skin Diseases.

12

*American Text-Book of Gynecology . . . io

*American Text-Book of Legal Medicine . 40

American Text-Book of Nursing . . . . 40

*American Text-Book of Obstetrics . . . 7

*American Text Book of Pathology . . . 40

*American Text-Book of Physiology . . . 5

*American Text-Book of Practice . . . . 8

*American Text-Book of Surgery . . 9 9

Anders' Theory and Practice of Medicine. I7

Ashton's Obstetrics . . . . . . . . . 39

Atlas of Skin Diseases . . . . . . . .24

Ball's Bacteriology . . . . . . . . . . 39

Bastin's Laboratory Exercises in Botany . 32

Beck's Surgical Asepsis . . . . . . . . 37

Boisliniere’s Obstetric Accidents . . . . . 35

Brockway's Physics . . . . . . . . . 39

Burr's Nervons Diseases . . . . . . . . 37

Butler's Materia Medica and 'therapeutics 20

Cerna's Notes on the Newer Remedies. . 28

Chapin's Compendium of Insanity . . . . 31

Chapman's Medical Jurisprudence . . . . 37

Church and Peterson's Nervons and Men-

tal Diseases .

Clarkson's Histolozy . . . . . . . . . 29

Colien and Eshner's Diagnosis. . . . . . 39

Corwin's Diagnosis of the Thorax . . . . 33

Cragin's Gynæcology . . . . . . . . 39

Crookshank's Text-Book of Bacteriology . 23

DaCosta's Manual of Surgery . . . . . . I9

De Schweinitz's Diseases of the Eye . . .25

Dorland's Pocket Medical Dictionary . . 31

Dorland's Obstetrics . . . . . . . 37

Frothingham's Bacteriological Guide . . . 26

Garrigues' Diseases of Women . . . . . . 30

Gleason's Diseases of the Ear . . . . . . 39

*Gould and Pyle's Curiosities of Medicine . 15

Grafstrom's Mlassage . . . . . . . . . 24

Griffith's Care of the Baby . . . . . 34

Griffith's Infant's IVeight Chart . . . . . 35

Gross's Autobiography . . . . . . . . . 22

Hampton's Nursing . . . . . . . . . 35

Hare's Physiology . . . . . . . . 39

Hart's Diet in Sickness and in Health . . 32

Haynes' Manual of Anatomy . . . . . . 37

Heisler's Embryology . . . . . . . . 40

Hirst's Obstetrics ....... . 16

Holmes' Manual of Surgery . . . . . . 4

Hyde's Syphilis and Venereal Dıseases. . 37

International Text-Book of Surgery . . . 4o

Jackson's Diseases of the Eye. . . 40

Jackson and Gleason's Diseases of the Eye,

Nose, and Throat .

Keating's Pronouncing Dictionary . . 22

Keating's Life Insurance . . . . . . . . . 35

Keen's Operation Blanks

Keen's Surgery of Typhoid Fever

Kyle's Diseases of Nose and Throat . PAGB

Lainé's l'emperature Charts . . . . . 28

Lockwood's Practice of Medicine . . 37

Long's Syllabus of Gynecology . . . . 30

Macdonald's Surgical Diagnosis and 'l'eatment

McFarland's Pathogenic Bacteria

Mallory and Wright's Pathological Technique

Martin's Surgery

Martin's Minor Surgery, Bandaging, and ${ }^{39}$

$\begin{array}{cc}\text { Venereal Diseases . } & 39 \\ \text { Meigs' Feeding in Early Infancy . . . . . } & 26\end{array}$

Moore's Orthopedic Surgery . . 19

Morris' Materia Medica and Therapentics .39

Morris' Practice of Medicine . . . . . 39

Morten's Nurses' Dictionary . . . . . . 34

Nancrede's Anatomy and Dissection. . . 27

Nancrede's Anatomy . . . . . . . . 39

Nancrede's Principles of Surgery . . . 40

Norris' Syilabus of Obstetrical Lectures . 33

Ogden's Urinary Analysis ...... . . 40

Penrose's Diseases of Women . . . . 20

Powell's Diseases of Children . . . . . 39 39

Pryor's Pelvic Inflammations . . . . . . 40

Pye's Bandaging and Surgical Dressing . 19

Raymond's Physiology . . . . . . . 37

Rowland's Clinical Skiagraphy . . . . 29

Saundby's Renal and Urinary Diseases . . 21

Saunders' American Year-liook of Nedicine and surgery

Saunders' Medical Hand-Atlases

Saunders' Pocket Medical Formulary 3, 34

Saunders' New Series of Manuals . . . 36,37

Saunders' Series of Question Compends 38, 39

Sayre's Practice of Pharmacy . . . . . . 39

Semple's Patholngy and Morbid Anatony 39

Semple's Legal Medicine. Toxicology, and

Hygiene

Senn's Genito-Urinary Tuberculosis . . $\quad 39$

Senn's Tumors ........... . . 21

Senn's syllabus of Lectures on Surgery . . 33

Shaw's Nervous Diseases and Insanity' . 39

Starr's Diet-Lists for Children . . . . . 34

Stelwagon's Diseases of the Skin . . . . 39

Stengel's Pathology ..... . . 16

Stevens' Materia NIedica and 'Therape tutics 28

Stevens' Practice of Medicine . . . . . 27

Stewart's Manual of Physiolngy . . . . 33

Stewart and Lawrance's Medical Electricity

Stoney's Materia Medica for Nurses . 40

Stoney's Practical Points in Nursing. . . 23

Sutton and Giles' Diseases of W'omen 25,37

Thomas's Diet-List and Sick-Room Diet-

Thornton's Dose-Book and Manual of Prescription-W riting

Thresh's Water and Water Supplies . 29

Van Valzah and Nisbet's Diseases of the Stomach

Vecki's Sexual Impotence

Vierordt and Stuart's Medical Iiaun sis 29

Warren's Surgical Pathology . . . . 2x

Wolff's Chemistry . .

Wolff's Examination of Urine . . . . 39 


\section{GENERAL INFORMATION.}

One Price.

One price absolutely without deviation. No discounts allowed, regardless of the number of books purchased at one time. Prices on all works have been fixed extremely low, with the view to selling them strictly net and for cash.

Orders.

An order accompanied by remittunce will receive prompt attention, books being sent to any address in the Inited states, by mail or express, all charges prepaid. We prefer to send bouks $\mathbf{~} \mathbf{y}$ express when possible.

Cash or Credit. To physicians of approved credit who furnish satisfactory references our books will be sent free of C. O. D. One volume or two on thirty days time if credit is desired; larger purehases on mouthly payment plan. See offer below.

\section{How to Send Money by Mail.}

Shipments.

Subscription Books.

Miscellaneous Books.

\section{Latest Editions. \\ Bindings.}

Special offer. Monthly Payment Plan.
There are fulr ways by which money ean be sent at our risk. namely: a post-office money order, an express money orler, a bank-check (draft), and in a registered letter. Money sent in any wher way is at the senter's risk. Silver should not be sent through the mail.

111 broks, being packed in patent metal-edged boxes, necessarily reach our patrons by mail or express in exeellent condition.

Books in this eatalogue marked with a star (*) are for sale by subseription only, and may be secured by ordering them through any of our authorized travelling salesmen, or direct from the Philadelphia office: they are not for sale by booksellers. All other books in our catalogne ean he procured of any bookseller at the advertised price, or directly from us.

We earry in stock only our own publications, but can supply the publications of other lolises (except subseription books) on receijt of publisher's price.

In every instance the latest revised edition is sent.

In ordering, be careful to state the style of binding desiredCloth, sheel, or Half Ioruceo.

To physicians of approved credit who furnish satisfactory references books will be sent express prepaid: terms. 5.00 eash upon delivery of books, and monthly payments of 8.5 of thereafter until full amount is paid. Any of the publications of $\mathrm{W}$. B. Saunders (1019 titles to seleot from) mat he had in this way at catalogue price, including the American Text-Buk series, the Yledieal HandAtlases, etc. All payments to be made by mail or otherwise, free of all expense to us, 


\section{SA U N DER S}

\section{MEDICAL HAND-ATLASES.}

THE series of books included under this title consists of authorized translations into English of the world-famous Lehmann Medicinische Handatlanten, which for scientific accuracy, pictorial beauty, compactness, and cheapness surpass any similar volumes ever published.

Each volume contains from 50 to roo colored plates, executed by the most skilful German lithographers, besides numerous illustrations in the text. There is a full and appropriate description, and each book contains a condensed but adequate outline of the subject to which it is deroted.

One of the most valuable features of these atlases is that they offer a ready and satisfactory substitute for clinical observation. Such observation, of course; is available only to the residents in large medical centers; and even then the requisite variety is seen only after long years of routine hospital work. To those unable to attend important clinics these books will be absolutely indispensable, as presenting in a complete and convenient form the most accurate reproductions of clinical work, interpreted by the most competent of clinical teachers.

While appreciating the value of such colored plates, the profession has heretofore been practically debarred from purchasing similar works because of their extremely high price, made necessary by a limited sale and an enormous expense of production. In planning this series, however, arrangements were macle with representative publishers in the chief medical centers of the world for the publication of translations of the atlases into nine different languages, the lithorraphic plates for all being made in Germany, where work of this kind has been brought to the greatest perfection. The enormous expense of making the plates being shared by the various pullishers, the cost to each one was reduced to practically one tenth. Thus by reason of their universal translation and reproduction, affording international distribution, the publishers liave been enabled to secure for these atlases the best artistic and professional talent, to produce them in the most elegant style, and yet to offer them at a price heretofore unapproached in cheapness. The great success of the undertaking is demonstrated by the fact that the volumes have already appeared in nine different languages-German, English, French, Italian, Russian, Spanish, Danish, Swedish, and Hungarian.

In view of the unprecedented success of these works, Mr. Saunders has contracted with the pullisher of the original German edition for one hundred thousand copies of the atlases. In consideration of this enormous undertaking, the publisher has been enabled to prepare and furnish special additional colored plates, making the series even handsomer and more complete than was originally intended.

As an indication of the great practical value of the atlases and of the immense favor with which they have been received, it should be noted that the Medical Department of the U. S. Army lias adopted the "Atlas of Operative Surgery" as its standard, and has ordered the book in large quantities for distribution to the various regiments and army posts.

The same careful and competent editorial supervision has been securet in the English edition as in the originals. The translations have been edited by the leading American specialists in the different subjects. The volumes are of a uniform and convenient size $(5 \times 7 \mathrm{Y} / 2$ inches), and are substantially bound.

$$
\text { (For List of Volumes in this Series, see next page.) }
$$




\section{SAUNDERS' MEDICAL HAND-ATLASES.}

\section{VOLUMES NOW READY.}

Atlas of Internal Medicine and Clinical Diagnosis. By DR. CHR. Jakor, of Erlangen. Edited by AUgustus A. EshNer, M. D., Professor of Clinical Medicine in the Philadelphia Polyclinic; Attending Physician to the Philadelphia Hospital. 68 colored plates, and 64 illustrations in the text. Cloth, $\$ 3.00$ net.

"The charm of the book is its clearness, conciseness, and the accuracy and beauty of its illustrations. It deals with facts. It vividly illustrates those facts. It is a scientific work put together for ready reference."-Brooklyn Medical Journal.

Atlas of Legal Medicine. By Dr. E. R. vox HufMaxs, of Vienna. Edited by Frederick I'ETERsox, il. D., Clinical Professor of Mental Diseases, Woman's Medical College, New York; Chief of Clinic, Nervous Dept., College of Physicians and Surgeons, New York. With I 20 colored figures on 56 piates, and 193 beautiful half-tone illustrations. Cloth, $\$ 3.50$ net.

“Hofmann's 'Atlas of Legal Medicine' is a unique work. This immense field finds in this book a pictorial presentation that far excels anything with which we are familiar in any other work." - Philadelphia Medical Journat.

Atlas of Diseases of the Larynx. By DR. L. Grü NwaLd, of Munich. Edited by Charles P. GRaYsox, M. D., Lecturer on Laryngology and Rhinology in the University of Penniylvania; Physician-in-Charge, Throat and Nose Department, Hospital of the University of Pennsylvania. With 107 colored figures on 44 plates, and 25 text-illustrations. Cloth, \$2.50 net. "Aided as it is by magnificently executed illustrations in color, it cannot fail of being of the greatest advantage to students, gener:al practitioners, and expert laryngologists."- $-S t$. Louis Medical and Surgical Journal.

Atlas of Operative Surgery. By Dr. O. ZuCk frkand, of Vienna. Edited by J. Chalmers DaCosta, M. D., Clinical Professor of Surgery, Jeffer:on Ifedical College, Philadelphia; Surgeon to the Philadelphia Hospital. With 24 colored plates and 2 I 7 text illustrations. Cloth, $\$ 3.00$ net.

"We know of no other work that combines such a wealth of beautiful illustrations with clearness and conciseness of langunge, that is so entirely abreast of the latest achievements, and so useful both for the beginner and for one who wishes to increase his knowledge of operative surgery."-Münchener Medicinische Wochenschrift.

Atlas of Syphilis and the Venereal Diseases. By PROF. Dr. FraNz MrACEK, of Vienna. Edited by L. Bolros BANGs, M. D., late Professor of Genito-Urinary and Venereal Diseases, New York Post-Graduate Medical School and Hospital. With $7 \mathrm{I}$ colored plates from original water-colors, and I 6 black-and-white illustrations. Cloth, $\$ 3 \cdot 50$ net.

"A glance thronglı the bonk is almost like actual attendance upon a famous clinic."Journal of the American Medical Association.

\section{IN PREPARATION.}

Atlas of External Diseases of the Eye. By Dr. O. HAAB, of Zurich. Edited by G. E. DE SCHWEINITZ, M. D., Professor of Ophthalmology, Jefferson Medical College, Philadelphia. With roo colored illustrations.

Atlas of Skin Diseases. By Prof. Dr. Franz Mracfk, of Vienna. Edited by Hexry W. Stelwagon, M. I), Clinical Professor of Dermatology, Jefferson Medical College, I'hilarlelphia. With So colored plates.

Atlas of Pathological Histology.

Atlas of Orthopedic Surgery,

Atlas of General Surgery.
Atlas of Operative Gynecology.

Atlas of Psychiatry.

Atlas of Diseases of the Ear. 
* AN AMERICAN TEXT-BOOK OF PHYSIOLOgY. Edited by

William H. Howell, Ph. D., M. D., Professor of Physiology in the Johns Hopkins University, Baltimore, Md. One handsome octavo volume of 1052 pages, fully illustrated. Prices: Cloth, $\$ 6.00$ net; Sheep or HalfMorocco, $\$ 7.00$ net.

This work is the most notable attempt yet made in America to combine in ne volume the entire subject of Human Physiology by well-known teachers who have given especial study to that part of the subject upon which they write. The completed work represents the present status of the science of Physiology, particularly from the standpoint of the student of medicine and of the medical practitioner.

The collaboration of several teachers in the preparation of an elementary textbook of physiology is unusual, the almost invariable rule heretofore having been for a single author to write the entire book. One of the advantages to be derived from this collaboration method is that the more limited literature necessary for consultation by each a.uthor has enabled him to base his elementary account upon a comprehensive knowledge of the subject assigned to him; another, and perhaps the most important, advantage is that the student gains the point of view of a number of teachers. In a measure he reaps the same benefit as would be obtained by following courses of instruction under different teachers. The different standpoints assumed, and the differences in emphasis laid upon the various lines of procedure, chemical, physical, and anatomical, should give the student a better insight into the methods of the science as it exists to-day. The work will also be found useful to many medical practitioners who may wish to keep in touch with the development of modern physiology.

\section{CONTRIBUTORS :}

HENRY P. BOWDITCH, M. D.,

Professor of Physiology, Harvard Medical School.

JOHN G. CURTIS, M. D.,

Professor of Physiology, Columbia University, N. Y. (College of Physicians and surgeons).

HENRY H. DONALDSON, Ph. D.,

Head-Professor of Neurology, University of Chicago.

W. H. HOWELL, Ph. D., M. D.,

Professor of Physiology, Johns Hopkins University.

FREDERIC S. LEE, Ph. D.,

Adjunct Professor of Physiology, Columbia University, N. Y. (College of Physicians and Surgenns).
WARREN P. LOMBARD, M. D.,

Professor of Physiology, University of Michigan.

GRAHAM LUSK, Ph. D.,

Professor of Pliysiology, Yale Medica ${ }^{\top}$ School.

W. T. PORTER, M. D.,

Assistant Professor of Physiology, Harvard Medical School.

EDWARD T. REICHERT, M. D.,

Professor of Physiology, University of Pennsylvania.

HENRY SEWALL, Ph. D., M. D.,

Professor of Physiology, Medical Depart ment, University of Denver.

"We can commend it most heartily, not only to all students of physiology, but to every physician and pathologist, as a valuable and comprehensive work of reference, written by men who are of eminent authority in their own special subjects." - London Lancet.

"To the practitioner of medicine and to the advanced student this volume constitutes, we believe, the best exposition of the present st tlus of the science of physioiogy in the English language."-American Fournal of the Hedical Sciences. 


\section{* AN AMERICAN TEXT-Book of applied THERAPEU-} TICS. For the Use of Practitioners and Students. Edited by Janes C. Wilson, M. D., Professur of the Practice of Medicine and of Clinical Medicine in the Jefferson Medical College. One handsome octavo volume of $\mathbf{I}_{326} 26$ pages. Illustrated. Prices: Cloth, $\$ 7.00$ net; Sheep or Half-Morocco, $\$ 8.00$ net.

The arrangement of this volume has been based, so far as possible, upon modem pathologic doctrines, beginning with the intoxications, and following with infections, diseases due to internal parasites, diseases of undetermined origin, and finally the disorders of the several bodily systems-digestive, respiratory, circulatory, renal, nervous, and cutaneous. It was thought proper to include also a consideration of the disorders of pregnancy.

The articles, with two exceptions, are the contributions of American writers. Written from the standpoint of the practitioner, the aim of the work is to facilitate the application of knowledge to the prevention, the cure, and the alleviation of disease. The endeavor throughout has been to conform to the title of the book-Applied Therapeutics-to indicate the course of treatment to be pursued at the bedside, rather than to name a list of drugs that have been used at one time or another.

The list of contributors comprises the names of many who have acquired distinction as practitioners and teachers of practice, of clinical medicine, and of the specialties.

\section{CON'TRIBU'TORS :}

Dr. I. E. Atkinson, Baltimore, Md.

Sanger Brown, Chicago, îl.

John B. Chapin, Philadelphia, Pa.

William C. Dabney, Charlotlesville, Va.

John Chalmers DaCosta, Philada., Pa.

I. N. Danforth, Chicago, Ill.

John L. Dawson, Jr., Charleston, S. C.

F. X. Dercum, Philadelphia, Pa.

George Dock, Ann Arbor, Mich.

Robert T. Edes, Jamaica Plain, Mass.

Augustus A. Eshner, Philadelphia, Pa.

J. T. Eskridge, Denver, Cel.

F. Forchheimer, Cincinnati, $\mathrm{O}$.

Carl Frese, Philadelphia, Pa.

Edwin E. Graham, Philadelphia, Pa.

John Guitéras, Philadelphia, $\mathrm{Pa}$.

Frederick P. Henry, Philadelphia, Pa.

Guy Hinsdale, Philadelphia, Pa.

Orville Horwitz, Philadelphia, Pa.

W. IV. Johnston, Washington, D. C.

Ernest Laplace, Philadelphia, Pa.

A. Laveran, Paris, France.
Dr. James Hendrie Lloyd, Philadelphia, Pa. John Noland Mackenzie, Baltiniore, Md. J. WV. McLaughlin, Austin, Texas.

A. Lawrence Mason, Boston, Mass. Charles K. Mills, Philadelphia, Pa. John K. Mitchell, Philadelphia, Pa. W. P. Northrup. New York City. William Osler, Baltimore, Md. Frederick A. Packard, Philadelphia. Pa. Theophilus Parvin, Philadelphia, $\mathrm{Pa}$. Beaven Rake, London, England. E. O. Shakespeare. Philadelphia, Pa. Wharton Sinkler, Philadelphia, Pa. Louis Starr, Philadelphia, Pa.

Henry W. Sielwagon, Philadelphia, Pa. James Stewart, Montreal, Canada. Charles G. Stockton, Buffalo, N. Y. James 'Iyson, Philadelphia, Pa. Victor C. Vaughan, Ann Arbor, Mich. James ' $\mathrm{T}$. Whittaker, Cincinnati, $\mathrm{O}$. J. C. Wilson, Philadelphia, Pa.

"As a work either for study or reference it will be of great valıe to the practitioner, as it is virtually an exposition of such clinical therapentics as experience has taught to be of the most value. Taking it all in all, no recent publication on therapeutics can be compared with this one in practical value to the working physician." - Chicago Clinical Reziez'.

"The whole field of medicine has been well covered. The work is thoronghly practical, and while it is intended for practitioners and students, it is a better book for the general practitioner than for the student. The young practitioner especially will find it extremely suggestive and helpful." - The Indian Lance't. 
* AN AMERICAN TEXT-BOOK OF OBStetrics. Edited by Richard C. Norris, M. D. ; Art Editor, Robert L. Dickinson, M. D. One handsome octavo volume of over Iooo pages, with nearly 900 colored and half-tone illustrations. Prices: Cloth, $\$ 7.00$; Sheep or Half-Norocco, $\$ 8.00$.

The advent of each successive volume of the series of the American TextBooks has been signalized by the most flattering comnient from both the Press and the Profession. The high consideration received by these text-books, and their attainment to an authoritative position in current medical literature, have been matters of deep international interest, which finds its fullest expression in the demand for these publications from all parts of the civilized world.

In the preparation of the "AMERICAN TEXT-BOOK OF OBSTETRICs" the editor has called to his aid proficient collaborators whose professional prominence entitles them to recognition, and whose disquisitions exemplify Practical Obstetrics. While these writers were each assigned special themes for discussion, the correlation of the subject-matter is, nevertheless, such as ensures logical connection in treatment, the deductions of which thoroughly represent the latest alvances in the science, and which elucidate the best modern methods of procedure.

The more conspicuous feature of the treatise is its wealth of illustrative matter. The production of the illustrations had been in progress for several years, under the personal supervision of Robert L. Dickinson, M. D., to whose artistic judgment and professional experience is due the most sumptuously illustrated work of the period. By means of the photographic art, combined with the skill of the artist and draughtsman, conventional illustration is superseded by rational methods of delineation.

Furthermore, the volume is a revelation as to the possibilities that may be reached in mechanical execution, through the unsparing hand of its publisher.

\section{CONTRI BUTORS :}

Dr. James C. Cameron. Edward P. Davis. Robert L. Dickinson. Charles Warrington Earle. James H. Etheridge. Henry J. Garricues. Barton Cooke Hirst. Charles Jewett.
Dr. Howard A. Kelly.

Richard C. Norris.

Chauncey D. Palmer.

Theophilus Parvin.

George A. Piersol.

Edward Reynolds.

Henry Schwarz.

"At first glance we are overwhelmed by the magnitude of this work in several respects, viz.: First, by the size of the volume, then by the array of eminent teachers in this department who have taken part in its production, then by the profuseness and character of the illustrations, and last, but not least, the conciseness and clearness with which the text is rendered. This is an entirely new composition, embodying the highest knowledge of the art as it stands to-day by authors who occupy the front rank in their specialty, and there are many of them. We cannot turn over these pages without being struck by the superb illustrations which adorn so many of them. We are confident that this must practical work will find instant appreciation by practitioners as well as students." - New York Medical Times.

Permit me to say that your American Text-Book of Obstetrics is the most magnificent medical work that $I$ have ever seen. I congratulate you and thank you for this superb work. which alone is sufficient to place you first in the ranks of medical publishers. 


\section{* AN AMERICAN TEXT-BOOK OF THE THEORY AND PRACTICE OF MEDICINE. By American Teachers. Edited} by William Pepper, M. D., LL.D., Provost and Professor of the Theory and Practice of Medicine and of Clinical Medicine in the University of Pennsylvania. Complete in two handsome royal-octavo volumes of about IOon pages each, with illustrations to elucidate the text wherever necessary. Price per Volume: Cloth, $\$ 5.00$ net; Sheep or Half-1Iorocco, $\$ 6.00$ net.

\section{VOLCME I. CONTAINS:}

Hygiene.-Fevers (Ephemeral, Simple Continued, Typhus, Typhoid, Epidemic Cerebrospinal Meningitis, and Relapsing)-Scarlatina, Measles, Rötheln, Variola, Varioloid, Vaccinia, Varicella, MI m ps, Whooping-cough, Anthrax, Hydrophobia, Trichinosis, Actino-

mycosis, Glanders, and Tetanus.-Tuberculosis, Scrofula, Syphilis, Diphtheria, Erysipelas, Nalaria, Cholera, and Yellow Fever.Nervous, Muscular, and Mental Diseases etc.

\section{VOLIVE II. CONTAINS:}

Urine (Chemistry and Microscopy).-Kid-1 - Peritoneum, Liver, and Pancreas._Diathetney and Lungs.-Air-passages (Larynx and Bronchi) and Pleura.-Pharynx, Esophagus, Stomach and Intestines (including Intestinal Parasites), Heart, Aorta, Arteries and Veins. ic Diseases (Rheumatism, Rheumatoid Arthritis, Gout, Lithæmia, and Diabetes.)Blood and Spleen.-Inflammation, Embolism, Thrombosis, Fever, and Bacteriology.

The articles are not written as though addressed to students in lectures, but are exhaustive descriptions of diseases, with the newest facts as regards Causation, Symptomatology, Diagnosis, Prognosis, and Treatment, including a large number of approved formule. The recent advances made in the study of the bacterial origin of various diseases are fully described, as well as the bearing of the knowledge so gained upon prevention and cure. The subjects of Bacteriology as a whole and of Immunity are fully considered in a separate section.

Methods of diagnosis are given the most minute and careful attention, thus enabling the reader to learn the very latest methods of investigation without consulting works specially devoted to the subject.

\section{CONTR I B CTORS :}

Dr. J. S. Billings, Philadelphia. Francis Delafield, New York.

Reginald H. Fitz, Boston.

James WV. Holland, Philadelphia.

Henry M. Lyman, Chicago.

William Osler, Baltimore.
Dr. William Pepper, Philadelphia. W. Gilman Thompson, New York. W. H. Welch, Baltimore. James T. Whittaker, Cincinnati. James C. Wilson, Philadelphia. Horatio C. Wood, Philadelphia.

" We reviewed the first volume of this work, and said: "It is undoubtedly one of the best text-books on the practice of medicine which we possess.' A consideration of the second and last volume leads us to modify that verdict and to say that the completed work ir, in our opinion, THE BEST of its kind it has ever been our fortune to see. It is complete, thorough, accurate, and clear. It is well written, well arranged, well printed, well illustrated, and well bound. It is a model of what the modern text-book should be." -New Yos kedical Fournal.

"A libiary upon modern medical art. The work must promote the wider diffusion of scund knowledge."-American Lancet.

"A trusty counsellor for the practitioner or senior student, on which he may implicitly rely."-Edinburgh Medical Fournal. 
* AN AMERICAN TEXT-Book of SURgery. Edited by William W. Keen, M. D., LL.D., and J. William White, M. D., Ph. D. Forming one handsome royal-octavo volume of 1250 pages ( $10 \times 7$ inches), with 500 wood-cuts in text, and 37 colored and half-tone plates, many of them engraved from original photographs and drawings furnished by the authors. Prices : Cloth, $\$ 7.00$ net; Sheep or Half-Morocco, $\$ 8.00$ net.

\section{SECOND EDITION, REVISED AND ENLARGED,}

\section{With a Section devoted to "The Use of the Röntgen Rays in Surgery."}

The want of a text-book which could be used by the practitioner and at the same time be recommended to the medical student has been deeply felt, especially by teachers of surgery; hence, when it was suggested to a number of these that it would be well to unite in preparing a text-book of this description, great unanimity of opinion was found to exist, and the gentlemen below named gladly consented to join in its production. While there is no distinctive American Surgery, yet America has contributed very largely to the progress of modern surgery, and among the foremost of those who have aided in developing this art and science will be found the authors of the present volume. All of them are teachers of surgery in leading medical schools and hospitals in the United States and Canada.

Especial prominence has been given to Surgical Bacteriology, a feature which is believed to be unique in a surgical text-book in the English language. Asepsis and Antisepsis have received particular attention. The text is brought well up to date in such important branches as cerebral, spinal, intestinal, and pelvic surgery, the most important and newest operations in these departments being described and illustrated.

The text of the entire book has been submitted to all the authors for their mutual criticism and revision-an idea in book-making that is entirely new and original. The book as a whole, therefore, expresses on all the important surgical topics of the day the consensus of opinion of the eminent surgeons who have joined in its preparation.

One of the most attractive features of the book is its illustrations. Very many of them are original and faithful reproductions of photographs taken directly from patients or from specimens.

\section{CONTRI BUTORS :}

Dr. Charles H. Burnett, Philadelphia. Phineas S. Conner, Cincinnati. Frederic S. Dennis, New York. William W. Keen, Philadelphia. Charles B. Nancrede, Ann Arbor, Mich. Roswell Park, Buffalo, N. Y.

Lewis S. Pilcher, New York.
Dr. Nicholas Senn, Chicago.

Francis J. Shepherd, Montreal, Canada.

Lewis A. Stimson, New York.

William Thomson, Philadelphia.

J. Collins Warren, Boston.

J. William White, Philadelphia.

"If this text-book is a fair reflex of the present position of American surgery, we must admit it is of a very high order of meric, and that English surgeons will have to look very carefully to their laurels if they are to preserve a position in the van of surgical practice." London Lancet. 
* AN AMERICAN TEXT-BOOK OF GYNECOLOGY, MEDICAL AND SURGICAL, for the use of Students and Practitioners. Edited by J. M. BAI.DY, M. D. Forming a handsome royal-octavo volume of 7 r 8 pages, with $34 \mathrm{r}$ illustrations in the text and 38 colored and halftone plates. Prices: Cloth, $\$ 6.00$ net; Sheep or Half-1Iorocco, $\$ 7.00$ net.

\section{SECOND EDITION, THOROUGHLY REVISED.}

In this volume all anatomical descriptions, excepting those essential to a clear understanding of the text, have been omitted, the illustrations being largely depended upon to elucidate the anatomy of the parts. This work, which is thoroughly practical in its teachings, is intended, as its title implies, to be a working text-book for physicians and students. A clear line of treatment has been laid down in every case, and although no attempt has been made to discuss mooted points, still the most important of these have been noted and explained. The operations recommended are fully illustrated, so that the reader, having a picture of the procedure described in the text under his eye, cannot fail to grasp the idea. All extraneous matter and discussions have been carefully excluded, the attempt being made to allow no unnecessary details to cumber the text. The subject-matter is brought up to date at every point, and the work is as nearly as possible the combined opinions of the ten specialists who figure as the authors.

In the revised edition much new material has been added, and some of the old eliminated or modified. Nore than forty of the old illustrations have been replaced by new ones, which add very materially to the elucidation of the text, as they picture methods, not specimens. The chapters on technique and after-treatment have been considerably enlarged, and the portions devoted to plastic work have been so greatly improved as to be practically new. Hysterectomy has been rewritten, and all the descriptions of operative procedures have been carefully revised and fully illustrated.

\section{CONTRIBUTORS :}

\author{
Dr. Henry T. Byford. \\ John M. Baldy. \\ Edwin Cragin. \\ f. H. Etheridge. \\ William Goodell.
}
Dr. Howard A. Kelly.
Florian Krug.
E. E. Montgomery.
William R. Pryor.
George M. Tuttle.

"The most notable contribution to gynecological literature since $1887, \ldots$ and the most complete exponent of gynecology which we have. No subject seems to have been neglected, $\ldots$. and the gynecologist and surgeon, and the general practitioner who has any desire to practise diseases of women, will find it of practical value. In the matter of illustrations and plates the book surpasses anything we have seen."-Boston Medical and Surgical Fourna?.

"A thoroughly modern text-book, and gives reliable and well-tempered advice and instruction."-Edinburgh Medical Journal.

"The harmony of its conclusions and the homogeneity of its style give it an individuality which suggests a single rather than a multiple authorship." - Annals of Surgery.

"It must command attention and respect as a worthy representation of our advanced clinical teaching."-American Fournal of Medical Sciences. 


\section{*AN AMERICAN TEXT-BOOK OF THE DISEASES OF CHIL-} DREN. By American Teachers. Edited by Louis STARr, M. D., assisted by Thompson S. WestcotT, M. D. In one handsome royal-8vo volume of 1250 pages, profusely illustrated with wood-cuts, half-tone and colored plates. Net Prices: Cloth, $\$ 7.00$; Sheep or IIalf-Morocco, \$8.00.

\section{SECOND EDITION, REVISED AND ENLARGED.}

The plan of this work embraces a series of original articles written by some sixty well-known prediatrists, representing collectively the teachings of the nost prominent medical schools and colleges of America. The work is intended to be a PRACTICAL book, suitable for constant and handy reference by the practi tioner and the advanced student.

Especial attention has been given to the latest accepted teachings upon the etiology, symptoms, pathology, diagnosis, and treatment of the disorders of children, with the introduction of many special formulæ and therapeutic procedures.

In this new edition the whole subject matter has been carefully revised, new articles added, some original papers emended, and a number entirely rewritten. The new articles include ".Iorlified Milk and Percentage Milk-Mixtures," "Lithemia," and a section on "Orthopedics." Those rewritten are "Typhoid Fever," "Rubella," "Chicken-pox," "Tuberculous Meningitis," "Hydrocephalus," and "Scurvy;" while extensive revision has been made in "Infant Feeding," "Neasles," "IDiphtheria," and " ('retinism." The volume has thus been much increased in size by the introduction of fresh material.

\section{CONTRI B U'TORS :}

Dr. S. S. Adams, Washington.

John Ashhurst, Jr., Philadelphia.

A. D. Blackader, Montreal, Canada.

David Povaird, New York.

Dillon Brown, New York.

Edward M. Buckingham, Boston.

Charles W. Burr, Philadelphia.

W. E. Casselberry, Chicago.

Henry Dwight Chapin, New York.

W. S. Christopher, Chicago.

Archibald Church, Chicago.

Floyd M. Crandall, New York.

Andrew F. Currier, New York.

Roland G. Curtin, Philadelphia

J. M. DaCosta, Philadelphia.

I. N. Danforth, Chicago.

Edward P. Davis, Philadelphia.

John B. Deaver, Philadelphia.

G. E. de Schweinitz. Philadelphia.

John Dorning, New York.

Charles Warrington Earle, Chicago.

Wm. A. Edwards, San Diego, Cal.

F. Forchheimer, Cincinnati.

J. Henry Fruitnight, New York.

f. P. Crozer Griffith, Philadelphia.

IW. A. Hardaway. St. Louis.

M. P Hatfield, Chicago.

Barton Cooke Hirst, Philadelphia.

H. Illoway, Cincinnati.

Henry Jackson, Boston.

Charles G. Jennings, Detroit.

Henry Koplik. New York.
Dr. Thomas S. Latimer, Baltimore.

Albert R. Leeds, Hoboken, N. J.

J. Hendrie Lloyd, Philadelphia.

George Roe Lockwood, New York.

Henry M. Lyman, Chicago.

Francis T. Niles, Baltimore.

Charles K Mills, Philadelphia.

James E Moore, Minneapolis.

F. Gordon Morrill, Boston.

John H. Musser, Philadelphia.

Thomas R. Neilson, Philadelphia

W. P. Northrup, New York.

William Osler, Baltimore.

Frederick A. Packard, Philadelphia.

William Pepper, Philadelphia.

Frederick Peterson, New York.

W. T. Plant, Syracuse, New York.

William N. Powell, Atlantic City.

B. K. Rachford, Cincinnati.

B. Alexander Randall, Philadelphia

Edward O. Shakespeare, Philadelpline

F. C. Shattuck, Boston.

$\mathrm{J}$. Lewis Smith, New York.

Louis Starr, Philadelphia.

M. Allen Starr, New York.

Charles W. Townsend, Boston.

James Tyson, Philadelphia.

W. S. Thayer, Baltimore.

Victor C. Vaughan, Ann Arbor, Micí 'Thompson S. Westcolt, Philadelphia.

Henry R. Wharton, Philadelphia.

J. William White, Philadelphia.

J. C. Wilson, Philadelphia. 


\section{* AN AMERICAN TEXT-BOOK OF GENITO-URINARY AND} SKIN DISEASES. By 47 Eminent Specialists and Teachers. Edited by L. Boltox Baxgs, M. D., Late Professor of Genito-Urinary and Venereal Diseases, New York Jost-Graduate Medical School and Hospital; and W. A. Hardaway, M. I., Professor of Diseases of the Skin, Missouri Medical College. Imperial octavo volume of 1229 pages, with 300 engravings and 20 full-page colored plates. Cloth, $\$ 7.00$ net; sheep or Half- Iorocco, \$\$.oo net.

This addition to the series of "American Text-Books," it is confidently believed, will meet the requirements of both students and practitioners, giving, as it does, a comprehensive and detailed presentation of the Diseases of the Genito-Urinary Organs, of the Venereal Diseases, and of the Affections of the Skin.

Having secured the collaboration of well-known authorities in the branches represented in the undertaking, the editors have not restricted the contributors i.. regard to the particular views set forth, but have offered every facility for the free expression of their individual opinions. The work will therefore be found to be original, yet homogeneous and fully representative of the several departments of medical science with which it is concerned.

\section{CONTRIBCTORS :}

Dr. Chas. W. Alien, New York.

I. E. Atkinson, Baltimore.

L. Bolton Bangs, New York.

P. R. Bulton, New York.

Lew is C. Bosher, Richmond, Va.

John T. Bowen, Boston.

J. Abbott Cantrell. Philadelphia.

William T. Corlett, Cleveland, Ohio.

B. Farquhar Curtis, New York.

Condict W. Cutler, New York.

Isadore Dyer, New Orleans.

Christian Fenger, Chicago.

John A. Fordyce. New York.

Eugene Fuller, New York.

R. H. Greene, New York.

Joseph Grindon, St. Louis.

Graeme MI. Hammond, New York.

W. A. Hardaway, St. Louis.

M. B. Hartzell, Philadelphia.

Louis Heitzmann. New York.

James $\&$. Howe, Boston

George T. Jackson, New York.

Abraham Jacohi, New York.

James C. Johuston, New York.
Dr. Hermann G. Klotz, New York.

J. H. Linsley, Burlington, Vt.

G. F. Lydston, Chicago.

Hartwell N. Lyon, St. Louis.

Edward Martin, Philadelphia.

D. G. Montgomery, San Francisco.

James Pedersen, New York.

S. Pollitzer, New York.

Thomas R. Pooley, New York.

A. R. Robinson, New York.

A. E. Regensburger, San Francisco.

Francis J. Shepherd, Montreal, Can.

S. C. Stanton, Chicago, Ill.

Emmanuel J. Stout, Philadelphia.

Alonzo E. Taylor Philadelphia.

Robert W. Taylor, New York.

Paul Thorndike, Boston.

H. Tuholske. St. Louis.

Arthur Van Harlingen, Philadelphia.

Francis S. Watson, Boston.

J. William White, Philadelphia.

J. McF. Winfield, Brooklyn.

Alfred C. Wood, Philadelphia.

"This voluminous work is thoroughly up to date, and the chapters on genito-urinary diseases are especially valuable. The illustrations are fine and are mostly original. The section on dermatology is concise and in every way admirable." - Journal of the American Medical Association.

"This volume is one of the best yet issued of the publisher's series of 'American TextBooks.' The list of contributors represents an extraordinary array of talent and extended experience. The book will easily take the place in comprehensiveness and value of the half dozen or more costly works on these subjects which have hitherto been necessary to a well-equipped library."-Neze York Polyclinic. 
* an american text-Book of diseases of the Eye, EAR, NOSE, AND THROAT. Edited by George E. In SCHWEINitz, A. M., M. D., Professor of Ophthalmology, Jefferson Medical College ; and B. Alexander Randall, A. M., M. D., Clinical Professor of Diseases of the Ear, University of Pennsylvania. One handsome imperial octavo volume of 1251 pages; 766 illustrations, 59 of them colored. Prices: Cloth, $\$ 7.00$ net; Sheep or Half- $\mathrm{H}$ Horocco, $\$ 8.00$ net.

\section{Just Issued.}

The present work is the only book ever published embracing diseases of the intimately related organs of the eye, ear, nose, and throat. Its special claim to favor is based on encyclopedic, authoritative, and practical treatment of the subjects.

Each section of the book has been entrusted to an author who is specially identified with the subject on which he writes, and who therefore presents his case in the manner of an expert. Uniformity is secured and overlapping prevented by careful editing and by a system of cross-references which forms a special feature of the volume, enabling the reader to come into touch with all that is said on any subject in different portions of the book.

Particular emphasis is laid on the most approved methods of treatment, so that the book shall be one to which the student and practitioner can refer for information in practical work. Anatomical and physiological problems, also, are fully discussed for the benefit of those who desire to investigate the more abstruse problems of the subject.

\section{CON'TRI B C'TORA :}

Dr. Henry A. Alderton, Brooklyn. Harrison Allen, Philadelphia. Frank Allport, Chicago.

Morris J. Asch. New York.

S. C. Ayres, Cincinnati.

R. O. Beard, Minneapolis.

Clarence J. Blake, Boston.

Arthur A Bliss, Philadelphia.

Albert P. Brubaker, Philadelphia.

J. H. Bryan, Washington, D. C.

Albert H. Buck, New York.

F. Buller, Montreal, Can.

Swan M. Burnett, Washington, D C.

Flemming Carrow, Ann Arbor, Nich.

W. E. Casselberry, Chicago.

Colman WV. Cutler, New York.

Edward B. Dench, New York.

William S. Dennett. New York.

George E. de Schweinitz, Philadelphia.

Alexander Duane, New York.

John WV. Farlow, Boston, Mass.

Walter $J$ Freeman, Philadelphia.

H. Gifford, Omaha, Neb.

VV. C. Glasgow, St. Louis

J Orne Green, Boston.

Ward A. Holden, New York.

Christian R. Holmes, Cincinnati.

William E. Hopkins, San Francisco.

F. C. Hotz, Chicago.

Lucien Howe, Buffalo, N. Y.
Dr. Alvin A. Hubbell, Buffalo, N. Y. Edward Jackson, Philadelphia.

J. Ellis Jennings. St. Louis.

Herman Knapp, New York

Chas. W. Kollock, Charleston, S. C.

G. A Leland, Boston.

J. A. Lippincott, Pittsburg, Pa.

G. Hudson Makuen, Philadelphia.

John H. McCollom, Boston.

H. G. Miller, I'rovidence, R, I.

B. L. Milliken, Cleveland, Ohio.

Robert C. AIyles, New York.

James E. Newcomb, New York.

R. J. Phiilips, Philadelphia

George A. Piersol, Philadelphia.

W. P. Porcher, Charleston, S. C.

B. Alex. Randall, I'hiladelphia.

Robert L. Randolph, Baltimore.

John O. Roe, Rochester, N. Y.

Charles E. de M. Sajous, Philadelphia.

J. E. Sheppard. Brooklyn, N. Y.

E. L. Shurly, Detroit, Mich.

William M. Sweet, Philadelphia.

Samuel Theobald. Paltimore, Md.

A. G. Thomson, Philadelphia.

Clarence A. Veasey, Philadelphia.

John E. Weeks, New York

Casey A. Wood, Chicago, Ill.

Jonathan Wright, Brooklyn.

H. V. Würdemann, Milwankee, Wis, 
* AN AMERICAN YEAR-BOOK OF MEDICINE AND SURGERY. A Yearly Digest of Scientific Progress and Authoritative Opinion in all branches of Medicine and Surgery, drawn from journals, monographs, and text-books of the leading American and Foreign authors and investigators. Collected and arranged, with critical editorial comments, by eminent American specialists and teachers, under the general editorial charge of GEORGE M. GoUld, M.D. One handsome imperial octavo volume of about I 200 pages. Uniform in style, size, and general make-up with the "American Text-Book" Series. Cloth, $\$ 6.50$ net; Half-Morocco, $\$ 7.50$ net.

\section{Now Ready, Volumes for 1896, 159;, 159s, 1899.}

Notwithstanding the rapid multiplication of medical and surgical works, still these publications fail to meet fully the requirements of the general physician, inasmuch as he feels the need of something more than mere text-books of wellknown principles of medical science.

This deficiency would best be met by current journalistic literature, but most practitioners have scant access to this almost unlimited source of information, and the busy practiser has but little time to search out in periodicals the many interesting cases whose study would doubtless be of inestimable value in his practice. Therefore, a work which places before the physician in convenient form an efitomization of this literature by persons competent to pronounce upon

\section{The Value of a Discovery or of a Method of Treatment}

cannot but command his highest appreciation. It is this critical and judicial function that is assumed by the Editorial staff of the "American Year-Book of Medicine and Surgery."

\section{CONTRIBU'TORS :}

Dr. Samuel W. Abbott, Boston. John J. Abel, Baltimore. J. M. Baldy, Philadelphia. Charles H. Burnett, Philadelphia. Archibald Church, Chicago. J. Chalmers DaCosta, Philadelphia. w. A. N. Dorland, Philadelphia. Louis A. Duhring. Philadelphia.

D. L. Edsall, Philadelphia. Virgil P. Gibney, New York. Henry A. Griffin, New York. J Gn Guitéras, Philadelphia. C. A. Hamann, Cleveland. Alfred Hand, Jr., Philadelphia.
Dr. Howard E. Hansell, Philadelphia. II. B. Hartzell. Philadelphia. Barton Cooke Hirst, Philadelphia. E. Fletcher lngals, Chicago. Wyatt Johnston, Montreal. W. W. Keen, Philadelphia. Henry G. Ohls, Chicago.

Wendell Reber, Philadelphia. David Kiesman. Philadelphia. I ouis Starr, Philadelphia. Alfred tengel, Philadelphia. G. N. Stewart: Cleveland. J. R. Tillinghast, New York. J. Hilton Waterman, New York.

"It is difficult to know which to admire $m o s$-the research and industry of the distinguished band of experts whom Dr. Gould has cnlisted in the service of the Year-Book, or the wealth and abundance of the contributions to every department of science that have been deemed worthy of analysis. . . It is much more than a mere compilation of abstracts, for, as each section is entrusted to experienced and able contributors, the reader has the advantage of certain critical commentaries and expositions. . proceeding from writers fully qualified to perform these tasks. . . . It is emphatically a book which should find a place in every medical library, and is in several respects more useful than the famous "Jahrbücher' of Germany." - London Lancet. 
* Anomalies and CuRiosities of medicine. By George M. Gould, M.D., and Walter L. Pyle, MI.D. An encyclopedic collection of rare and extraordinary cases and of the most striking instances of abnormality in all branches of Medicine and surgery, derived from an exhaustive research of medical literature from its origin to the present day, abstracted, classified, annotated, and indexed. Handsome imperial octavo volume of 968 pages, with 295 engravings in the text, and 12 full-page plates. Cloth, $\$ 6.00$ net; Half-Horocco, $\$ 7.00$ net.

Several years of exhaustive research have been spent by the authors in the creat medical libraries of the United States and Europe in collecting the material for this work. Medical literature of all ages and all languages has been carefully searched, as a glance at the Bibliographic Index will show. The facts, which will be of extreme value to the author and lecturer, have been arranged and annotated, and full reference footnotes given, indicating whence they have been obtained.

In view of the persistent and dominant interest in the anomalous and curious, a thorough and systematic collection of this kind (the first of which the authors have knowledge) must have it; own peculiar sphere of usefulness.

As a complete and authoritative Book of Reference it will be of value not only to members of the medical profession, but to all persons interested in general scientific, sociologic, and medico-legal topics; in fact, the general interest of the subject and the dearth of any complete work upon it make this volume one of the most important literary innovations of the day.

\footnotetext{
"One of the most valuable contributions ever made to medical literature. It is, so far as we know, absolutely unique, and every page is as fascinating as a novel. Not alone for the medical profession has this volume value: it will serve as a book of reference for all who are interested in general scientific, sociologic, or medico-legal topics."-Brooklyn Medical Fournal.
}

NERVoUs AND MENTAL Diseases. By Archibald Church, M. D., Professor of Clinical Neurology, Mental Diseases, and Medical Jurisprudence, Northwestern University Medical School; and Frederick Peterson, M. D., Clinical Professor of Mental Diseases, Woman's Medical College, New York. Handsome octavo volume of 843 pages, with over 300 illustrations. Prices: (Cloth, $\$ 5.00$ net; Half-1Iorocco, $\$ 6.00$ net.

\section{Just Issued.}

This book is intended to furnish students and practitioners with a practical, working knowledge of nervous and mental diseases. Written by men of wide experience and authority, it will present the many recent additions to the sul.ject. The book is not filled with an extended dissertation on anatomy and pathology, but, treating these points in connection with special conditions, it lays particular stress on methods of examination, diagnosis, and treatment. In this respect the work will be unusually complete and valuable. laying down the definite courses of procedure which the authors have found to be most generally satisfactory. 
A TeXt-BoOK of Pathology. By Alfred Stengel, M. D., Instructor in Clinical Medicine in the University of Pennsylvania; Clinical Professor of Medicine in the Woman's Medical College of Pennsylvania; Physician to the Philadelphia Hospital ; Physician to the Children's Hospital, Philadelphia. Handsome octavo volume of 848 pages, with 362 illustrations, many of which are in colors. Prices: Cloth, $\$ 4.00$ net; Half-Norocco, $\$ 5.00$ net.

\section{Just Issued.}

In this work the practical application of pathological facts to clinical medicine is corisidered more fully than is customary in works on pathology. While the subject of pathology is treated in the broadest way consistent with the size of the book, an effort has been made to present the subject from the point of view of the clinician. The general relations of bacteriology to pathology are discussed at considerable length, as the importance of these branches deserves. It will be found that the recent knowledge is fully considered, as well as older and more widely-known facts.

In the second part of the work the pathology of individual organs and tissues is treated systematically and quite fully under subheadings that clearly indicate the subject-matter of each page.

The particular points of the book to be emphasized are the clear, concise language, the convenient arrangement of matter, the practical teaching value of the large collection of illustrations, and the modern and judicious treatment of the entire subject.

A TEXT-BOOK OF OBStetrics. By Barton Cooke Hirst, M.D., Professor of Obstetrics in the University of Pennsylvania. Handsome octavo volume of $8+6$ pages, with 618 illustrations and seven colored plates. Prices: Cloth, $\$ 5.00$ net; Half-210rocco, $\$ 6.00$ net.

\section{Just Issued.}

This work, which has been in course of preparation for several years, is intended as an ideal text-book for the student no less than an advanced treatise for the obstetrician and for general practitioners. It represents the very latest teaching in the practice of obstetrics by a man of extended experience and recognized authority. The book emphasizes especially, as a work on obstetrics should, the practical side of the subject, and to this end presents an unusually large collection of illustrations. A great number of these are new and original, and the whole collection will furm a complete atlas of obstetrical practice. An extremely valuable feature of the book is the large number of references to cases. authorities, sources, etc., forming, as it does, a valuable bibliography of the most recent and authoritative literature on the subject of obstetrics. As already stated, this work records the wide practical experience of the author, which fact, combined with the brilliant presentation of the subject, will doubtless render this one of the most notable books on obstetrics that has yet appeared. 


\section{A TEXT-BOOK OF THE PRACTICE OF MEDICINE. By}

James M. Anders, M.D., Ph.D., LL.D., Professor of the Practice of Medicine and of Clinical Medicine, Medico-Chirurgical College, Philadelphia. In one handsome octavo volume of 1287 prages, fully illustrated. Cloth, $\$ 5.50$ net; Sheep or Half-Morocco, $\$ 6.50$ net.

\section{Second Edition. First Edition Exhansted in, Five Houths.}

This work gives in a comprehensive manner the results of the latest scientific studies bearing upon medical affections, and portrays with rare force and clearness the clinical pictures of the clifferent diseases considered. The practical points, particularly with reference to diagnosis and treatment, are completely stated and are presented in a most convenient form; for example, the differential diagnosis has in many instances been tabulated, no less than fifty-six diagnostic tables being given.

The first edition of this work having been exhausted in so short a time, the author has not found it necessary to make an extensive revision, but has simply availed himself of the opportunity to make a few changes of minor importance.

"It is an excellent book-concise, comprehensive, thorough, and up to date. It is a credit to you ; but, more than that, il is a credit to the profession of Philadelphia - to us." -James C. Witson, Professor of the Practice of Medicine and Clinical Medicine, Fefferson Medical College, Philadelphia.

"I consider Dr. Anders' book not only the best late work on Medical Practice, but by far the best that has ever been published. It is concise, systematic, thorough, and fully up in date in everything. I consider it a great credit to both the author and the publisher."-A. C. Cowperthivaite, President of the Illinois Homeopathic Medical Association.

Diseases of THE STOMACH. By William W. Van Valzah, M. D., Professor of General Medicine and Diseases of the Digestive System and the Blood, New York Polyclinic; and J. Dudglas Nisbet, M. D., Adjunct Professor of General Medicine and Diseases of the Digestive System and the Blood, New York Polyclinic. Octavo volume of 674 pages, illustrated. Cloth, $\$ 3.50$ net.

An eminently practical book, intended as a guide to the student. an aid to the physician, and a contribution to scientific medicine. It aims to give a complete description of the modern methods of diagnosis and treatment of diseases of the stomach, and to reconstruct the pathology of the stomach in keeping with the revelations of scientific research. The book is clear, practical, and complete, and contains the results of the authors' investigations and of their extensive experience as specialists. Particular attention is given to the important sulject of dietetic treatment. The diet-lists are very complete, and are so arranged that selections can readily be made to suit inclividual cases.

"This is the most satisfactory work on the subject in the English language."-Chicago Nedical Recorder.

"The article on diet and general medication is one of the most valuable in the book, and should be read by every practising physician."-New York Medical fournal. 
SURGICAL DIAGNOSIS AND TREATMENT. By I. W. MaCDoNald, M. D., Edin., F. R. C.S., Edin., Professor of the Practice of Surgery and of Clinical Surgery in Hamline University; Visiting Surgeon to St. Barnabas' Hospital, Minneapolis, etc. Handsome octavo volume of 800 pages, profusely illustrated. Cloth, $\$ 5.00$ net; Half-Morocco, $\$ 6.00$ net.

This work aims in a comprehensive manner to furnish a guide in matters of surgical diagnosis. It sets forth in a systematic way the necessities of examinations and the proper methods of making them. The various portions of the body are then taken up in order and the diseases and injuries thereof succinctly considered and the treatment briefly indicated. Practically all the modern and approved operations are described with thoroughness and clearness. The work concludes with a chapter on the use of the Röntgen rays in surgery.

"The work is brimful of just the kind of practical information that is useful alike to students and practitioners. It is a pleasure to commend the book because of its intrinsic value to the medical practitioner,"-Cincinnatz Lancet-Clinic.

\section{PATHOLOGICAL TECHNIQUE. A Practical Manual for Laboratory}

Work in Pathology, Bacteriology, and Morbil Anatomy, with chapters on Post-Mortem Techni jue and the Performance of Autopsies. By Frank B. Mallory, A. II., II. L., Assistant Professor of Pathology, Harvard University Medical School, Boston; and Janies H. WrighT, A. M., M. D., Instructor in Patholngy, Harvard University Medical School, Boston. Octavo volume of 396 pages, handsomely illustrated. Cloth, $\$ 2.50$ net.

This book is designed especially for practical use in pathological laboratories, both as a guide to beginners and as a source of reference for the advanced. The book will also meet the wants of practitioners who have opportunity to do general pathological work. Besides the methods of post-mortem examinations and of bacteriological and histological investigations connected with autopsies, the special methods employed in clinical bacteriology and pathology have been fully discussed.

"One of the most complete works on the subject, and one which should be in the library of every physician who hopes to keep pace with the great advances made in pathology." Fourmal of tmerican Medical Association.

\section{THE SURGICAL COMPLICATIONS AND SEQUELS OF TY-}

PHOID FEVER. By War. W. KeEx, M. D., LL.D., Professor of the Principles of Surgery and of Clinical Surgery, Jefferson Medical College,

Philadelphia. Octaro volume of 386 pages, illustrated. Cloth, $\$ 3.00$ net.

This monograph is the only one in any language covering the entire subject of the Surgical Complications and Sequels of Typhoid Fever. The work will prove to be of importance and interest not only to the general surgeon and physician, but also to many specialists-laryngologists, ophthalmologists, gynecologists, pathologists, and bacteriologists-as the subject has an important bearing upon each one of their spheres. 'The author's conclusions are based on reports of over 1700 cases, including practically all those recorled in the last fifty years. Reports of cases have been brought down to date, many having been added while the work was in press.

"This is probably the first and only work in the English language that gives the reader a clear view of what typhoid fever really is, and what it does and can do to the human organism. This book should be in the possession of every medical man in America,"-American Medico-Surgical Bulletin. 
MODERN SURGERY, GENERAL AND OPERATIVE. By JohN Chalmers DaCosta, M.D., Clinical Professor of Surgery, Jefferson Medical College, Philadelphia; Surgeon to the Philadelphia Hospital, etc. Handsome octavo volume of 9 II pages, profusely illustrated. Cloth, $\$ 4.00$ net; I Half-.Morocco, $\$ 5.00$ net.

\section{Second Edition, Rewritten and Greatly Enlarged.}

The remarkable success attending DaCosta's Manual of Surgery, and the general favor with which it has been received, have led the author in this revision to produce a complete treatise on modern surgery along the same lines that made the former edition so successful. The book has been entirely rewritten and very much enlarged. The old edition has long been a favorite not only with students and teachers, but also with practising physicians and surgeons, and it is believed that the present work will find an even wider field of usefulness.

"We know of no small work on surgery in the Finglish language which so well fulfils the requirements of the modern student."-Medico-Chirurgical Journal, Bristol, England.

"The author has presented concisely and accurately the principles of modern surgery. The book is a valuable one which can be recommended to students and is of great value to the general practitioner."-American Journal of the lledical Sciences.

A Manual of orthopedic Surgery. By James E. Moore, M.D., Professor of Orthopedics and Adjunct Professor of Clinical Surgery, University of Minnesota, College of Medicine and Surgery. Octavo volume of $35^{6}$ pages, with $\mathbf{I} 77$ beautiful illustrations from photographs made specially for this work. Cloth, \$2.50 net.

A practical book based upon the author's experience, in which special stress is laid upon early diagnosis and treatment such as can be carried out by the general practitioner. The teachings of the author are in accordance with his belief that true conservatism is to be found in the middle course between the surgeon who operates too frequently and the orthopedist who seldom operates.

"A very demonstrative work, every illustration of which convey's a lesson. The work is a most excellent and commendable one, which we can certainly endorse with pleasure." St. Louis Medical and Surgical Fournal.

\section{ELEMENTARY BANDAGING AND SURGICAL DRESSING.}

With Directions concerning the Immediate Treatment of Cases of Emergency. For the use of Dressers and Nurses. By Walter Pye, F.R.C.S., late Surgeon to St. Mary's Hospital, London. Small I zmo, with over So illustrations. Cloth, flexible covers, 75 cents net.

This little book is chiefly a condensation of those portions of Pye's "Surgical Handicraft" which deal with bandaging, splinting, etc., and of those which treat of the management in the first instance of cases of emergency. The directions given are thoroughly practical, and the book will prove extremely useful to students, surgical nurses, and dressers.

"The author writes well, the diagrams are clear, and the book itself is small and portable, although the paper and type are good."-British Iledical fournal. 


\section{A TEXT-BOOK OF MATERIA MEDICA, THERAPEUTICS}

AND Pharmacology. By George F. Butler, Ph.G., M.D., Professor of Materia Medica and of Clinical Medicine in the College of Physicians and Surgeons, Chicago; Professor of Materia Medica and Therapeutics, Northwestern University, Woman's Medical School, etc. Octavo, 860 pages, illustrated. Cloth, $\$ 4.00$ net; sheep, $\$ 5.00$ net.

\section{Second Edition, Thoroughly Revised.}

A clear, concise, and practical text-book, adapted for permanent reference no less than for the requirements of the class-room.

The recent important additions made to our knowledge of the physiological action of drugs are fully discussed in the present edition. Many alterations also have been made in the chapters on Diuretics and Cathartics.

"Taken as a whole, the book may fairly be considered as one of the most satisfactory of any single-volume works on materia nedica in the market." - Journal of the American lledical Association.

\section{TUBERCULOSIS OF THE GENITO-URINARY ORGANS,}

MALe AND Female. By Nicholas Sexi, M.D., Ph.D., Ll.D.,

Professor of the Practice of Surgery and of Clinical surgery, Rush Medical College, Chicago. Handsome octaro volume of 320 pages, illustrated. Cloth, $\$ 3.00$ net.

Tuberculosis of the male and female genito-urinary organs is such a frequent, distressing, and fatal affection that a special treatise on the subject appears to fill a gap in medical literature. In the present work the bacteriology of the subject has received due attention, the modern resources employed in the differential diasnosis between tubercular and other inflammatory affections are fully described, and the medical and surgical therapeutics are discussed in detail.

"An important book upon an important subjert, and writlen by a man of mature judgment and wide experience. The anthor has given us an instructive book upon one of the most important subjects of the day."-Clinical Reporter.

"A work which adds another to the many obligations the profession owes the talented author."-Chicago Medical Recorder.

\section{A TEXT-BOOK OF DISEASES OF WOMEN. By Charles B.}

Penrose, M.D., Ph.D., Professor of Gynecology in the Lniversity of Pennsylvania; Surgeon to the Gynecean Hospital, Philadelphia. Octavo volume of 529 pages, with 217 illustrations, nearly all from drawings made for this work. Cloth, $\$ 3.50$ net.

\section{Second Edition, Revised.}

In this work, which has been written for both the student of grnecology and the general practitioner, the author presents the best teaching of modern gynecology untrammelled by antiquated theories or methods of treatment. In most instances but one plan of treatment is recommended, to aroid confusing the student or the physician who consults the book for practical guidance.

"I shall value very highly the copy of Penrose's 'Diseases of Women' received. I have already recommended it to my class as THE BEST book."-HowARD A. KELLY, Professor of Gynecology and Obstetrics, Johns Hopkins Litiversity, Faltimore, Ild.

"The book is to be commended without reserve, not only to the sludent but to the general practitioner who wishes to have the latest and best modes of treatment explained with absolute clearness." - Therapeutic Gazette. 


\section{SURGICAL PATHOLOGY AND THERAPEUTICS. By JOHN}

Collins Warren, M. D., LL.D., Professor of Surgery, Medical Department Harvard University; Surgeon to the Massachusetts General Hospital, etc. A handsome octavo volume of $\delta_{32}$ pages, with $1_{3} 6$ relief and lithographic illustrations, 33 of which are printed in colors, and all of which were drawn by William J. Kaula from original specimens. Prices: Cloth, $\$ 6.00$ net; Half-Morocco, $\$ 7.00$ net.

\section{Without Exception, the Illustrations are the Best ever Seen in a Work of this Kind.}

"A most striking and very excellent feature of this book is its illustrations. Without exception, from the point of accuracy and artistic merit, they are the best ever seen in a work of this kind. *** Many of those representing microscopic pictures are so perfect in their coloring and detail as almost to give the heholder the impression that he is looking down the barrel of a microscope at a well-mounted section."-Annals of Surgery", Philadelphia.

"It is the handsomest specimen of book-making *** that has ever been issued from the American medical press."-American Fournal of the Medical Sciences, Philadelphia.

\section{PATHOLOGY AND SURGICAL TREATMENT OF TUMORS.}

By N. Senn, M. D., Ph. D., LL. D., Professor of Practice of Surgery and of Clinical Surgery, Rush Medical College; Professor of Surgery, Chicago Polyclinic; Attending Surgeon to Presbyterian Hospital; Surgeon-in-Chief, St. Joseph's Hospital, Chicago. One volume of 7 Io pages, with 515 engravings, including full-page colored plates. Prices: Cloth, $\$ 6.00$ net; IIalf-Morocco, $\$ 7.00$ net.

Books specially devoted to this subject are few, and in our text-books and systems of surgery this part of surgical pathology is usually condensed to a degree incompatible with its scientific and clinical importance. The author spent many years in collecting the material for this work, and has taken great pains to present it in a manner that should prove useful as a text-book for the student, a work of reference for the practitioner, and a reliable guide for the surgeon.

"The most exhaustive of any recent book in English on this subject. It is well illustrated, and will doubtless remain as the principal monograph on the subject in our language for some years. The book is handsomely illustrated and printed, . . . . and the author has given a notable and lasting contribution to surgery." - Fournal of American Medical Asso ciation, Chicaģo.

\section{LECTURES ON RENAL AND URINARY DISEASES. By}

Rober' Saundby, M. D., Edin., Fellow of the Royal College of Physicians, London, and of the Royal Medico-Chirurgical Society; Physician to the General Hospital. Octavo volume of 434 pages, with numerous illustrations and 4 colored plates. Cloth, \$2.50 net.

"The volume makes a favorable impression at once. The style is clear and succinct. We cannot find any part of the subject in which the views expressed are not carefully thought ont and fortified by evidence drawn from the most recent sources. The book miay be cordially recommended." - British . ledical Fournal.

"'The work represents the present knowledge of renal and urinary diseases. It is admirably written and is accurately scientific."-Medical Nezus. 
A NEW PRONOUNCING DICTIONARY OF MEDICINE, with Phonetic Pronunciation, Accentuation, Etymology, etc. By JoHN M. Keating, M. D., LL.D., Fellow of the College of Physicians of Philadelphia; Vice-President of the American Pædiatric Society; Ex-President of the Association of Life Insurance Medical Directors; Editor "Cyclopædia of the Diseases of Children," etc.; and Henry Hamilton, author of “A New Translation of Virgil's Eneid into English Rhyme;" coauthor of "Saunders' Medical Lexicon," etc.; with the Collaboration of J. Chalmers DaCosta, M. D., and Frederick A. Packard, M. D. With an Appendix containing important Tables of Bacilli, Nicrococci, Leucomaines, Ptomaines, Drugs and Materials used in Antiseptic Surgery, Poisons and their Antidotes, Weights and Measures, Thermometric Scales, New Official and Unofficial Drugs, etc. One very attractive volume of over 800 pages. Second Revised Edition. Prices: Cloth, $\$ 5.00$ net; Sheep or Half-Morocco, $\$ 6.00$ net; with Denison's Patent Ready-Reference Index; without patent index, Cloth, $\$ 4.00$ net; Sheep or HalfMorocco, \$5.00 net.

\section{PROFESAIONA I. OPINIONS.}

"I am much pleased with Keating's Dictionary, and shall take pleasure in recommending it to my classes."

Henky M. Lyman, M. D.,

Professor of Principles and Practice of Medicine, Rush Medical College, Chicago, Ill.

"I am convinced that it will be a very valuable adjunct to my study-table, convenient in size and sufficiently full for ordinary use."

C. A. Lindsley, M. D.,

Professor of Theory and Practice of Medicine, Medical Dept. Yale University: Secretary Connecticut State Board of Health, New Haven, Conn,

AUTOBIOGRAPHy OF SAMUEL D. GROSS, M. D., Emeritus Professor of Surgery in the Jefferson Medical College of Philadelphia, with Reminiscences of His Times and Contemporaries. Edited by his sons, Samuel IV. Gross, M. D., LL.D., late Professor of Principles of Surgery and of Clinical Surgery in the Jefferson Medical College, and A. HaLler Gross, A. M., of the Philadelphia Bar. Preceded by a Memoir of Dr. Gross, by the late Austin Flint, M. D., LL.D. In two handsome volumes, each containing over 400 pages, demy 8 vo, extra cloth, gilt tops, with fine Frontispiece engraved on steel. Price per Volume, \$2.50 net.

This autobiography, which was continued by the late eminent surgeon until within three months of his death, contains a full and accurate history of his early struggles, trials, and subsequent successes, told in a singularly interesting and charming manner, and embraces short and graphic pen-portraits of many of the most distinguished men-surgeons, physicians, divines, lawyers, statesmen, scientists, etc. - with whom he was brought in contact in America and in Europe ; the whole forming a retrospect of more than three-quarters of a century. 
PRACTICAL POINTS IN NURSING. For Nurses in Private Practice. By Emily A. M. Stoney, Graduate of the Training-School for Nurses, Lawrence, Mass.; Superintendent of the Training-School for Nurses, Carney Hospital, South Boston, Mass. $45^{6}$ pages, handsomely illustrated with 73 engravings in the text, and 9 colored and half-tone plates. Cloth. Price, $\$ \mathbf{I} .75$ net,

\section{SECOND EDITION, THOROUGHLY REVISED.}

In this volume the author explains, in popular language and in the shortest possible form, the entire range of private nursing as distinguished from hospital nursing, and the nurse is instructed how best to meet the various emergencies of medical and surgical cases when distant from medical or surgical aid or when thrown on her own resources.

An especially valuable feature of the work will be found in the directions to the nurse how to improzise everything ordinarily needed in the sick-room, where the embarrassment of the nurse, owing to the want of proper appliances, is frequently extreme.

The work has been logically divided into the following sections:

I. The Nurse: her responsibilities, qualifications, equipment, etc.

II. The Sick-Room : its selection, preparation, and management.

III. The Patient: duties of the nurse in medical, surgical, obstetric, and gynecologic cases.

IV. Nursing in Accidents and Emergencies.

V. Nursing in Special Medical Cases.

VI. Nursing of the New-born and sick Children.

VII. Physiołogy and Descriptive Anatomy.

The Appendix contains much information in compact form that will be found of great value to the murse, including Rules for Feeding the Sick; Recipes for Invalid Foods and Beverages; Tables of Weights and Measures; Talle for Computing the Date of Labor; List of Abbreviations; Dose-List; and a full and complete Glossary of Medical Terms and Nursing Treatment.

"This is a well-written, eminently practical volume, which covers the entire range of private nursing as distinguished from hospital nursing, and instructs the nurse how best to meet the various emergencies which may arise and how to prepare everything ordinarily needed in the illness of her patient."-American Journal of Obstetrics and Diseases of Women and Children, Aug., 1896.

A TEXT-BOOK OF BACTERIOLOGY, including the Etiology and Prevention of Infective Diseases and an account of Yeasts and Moulds, Hæmatozoa, and Psorosperms. By Edgar M. Crookshank, M. B., Professor of Comparative Pathology and Bacteriology, King's College, London. A handsome octavo volume of 700 pages, with 273 engravings in the text, and 22 original and colored plates. Price, $\$ 6.50$ net.

This book, though nominally a Fourth Edition of Profe-sor Crookshank's "MANUAL OF BACTERIOlOgY," is practically a new work, the old one having been reconstructed, greatly enlarged, revised throughout, and largely rewritten, forming a text-book for the Bacteriological Laboratory, for Medical Offncers of Health, and for Veterinary Inspectors. 
MEDICAL DIAGNOSIS. By Dr. OSWALD VierordT, Prufessor of Medicine at the University of Heidelberg. Translated, with additions, from the Fifth Enlarged Geman Edition, with the author's permission, by Fraxcis H. STUART, A. M., M. D. In one handsome royal-octavo volume of 600 pages. 194 fine wood-cuts in the text, many of them in colors. Prices: Cloth, \$4.00 net; Sheep or Half-Morocco, \$5.00 net.

\section{FOURTH AMERICAN EDITION, FROM THE FIFTH REVISED AND ENLARGED GERMAN EDITION.}

In this work, as in no other hitherto published, are given full and accurate explanations of the phenomena observed at the bedside. It is distinctly a clinical work by a master teacher, characterized by thoroughness, fulness, and accuracy. It is a mine of information upon the points that are so often passed over without explanation. Especial attention has been given to the germ-theory as a factor in the origin of disease.

The present edition of this highly successful work has been translated from the fifth German edition. Many alterations have been made throughout the book, but especially in the sections on Gastric Digestion and the Nervous System.

It will be found that all the qualities which served to make the earlier editions so acceptable have been developed with the evolution of the work to its present form.

\section{THE PICTORIAL ATLAS OF SKIN DISEASES AND SYPHI-} LITIC AFFECTIONS. (American Edition.) Translation from the French. Edited by J. J. Pringle, M. B., F. R. C. P., Assistant Physician to, and Physician to the department for Diseases of the Skin at, the Middlesex Hospital, London. Phnto-lithochromes from the famous models of dermatological and syphilitic cases in the Museum of the Saint-Louis Hospital, Paris, with explanatory wood-cuts and letter-press. In 12 Parts, at $\$ 3.00$ per Part.

"Of all the atlases of skin diseases which have been published in recent years, the present one promises to be of greatest interest and value, especially from the standpoint of the general practitioner" -American Medico-Surgical Bulletin, Feb. 22, 1896.

"The introduction of explanatory wood-cuts in the text is a novel and most important feature which greatly furthers the easier understanding of the excellent plates, than which nothing, we venture to say, has been seen better in point of correctness, beauty, and general merit."-Neav Jork Medical Journal, Feb. 15, 1896.

"An interesting feature of the Atlas is the descriptive text, which is written for each picture hy the physician who treated the case or at whose instigation the models have been made. iVe predict for this truly beautiful work a large circulation in all parts of the medical world where the names St. Louis and Baretta have preceded it."-Medical Record, N. Y., Feb. I, i 96.

\section{A TEXT-BOOK OF MECHANO-THERAPY (MASSAGE AND} MEDICAL GYMNASTICS. By AXFL V. GRAfSTron, B. Sc., II. I), late I,ieutenant in the Royal Swedish Army; late House Physician, ('ity Inspital, Blackwell's Island, New York. I 2mo, I39 pages, illustrated. Cloth, \$1.00 net. 
DISEASES OF THE EYE. A Hand-Book of Ophthalmic Practice. By G. E. DE Schweinitz, M. D., Professor of Ophthalmology in the Jefferson Medical College, Philadelphia, etc. A handsome royaloctavo volume of 696 pages, with 255 fine illustrations, many of which are original, and 2 chromo-lithographic plates. Prices: Cloth, $\$ 4.00$ net; Sheep or Half-Morocco, $\$ 5.00$ net.

\section{THIRD EDITION, THOROUGHLY REVISED.}

In the third edition of this text-book, destined, it is hoped, to meet the favorable reception which has been accorded to its predecessors, the work has been revised thoroughly, and much new matter has been introduced. Particular attention has been given to the important relations which micro-organisms bear to many ocular diseases. A number of special paragraphs on new subjects have been introduced, and certain articles, including a portion of the chapter on Operations, have been largely rewritten, or at least materially changed. A number of new illustrations have been added. The Appendix contains a full description of the method of determining the corneal astigmatism with the ophthalmometer of Javal and Schiötz, and the rotation of the eyes with the tropometer of Stevens.

"A work that will meet the requirements not only of the specialist, but of the general practitioner in a rare degree. I am satisfied that unusual success awaits it."

William Pepper, M D.

Provost and Professor of Theory and Practice of Medicine and Clinical Medicine in the University of Pennsylvania.

"A clearly written, comprehensive manual. . . One which we can commend to students as a reliable iext-book, written with an evident knowledge of the wants of those entering upon the study of this special branch of medical science."-British Medical Journal.

"It is hardly too much to say that for the student and practitioner beginning the study of Ophthalmology, it is the best single volume at present published."-Nedical Neres.

"It is a very useful, satisfactory, and safe guide for the student and the practitioner, and one of the best works of this scope in the English language." -Annals of Ophthalmology.

Diseases OF WOMEN. By J. Bland Sutron, F. R. C. S., Assistant Surgeon to Middlesex Hospital, and Surgeon to Chelsea Hospital, London ; and Arthur E. Gir.es, M. D., B. Sc., Lond., F. R. C. S., Edin., Assistant Surgeon to Chelsea Hospital, London. 436 pages, handsomely illustrated. Cloth, \$2.50 net.

The authors have placed in the hands of the physician and student a concise yet comprehensive guide to the study of gynecology in its most modern development. It has been their aim to relate facts and describe methods belonging to the science and art of gynecology in a way that will prove useful to students for examination purposes, and which will also enable the general physician to practice this important department of surgery with advantage to his patients and with satisfaction to himself.

"The book is very well prepared, and is certain to be well received by the medical public." - British Medical Journal.

"The text has been carefully prepared. Nothing essential has been omitted, and its teachings are those recommended by the leading authorities of the day." - Journal of the American Medical Association. 
TEXT-BOOK UPON THE PATHOGENIC BACTERIA. SPecially written for Students of Medicine. By Joseph MCFARLAND, M. D., Professor of Pathology and Bacteriology in the Medico-Chirurgical College of Philadelphia, etc. 497 pages, finely illustrated. Price, Cluth, $\$ 2.50$ net.

\section{SECOND EDITION, REVISED AND GREATLY ENLARGED.}

The work is intended to be a text-book for the medical student and for the practitioner who has had no recent laboratory training in this department of medical science. The instructions given as to needed apparatus, cultures, stainings, microscopic examinations, etc. are ample for the student's needs, and will afford to the physician much information that will interest and profit him relative to a subject which modern science shows to go far in explaining the etiology of many diseased conditions.

In this second edition the work has been brought up to date in all departments of the subject, and numerous additions have been made to the technique in the endeavor to make the book fulfil the double purpose of a systematic work upon bacteria and a laboratory guide.

"It is excellently adapted for the medical students and practitioners for whom it is avowedly written. ... The descriptions given are accurate and readable, and the book should prove useful to those for whom it is written.-London Lancet, Aug. 29, 1896 .

"The author has succeded admirably in presenting the essential details of bacteriological technics, together with a judiciously chosen summary of our present knowledge of pathogenic bacteria. .. . The work, we think, should have a wide circulation among English-speaking students of medicine."-N. Y. Medical Journal, April 4, 1896.

"The book will be found of considerable use by medical men who have not had a special bacteriological training, and who desire to understand this important branch of medical science." -Edinburgh Mledical Fournal, July, 1896.

\section{LABORATORY GUIDE FOR THE BACTERIOLOGIST. By}

LANGdox FrothinghaM, M. D. V., Assistant in Bacteriology and Veterinary Science, Sheffield Scientific School, Yale University. Illustrated. Price, Cloth, 75 cents.

The technical methods involved in bacteria-culture, methods of staining, and microscopical study are fully described and arranged as simply and concisely as possible. The book is especially intended for use in laboratory work

"It is a convenient and useful little work, and will more than repay the outlay necessary for its purchase in the saving of time which would otherwise be consumed in looking up the various points of technique so clearly and concisely laid down in its pages." - American Med.Surg. Bulletin.

FEEDing in EARLy INFANCy. By Arthur V. Meigs, M. I) Bound in limp cloth. flush edges. Price, 25 cents net.

Synopsis: Analyses of Milk-Importance of the Subject of Feeding in Early Infancy-Proportion of Casein and Sugar in Human Milk-Time to Begin Artificial Feeding of Infants-Amount of Food to be Administered at Each Feeding-Intervals between Feedings-Increase in Amount of Food at Different Periods of Infant Development-Unsuitableness of Condensed Nilk as a Substitute for Mother's Milk-Objections to Sterilization or "Pasteurization" of Milk-Advances made in the Method of Artificial Feeding of Infants. 
MATERIA MEDICA FOR NURSES. By EMILY A. M. STONEY, Graduate of the Training-school for Nurses, Lawrence, Mass.; late Superintendent of the Training-school for Nurses, Carney Hospital, South Boston, Mass. Handsome octavo, 300 pages. Cloth, \$I.50 net.

The present book differs from other similar works in several features, all of which are introduced to render it more practical and generally useful. The general plan of contents follows the lines laid down in training-schools for nurses, but the book contains much useful matter not usually included in works of this character, such as Poison-emergencies, Ready Dose-list, Weights and Measures, etc., as well as a Glossary, defining all the terms in Materpi Medica, and describing all the latest drugs and remedies, which have been generally neglected by other books of the lind.

\section{ESSENTIALS OF ANATOMY AND MANUAL OF PRACTI-} CAL DISSECTION, containing "Hints on Dissection." By CHARles B. NANCrede, M. D., Professor of Surgery and Clinical Surgery in the University of Michigan, Ann Arbor; Corresponding Member of the Royal Academy of Medicine, Rome, Italy; late Surgeon Jefferson Medical College, etc. Fourth and revised edition. lost 8vo, over 500 pages, with handsome full-page lithographic plates in co:ors, and over 200 illustrations. Price: Extra Cloth or Oilcloth for the dissection-room, $\$ 2.00$ net.

Neither pains nor expense has been spared to make this work the most exhaustive yet concise Student's Manual of Anatomy and Dissection ever published, either in America or in Europe.

The colored plates are designed to aid the student in dissecting the muscles arteries, veins, and nerves. The wood-cuts have all been specially drawn and engraved, and an Appendix added containing 60 illustrations representing the structure of the entire human skeleton, the whole being based on the eleventh edition of Gray's Anatomy.

A Manual of practice of Medicine. By A. A. Stevens, A. M., M. D., Instructor in Physical Diagnosis in the Lniversity of Pennsylvania, and Professor of Pathology in the Woman's Medical College of Pennsylvania. Specially intended for students preparing for graduation and hospital examinations. Post Sro, 519 pages. Numerous illustrations and selected formulæ. Price, bound in flexible leather, \$2.00 net.

\section{FIFTH EDITION, REVISED AND ENLARGED.}

Contributions to the science of medicine have poured in so rapidly during the last quarter of a century that it is well-nigh impossible for the student, with the limited time at his disposal, to master elaborate treatises or to cull from them that knowledge which is absolutely essential. From an extended experience in teaching, the author has been enabled, by classification, to group allied symptoms, and by the judicious elimination of theories and redundant explanations to bring within a comparatively small compass a complete outline of the prac. tice of medicine. 


\section{MANUAL OF MATERIA MEDICA AND THERAPEUTICS.}

By A. A. Srevens, A. M., M. D., Instructor of Physical Diagnosis in the University of Pennsylvania, and Professor of Pathology in the Woman's Medical College of Pennsylvania. 445 pages. Price, bound in flexible leather, $\$ 2.25$.

\section{SECOND EDITION, REVISED.}

This wholly new volume, which is based on the last edition of the Pharmacopcia, comprehends the following sections: Physiological Action of Drugs; Drugs; Remedial Measures other than Drugs; Applied Therapeutics; Incompatibility in Prescriptions; Table of Doses; Index of Drugs; and Index of Diseases; the treatment being elucidated by more than two hundred formulæ.

"The author is to be congratulated upon having presented the medical student with as accurate a manual of therapeutics as it is possible to prepare." - Therapeutic Gazette.

"Far superior to most of its class; in fact, it is very good. Moreover, the book is reliable and accurate."-New York Medical Journal.

"The author has faithfully presented modern therapeutics in a comprehensive work, . . . and it will be found a reliable guide."-University Medical Magazine.

NOTES ON THE NEWER REMEDIES : their Therapeutic Applications and Modes of Administration. By David Cerna, M. D., PH. D., Demonstrator of and Lecturer on Experimental Therapeutics in the University of Pennsylvania. Post-octavo, 253 pages. Price, \$I.25.

\section{SECOND EDITION, RE-WRITTEN AND GREATLY ENLARGED.}

The work takes up in alphabetical order all the newer remedies, giving their physical properties, solubility, therapeutic applications, administration, and chemical formula.

It thus forms a very valuable addition to the various works on therapeutics now in existence.

Chemists are so multiplying compounds, that, if each compound is to be thoroughly studied, investigations must be carried far enough to determine the practical importance of the new agents.

"Especially valuable because of its completeness, its accuracy, its systematic consideration of the properties and therapy of many remedies of which doctors generally know but little, expressed in a brief yet terse manner."-Chicago Clinical Review.

TEMPERATURE CHART. Prepared by D. T. LAINE, M. D. Size $8 \times 13 \frac{1}{2}$ inches. Price, per pad of 25 charts, 50 cents.

A conveniently arranged chart for recording Temperature, with columns for daily amounts of Urinary and Fecal Excretions, Food, Remarks, etc. On the back of each chart is given in full the method of Brand in the treatment of Typhoid Fever. 
A TEXT-BOOK OF HISTOLOGY, DESCRIPTIVE AND PRACTICAL. For the Use of Students. By Arthur Clarkson, M. B., C. M., Edin., formerly Demonstrator of Physiology in the Owen's College, Manchester; late Demonstrator of Physiology in the Yorkshire College, Leeds. Large 8vo, 554 pages, with 22 engravings in the text, and 174 beautifully colored original illustrations. Price, strongly bound in Cloth, $\$ 6.00$ net.

The purpose of the writer in this work has been to furnish the student of His. tology, in one volume, with both the descriptive and the practical part of the science. The first two chapters are devoted to the consideration of the general methods of Histology ; subsequently, in each chapter, the structure of the tissue or organ is first systematically described, the student is then taken tutorially over the specimens illustrating it, and, finally, an appendix affords a short note of the methods of preparation.

"The work must be considered a valuable addition to the list of available text-books, and is to be highly recommended."-Nere York Medical Journal.

"One of the best works for students we have ever noticed. We predict that the book will attain a well-deserved popularity among our students."-Chicago Mledical Recorder.

THE PATHOLOGY AND TREATMENT OF SEXUAL IMPOTENCE. By Victor G. Vecki, M. D. From the second German edition, revised and rewritten. Demi-octavo, about 300 pages. Cloth, \$2.00 net.

\section{Just Issued.}

The subject of impotence has but seldom been treated in this country in the truly scientific spirit that it deserves, and this volume will come to many as a revelation of the possibilities of therapeusis in this important field. Lr. Vecki's work has long been favorably known, and the German book has received the highest consideration. This edition is more than a mere translation, for, although hased on the German edition, it has been entirely rewritten by the author in English.

ARCHIVES OF CLINICAL SKIAGRAPHY. By Sydney Rowland, B. A., Camb. A series of collotype illustrations, with descriptive text, illustrating the applications of the New Photography to Medicine and Surgery. Price, per Part, $\$$ I.00. Parts I. to V. now ready.

The object of this publication is to put on record in permanent form some of the most striking applications of the new photography to the needs of Medicine and Surgery.

The progress of this new art has been so rapid that, although Prof. Röntgen's discovery is only a thing of yesterday, it has already taken its place among the approved and accepted aids to diagnosis. 
Diseases of WoMen. By HeNry J. Garrigues, A.M., M. D., Professor of Gynecology in the New York School of Clinical Medicine; Gynecologist to St. Mark's Hospital and to the German Dispensary, New York City. In one handsome octavo volume of $72 S$ pages, illustrated by 335 engravings and colored plates. l'rices: Cloth, $\$ 4.00$ net; sheep or Half-1Iorocco, $\$ 5.00$ net.

A PRACTICAL work on gynecology for the use of students and practitioners, written in a terse and concise manner. The importance of a thorough knowledge of the anatomy of the female pelvic orguns has been fully recognized by the author, and considerable space has been devoted to the subject. The chapters on Operations and on Treatment are thoroughly modern, and are based upon the large hospital and private practice of the author. The text is elucidated by a large number of illustrations and colored plates, many of them being original, and forming a complete atlas for studying embryology and the anatomy of the female genitalia, besides exemplifying, whenever needed, morbid conditions, instruments, apparatus, and operations.

\section{Second Edition, Thoroughly Revised.}

The first edition of this work met with a most appreciative reception by the medical press and profession both in this country and abroad, and was adopted as a text-book or recommended as a book of reference by nearly one hundred colleges in the United States and Canada. The author has availed himself of the opportunity affurded by this revision to embody the latest approved advances in the treatment employed in this important branch of Medicine. He has also more extensively expressed his own opinion on the comparative value of the different methods of treatment employed.

"One of the best text-books for students and practitioners which has been published in the English language; it is condensed, clear, and comprehensive. The profound learning and great clinical experience of the distinguished anthor find expression in this book in a most attractive and instructive form. Young practitioners, to whom experienced consultants nua not be available, will find in this book invaluable connsel and help."

Thad. A. Reamy, M. D., LL.D.,

Professor of Clinical Gynecology, Medical College of Ohio: Gynecologist to the Good Samaritan and Cincinnati Hospitals.

A SYLLABUS OF GYNECOLOGY, arranged in conformity with "An American Text-Book of Gynecolegy." By J. W. Lovg, M. D., Professor of Diseases of Women and (Gildren, Medical College of Virginia, etc. Price, Cloth (interleave $)$ \$1.00 net.

Based upon the teaching and methods laid down in the larger work, this will not only be nseful as a supplementary volume, but to those who do not already possess the text-book it will also have an independent value as an aic to the practitioner in gynecological work, and to the student as a guide in the lectureroom, as the subject is ! : iesented in a manner at once systematic, clear, succinct, and practical. 
THE AMERICAN POCKET MEDICAL DICTIONARY. Edited by W. A. Newman Dorlani, M. D., Assistant Obstetrician to the IIospital of the University of Pennsylvania; Fellow of the American Academy of Medicine. Containing the pronunciation and definition of over 26,000 words used in medicine and the kindred sciences, with 64 extensive tables. Handsomely bound in flexible leather, limp, with gold edges. Price, $\$ 1.25$ net.

\section{Orev 26,000 Words, $6 \pm$ Taluable Tables.}

This is the ideal pocket lexicon. It is an absolutely new book, and not a revision of any old work. It is complete, defining all the terms of modern medicine and forming a vocabulary of over 26,000 words. It gives the pronunciation of all the terms. It makes a special feature of the newer words neglected by other dictionaries. It contains a wealth of anatomical tables of special value to students. It forms a handy volume, indi-pensable to every medical man.

SAUNDERS' POCKET MEDICAL FORMULARY. By WILlIAM M. Powel. L, M. D., Attending Physician to the Mercer House for Invalid Women at Atlantic City. Containing I 800 Formulæ, selected from several hundred of the best-known authorities. Forming a handsome and convenient pocket companion of nearly 300 printed pages, with blank leaves for Additions; with an Appendix containing Posological Table, Formulæ and Doses for Hypodermatic Medication, Poisons and their Antidotes, Diameters of the Pemale Pelvis and Fœtal Head, Obstetrical Table, Diet List for Various Diseases, Materials and Drugs userl in Antiseptic Surgery, Treatment of Asphyxia from Drowning, Surgical Remembrancer, Tables of Incompatibles, Eruptive Fevers, Weights and Measures, etc. Handsomely bound in morocco, with side index, wallet, and flap. Price, $\$ \mathbf{1 . 7 5}$ net.

\section{FIFTH EDITION, THOROUGHLY REVISED.}

"This little book, that can be conveniently carried in the pocket, contains an immense amount of material. It is very usefui, and as the name of the author of each prescription is given, is unusually reliable."-Nez Fork Medical Record.

A COMPENDIUM OF INSANITY. By John B. ChapIN, M.D., LL.D., Physician-in-Chief, Pennsylvania Hospital for the Insane; late PhysicianSuperintendent of the Willard State Hospital, New York; Honorary Member of the Medico-Psychological Society of Great Britain, of the Society of Mental Medicine of Belgium. I 2mo, 2.34 pages, illust. Cloth, \$1.25 net.

The author has given, in a condensed and concise form, a compendium of Diseases of the Mind, for the convenient use and aid of physicians and students. It contains a clear, concise statement of the clinical aspects of the various abnormal mental conditions, with directions as to the most approved methods of managing and treating the insane.

"The practical parts of Dr. Chapin's book are what constitule its distinctive merit. We desire especially, however, to call attention to the fact that in the subject of the therapentics of insanity the work is exceedingly valuable. The author has made a distinct addition to the literature of his specialty."-Philadelphia Medical Journal. 
AN OPERATION BLANK, with Lists of Instruments, etc. required in Various Operations. Prepared by W. W. Keen, M. D., LL.D., Professor of Principles of Surgery in the Jefferson Medical College, Philadelphia. Price per Pad, containing Blanks for fifty operations, 50 cents net.

\section{SECOND EDITION, REVISED FORM.}

A convenient blank, suitable for all operations, giving complete instructions regarding necessary preparation of patient, etc., with a full list of dressings and medicines to be employed.

On the back of each blank is a list of instruments used-viz. general instru ments, etc., required for all operations; and special instruments for surgery of the brain and spine, mouth and throat, abdomen, rectum, male and female genito-urinary organs, the bones, etc.

The whole forming a neat pad, arranged for hanging on the wall of a surgeon's office or in the hospital operating-room.

"Will serve a useful purpese for the surgeon in reminding him of the details of preparation for the patient and the room as well as for the instruments, dressings, and antiseptics needed "- Vezu York Medical Record

"Covers about all that can be needed in any operation."-American Lancet.

"The plan is a capital one."-Boston Medical and Surgical Fournal.

LABORATORY EXERCISES IN BOTANY. By EDSON S. BASTIN, M. A., Professor of Materia Medica and Botany in the Philadelphia College of Pharmacy. Octavo volume of 536 pages, 87 full-page plates. Price, Cloth, $\$ 2.50$.

This work is intended for the beginner and the advanced student, and it fully covers the structure of flowering plants, ronts, ordinary stems, rhizomes, tubers, bulbs, leaves, flowers, fruits, and seeds. Particular attention is given to the gross and microscopical structure of plants, and to those used in medicine. Illustrations have freely been used to elucidate the text, and a complete index to facilitate reference has been added.

"There is no work like it in the pharmaceutical or botanical literature of this country, and we predict for it a wide circulation."-American Fournal of Pharmacy.

DIET IN SiCkNESS AND IN HeALTh. By Mrs. ERnest Hart, formerly Student of the Faculty of Medicine of Paris and of the London School of Medicine for Women; with an Introduction by Sir Henry Thompson, F. R. C. S., M. D., London. 220 pages; illustrated. Price, Cloth, \$1.50.

Useful to those who have to nurse, feed, and prescribe for the sick. In each case the accepted causation of the disease and the reasons for the special diet prescribed are briefly described. Medical men will find the dietaries and recipes practically useful, and likely to save them trouble in directing the dietetic treatment of patients. 
A MANUAL OF PHYSIOLOGY, with Practical Exercises. For Students and Practitioners. By G. N. Stewart, M. A., M. D., D. Sc., lately Examiner in Physiology, University of Aberdeen, and of the New Nuseums, Cambridge University; Professor of Pliysiology in the Western Reserve University, Cleveland, Ohio. Handsome octavo volume of 848 pages, with 300 illustrations in the text, and 5 colored plates. Price, Cloth, $\$ 3.75$ net.

\section{I'HIRD EDITION, REVISED.}

"It will make its way by sheer force of merit, and amply deserves to do so. It is one of the very best English text-books on the subject." - London Lancet.

"Of the many text-books of physiology published, we do not know of one that so nearly comes up to the ideal as does Professor Stewart's volume." - British Nedical Journal.

ESSENTIALS OF PHYSICAL DIAGNOSIS OF THE THORAX. By Arthur M. Corwin, A. M., M. D., Demonstrator of Physical Diagnosis in the Rush Medical College, Chicago; Attending Physician to the Central Free Dispensary, Department of Rhinology, Laryngology, and Diseases of the Chest. 200 pages. Illustrated. Cloth, flexible covers. Price, \$I.25 net.

\section{SYLLABUS OF OBSTETRICAL LECTURES in the Medical} Department, University of Pennsylvania. By RICHARD C. NORRIS, A. M., M. D., Lecturer on Clinical and Operative Obstetrics, University of Pennsylvania. Third edition, thoroughly revised and enlarged. Crown 8vo. Price, Cloth, interleaved for notes, $\$ 2.00$ net.

" This work is so far superior to others on the same subject that we take pleasure in calling attention briefly to its excellent features. It covers the subject thoroughly, and will prove invaluable both to the student and the practitioner. The author has introduced a number of valuable hints which would only occur to one who was himself an experienced teacher of obstetrics. The subject-matter is clear, forcible, and modern. We are especially pleased with the portion devoted to the practical duties of the accoucheur, care of the child, etc. The paragraphs on antiseptics are admirable; there is no doubtful tone in the directions given. No details are regarded as unimportant; no minor matters omitted. We venture to say that even the old practitioner will find useful hints in this direction which he cannot afford to despise."-New York Medical Record.

\section{A SYLLABUS OF LECTURES ON THE PRACTICE OF SUR-} GERY, arranged in conformity with "An American Text-Book of Surgery." By N. Senn, M. D., Ph. D., Professor of Surgery in Rusk Medical College, Chicago, and in the Chicago Polyclinic. Price, \$2.00.

This work by so eminent an author, himself one of the contributors to "An American Text-Book of Surgery," will prove of exceptional value to the advanced student who has adopted that work as his text-book. It is not only the syllabus of an unrivalled course of surgical practice, but it is also an epitome of or supplement to the larger work.

"The author has evidently spared no pains in making his Syllabus thoroughly comprehen. sive, and has added new matter and alluded to the most recent authors and operations. Ful! references are also given to a!l requisite details of surgical anatomy and pathology." - British Medical Journal, London. 
THE CARE OF THE BABY. By J. P. Crozer Griffith, M. D., Clinical Professor of Diseases of Children, University of Pennsylvania; I'hysician to the Children's Hospital, Philadelphia, etc. 404 pages, with 67 illustrations in the text, and 5 plates. I2mo. Frice, $\$ 1.50$.

\section{SECOND EDITION, REVISED.}

A reliable guide not only for mothers, but also for medical students and practitioners whose opportunities for observing children have been limited.

"The whole book is characterized by rare good sense, and is evidently written by a mas. ter hand. It can be read with benefit not only by mothers, but by medical students and by iny practitioners who have not had large opportunities for observing children." - American inrnal of Obstetrics.

\section{THE NURSE'S DICTIONARY of Medical Terms and Nursing} Treatment, containing Definitions of the Principal Medical and Nursing Terms, Abbreviations, and Physiological Names, and Descriptions of the Instruments, Drugs, Diseases, Accidents, Treatments, Operations, Foods, Appliances, etc. encountered in the ward or the sick-room. By Hoxior Mortex, author of "How to Become a Nurse," "Sketches of Hospital Life," etc. I6mo, I40 pages. Price, Cloth, \$I.00.

This little volume is intended for use merely as a small reference-book which can be consulted at the bedside or in the ward. It gives sufficient explanation to the nurse to enable her to comprehend a case until she has leisure to look up larger and fuller works on the subject.

DIET LISTS AND SICK-ROOM DIETARY. By JEROME B. ThOMAS, M. D., Visiting Physician to the Home for Friendless Women and Children and to the Newsboys' Home; Assistant Visiting Physician to the Kings County Hospital; Assistant Bacteriologist, Brooklyn Health Department. Price, Cloth, \$1.50 (Send for specimen List.)

One hundred and sixty detachable (perforated) diet lists for Albuminuria, Anæmia and Debility, Constipation, Diabetes, Diarrhœa, Dyspepsia, Fevers, Gout or Uric-Acid Diathesis, Obesity, and Tuberculosis. Also forty detachable sheets of Sick-Room Dietary, containing full instructions for preparation of easily-digested foods necessary for invalids. Each list is mumbered only, the disease for which it is to be used in no case being mentioned, an index key being reserved for the physician's private use.

\section{DIETS FOR INFANTS AND CHILDREN IN HEALTH AND}

IN DISEASE. By Louis STARr, M. I., Editor of "An American Text-Book of the Diseases of Children." 230 blanks (pocket-book size) perforated and neatly bound in flexible morocco. Price, \$r.25 net.

The first series of blanks are prepared for the first seren months of infant life; each blank indicates the ingredients, but not the quantities, of the foud. the latter directions being left for the physician. After the seventh month, modifications being less necessary, the diet lists are printed in full. Formulis fo- the preparation of diluents and foods are appended. 


\section{HOW TO EXAMINE FOR LIFE INSURANCE. By JOHN M.}

Keating, M. D., Fellow of the College of Physicians and Surgeons of Philadelphia; Vice-President of the American Pædiatric Society; Ex. President of the Association of Life Insurance Medical Directors. Royal 8vo, 2 I I pages, with two large half-tone illustrations, and a plate prepared by Dr. McClellan from special dissections; also, numerous cuts to elucidate the text. Third edition. Price, Cloth, $\$ 2.00$ net.

“This is by far the most useful book which has yet appeared on insurance examination, a subject of growing interest and importance. Not the least valuable portion of the volume is Part II., which consists of instructions issued to their examining physicians by twenty-four representative companies of this country. As the proofs of these instructions were corrected by the directors of the companies, they form the latest instructions obtainable. If for these alone, the book should be at the right hand of every physician interested in this special branch of medical science." - The Mledical News, Philadelphia.

NURSING: ITS PRINCIPLES AND PRACTICE. By ISABEL Adans Hanpton, Graduate of the New York Training School for Nurses attached to Bellevue Hospital; Superintendent of Nurses and Principal of the Training School for Nurses, Johns Hopkins Hospital, Baltimore, Md.; late Superintendent of Nurses, Illinois Training School for Nurses, Chicago, Ill. In one very handsome I 2 mo volume of 512 pages, illustrated. Price, Cloth, \$2.00 net.

\section{SECOND EDITION, REVISED AND ENLARGED.}

This original work on the importart subject of nursing is at once comprehensive and systematic. It is written in a clear, accurate, and readable style, suitable alike to the student and the lay reader. Such a work has long been a desideratum with those entrusted with the management of hospitals and the instruction of nurses in training-schools. It is also of especial value to the graduated nurse who desires to acquire a practical working knowledge of the care of the sic.. and the hygiene of the sick-room.

\section{OBSTETRIC ACCIDENTS, EMERGENCIES, AND OPERA-}

TIONS. By L. Ch. Boisliniere, M. D., late Emeritus Professor of Obstetrics in the St. Louis Medical College. $38 \mathrm{I}$ pages, handsomely illustrated. Price, $\$ 2.00$ net.

"For the use of the practitioner who, when away from home, has not the opportunity of consulting a library or of calling a friend in consultation. $\mathrm{He}$ then, being thrown upon his own resources, will find this book of benefit in guiding and assisting him in emergencies."

INFANT'S WEIGHT CHART. Designed by J. P. Crozer GrIfFith, M. D., Clinical Professor of Diseases of Children in the University of Penr sylvania. 25 charts in each pad. Price per pad, 50 cents net.

A convenient blank for keeping a record of the child's weight during the first two years of life. Printed on each chart is a curve representing the average weight of a healthy infant, so that any deviation from the normal can readily be detected. 


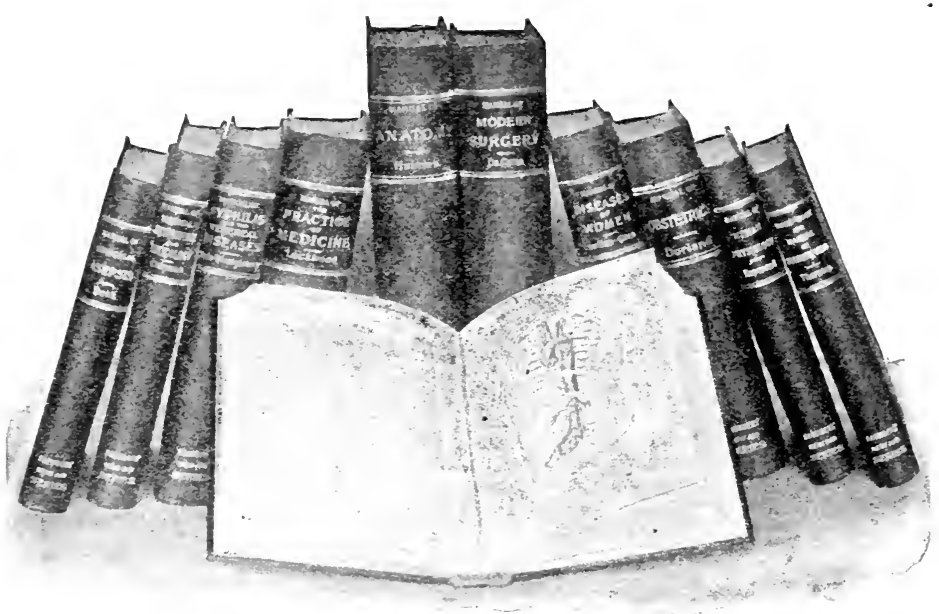

SAUNDERS'

for Students

NEW SERIES

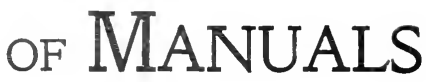

and

Practitioners.

$\mathrm{T}^{\mathrm{H}}$

T there exists a need for thoroughly reliable hand-books on the leading favor with which the SAUNDERS NEW SERIES OF MANUAIS have been received by medical students and practitioners and by the Medical Press. These manuals are not merely condensations from present literature, but are ably written by well-known authors and practitioners, most of them being teachers in representative American colleges. Each volume is concisely and authoritatively written and exhaustive in detail, without being encumbered with the introduction of "cases," which so largely expand the ordinary textbook. These manuals will therefore form an admirable collection of advanced lectures, useful alike to the medical student and the practitioner: to the latter, too busy to search through page after page of elaborate treatises for what he wants to know, they will prove of inestimable value; to the former they will afford safe guides to the essential points of study.

The SAUNDERS NEW SERIES OF MANUALS are conceded to be superior to any similar books now on the market. No other manuals afford so much information in such a concise and available form. A liberal expenditure has enabled the publisher to render the mechanical portion of the work worthy of the high literary standard attained by these books.

Any of these Manuals will be mailed on receipt of price (see next page (or List). 


\section{SAUNDERS' NEW SERIES OF MANUALS.}

\section{VOLUMES PUBLISHED.}

PHYSiOlOGY. By Joseph Howard Raymond, A. M., M. D., Professor of Physiology and Hygiene and Lecturer on Gynecology in the Long Island College Hospital, etc. Price, $\$ 1.25$ net.

SURGERY, General and Operative. By John Chalmers DaCosta, M. D., Professor of Clinical Surgery, Jefferson Medical College, Philadelphia. Second edition, revised and greatly enlarged. Octavo, 9I I pages, 386 illustrations. Cloth, $\$ 4.00$ net; Half-Morocco, $\$ 5.00$ net.

DOSE-BOOK AND MANUAL OF PRESCRIPTION-WRITING. By E. Q. Thornton, M. D., Demonstrator of Therapeutics, Jefferson Medical College, Philadelphia. Price, $\$$ I.25 net.

MEdical JURisprudenCe. By Henry C. Chapman, M. D., Professor of Institutes of Medicine and Medical Jurisprudence in the Jefferson Medical College of Philadelphia, etc, Price, \$I.50 net.

SURGICAL ASEPSIS. By CARL BECK, M.D., Surgeon to St. Mark's Hospital and to the German Poliklinik; Instructor in Surgery, New York Post-Graduate Medical School, etc. Price, $\$ \mathbf{I} .25$ net.

MANUAL OF ANATOMY. By Irving S. Haynes, M.D., Adjunct Professor of Anatomy and Demonstrator of Anatomy, Medical Department of the New York University, etc. Price, $\$ 2.50$ net.

SYPHILIS AND THE VENEREAL DISEASES. By JAMES Nevins Hyde, M. D., Professor of Skin and Venereal Diseases, and Frank H. Montgomery, M. D., Lecturer on Dermatology and Genitourinary Diseases in Rush Medical College, Chicago. Price, $\$ 2.50$ net.

PRACTICE OF MEDICINE. By George Roe Lockwood, M. D., Professor of Practice in the Woman's Medical College of the New York Infirmary, etc. Price, $\$ 2.50$ net.

OBSTetrics. By W. A. Newman Dorland, M. D., Assistant Demonstrator of Obstetrics, University of Pennsylvania; Chief of Gynecological Dispensary, Pennsylvania Hospital. Price, $\$ 2.50$ net.

Diseases of Women. By J. Bland Sutton, F. R. C. S., Assistant Surgeon to the Middlesex Hospital, and Surgeon to the Chelsea Hospital for Women, London; and ARThUR E. Giles, M. D., B. Sc. Lond., F. R. C.S. Edin., Assistant Surgeon to the Chelsea Hospital for Women, London. 436 pages, handsomely illustrated. Price, $\$ 2.50$ net.

\section{IN PREPARATION.}

Nervous Diseases. By Charles IV. Burr, M. D., Clinical Professor of Nervous Diseases, Medico-Chirurgical College, Philadelphia, etc.

*** There will be published in the same series, at short intervals, carefully prepared works on various subjects, by prominent specialists. 


\section{SAUNDERS' QUESTION COMPENDS. Arranged in Question and Answer Form.}

\section{THE LATEST, MOST COMPLETE, and BEST ILIUSTRATED SERIES OF COMPENDS EVER ISSUED.}

\section{Now the Standard Authorities in Medical Literature}

WITH

Students and Practitioners in every City of the United States and Canada.

\section{THE REASON WHY.}

They are the advance guard of "Student's Helps"-that Do Help; they are the leaders in their special line, well and authoritatively written by able men, who, as teachers in the large colleges, know exactly what is wanted by' a student preparing for his examinations. The judgment exercised in the selection of authors is fully demonstrated by their professional elevation. Chosen from the ranks of Demonstrators, Quiz-masters, and Assistants, most of them have become Professors and Lecturers in their respective colleges.

Each book is of convenient size $(5 \times 7$ inches), containing on an average 250 pages, profusely illustrated, and elegantly printed in clear, readable type, on fine paper.

The entire series, numbering twenty.four subjects, has been kept thoroughly revised and enlarged when necessary, many of them being in their fourth and fifth editions.

\section{TO SUM UP.}

Although there are numerous other Quizzes, Manuals, Aids, etc. in the market, none of them approach the "Blue Series of Question Compends;" and the claim is made for the following points of excellence :

I. Professional distinction and reputation of authors.

2. Conciseness, clearness, and soundness of treatment.

3. Size of type and quality of paper and binding.

$*_{*}^{*}$ Any of these Compends will be mailed on receipt of price (see next page for List). 


\section{SAUNDERS' QUESTION-COIMPEND SERIES.}

Price, Cloth, $\$ 1.00$ per copy, except when otherwise noted.

1. ESSENTIALS OF PHYSIOLOGY. 4th edition. Illustrated. Revised and enlarged. By H. A. HARE, M. D. (Price, $\$$ I.0O net.)

2. ESSENTIALS OF SURGERY. oth edition, with an Appendix on Antiseptic Surgery. 90 illustrations. By EdWARd M.ARTin, M. D.

3. ESSENTIALS OF ANATOMY. 5th edition, with an Appendix, 180 illustrations. By Charles B. Nancrede, M. D.

4. ESSENTIALS OF MEDICAL CHEMISTRY, ORGANIC AND INORGANIC. $4^{\text {th }}$ edition, revised, with an Appendix. By LAWrence WOLFF, M. D.

5. ESSENTIALS OF OBSTETRICS. 4th edition, revised and enlarged. 75 illustrations. By W. Easterly Ashton, M. D.

6. ESSENTIALS OF PATHOLOGY AND MORBID ANATOMY. 7 th thousand. 46 illustrations. By C. E. Armand Sempte, M. D.

7. ESSENTIALS OF MATERIA MEDICA, THERAPEUTICS, AND PRESCRIPTION-WRITING. sth edition. By HuNRY MORRIS, M. D.

8, 9. ESSENTIALS OF PRACTICE OF MEDICINE. By HENRY MORRIS, M. I) An Appendix on URine Examin atjon. Illustrated. By Lawrence WolfF, M. D. 3d edition, enlarged by some 300 Essential Formula, selected from eminent authorities, by WM. MI. Powell, M. D. (Double number, price \$2.00.)

10. ESSENTIALS OF GYNÆCOLOGY. 4th edition, revised. With 62 illustrations. By Edwin B. Cragin, M. D.

II. ESSENTIALS OF DISEASES OF THE SKIN. 3d edition. revised and enlarged. 7r letter-press cuts and 5 half-tone illustrations. By Henry W. Stelwagon, M.D. (Price, \$1.00 net.)

12. ESSENTIALS OF MINOR SURGERY, BANDAGING, AND VENEREAL DISEASES. 2d edition, revised and enlarged. 78 illustrations. By EDWARD MARTIN, M. D.

13. ESSENTIALS OF LEGAL MEDICINE, TOXICOLOGY, AND HYGIENE. izo illustrations. By C. E. Arinand Semple, MI. D.

14. ESSENTIALS OF DISEASES OF THE EYE, NOSE, AND THROAT. I24 illustrations. 2 d edition, revised. By Edward Jackson, M. D., and E. Baldive Gleason, M. D.

15. ESSENTIALS OF DISEASES OF CHILDREN. zd edition. By William M Poivel. M. D.

16. ESSENTIALS OF EXAMINATION OF URINE. Colored "Voger. Scale," and numerous illustrations. By LAwrence WOLFF, M. D. (Price, 75 cents.)

17. ESSENTIALS OF DIAGNOSIS. 55 illustrations, some in colors. By S. SolisCohen, M. D., and A. A. Eshner, M. D. (Price, \$I.5o net.)

18. ESSENTIALS OF PRACTICE OF PHARMACY. 2d edition, revised. By L. E. SAYRE.

20. ESSENTIALS OF BACTERIOLOGY. 3d edition. 82 illustrations. By $M . \mathrm{V}$ BALL, M. D.

21. ESSENTIALS OF NERVOUS DISEASES AND INSANITY. 48 illustrations. 3d edition, revised. BY JOHN C. SHAw, M. D.

22. ESSENTIALS OF MEDICAL PHYSICS. I55 illustrations. 2d edition, revised. By Fred J. Brockivay, M. D. (Price, \$1.0o net.)

23. ESSENTIALS OF MEDICAL ELECTRICITY. 65illustrations. By DAvid D. Stewart, M. D., and Edward S. Lawrance, Mi. L.

24. ESSENTIALS OF DISEASES OF THE EAR. II4 illustrations. 2d edition, revised and enlarged. By E. Baldwin Gleason, M. D. 


\section{IN PREPARATION.}

\section{$-* * x-$}

THE INTERNATIONAL TEXT=BOOK OF SURGERY. In two volumes.

By American and British authors. Edited by J. Collins WArrex, M. D., LL.D., Pro. fessor of Surgery, Harvard Medical School, Boston; Surgeon to the Massachusetts General Hospital; and A. Pearce Gould, M.S., F. R. C.S., England, Lecturer on Practical Surgery and Teacher of Operative Surgery, Middlesex Hospital Medical School; Surgeon to the Middlesex Hospital, London, England.

AN AMERICAN TEXT=BOOK OF PATHOLOGY.

Edited by John Guiteras, M. D., Professor of General Pathology and of Morbid Anatomy, University of Pennsylvania; and David Riesman, M. D., Demonstrator of Pathological Histology, University of Pennsylvania.

AN AMERICAN TEXT=BOOK OF LEGAL MEDICINE AND TOXICOLOGY.

Edited by Frederick Peterson, M. D., Clinical Professor of Mental Diseases, Woman's Medical College, New York; and Walter S. Haines, M. D., Professor of Chemistry, Pharmacy, and Toxicology, Rush Medical College, Chicago.

\section{AN AMERICAN TEXT $=$ BOOK OF DIAGNOSIS.}

Edited by Alfred Stexgel, M. D., Physician to the Philadelphia Hospital: Professor of Clinical Medicine in the Woman's Medical College; Physician to the Children's Hospital ; late Pathologist to the German Hospital, Philadelphia, etc.

\section{AN AMERICAN TEXT=BOOK OF CHEMISTRY.}

Edited by Herbert M. Hill, Ph.D., Professor of Chemistry, Toxicology, and Physics, Medical Department of the University of Buffalo, New York.

AN AMERICAN TEXT-BOOK OF NURSING.

By American Teachers. Edited by Roberta M. West, late Superintendent of Nurses in the Hospital of the University of Pennsylvania.

KYLE ON THE NOSE AND THROAT.

Diseases of the Nose and Throat. By D. Braden Krle, M.D., Clinical Professor of Laryngology and Rhinology, Jefferson Medical College, Philadelphia.

HEISLER'S EMBRYOLOGY.

A Text=Book of Embryology. By John C. Heisler, M. D., Professor of Anatomy in the Medico-Chirurgical College, Philadelphia.

PRYOR-PELVIC INFLA MMATIONS.

The Treatment of Pelvic Inflammations through the Vagina. By W. R. PRYOR, 11. D., Professor of Gynecology in the New York Polyclinic.

VECKI-SEXUAL IMPOTENCE.

The Pathology and Treatment of Sexual Impotence. By Victor G. Vecki, M. D. From the second German edition, revised and enlarged.

HOLMES-SURGERY.

A Manual of Surgery. By Edmend W. Holmes, M. D., Demonstrator of Anatomy in the University of Pennsylvania.

JACKSON-DISEASES OF THE EYE.

A Manual of Diseases of the Eye. By EdWARD JACkson, A. M., M. D., Prolessor of Diseases of the Eye in the Philadelphia Polyclinic and College for Graduates in Medicine.

NANCREDE-PRINCIPLES OF SURGERY.

The Principles of Surgery. By Charles P. Nancrede, M. D., Professor of Surgery and of Clinical Surgery, University of Michigan, Ann Arbor.

OGDEN-URINARY ANALYSIS.

A Manual of Urinary Analysis. By J. Bergex OGdex, M. D., Assistant in Chemistry, Harvard University Medical School, Boston, Mass.

STONEY-MATERIA MEDICA FOR NURSES.

Materia Medica for Nurses. Dy Lmily A. M. Stoney, Graduate of the Training School for Nurses, Lawrence, Mass.; late Superintendent of the Training School for Nurses, Carney Hospital, South Boston, Mass. 



UNIVERSITY OF CALIFORNIA LIBRARY

Los Angeles

This book is DUE on the last date stamped below. 
Atlas of Internal Medicine and Clinical Diagnosis. By Dr. Chr. Jakob, of Erlangen. Edited by Augustus A: Eshner, M.D., Professor of Clinical Medicine in the Philadelphia Polyclinic; Attending Physician to the Philadelphia Hospital. 68 colored plates. Cloth, $\$ 3.00$ net.

Atlas of Legal Medicine. By Dr. E. von Hofniann, of Vienna. Edited by Frederick Peterson, M.D., Clinical Professor of Mental Diseases, Woman's Medical College, New York; Chief of Clinic, Nervous Dept., College of Physicians and Surgeons, New York. With 120 colored figures on 56 plates, and I93 half-tone illustrations. Cloth, $\$ 3.50$ net.

Atlas of Diseases of the Larynx. By DR. L. GRÜNwALD, of Munich. Edited by Charles P. Grayson, M.D., Lecturer on Laryngology and Rhinology in the University of Pennsylvania ; Physician-in-Charge, Throat and Nose Department, Hospital of the University of Penna. With Io7 colored figures on 44 plates, and 25 text-illustrations. Cloth, $\$ 2.50$ net.

Atlas of Operative Surgery. By Dr. O. Zuckerkande, of Vienna. Edited by J. Chalmers DaCosta, M.D., Clinical Professor of Surgery, Jefferson Medical College, Philadelphia; Surgeon to the Philadelphia Hospital. IVith 24 colored plates, and $2 \mathrm{I} 7$ illustrations in the text. Cloth, $\$ 3.00$ net.

Atlas of Syphilis and the Venereal Diseases." By Prof. Dr. Franz Mracek, of Vienna. Edited by L. Bolton Bangs, M.D., late Professor of Genito-Urinary and Venereal Diseases, New York Post-Graduate Medical School and Hospital. With 7 I colored plates from original water-colors by A. Schintson. Cloth, $\$ 3.50$ net.

Atlas of External Diseases of the Eye.-By $D_{R}$. O. HAAB, of Zurich. Edited by (r. E. De Schwernitz, M. D., Professor of Ophthalmology, Jefferson Medical College, Philadelphia. With 76 colored illustrations on to plates. Cloth, $\$ 3.00$ net.

Atlas of Skin Diseases.-By Prof. Dr. Franz Mračer, of Vienna. Edited by Henry WV. Stelwagon, M. D., Clinical Professor of Dermatology, Jefferson Medical College, Philadelphia. With 63 colored plates and 39 beautiful half-tone illustrations.

\section{IN PREPARATION.}

Atlas of Pathological Histology. Atlas of Orthopedic Surgery. Atlas of General Surgery.
Atlas of Operative Gynecology. Atlas of Psychiatry.

Atlas of Diseases of the Ear. 
